UNIVERSIDAD DE BURGOS

FACULTAD DE HUMANIDADES Y EDUCACIÓN DEPARTAMENTO DE CIENCIAS DE LA EDUCACIÓN

TESIS DOCTORAL

\title{
UTILIDAD DE LA CARTOGRAFÍA CEREBRAL EN EL DIAGNÓSTICO DEL TDAH
}

\author{
$D^{a}$. Elvira Mercado Val
}

Directores de la Tesis:

Dr. D. Xose Ramón García Soto

Dra. $\mathrm{D}^{\mathrm{a}}$. M $\mathrm{M}^{\mathrm{a}}$ Isabel García Alonso

Burgos, mayo de 2014 


\section{XOSE RAMÓN GARCÍA SOTO Y Da . MARÍA ISABEL GARCÍA ALONSO,}

Profesores Doctores del Servicio de Psiquiatría, Servicio Infanto Juvenil y del Área de Personalidad, Evaluación y Tratamiento Psicológicos de la Universidad de Burgos.

Hacen constar que el trabajo de investigación:

\section{UTILIDAD DE LA CARTOGRAFÍA CEREBRAL EN EL DIAGNÓSTICO DEL TDAH}

Que presenta Da . ELVIRA MERCADO VAL ha sido realizado bajo nuestra dirección y supervisión y reúne, a nuestro juicio, los méritos suficientes de originalidad y rigor para que la autora pueda optar con el título de Doctora.

Burgos, mayo de 2014.

Fdo.: Dr. D. Xose Ramón García Soto

Fdo.: Dra. $\mathrm{D}^{\mathrm{a}}$. M $\mathrm{M}^{\mathrm{a}}$ Isabel García Alonso

ILMO. SR. PRESIDENTE DE LA ESCUELA DE DOCTORADO DE LA UNIVERSIDAD DE BURGOS 


\section{AGRADECIMIENTOS}

El camino recorrido para la elaboración de esta tesis doctoral ha supuesto un largo trayecto desde que surgió como una mera idea en sus inicios, hasta por fin verla finalizada.

El trabajo que se presenta ha sido posible gracias al apoyo de muchas personas que me han ayudado y han colaborado conmigo, a veces sin saberlo, durante todo este tiempo. Todas ellas han sido el motor que me ha servido para mantenerme en la tarea con energía.

Me gustaría comenzar dando las gracias a mis directores de tesis. El profesor Dr. D. Xosé Ramón García Soto, porque el trabajo que a continuación se expone no hubiera sido posible sin sus conocimientos, experiencia y asesoramiento. A la profesora Dra. $\mathrm{D}^{\mathrm{a}}$ Isabel García Alonso quien ha depositado en mí su confianza y apoyo y ha sabido guiarme con sus orientaciones, en la toma de decisiones por el camino de la investigación.

Quiero dar gracias también a Ana Gómez, por sus correcciones, la paciencia y disponibilidad infinita que ha tenido conmigo a la hora de corregir fallos y orientarme en todo lo relativo a la parte Neurofisiológica de la tesis.

Al servicio de Neurofisiologia Clinica del Complejo Hospitalario de Burgos, a las enfermeras y auxiliares, a Ignacio Arroyo y a Pablo. Gracias por enseñarme tantas cosas sobre el EEG y la EEGq, por vuestra generosidad y por todos aquellos buenos momentos que pasé durante mi formación. 
A mi familia, a mi madre a mi hermana y a mi abuela, pero sobretodo a mi sobrina Paula, máster en travesuras y alegría de mis días.

A mis amigas, Alba, Pilar, Silvia, Esperanza, Montse y Begoña por estar siempre ahí, en los momentos buenos y en los malos. Al pie del cañón siempre conmigo.

A mis compañeros de batalla y futuros doctores, Álvaro y Eva, con los que he compartido conversaciones y desvaríos sobre nuestras investigaciones y demás cuestiones.

A los niños, adolescentes con TDAH y sus familias, de las que tanto he aprendido y seguiré aprendiendo.

Pero sobretodo quiero agradecer esta tesis a mi padre, el Dr. Alberto Mercado, Neurofisiologo clínico del antiguo Hospital General Yagüe. Lamentablemente no estás para ver los resultados finales de esta tesis, pero sé que desde algún lugar estarás celebrando conmigo bien orgulloso, los resultados que hemos obtenido. Gracias por enseñarme tanto.

No quiero olvidar a nadie, por eso doy las gracias a todos los que habéis compartido esta experiencia conmigo. 


\section{ÍNDICE DE CONTENIDOS}

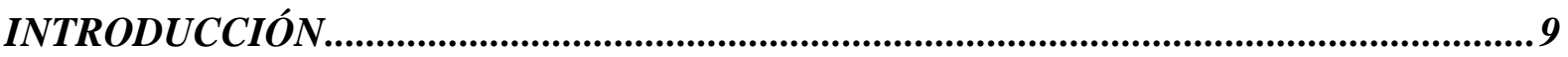

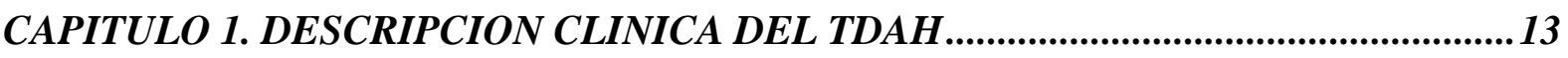

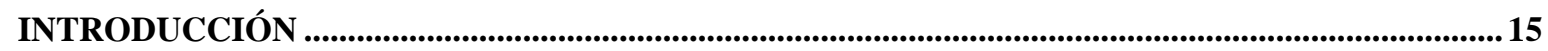

1.1. RECORRIDO HISTORICO POR EL CONCEPTO DE TDAH ........................................................ 15

1.1.1. ALEXANDER CRICHTON Y LA INCAPACIDAD PARA ATENDER CON UN NECESARIO GRADO DE CONSTANCIA HACIA UN OBJETO .................................................................15

1.1.2. UN POSIBLE ANTECEDENTE EN LA LITERATURA INFANTIL ................................................18

1.1.3. LA DESCRIPCIÓN DE GEORGE STILL Y ALFRED TREDGOLD: EL DEFECTO DE

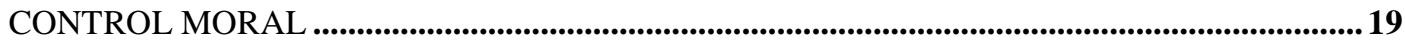

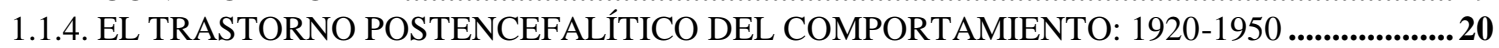

1.1.5. EL TRASTORNO HIPERCINÉTICO DE LA INFANCIA (FRANZ KRANNER 1878- 1967 Y HANS POLLNOW 1902-1943)..............................................................................................................21

1.1.6. LA IMPORTANCIA DEL CONCEPTO DEL SÍNDROME DE DAÑO CEREBRAL. LOS ORÍGENES DEL MINIMAL BRAIN DAMAGE .....................................................................22

1.1.7. EL DESARROLLO DE LA PSICOFARMACOLOGÍA DEL TDAH ............................................23

1.1.8. EL PERIODO DE 1960 A 1969 .........................................................................................................24

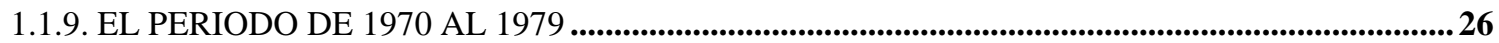

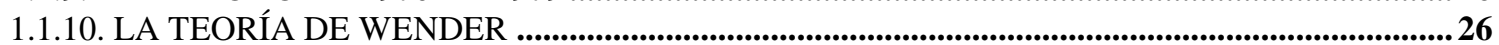

1.1.11. LA EMERGENCIA DE LOS DÉFICITS DE ATENCIÓN: LA TEORÍA DE VIRGINIA

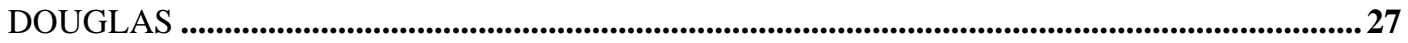

1.2. EVOLUCIÓN DEL TDAH EN LAS CLASIFICACIONES DSM .................................................28

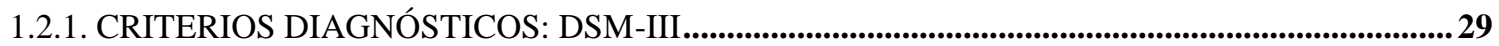

1.2.2.CRITERIOS DSM-IV Y DEL DSM-IV-TR DEL TDAH ...........................................................................30

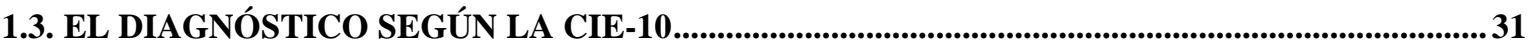

1.4. UNA NUEVA TERMINOLÓGICA: TEMPO COGNITIVO LENTO COMO NUEVA ENTIDAD

CLÍNICA (SLUGGISH COGNITIVE TEMPO),.....................................................................................34

1.4.1. EL CONSTRUCTO TEMPO COGNITIVO LENTO...................................................................................35

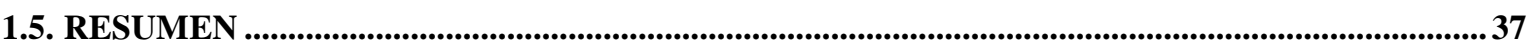

CAPITULO 2. CARACTERISTICAS DEL NIÑO CON TDAH ........................................39

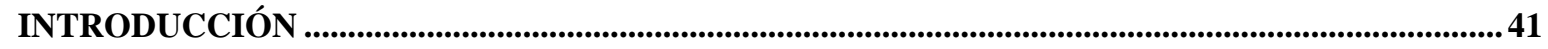

2.1. PERFIL COGNITIVO Y COMPORTAMENTAL .................................................................................. 41

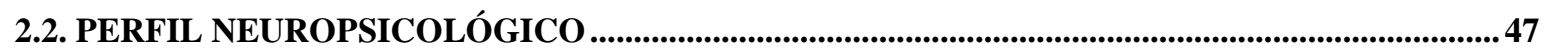

2.3. PERFIL NEUROANATÓMICO Y DE NEUROIMAGEN ..............................................................48

2.3.1. ANORMALIDADES NEUROANATÓMICAS ............................................................................................49

2.3.1.1. DISMINUCION DEL VOLUMEN CEREBRAL TOTAL ....................................................50

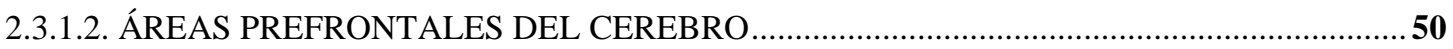

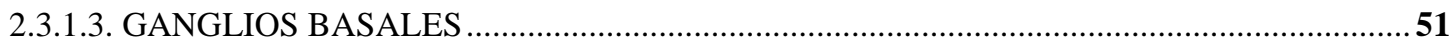

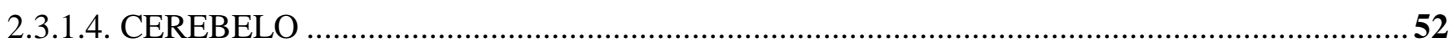

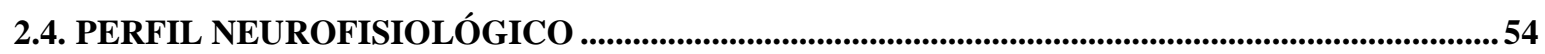

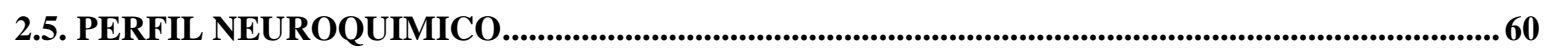

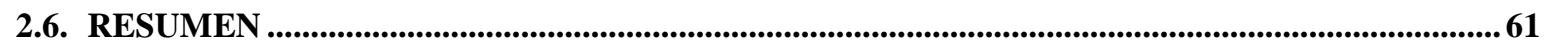

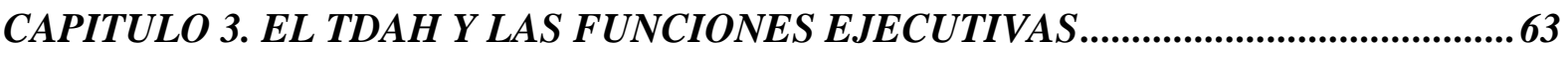

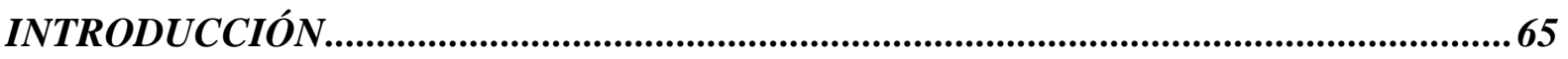


3.1. EL MODELO EXPLICATIVO DE RUSSELL BARKLEY (1997): EL MODELO DE AUTORREGULACION

3.2. EL PATRON TDAH APLICADO AL MODELO TEORICO DE RUSSELL BARKLEY .............70

3.3 RESUMEN 72

CAPITULO 4. HISTORIA DEL DESARROLLO DE LA ELECTROENCEFALOGRAFIA

4.1. HISTORIA DEL DESARROLLO DEL EEG . .75

4.2. DESARROLLO DE LOS MÉTODOS CUANTITATIVOS EN EL EEG: DEL EEG AL EEG CUANTITATIVO O CARTOGRAFÍA CEREBRAL (EEGq) . .80

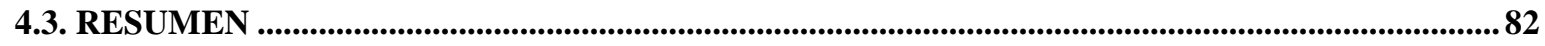

CAPITULO 5. ASPECTOS TÉCNICOS DEL EEG Y LA EEGq ..................................85

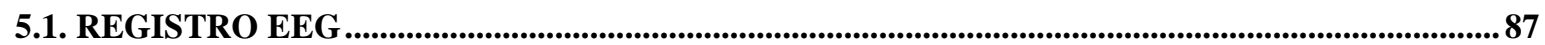

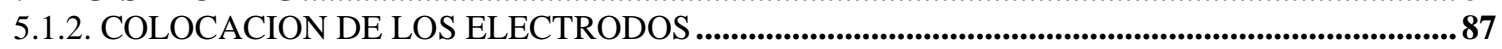

5.1.3. DERIVACIONES .................................................................................................................................................90

5.1.4. TIPOS DE MONTAJES EN EL EEG.............................................................................................................90

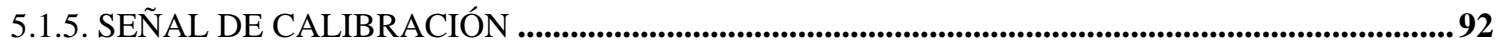

5.2 TÉCNICA Y METODOLOGIA DEL EEGQ: ASPECTOS PRÁCTICOS.............................................93

5.2.1. MÉTODOS DE ANÁLISIS ...............................................................................................................95

5.3. METODOLOGIA DE LOS MAPAS DE ACTIVIDAD ELECTRICA CEREBRAL ......................96

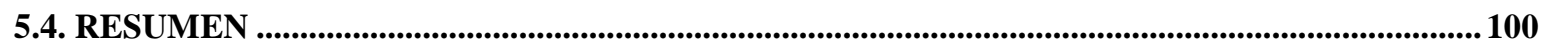

CAPITULO 6. MODELOS NEUROFISIOLÓGICOS EN EL TDAH.............................. 101

6.1. HISTORIA DE LA INVESTIGACIÓN CIN EL EEG EN EL TDAH. REGISTRO EEG ..............103

6. 2. ESTUDIOS CUANTITATIVOS DEL EEG: DEL EEG A LA EEGq ……...................................105

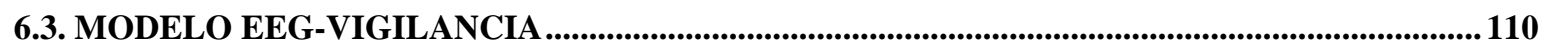

6.3.1.EEG VIGILANCIA-ALGORITMO VIGALL.........................................................................................111

6.3.2 MODELO EEG -VIGILANCIA EN EL TDAH .............................................................................................113

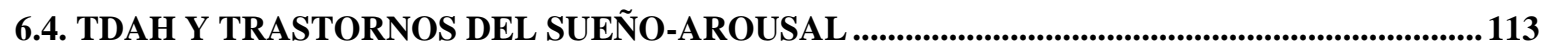

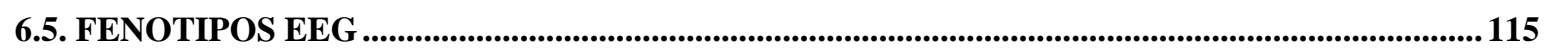

6.5.1. PRINCIPALES FENOTIPOS EEG ..................................................................................116

6.6. MODELOS EXPLICATIVOS TDAH BASADOS EN EL EEG y la EEGq ...................................117

6.6.1. LA PERSPECTIVA DEL RETRASO MADURATIVO ..................................................................117

6.6.2. LOS CLUSTER-EEG Y LA DISFUNCION DEL SNC ..................................................................119

6.7. EL EEG COMO HERRAMIENTA DIAGNÓSTICA EN EL TDAH. PRE-DICCIÓN DE LA RESPUESTA AL TRATAMIENTO FARMACOLÓGICO EN EL TDAH .......................................120

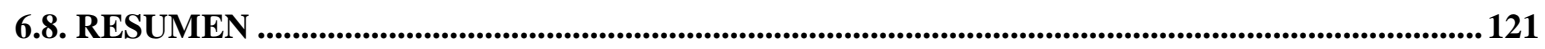

CAPITULO 7. INSTRUMENTOS DE EVALUACION DEL TDAH .............................. 123

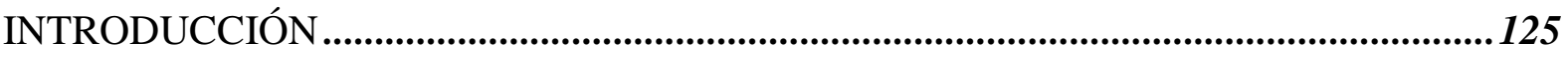

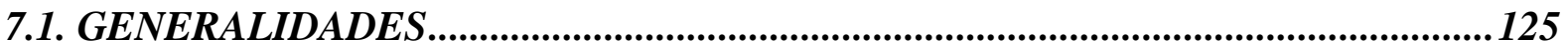

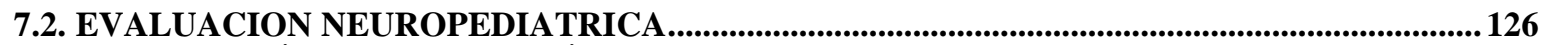

7.3. EVALUACIÓN PSICOPATOLÓGICA......................................................................129

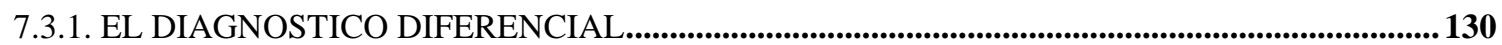

7.3.2. INSTRUMENTOS DE EVALUACIÓN................................................................................................132

7.3.3. INSTRUMENTOS DE ENTREVISTA ..........................................................................................132

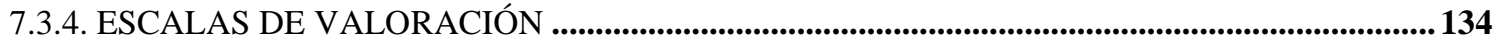

7.3.5. ESCALAS DE VALORACION DE AMPLIO ESPECTRO .....................................................................135

7.3.6. ESCALA DE VALORACIÓN ESPECÍFICA DEL TDAH....................................................................136 


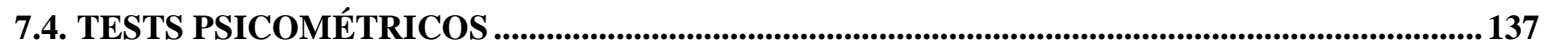

7.4.1.EVALUACION GENERAL DE APTITUDES COGNOSCITIVAS ....................................................138

7.4.2.TESTS DE ATENCIÓN ..................................................................................................................139

7.4.3.PRUEBAS DE MEMORIA ............................................................................................................................... 139

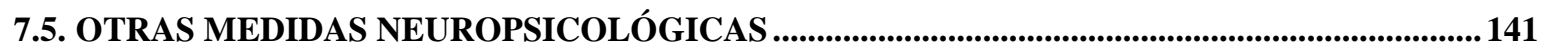

7.5.1 EL TEST DE LA FIGURA COMPLEJA DE REY-OSTERRIETH.......................................................143

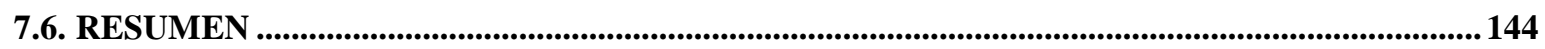

CAPITULO 8. INSTRUMENTOS COMPLEMENTARIOS DE .................................... 147

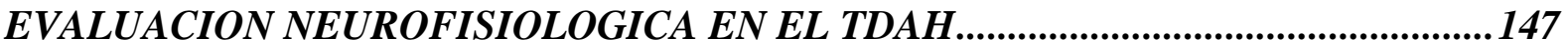

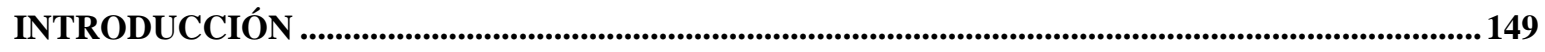

8.1. CARACTERISTICAS TÉCNICAS DE LOS ESTUDIOS NEUROFISIOLÓGICOS ......................150

8.1.1. EL ELECTROENCEFALOGRAMA (EEG) .....................................................................................150

8.1.2. LA CARTOGRAFIA CEREBRAL O EEG CUANTIFICADO (EEGq)............................................151

8.1.3. POTENCIALES EVOCADOS (PE) ................................................................................................153

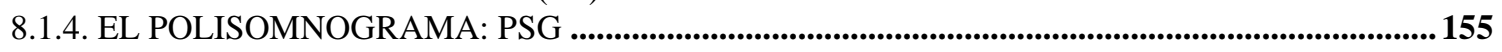

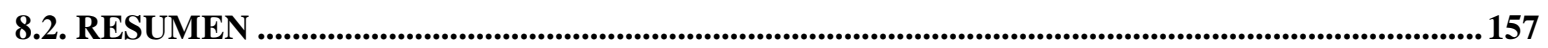

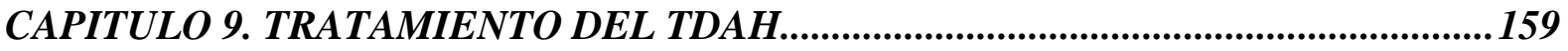

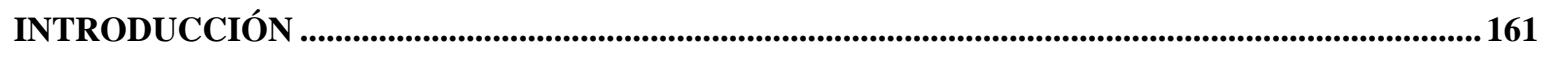

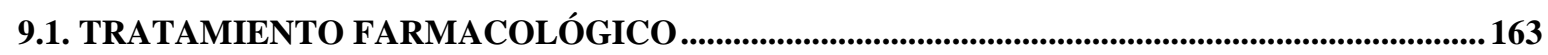

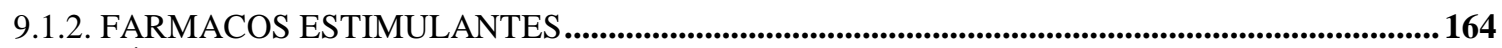

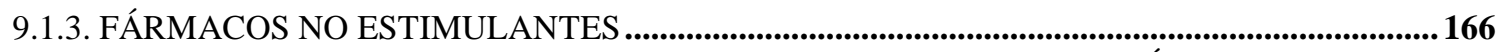

9.1.4. LA PREOCUPACION SOCIAL POR EL TRATAMIENTO FARMACOLÓGICO.........................167

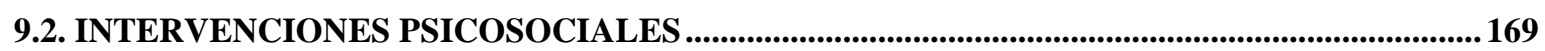

9.2.1. INTERVENCIONES PARA INFORMAR SOBRE EL TDAH Y LOS TRASTOR-NOS

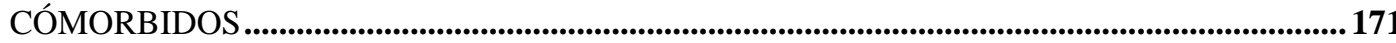

9.2.2. INTERVENCIONES PARA INFORMAR SOBRE EL TRATAMIENTO........................................171

9.2.3. INTERVENCIONES PARA REGISTRAR Y MODIFICAR EL CURSO DEL TRATAMIENTO

. TDAH SUS FAMILIAS Y PROFESORES .........................................................................174

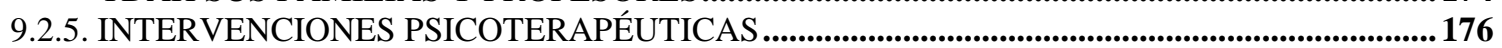

9.2.6. INTERVENCIONES EN EL MEDIO ESCOLAR ....................................................................................177

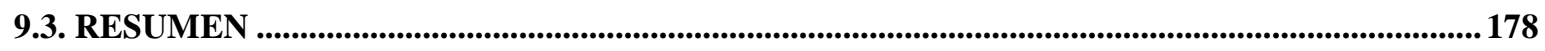

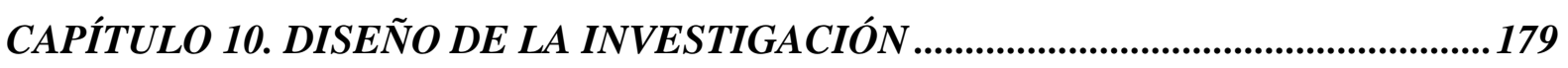

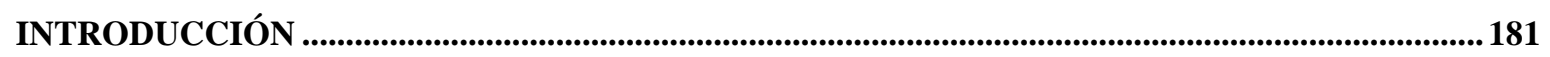

10.1. PLANTEAMIENTO DEL PROBLEMA...............................................................................................183

1.2. OBJETIVOS............................................................................................................................................ 185

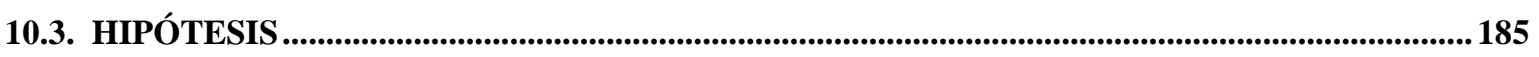

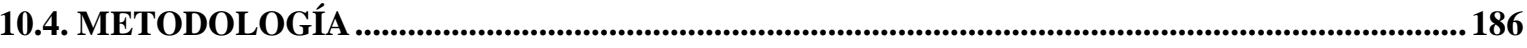

10.4.1. PROCEDIMIENTO ............................................................................................................................ 186

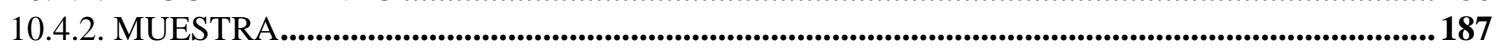

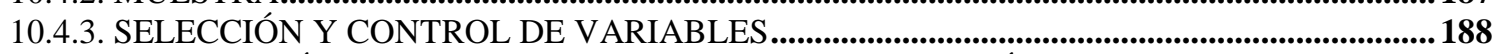

10.4.4. DESCRIPCIÓN DE LOS INSTRUMENTOS NEUROFISIO-LÓGICOS ........................................190

10.4.5. RECOGIDA Y ANÁLISIS DE DATOS..............................................................................................192

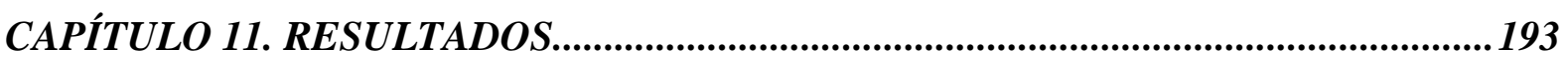

11.1. CARACTERÍSTICAS DE LAS MUESTRAS.......................................................................195

11.2. COMPROBACIÓN DE LA ASOCIACIÓN Y EL RIESGO DE LAS ALTERACIONES EN LA CARTOGRAFIA EN LAS DIFERENTES MUESTRAS ……..........................................................203 
11.2.1. ESTUDIO DE ASOCIACIÓN DE LA ALTERACIÓN EN LA CARTOGRAFIA CON LA EXISTENCIA O NO DE DIAGNÓSTICO

11.2.2. ESTUDIO DE ASOCIACIÓN DE LA ALTERACIÓN DE LA CARTOGRAFÍA CON LA MUESTRACOMPLETA DE TDAH.

11.2.3.ESTUDIO DE ASOCIACIÓN DE LA ALTERACIÓN EN LA CARTOGRAFÍA CON LOS DIAGNÓSTICOS DE TDAH TIPO COMBINADO .

11.2.4. ESTUDIO DE ASOCIACIÓN DE LA ALTERACIÓN DE LA CARTOGRAFÍA CON LOS DIAGNÓSTICOS DE TDAH TIPO DEFICIT DE ATENCIÓN .

11.2.5. ESTUDIO DE ASOCIACIÓN DE LA ALTERACIÓN DE LA CARTOGRAFÍA CON LOS DIAGNÓSTICOS DE TDAH TIPO IMPULSIVO HIPERACTIVO

11.2.6. ESTUDIO DE ASOCIACIÓN DE LA ALTERACIÓN DE LA CARTOGRAFÍA CON LOS DIAGNÓSTICOS DE TDAH SIN ESPECIFICAR

11.3. COMPROBACIÓN DEL RIESGO QUE RELACIONA LAS ALTERACIONES EN LA CARTOGRAFIA EN EL TDAH COMPARANDOLO CON OTROS DIAGNÓSTICOS PSICOPATOLÓGICOS

11.3.1. ESTUDIO DE ASOCIACIÓN DE LA ALTERACIÓN DE LA CARTOGRAFÍA CON TODOS LOS TIPOS DE DIAGNÓSTICOS DE TDAH.

11.3.2. ESTUDIO DE ASOCIACIÓN DE LA ALTERACIÓN DE LA CARTOGRAFÍA CON LOS DIAGNÓSTICOS DE TDAH TIPO COMBINADO

11.3.3. ESTUDIO DE ASOCIACIÓN DE LA ALTERACIÓN DE LA CARTOGRAFÍA CON LOS DIAGNÓSTICOS DE TDAH-DEFICIT DE ATENCIÓN.

11.3.4. ESTUDIO DE ASOCIACIÓN DE LA ALTERACIÓN DE LA CARTOGRAFÍA CON LOS DIAGNÓSTICOS DE TDAH TIPO IMPULSIVO HIPERACTIVO

11.3.5. ESTUDIO DE ASOCIACIÓN DE LA ALTERACIÓN DE LA CARTOGRAFÍA CON LOS DIAGNÓSTICOS DE TDAH TIPO SIN ESPECIFICAR

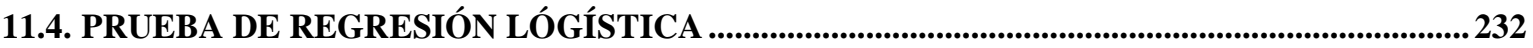

CAPÍTULO 12. CONCLUSIONES, DISCUSION Y LÍNEAS FUTURAS .......................237

12.1. CONCLUSIONES DEL ESTUDIO ...................................................................................................239

12.2. DISCUSIÓN Y LINEAS FUTURAS DE INVESTIGACION............................................................241 


\section{ÍNDICE DE TABLAS}

TABLA 1. CRITERIOS DIAGNóSTICOS PARA EL TDAH EN LA CIE- 10 (MENÉNDEZ, 2001) ................................... 32

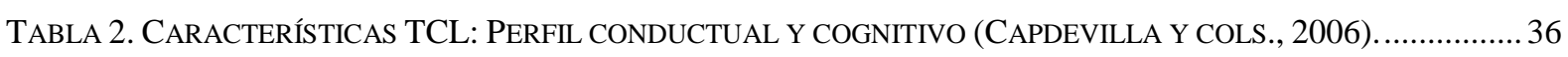

TABLA 3. METANÁLISIS DEL VOLUMEN TOTAL CEREBRAL EN EL TDAH, CASTELLANOS Y COLS., 2004)...............53

TABLA 4. RESUMEN DE LOS HALLAZGOS ANATÓMICOS EN EL TDAH Y LAS CARACTERÍSTICAS OBSERVABLES EN NEUROIMAGEN (CASTELLANOS Y COL., 2004; POPPER Y WEST ,2005) …………………........................... 53

TABla 5. PARÁMETROS DE SUEÑo EN NIÑOS NORMALES Y CON TDAH. (BERNAL-LA FUENTE Y COLS 2002)...... 58

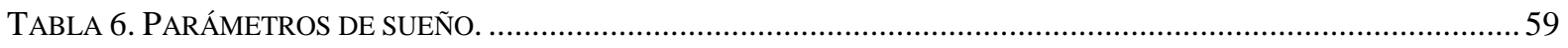

TABLA 7 Sistema INTERNACIONAL COLOCACIÓN ELECTRODOS 10-20 (TEJEIRO, 2005) …................................... 89

TABLA 8 PROPIEDAdES DE LOS Distintos MÉTOdOS DE DERIVACIÓN. (BINNIE, 1982; GIL-NAGEL Y COLS ,2001)

TABla 9. CARACTERísticas téCNICAS DE LA QEEG (CABANYES-TRUFino, 2004). 100

TABla 10. Efectos terapéuticos de los Psicoestimulantes. (DíAZ de ATIENZA, 2006; Toro y Cols, 1998) 165

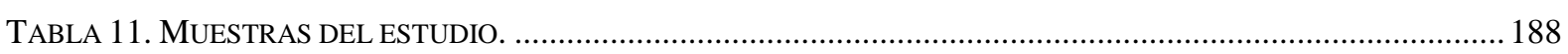

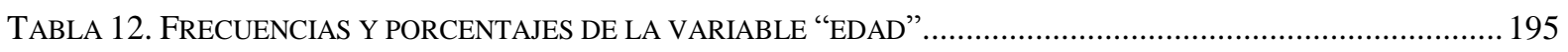

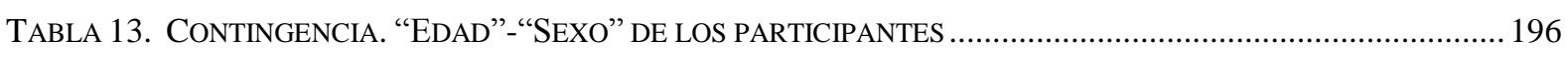

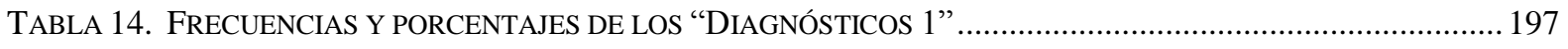

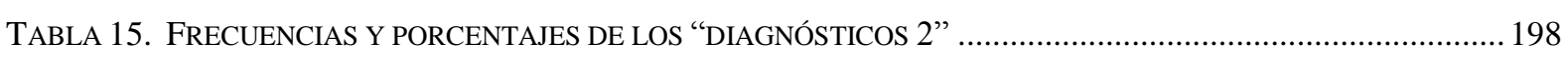

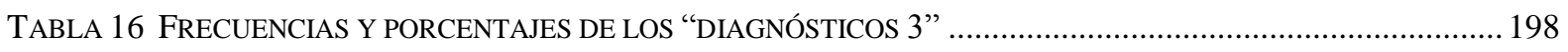

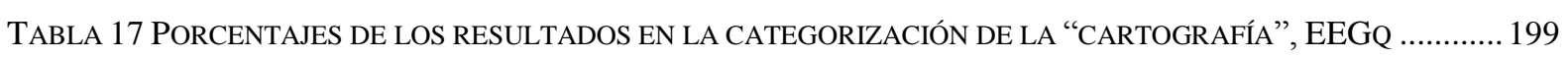

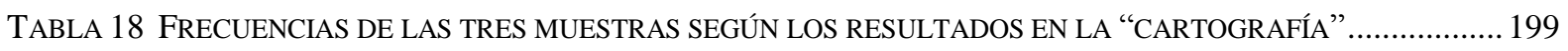

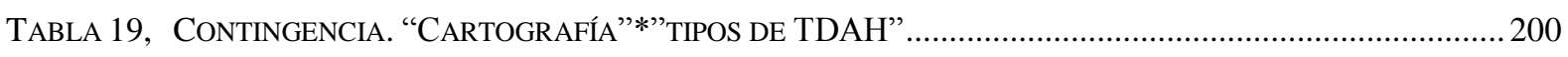

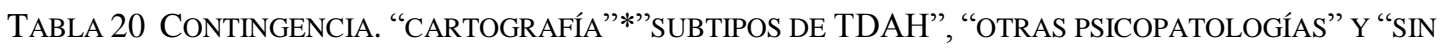

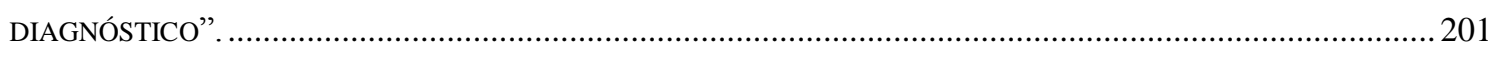

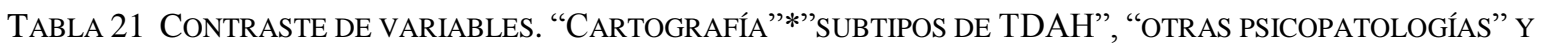

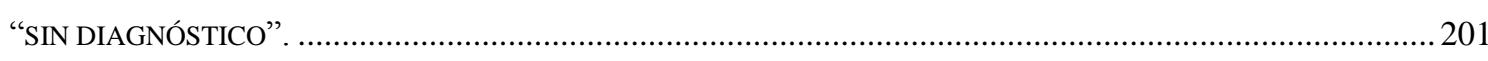

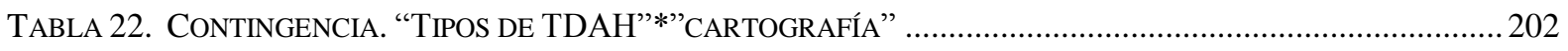

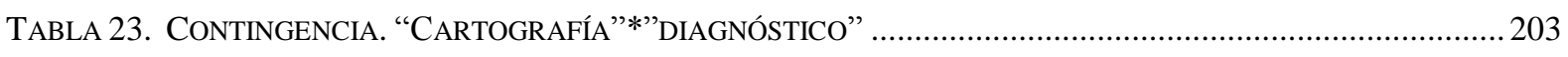

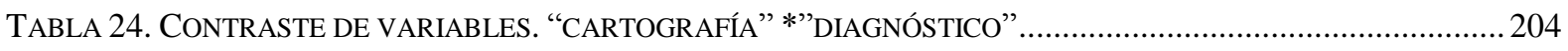


TABLA 25. ESTIMACIÓN DE RIESGO. “CARTOGRAFÍA”*”DIAGNÓSTICO”. 205

TABLA 26 CONTINGENCIA. “CARTOGRAFÍA”*TDAHT Y” SIN DIAGNÓSTICO” 207

TABla 27 CONTRASTE DE VARIABLES. “CARTOGRAFÍA”*TDAHT Y” Sin DiAGNÓSTICO” 208

TABLA 28 ESTIMACIÓN DE RIESGO. “CARTOGRAFÍA”*TDAHT Y” SIN DIAGNÓSTICO” 208

TABLA 29 CONTINGENCIA. ALTERACIÓN EN LA “CARTOGRAFÍA”* “TDAH-COMBINADO” 209

TABla 30. CONTRASTE de VARIABles. AltERACIÓN EN LA "CARTOGRAFÍA"* “TDAH-COMBINADO". 210

TABLA 31 ESTIMACiÓN DE RIESGO. ALTERACIÓN EN LA “CARTOGRAFÍA”* TDAH-COMBINADO. 211

TABlA 32 CONTINGENCIA. "CARTOGRAFÍA”* “TDAH-DÉFICIT ATENCIÓN” 212

TABla 33. CONTRASTE DE VARIABLES. “CARTOGRAFÍA” *” TDAH-DÉFicit ATENCIÓN”. 213

TABLA 34. ESTIMACIÓN DE RIESGO. “CARTOGRAFÍA"*”TDAH-DÉFICIT ATENCIÓN”. 214

TABLA 35. CONTINGENCIA. “CARTOGRAFÍA”*TDAH-IMPULSIVO-HIPERACTIVO. 215

TABla 36. CONTRASTE DE VARIABLES. “CARTOGRAFÍA”*”TDAH-IMPULSIVO-HIPERACTIVO”. 216

TABLA 37. ESTIMACIÓN DE RIESGO. “CARTOGRAFÍA”*”TDAH-IMPULSIVO HIPERACTIVO”. 216

TABLA 38. CONTINGENCIA. "CARTOGRAFÍA"*TDAH-“SIN ESPECIFICAR”, 217

TABla 39. CONTRASTE DE VARIABLES. “CARTOGRAFÍA”*'TDAH-Sin ESPECIFICAR” 218

TABLA 40. ESTIMACIÓN DE RIESGO. “CARTOGRAFÍA” *”TDAHS-SIN ESPECIFICAR” 219

TABLA 41. CONTINGENCIA “CARTOGRAFÍA”*”TDAHT Y OTRO DIAGNÓSTICO”. 220

TABLA 42. CONTRASTE DE VARIABLES. “CARTOGRAFÍA”*”TDAHT Y OTRO DIAGNÓSTICO”. 221

TABLA 43. ESTIMACIÓN DE RIESGO. “CARTOGRAFÍA”*”TDAHT” Y “OTRO DIAGNÓSTICO”. 222

TABLA 44. CONTINGENCIA. "CARTOGRAFÍA"*”TDAH-COMBINADO” Y “OTRO DIAGNÓSTICO”. 222

TABla 45. CONTRASTE DE VARIABLES. “CARTOGRAFÍA”*”TDAH-COMBINADO” Y “OTRO DiAGNÓSTICO”. ......223

TABLA 46. ESTIMACIÓN DE RIESGO. “CARTOGRAFÍA”*”TDAH-COMBINADO” Y “OTRO DIAGNÓSTICO”. .224

TABla 47. CONTINGENCIA. “CARTOGRAFÍA”*”TDAH-DÉF. DE ATENCIÓN” Y “OTRO DiAGNÓSTICO”. 225

TABla 48. CONTRASTE DE VARIABLES. “CARTOGRAFÍA”*”TDAH-DÉF. DE ATENCIÓN" Y “OTRO DIAGNÓSTICO”

TABLA 49. ESTIMACIÓN DE RIESGO. “CARTOGRAFÍA”*”TDAH-DÉF. DE ATENCIÓN” Y “OTRO DIAGNÓSTICO”. . 226

TABla 50. CONTINGENCIA. “CARTOGRAFÍA”*”TDAH-IMPULSIVO-HIPERACTIVO Y OTRO DIAGNÓSTICO”. ....... 227

TABLA 51. CONTRASTE DE VARIABLES. “CARTOGRAFÍA”*”TDAH-IMPUL.-HIPER.” Y “OTRO DIAGNÓSTICO”.... 228

TABLA 52. ESTIMACIÓN DE RIESGO. “CARTOGRAFÍA”*TDAH-IMP.-HIPERACTIVO Y OTRO DIAGNÓSTICO 229

TABLA 53. CONTINGENCIA. “CARTOGRAFÍA”*TDAH-SIN ESPECIFICAR Y OTRO DIAGNÓSTICO 230 
TABla 54. CONTRASTE DE VARIABLES. “CARTOGRAFÍA”*TDAH-Sin ESPECIFICAR Y OTRO DIAGNÓSTICO....... 231

TABLA 55. ESTIMACIÓN DE RIESGO. “CARTOGRAFÍA”*TDAH-SIN ESPECIFICAR Y OTRO DIAGNÓSTICO..............2231

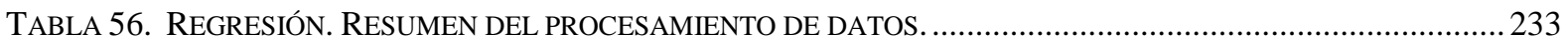

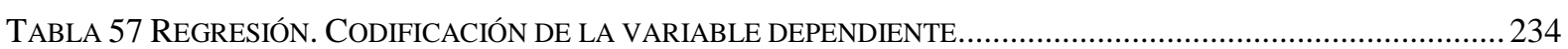

TABLA 58. REGRESION. CODIFICACIÓN DE LAS VARIABLES CATEGÓRICAS..................................................235

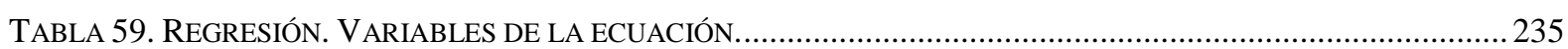

\section{ÍNDICE DE FIGURAS}

FIGURA 1 CARACTERÍSTICAS DEL TDAH A PARTIR DEL MODELO DE AUTORREGULACIÓN DE RUSSELL BARKLEY

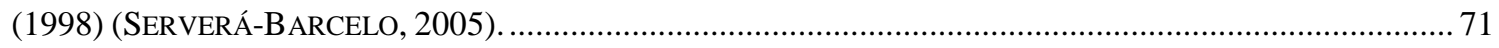

FigURA 2 ALTERACIÓN DE LAS FUNCIONES EJECUTIVAS EN EL TDAH (BROWN, 2001; BROWN, 2006) ................71

FIGURA 3. EEG VIGILANCIA DENTRO DE UN CONTINUO DE ALTO Y BAJO NIVEL DE VIGILANCIA (ARNS Y COLS, 2011).

FIGURA 4 ELECTROENCEFALOGRAFÍA BÁSICA TEJEIRO, 2005.

FIGURA 5. MAPAS DE SIGNIFICACIÓN ESTADÍSTICAS DE UN EEG CUANTIFICADO. (CABANYES-TRUFINO, 1999) 152

Figura 6 REgistro PSG CONVENCIONAL. AlgunAS PARTES DEL REGISTRO (TEJEIRO, 2005) ..... 157

FIGURA 7. CARACTERÍSTICAS DE LA VARIABLE “GÉNERO” DE LAS MUESTRAS 195

Figura 8. GRAFICO DE BARRAS. "CARTOGRAFÍA"*”TIPOS DE TDAH”, 202

FIGURA 9. GRÁFICO DE BARRAS.”CARTOGRAFÍA"*”DIAGNÓSTICO” 204

FIGURA 10 “CARTOGRAFÍA” SI/ NO * TDAHT Y” SIN DIAGNÓSTICO”. 207

Figura 11. Chi CUADRADO. Alteración EN LA "CARTOGRAFÍA”* “TDAH COMBINADO”. 210

FIGURA 12, “CARTOGRAFÍA” * “TDAH DÉFICIT ATENCIÓN"

FIGURA 13. “CARTOGRAFÍA"*”TDAH-IMPULSIVO HIPERACTIVO.” 215

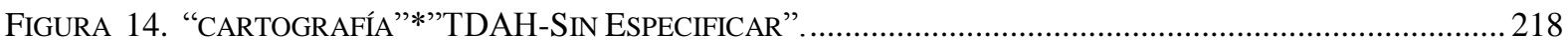

FIGURA 15. GRÁFICO DE BARRAS “CARTOGRAFÍA”*”TDAHT Y OTRO DIAGNÓSTICO”....................................220

FIGURA 16. GRAFICO DE BARRAS. “CARTOGRAFÍA”*”TDAH-COMBINADO” Y “OTRO DIAGNÓSTICO”223

FIGURA 17 GRÁFICO DE BARRAS. “CARTOGRAFÍA”*”TDAH-DÉFICIT DE ATENCIÓN” Y “OTRO DIAGNÓSTICO”. 225 FIGURA 18. GRÁFICO DE BARRAS. “CARTOGRAFÍA”*”TDAH-IMPULSIVO-HIPERACTIVO Y OTRO DIAGNÓSTICO”. 
Utilidad de la cartografía cerebral en el diagnóstico del TDAH 


\section{INTRODUCCIÓN}

El trastorno por déficit de atención/hiperactividad (TDAH) es una entidad neurobiológica marcadamente heterogénea. Es la alteración del neurodesarrollo más frecuente en la población infantil. Basándonos en Fernández- Perrone y cols. (2013), se estima que su prevalencia es del 3 al $6 \%$ en niños en edad escolar.

Presentan alteraciones en los mecanismos atencionales y/o en los procesos de control inhibitorio (impulsividad e hiperactividad), que afectan de distinta manera a su rendimiento académico, socioemocional y conductual. (Abad-Mas y cols, 2013).

Nuestro interés en esta tesis tras revisar el campo teórico, es comprobar la importancia que tiene la Técnica de la Cartografía Cerebral en la identificación y diagnóstico de los niños y jóvenes afectados de Trastorno por Déficit de Atención con Hiperactividad (TDAH), trastorno incluido en los sistemas de clasificación dentro del apartado Trastornos de inicio en la infancia, la niñez o la adolescencia. La experiencia personal en los servicios de psicología y en neurofisiología clínica me ha posibilitado reflexionar sobre la amplia presencia de perfiles neurofisiológicos con alteraciones en este trastorno. Observando que la comunidad de profesionales, cuyo interés se centra en el estudio diagnóstico de los niños y jóvenes con TDAH, demanda pruebas que posibiliten una mayor concreción y objetividad.

La secuencia de esta tesis dividida en dos partes, la parte teórica y la de investigación, contiene 12 capítulos. En los nueve primeros exponemos el marco conceptual del trastorno, para ello y en un primer abordaje descriptivo, analizamos la historia del trastorno, desde los 
primeros inicios terminológicos hasta llegar a los criterios diagnósticos actuales que se manejan en clínica.

En el segundo capítulo, analizamos descriptivamente las características que presentan estos niños, abordamos este capítulo desde un enfoque basado en perfiles, describimos la cognición y el comportamiento, el perfil neuropsicológico, el perfil neuroanatómico y de neuroimagen, el perfil neurofisiológico y el perfil neuroquímico.

En un tercer capítulo, describimos lo que se conoce sobre el trastorno, desde lo que entendemos por funciones ejecutivas hasta los modelos explicativos del TDAH basado en las funciones ejecutivas, (FE).

En el cuarto capítulo, nos centramos en hacer una revisión sobre la historia del desarrollo de la electroencefalografía, revisamos y exponemos las primeras descripciones de la actividad eléctrica y los primeros registros del electroencefalograma, (EEG), hasta el desarrollo de los métodos cuantitativos en el EEG por medio de la cartografía cerebral, (EEGq).

En el quinto capítulo, nos centramos en los aspectos técnicos del registro EEG y describimos los aspectos técnicos de la EEGq, así como su metodología y su posterior interpretación o análisis.

En el sexto capítulo revisamos los principales modelos neurofisiológicos que explican los perfiles TDAH basados en el EEG y la EEGq e incluimos una descripción de los modelos explicativos del TDAH basados en el EEG y la EEGq.

En el séptimo, hacemos un repaso global de los instrumentos de evaluación que se utilizan para ayudar al diagnóstico de este trastorno, desde la valoración de los diferentes profesiones que evalúan este trastorno, hasta la descripción de las principales pruebas psicométricas de evaluación de los diferentes procesos cognitivos implicados; emocionales, familiares, sociales y escolares que en este trastorno se evalúa. 
En el ocho, tratamos el tema de los tratamientos disponibles en el TDAH una vez realizado el diagnóstico de este trastorno. En este capítulo hacemos un abordaje general de los actuales tratamientos disponibles. En sus diferentes epígrafes podemos encontrarnos con la descripción del tratamiento cognitivo- conductual, farmacológico, multimodal, psicosocial y tratamiento escolar.

En el noveno capítulo, desarrollamos el tema de los instrumentos complementarios en la evaluación neurofisiológica del TDAH, haciendo una descripción de aquellos elementos de evaluación que nos ayudan a delimitar más claramente el diagnóstico.

La segunda parte contiene 3 capítulos, tras el décimo, en el que se realiza el diseño y planteamiento de nuestro estudio cuyo objetivo es corroborar empíricamente la utilidad que tiene la cartografía cerebral en el diagnóstico del TDAH, le sigue el de resultados obtenidos.

El último capítulo lo dedicamos a exponer las conclusiones, la discusión y las posibles líneas futuras de investigación. 
Utilidad de la cartografía cerebral en el diagnóstico del TDAH 
Capítulo 1. Descripción clínica del TDAH

CAPITULO 1. DESCRIPCION CLINICA DEL TDAH 
Utilidad de la cartografía cerebral en el diagnóstico del TDAH 


\section{INTRODUCCIÓN}

El TDAH es la etiqueta diagnóstica más comúnmente utilizada en niños, jóvenes y recientemente también en adultos (Ministerio de Sanidad, política social e igualdad 2010). Se caracteriza por problemas significativos de atención, asociados o no a impulsividad y actividad excesiva. Además, con gran frecuencia existen otros cuadros psicopatológicos asociados (APA, 2002, Barkley, 2006). Aunque la idea actual del trastorno es relativamente nueva, las primeras descripciones clínicas aparecieron hace un siglo. Los síntomas identificados entonces se han mantenido en la definición del trastorno. Sin embargo, la nomenclatura, el modo de entenderlo, los criterios diagnósticos y las teorías etiológicas han ido cambiando a medida que se desarrollaba el conocimiento de la enfermedad. En este capítulo revisaremos brevemente los principales trabajos que han contribuido a definirla tal y como hoy la entendemos, así como la evolución de los criterios diagnósticos.

\subsection{RECORRIDO HISTORICO POR EL CONCEPTO DE TDAH}

\subsubsection{ALEXANDER CRICHTON Y LA INCAPACIDAD PARA ATENDER CON UN NECESARIO GRADO DE CONSTANCIA HACIA UN OBJETO}

La primera descripción del trastorno similar a lo que hoy conocemos como TDAH se debe a Alexander Crichton, en 1798. Crichton (1763-1856) nació en Edimburgo y estudió Medicina en la Universidad de Leiden (Holanda). Durante su estancia en Paris, Stuttgart y 
Viena observó casos de locura y se interesó por las enfermedades mentales. En 1798 publicó un libro en tres volúmenes, que tituló "An inquiry into the nature and origin of mental derangement: comprehending a concise system of the physiology and pathology of the human mind and a history of the passions and their effects". En él recoge observaciones de casos clínicos de enfermedad mental, analizados desde el punto de vista médico-fisiológico. Este enfoque de la patología mental era inusual en la época en que Crichton publicó su investigación (Palmer y Finger, 2001).

Dedicó un capítulo a la atención y sus trastornos. Comienza con una definición de lo que es la atención. Según su idea, la intensidad de la atención sana varía entre individuos e incluso en una persona a lo largo del día. Por tanto, la distracción no tiene por qué ser patológica. Algunos factores que afectan a la intensidad de la atención son la estimulación mental, la volición o la educación. Pueden tener un gran impacto en una atención sana.

Distingue dos posibilidades de alteración de la atención, que considera polos opuestos del funcionamiento de la "sensibilidad de los nervios". La primera es la incapacidad de atender con el necesario grado de constancia hacia un objeto. La segunda es la suspensión total de la atención. La incapacidad de atender con el necesario grado de constancia hacia un objeto se presenta casi siempre desde una sensibilidad antinatural o mórbida de los nervios, por lo que se retira de una impresión a otra. Ésta incapacidad podía estar presente desde el nacimiento en una persona o ser consecuencia de un trastorno accidental.

Cuando es congénita o, en palabras de Crichton, nacida con la persona, se hace evidente en las primeras etapas de la vida y tiene graves consecuencias puesto que imposibilita al niño para atender con constancia hacia ningún objeto de educación. Su magnitud impide totalmente la instrucción. En los casos más favorables disminuye con la edad (Crichton, 1789). 
En esta corta descripción del primer tipo de alteración de la atención, Crichton da varias indicaciones que se asemejan al trastorno que la actual DSM-IV-TR (APA, 2002) denomina TDAH. En primer lugar, la caracterización del trastorno como "la incapacidad de atender con el necesario grado de constancia hacia un objeto" es consistente con el segundo síntoma del criterio A1, que corresponde a la inatención, definida en la DSM-IV-TR como la dificultad en mantener la atención en tareas o actividades lúdicas. En segundo lugar, afirma que "esta facultad es incesantemente retirada de una impresión a otra". Esta descripción coincide con el criterio de la DSM-IV-TR “a menudo es distraído con facilidad por estímulos externos". En tercer lugar, considera que el trastorno puede ser "nacido con la persona" y que “cuando nace con la persona comienza a ser evidente en un periodo temprano de la vida". Según la DSM-IV-TR, los síntomas del TDAH tienen que estar presentes antes de los siete años de edad. Finalmente, la observación sobre "la incapacidad de atender con constancia hacia nigún objeto de educación" sugiere que Crichton identificó las dificultades escolares comunmente observadas en la actualidad en niños con TDAH.

Por otra parte, consideraba que el trastorno "generalmente disminuye con la edad" (Crichton, 1798). Esta noción es similar a la que se mantuvo hasta los años 90, que veía en el TDAH un trastorno de la infancia, que afecta a niños en crecimiento hasta la pubertad (Barkley, 2006a; Okie,2006). Hay que señalar que actualmente esta idea no se mantiene. Según estudios recientes el 50\% de los niños diagnosticados con TDAH mantienen los síntomas durante la vida adulta (Arolt, 2008; Okie, 2006).

Para Crichton la incapacidad de atender, si no es innata, puede ser causada por trastornos nerviosos. Este concepto más tarde se reconceptualizó como "daño cerebral mínimo o disfunción cerebral mínima”.

Los pacientes que observó Crichton mostraban una gran distraibilidad ante estímulos externos, incluso de leve intensidad, una considerable inquietud mental y quizás un cierto 
tipo de impulsividad en los caso en que el trastorno "excitaba tanto en grado de ira como en la frontera de la locura" (Crichton, 1798).

Aunque los síntomas observados por Crichton pueden ser asociados con el TDAH, sus descripciones no reflejan totalmente el actual concepto de la enfermedad. Concretamente, no menciona ningún síntoma de hiperactividad. Es posible que Crichton observara síntomas de hiperactividad e impulsividad en sus pacientes, pero no estableció una correlación entre estas variables y decidió no incluirlas en sus descripciones. Otra posibilidad es que Crichton haya obervado el subtipo inatento del TDAH, más coherente con sus descripciones. En cualquier caso, no observó todos los criterios que hoy se utilizan en el diagnóstico clínico (Palmer y Finger, 2001, 2010).

\subsubsection{UN POSIBLE ANTECEDENTE EN LA LITERATURA INFANTIL}

Otros autores han querido ver la primera descripción del TDAH en un libro para niños del médico alemán Heinrich Hoffmann (1809-1894). La obra, titulada Struwwelpeter, tuvo un gran éxito y fue traducida a numerosos idiomas. En castellano se tituló Pedro Melenas (Hoffman, 2007). En ella se describe en verso el mal comportamiento de diferentes niños y el castigo que reciben. Uno de ellos, Felipe el Berrrinchudo, o en otras traducciones Felipe Revueltas, es un niño inquieto e indisciplinado, retratado durante una comida con sus padres. Su inquietud y movimiento continuo provocan un accidente: acaba cayéndose de la silla y arrastrando con él mantel y comida.

A simple vista es una escena familiar para familias niños con TDAH. Sin embargo, hay que señalar que el propio contexto, descripciones de mal comportamiento infantil, como falta de higiene, crueldad con los animales, juegos peligrosos, burlas racistas, caprichos con 
la comida, o chuparse el dedo, sugiere que Hoffmann no consideraba patológico el comportamiento de Felipe. De hecho, a pesar de su gran difusión, sólo recientemente se ha sugerido que Felipe el Berrinchudo retrata un niño hiperactivo (Sandberg, 2002).

\subsubsection{LA DESCRIPCIÓN DE GEORGE STILL Y ALFRED TREDGOLD: EL DEFECTO DE CONTROL MORAL}

La primera descripción clínica unánimente admitida fue obra del pediatra inglés George Frederick Still (1868-1941). Autor de varios textos médicos sobre enfermedades infantiles, en 1902 describió lo que llamó defecto del control moral en niños (Still, 1902). Entendía por control moral el control de la acción de acuerdo con la idea de lo bueno para todos y consideraba que dependía de tres factores: la relación cognitiva con el entorno, la conciencia moral y la volición. Dado que se trata de capacidades intelectuales, el defecto de control moral sería esperable en niños con dificultades intelectuales. Sin embargo, según sus observaciones, existían otros niños en los que, en ausencia de retraso mental o enfermedades físicas, aparecía el defecto de control moral, con las siguientes características: Vehemencia, rencor-crueldad, celos, tendencias criminales, falta de honradez, travesuras inmoralestendencia a la destrucción, falta de vergüenza, inmoralidad sexual y brutalidad. El elemento común a todas ellas es la búsqueda de gratificación inmediata, sin consideración de las otras personas o de las consecuencias para el propio sujeto. Es un elemento que hoy asociamos con la impulsividad.

También observó que en muchos casos había una clara incapacidad para mantener la atención, otro elemento central en el diagnóstico de TDAH. Esto sugiere que algunos de sus casos cumplirían los criterios diagnósticos actuales. Sin embargo, hay que señalar que el 
concepto de defecto de control moral de Still no representa el actual concepto de TDAH. Sus descripciones cubren, más bien, la totalidad de lo que hoy denominamos trastornos del comportamiento (Conners, 2000). Por otra parte, Still asoció el déficit de control moral a problemas cerebrales durante la primera infancia, iniciando la tradición científica que relaciona daño cerebral y comportamiento anómalo (Ross and Ross 1976).

La hipótesis del bajo control moral tuvo un nuevo desarrollo pocos años después. Otro médico inglés, Alfred Tredgold (1870-1952) publicó una influente obra: Deficiencia Mental (Tredgold, 1910). En ella describió una serie de niños con problemas de conducta, a los que consideraba deficientes mentales no idiotas o débiles mentales, incapaces de recibir beneficios de la educación ordinaria, pero que progresaban con atención individual y ayuda especializada. Según sus observaciones, mostraban anomalías físicas en el paladar y tamaño y forma del cráneo, signos neurológicos menores y problemas de coordinación. Mentalmente se caracterizaban por falta de sentido común, escaso juicio, pobre control inhibitorio de reacciones primitivas y baja atención. En otros casos observó inquietud motriz, impulsividad, desobediencia y conducta antisocial. Atribuyó el cuadro a diversos problemas orgánicos, como la herencia genética y problemas durante el parto, en particular anoxia perinatal y daño consiguiente del área cerebral responsable del sentido de la moral (Tredgold, 1908).

\subsubsection{EL TRASTORNO POSTENCEFALÍTICO DEL COMPORTAMIENTO: 1920- 1950}

La hipótesis de Tredgold relacionaba problemas cerebrales y dificultades de comportamiento y aprendizaje posteriores. Esta visión recibió un fuerte impulso tras la epidemia de encefalitis de 1917-1918. Gran número de niños que sobrevivieron a la infección mostraban cambios de personalidad, inestabilidad emocional, déficits cognitivos, dificultades 
de aprendizaje, tics, problemas de sueño, depresión y bajo control motor. También se observó con frecuencia hiperactividad, distraibilidad, irritabilidad y comportamiento destructivo y difícil de controlar. Muchos presentaban conductas disruptivas semejantes a las que actualmente incluimos en el trastorno oposicionista desafiante y otros trastornos de la conducta. El cuadro fue denominado trastorno postencefalítico del comportamiento (Barkley, 2006).

\subsubsection{EL TRASTORNO HIPERCINÉTICO DE LA INFANCIA (FRANZ KRANNER 1878- 1967 Y HANS POLLNOW 1902-1943)}

En 1932 los médicos alemanes Franz Kranner y Hans Pollnow presentaron la obra "Un trastorno hipercinético de la infancia”. En ella proponían un cuadro infantil que pasó a la historia como Síndrome de Kramer-Pollnow, cuyo síntoma más característico era la inquietud motora acusada (Kranner y Pollnow, 1932). Los autores señalan que los síntomas de este "trastorno hipercinético" habían sido previamente observados por otros autores, pero el trastorno no se había distinguido de otros cuadros con síntomas similares, como podían ser los efectos residuales en el caso de la epidemia de encefalitis letárgica. Dos ejemplos eran los trastornos del sueño o agitación nocturna, síntomas específicos del trastorno postencefálico. Por el contrario, la inquietud motora descrita por Kranner y Pollnow sólo se observaba durante el día. Los síntomas principales del trastorno hipercinético descrito por estos autores son muy similares al concepto actual del TDAH.

Para Kranner y Pollnow (1932) el síntoma más obvio de los niños con trastorno hipercinético es una notable actividad motora, carente de propósito. Según su descripción, los niños hiperquinéticos son incapaces de pararse durante un segundo, van de un lado para otro 
por la habitación, trepan prefiriendo muebles altos en particular y se disgustan cuando se les disuade de hacer algo siguiendo sus impulsos. La descripción es muy similar a la caracterización actual de la hiperactividad, uno de los principales síntomas presentes en el TDAH. La asociación americana de psiquiatría (APA, 2002) describe a niños con este trastorno que dejan sus asientos cuando permanecer sentado es lo esperado. Trepar en exceso podría considerarse como síntoma explícito de hiperactividad. A menudo se describe a los niños con TDAH como si estuvieran movidos por un motor.

\subsubsection{LA IMPORTANCIA DEL CONCEPTO DEL SÍNDROME DE DAÑO CEREBRAL. LOS ORÍGENES DEL MINIMAL BRAIN DAMAGE}

La epidemia de encefalitis hizo evidente la asociación entre daño cerebral y alteraciones conductuales, ya postulada por Still y Tredgold. Durante los años 30 se amplió esta noción, observándose que niños con traumatismo craneoencefálico desarrollaban problemas de comportamiento semejantes a los observados en el trastorno postencefalítico. También se asociaron las infecciones, intoxicación por plomo y la epilepsia con diferentes problemas cognitivos y conductuales. Finalmente, se encontraron semejanzas entre el comportamiento hiperactivo infantil y el de monos que habían sufrido ablación de los lóbulos frontales (Barkley, 2006). Se impuso la idea de que existía una explicación fisiológica de los

problemas de comportamiento y se acuñaron los conceptos de lesión cerebral y lesión cerebral mínima en aquellos casos en que la lesión no podía objetivarse (Kessler, 1980).

A partir de los trabajos de Strauss y Lehtinen (1947) y Strauss y Kephart (1955), se convirtió en habitual diagnosticar lesiones cerebrales a partir de síntomas conductuales, sin evidencia neurológica de cualquier lesión. Strauss y sus colaboradores identificaron diversos 
patrones conductuales que permitían diferenciar niños deficientes mentales con y sin lesión. En particular, consideraron que la hiperactividad era un signo suficiente para diagnosticar una lesión cerebral (Ross y Ross, 1976). De este modo, se aceptó que un síntoma específico estaba claramente asociado con una lesión cerebral (Conners, 2000). Las consecuencias diagnósticas y rehabilitadoras fueron grandes. Por una parte, se abría la puerta a la evaluación del funcionamiento cerebral a partir de observaciones conductuales. Por otra, proporcionaba una hipótesis de investigación y trabajo. Finalmente, favoreció la sistematización de alternativas de tratamiento. A medida que iba tomando cuerpo la teoría, se fueron creando programas especiales de educación para estos niños, en los que se incluían diferentes metodologías para evitar que se distrajeran con estímulos nuevos o extraños (Calderón, 2003).

\subsubsection{EL DESARROLLO DE LA PSICOFARMACOLOGÍA DEL TDAH}

En 1937 Charles Bradley dio a conocer sus trabajos sobre los efectos de la medicación estimulante en niños con diferentes problemas de comportamiento. Trabajaba con niños con problemas neurológicos, supervivientes de la epidemia de encefalitis y niños hospitalizados por problemas emocionales. De modo casual, observó que la benzedrina provocaba en algunos niños una gran mejoría del comportamiento y rendimiento escolar. Comenzó entonces un estudio con 30 niños, que confirmó su observación: La benzedrina disminuía la inquietud, aumentaba la concentración y la motivación. Fue el comienzo de la terapia farmacológica de la hiperactividad y la psicofarmacología infantil (Barkley, 2006; Bradley, 1937; Tomás y Casas, 2003). 
Aunque Bradley y sus colaboradores comunicaron sus hallazgos a través de publicaciones de relevancia, su descubrimiento no tuvo influencia en la investigación o práctica durante al menos 25 años (Brown, 1998; Conners, 2000). Esto se debió a la fuerte influencia del psicoanálisis en ese momento y sobre todo a la premisa, entonces mayoritariamente aceptada, de que los trastornos comportamentales no tenían base biológica y sólo requerían intervenciones psicológicas.

El cuadro comenzó a cambiar en la década de los 50. Durante esos años un número importante de investigaciones se centraron en los mecanismos neurológicos de la hiperactividad. Luafer y colaboradores (1957) acuñaron el nombre trastorno impulsivo hiperquinético y aumentaron el interés por investigar los tratamientos estimulantes de los niños hiperquinéticos (Rothenberger y Neumärker, 2005).

La benzedrina fue el primer estimulante administrado en los niños hiperactivos, al que siguió el metilfenidato, cuyo componente fue sintetizado por primera vez en 1944. Antes de utilizarse para el tratamiento del TDAH, se utilizó en cuadros como fatiga crónica, letargia, estados depresivos, alteraciones comportamentales seniles, psicosis asociada a la depresión y la narcolepsia (Leonard et cols, 2004). Sin embargo, se observó que su mayor efectividad era en la reducción de los síntomas que aparecen en el TDAH (Morton y Stockton, 2000). Actualmente es considerado el psicoestimulante más efectivo y es el fármaco más prescrito en el tratamiento del TDAH (Döofner et al, 2000; Wender, 2002).

\subsubsection{EL PERIODO DE 1960 A 1969}

A principios de los sesenta las revisiones críticas comienzan a cuestionar el concepto de un síndrome unitario originado exclusivamente en el daño cerebral. Birch (1964) y Rapin 
(1964) cuestionaron la validez del concepto de daño cerebral para explicar signos neurológicos que podrían tener otro origen. El término daño cerebral mínimo podía ser reemplazado por otros más específicos aplicados a algo más homogéneo, como podían ser los aspectos cognitivos, de aprendizaje o trastorno de conducta e hiperactividad. Estas nuevas etiquetas, basadas en la observación y la descripción de los déficits, eran preferibles a mecanismos etiológicos inobservables.

Como consecuencia de la insatisfacción con el término lesión cerebral mínima, los investigadores clínicos se centraron en los síntomas conductuales ya conocidos, dando más importancia a la hiperactividad. Surgió así la denominación “Síndrome hiperactivo”, en línea con los trabajos de Laufer y colaboradores (1957). Chess (1960) definió la hiperactividad como:

1) El niño hiperactivo realiza las actividades con un nivel superior de actividad, constantemente en movimiento o con la conjugación de ambas sintomatologías.

2) Destaca que ésta actividad es la manifestación definitoria del trastorno, más allá de la importancia especulativa de causas neurológicas, como eran las conclusiones científicas del momento.

3) Subraya la necesidad de considerar la evidencia objetiva del síntoma más allá de los datos subjetivos de los padres y profesores.

4) Se elimina la idea de culpabilidad de los padres de la sintomatología.

5) Se separa el síndrome de hiperactividad del síndrome de daño cerebral.

Desde este punto de vista, se puede afirmar que la hiperactividad es un síndrome conductual con o sin etiología orgánica. Con frecuencia provoca dificultades académicas, con logros inferiores a las posibilidades de los niños, y en algunos casos aparecen conductas desafiantes oposicionista y déficit en las relaciones sociales. También puede estar asociada a retraso mental, daño cerebral orgánico o enfermedades mentales (Chess, 1960). De modo 
semejante a los enfoques terapéuticos actuales, recomendaba la intervención multimodal, el asesoramiento parental, la modificación de conducta, psicoterapia, medicación y la educación especial. A diferencia de Still, Chess (1960) subrayó la naturaleza relativamente benigna de la hiperactividad y afirmaba que en muchos casos el cuadro se resolvía en la pubertad.

\subsubsection{EL PERIODO DE 1970 AL 1979}

En este periodo la investigación comienza a centrarse en la hiperactividad. Se observa la heterogeneidad del trastorno y se apunta más allá del daño cerebral mínimo. Éste término va perdiendo interés desde el punto de vista científico ya que cada vez va obteniendo menor evidencia en los nuevos estudios. En esta época, se considera la hiperactividad como un componente mayoritariamente conductual y no tanto un componente orgánico (Barkley, 2006).

\subsubsection{LA TEORÍA DE WENDER}

Wender (1971), partiendo de las características psicológicas con niños con daño cerebral mínimo, agrupó los síntomas en seis dominios:
1) Conducta motora.
2) Atención y percepción (funciones cognitivas).
3) Aprendizaje.
4) Control del impulso.
5) Relaciones interpersonales.
6) Emoción. 
Estos seis dominios de funcionamiento, venían asociados a tres déficits primarios. El primer déficit, implicaba la disminución de la experiencia de placer o de dolor. Estos niños tenían una menor sensibilidad a recompensas y castigos. El segundo déficit, venía asociado a una pobre o una baja modulación del nivel de activación, baja tolerancia a la frustración, mayor emocionalidad y temperamento. El tercer déficit, se asociaba a estos dos anteriores y hacía referencia a la extraversión y a la hiperactividad. Estos déficits tendrían como consecuencia problemas interpersonales y dificultades en el rendimiento académico

Las críticas a la teoría de Wender vendrían en relación a la descripción del arousal como activación y la distinción clara de los síntomas que denominaban hiperactividad como un aumento de la activación.

\subsubsection{LA EMERGENCIA DE LOS DÉFICITS DE ATENCIÓN: LA TEORÍA DE VIRGINIA DOUGLAS}

Virginia Douglas (1972) argumentó que los déficits en la atención sostenida y en el control de los impulsos eran probablemente la base causal de las alteraciones conductuales, y no sólo la hiperactividad, eje central de las investigaciones en aquel momento (Barkley, 2006, Calderón, 2003). Douglas y su equipo dieron relevancia a los aspectos cognitivos del trastorno y desarrollaron la idea fundamental de que la deficiencia básica de la hiperactividad no era la excesiva actividad motriz, sino la incapacidad para mantener la atención y controlar la impulsividad asociada a este trastorno. Esta definición es uno de los antecedentes más próximos a la descripción del TDAH (APA, 1984).

Douglas (1972) encontró que la hiperactividad en los niños no era necesariamente uniforme. Estos niños tenían más problemas de aprendizaje y de lectura que otros niños y no 
perseveraban en las tareas dadas. Su modelo de hiperactividad se basa en cuatro déficits centrales:

1) Déficits en la inversión, organización y mantenimiento de la atención y el esfuerzo.

2) Déficits en la inhibición de la respuesta impulsiva.

3) Déficits en la modulación de los niveles del arousal para atender las demandas situacionales.

4) Una fuerte inclinación a buscar el refuerzo inmediato.

Todos estos déficits constituyen el modelo o paradigma que Douglas y su equipo formularon sobre las características del trastorno y asienta las bases científicas de la atención como otro elemento nosológico de importancia en la historia del TDAH (Barkley, 2006).

\subsection{EVOLUCIÓN DEL TDAH EN LAS CLASIFICACIONES DSM}

En la década de los ochenta se publicó la versión americana del DSM-III, editada en nuestro país en 1984 (APA, 1984). Establecía una radical reconceptualización con respecto a la anterior edición del DSM. Los criterios diagnósticos del DSM-III daban un mayor énfasis a la atención y a la impulsividad, definida como la manifestación del trastorno que deteriora el control de la propia conducta. Además, incorporaba una lista de síntomas más específicos y concretaba la edad de inicio del trastorno y la duración mínima de los síntomas (Barkley, 2006).

La DSM-III añadió un nuevo subtipo del TDAH, el trastorno con predominio del déficit de atención y sin hiperactividad. En este punto se tomaron como referencia los desarrollos de Douglas, aceptando que el déficit básico del trastorno radica en un fallo en la regulación de la atención y el control inhibitorio, déficit más importante que la propia 
hiperactividad (Alcaina y cols., 2000). Se describen tres componentes fundamentales, la inatención por un lado, la impulsividad e inquietud. Cada uno de estos tres elementos formaría parte de un "cluster" de síntomas relacionados.

La diferenciación de los tres componentes nucleares del síntoma hipercinético fue efímera. El DSM-III-R cambió la terminología, hablando de Trastorno de la hiperactividad con déficit de la atención, atribuyendo de nuevo a la inquietud una importancia primaria en el trastorno hiperquinético, y suprimiendo la categoría diagnóstica Trastorno por déficit de atención (sin hiperactividad). En la descripción del TDAH se enumera una lista de catorce síntomas, de los cuales se exige la presencia de un número total de ocho para efectuar el diagnóstico.

\subsubsection{CRITERIOS DIAGNÓSTICOS: DSM-III}

En el DSM-IV la terminología sigue siendo la misma, TDAH, y el trastorno se describe dentro del grupo de los trastornos por déficit de atención y comportamiento perturbador. No obstante, en esta clasificación un paciente puede ser diagnosticado si cumple 6 de los 9 síntomas relacionados con la desatención, y si estos síntomas han persistido por menos durante 6 meses con una intensidad que es desadaptativa e incoherente con el nivel de desarrollo tanto para el tipo desatento como para el tipo hiperactivo-impulsivo. Se añade el subtipo TDAH- combinado (Alcaina, 2000).

En la revisión DSM-IV-TR (APA, 2002) se mantienen los mismos criterios y subtipos del DSM-IV, esto es, TDAH de predominio hiperactivo (TDAH-HI) y el TDAH predominio desatento (TDAH-D). 


\subsubsection{CRITERIOS DSM-IV Y DEL DSM-IV-TR DEL TDAH}

\section{DESATENCION:}

1. A menudo no muestra atención suficiente a los detalles y comete errores por descuido en las tareas escolares, en el trabajo o en otras actividades.

2. A menudo tiene dificultades para mantener la atención en tareas o en actividades lúdicas.

3. A menudo parece no escuchar cuando se le habla directamente.

4. A menudo no sigue instrucciones y no finaliza tareas escolares, encargos u obligaciones en el centro de trabajo( no se debe a comportamiento negativista o la incapacidad para comprender instrucciones)

5. A menudo tiene dificultades para organizar tareas y actividades.

6. A menudo evita, le disgusta o es renuente en cuanto a dedicarse a tareas que requieren un esfuerzo mental sostenido (como son trabajos escolares o domésticos)

7. A menudo extravía objetos necesarios para tareas o actividades(por ejemplo juguetes, ejercicios escolares, lápices, libros o herramientas)

8. A menudo es descuidado en las actividades diarias.

\section{IMPULSIVIDAD:}

1. A menudo precipita respuestas antes de haberse completado las preguntas.

2. A menudo tiene dificultades para guardar turno.

3. A menudo interrumpe o se inmiscuye en las actividades de otros (por ejemplo, se entrometen en conversaciones o juegos)

4. A menudo habla en exceso.

\section{HIPERACTIVIDAD:}

1. A menudo mueve en exceso manos o pies, o se remueve en su asiento.

2. A menudo abandona su asiento en la clase o en otras situaciones en que se espera que permanezca sentado.

3. A menudo corre o salta excesivamente en situaciones en que es inapropiado hacerlo (en adolescente o adultos puede limitarse a sentimientos subjetivos de inquietud)

4. A menudo habla en exceso. 
5. A menudo tiene dificultades para jugar o dedicarse tranquilamente a actividades de ocio.

6. A menudo está en marcha o suele actuar como si tuviera un motor.

Se describen tres subtipos diferenciados de TDAH, según predominen los síntomas de desatención y/o impulsividad-hiperactividad. Los subtipos especifican el síntoma predominante. Así pues encontramos;

1) TDAH con predominio del déficit de atención (TDA).

2) TDAH con predominio hiperactivo-impulsivo (TDA-H)

3) TDAH combinado (TDAH) (si hay síntomas de hiperactividad, impulsividad y déficit de atención).

4) En el caso de que no se cumplan los criterios establecidos en estas tres delimitaciones, nos encontraríamos con el diagnóstico del trastorno por déficit de atención con hiperactividad no especificado.

Se considera la variabilidad inter-sujeto e intra-sujeto y la no existencia exacta, ni el grado de intensidad de la enumeración estos síntomas en todas las personas aquejadas por este trastorno. Es importante distinguir el trastorno de otros trastornos, para lo que se debe tener en cuenta los criterios diferenciales (Menéndez, 2001).

\subsection{EL DIAGNÓSTICO SEGÚN LA CIE-10}

La décima revisión de la clasificación internacional de las enfermedades (CIE-10) parte de un concepto de enfermedad diferente al del DSM-IV (Tabla 1). La CIE-10 consta de tres ejes:

I) Eje clínico que abarca toda la patología, psiquiátrica y médica en general. 
II) Eje de la discapacidad en el funcionamiento personal, familiar, social y laboral.

III) Eje de los factores ambientales y el estilo de vida que hacen referencia a la enfermedad; hace referencia tanto a circunstancias del pasado como del momento actual del desarrollo de la enfermedad.

Se establece un grupo de trastornos hipercinéticos con cuatro entidades diferenciadas:

1) Trastorno de la actividad y de la atención

2) Trastorno hipercinético disocial

3) Otros trastornos hipercinéticos.

4) Trastorno hipercinético no especificado.

Tabla 1. Criterios diagnósticos para el TDAH EN LA CIE- 10 (Menéndez, 2001)

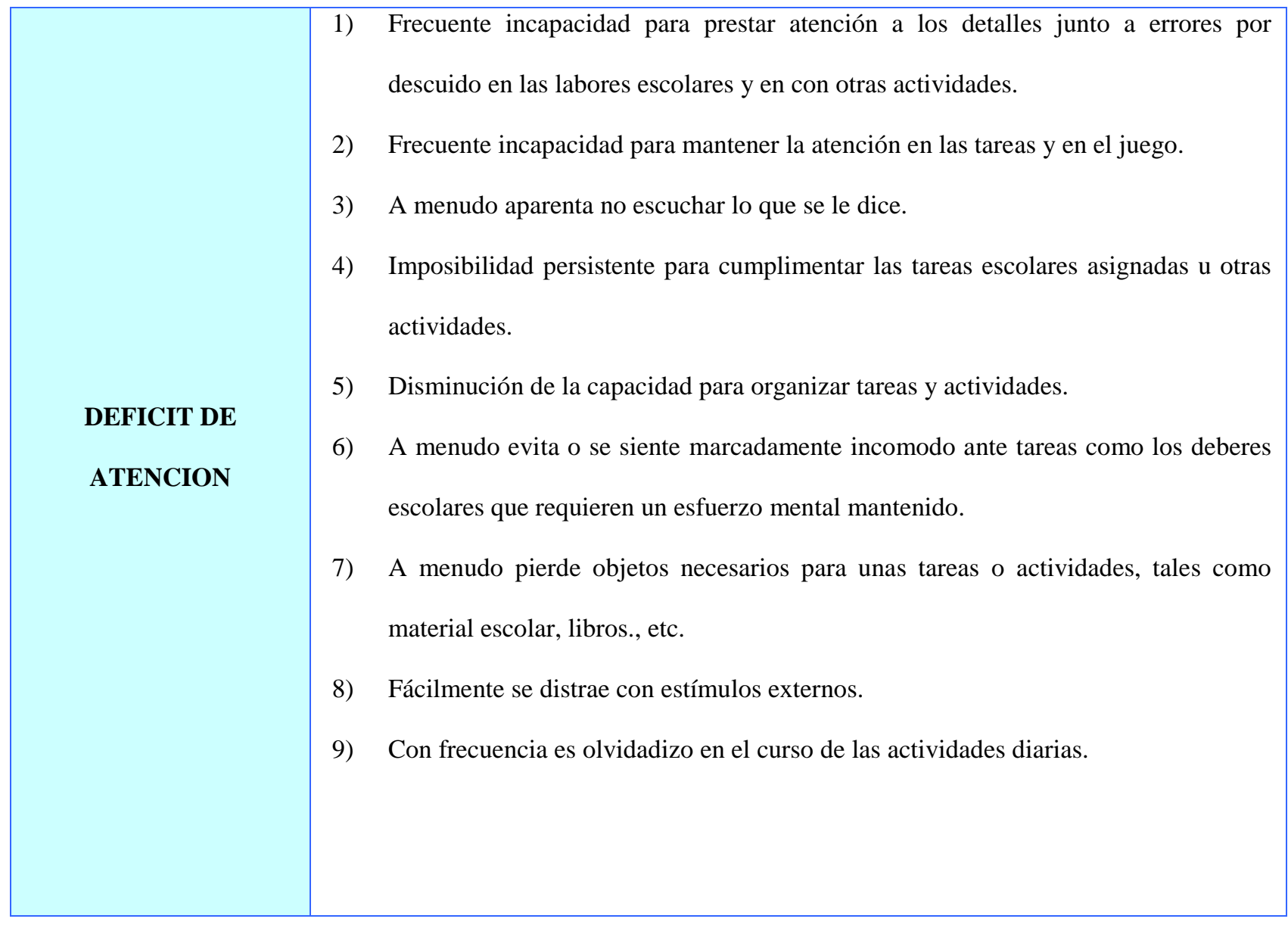




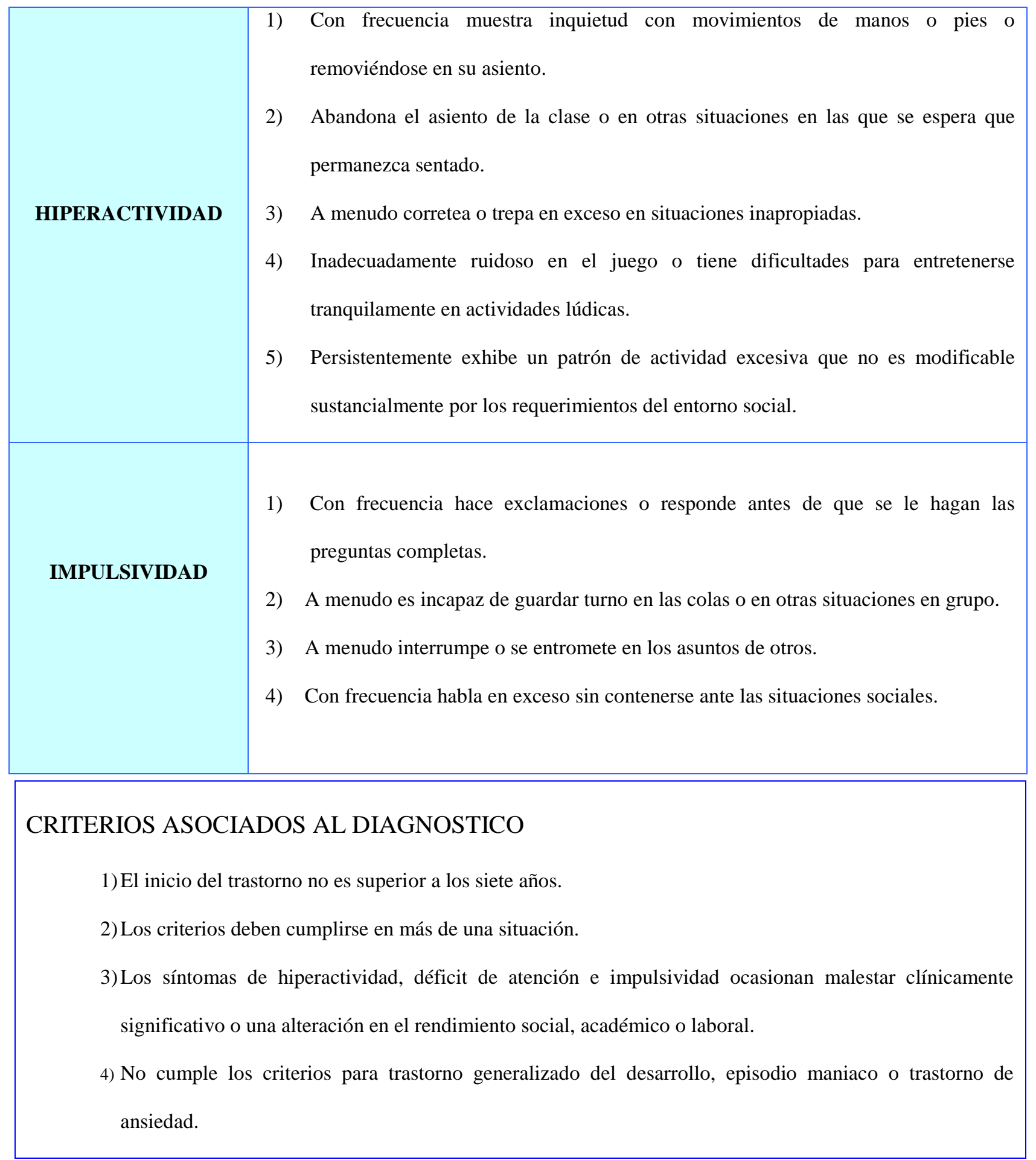




\subsection{UNA NUEVA TERMINOLÓGICA: TEMPO COGNITIVO LENTO COMO NUEVA ENTIDAD CLÍNICA (SLUGGISH COGNITIVE TEMPO)}

En la actualidad los criterios diagnósticos de la CIE-10 y el DSM-IV TR gozan de aceptación generalizada. Sin embargo, sus bases científicas se sustentan en una rigurosa investigación, todavía existen algunas cuestiones clínicas sin resolver. Capdevila y cols, (2006) señalan las siguientes:

1) Los subtipos TDAH no son estables a lo largo de los años, mientras que los criterios diagnósticos son idénticos para todas las edades. Los síntomas de hiperactividad e impulsividad, declinan conforme aumenta la edad.

2) No queda suficientemente claro si el TDAH-Combinado sea diferente del TDAH con predominio hiperactividad. El DSM-IV-TR mantiene que puede tratarse de un precursor del TDAH-C y evolucionar hacia él o viceversa. Los problemas con la atención, se hacen evidentes a medida que aumentan las demandas escolares.

3) Los síntomas desatencionales son los mismos para el TDAH de tipo desatento que para el TDAH-Combinado.

4) No hay criterios específicos positivos para el subtipo desatento (TDA), como los criterios positivos para la impulsividad y la hiperactividad en el TDAH-H y TDAH-C.

5) El subtipo TDA no tiene una aceptación consensuada como subtipo entre todos los investigadores. Se piensa que es un trastorno independiente puesto que se han descrito diferencias en su sintomatología central en relación a los otros subtipos. Según Barkley (1990) el TDA se asocia más a problemas de atención selectiva y a un procesamiento de información enlentecido. El subtipo combinado tendría más problemas en la persistencia del esfuerzo, la atención sostenida y la distracción. 
Capdevilla y cols (2006) consideran que la teoría que mejor permite diferenciar los subtipos TDA sin hiperactividad y el TDAH es la conocida como "Tiempo cognitivo lento", que supone la reapertura de una línea de investigación abandonada con el paso del DSM-III al DSM-III-R.

\subsubsection{EL CONSTRUCTO TEMPO COGNITIVO LENTO}

Lahey $(1985,1987)$, centrándose en el déficit de atención, elaboró un término que vendría a describir estas conductas, este término, denominado Sluggish cognitive tempo, surgió como constructo para reunir tales características. Su descripción incluía la presencia de un estado de alerta y orientación irregulares, una actividad en la vida diaria lenta, calmada y torpe. Varios de estos síntomas aparecen en el inventario de Achenbach, (Achenbach, 1991) de comportamiento de niños y niñas de edades de 6 a 18 años:

1) Está confundido o parece que está en las nubes.

2) Sueña despierto, se pierde en sus pensamientos.

3) Se queda mirando al vacío.

4) Poco activado, lento, le falta energía.

La investigación selectiva de estos ítems puede utilizarse para identificar signos de posibles cuadros de Tiempo cognitivo lento (TCL). La descripción de Capdevila y cols (2006) de en niños y adultos con TCL es: “lento, somnoliento, en las nubes, confundido, desmotivado, en sus mundos", síntomas asociados a su vez con bajo rendimiento en algunas subescalas neuropsicológicas del WISC o la prueba de búsqueda visual.

El fenotipo conductual de los niños con TCL puede ser evidenciado a partir de la información aportada por la familia y el colegio, además de la observación directa en la práctica clínica. Este constructo se ajustaría a un perfil de niños con unas características 
conductuales y cognitivas lo suficientemente característico como para ser individualizado entre el conjunto de pacientes con TDAH. Si bien aún no se ha podido identificar un perfil neurocognitivo específico a partir de pruebas psicométricas aspectos son bastantes característicos (Capdevilla y cols., 2006).

Tabla 2. Características TCL: Perfil conductual y cognitivo (Capdevilla y cols., 2006).

\begin{tabular}{|c|c|c|}
\hline $\begin{array}{l}\text { Características. } \\
\text { Sintomatología } \\
\text { central }\end{array}$ & 1) & $\begin{array}{l}\text { Déficit en la velocidad del procesamiento de la información en general y en } \\
\text { atención selectiva, específicamente. } \\
\text { Sintomatología hiperactiva ausente o leve }\end{array}$ \\
\hline Comorbilidad & 1) & $\begin{array}{l}\text { Depresión. } \\
\text { Ansiedad. } \\
\text { Trastornos de aprendizaje. } \\
\text { Trastornos internalizantes. }\end{array}$ \\
\hline $\begin{array}{c}\text { Funcionamiento } \\
\text { social }\end{array}$ & 4) & $\begin{array}{l}\text { Poca popularidad, descuido por parte de los compañeros. } \\
\text { Aislamiento social } \\
\text { Menor interacción social } \\
\text { Déficit en el autoconocimiento social y pasividad social }\end{array}$ \\
\hline Neuropsicología & 4) & $\begin{array}{l}\text { Alteración en la memoria de trabajo } \\
\text { Funciones ejecutivas: Alteración en la planificación/organización, } \\
\text { metacognición. Monitorización } \\
\text { Problemas atencionales } \\
\text { Habilidades motrices finas más pobres ( destreza manual) }\end{array}$ \\
\hline $\begin{array}{c}\text { Características } \\
\text { biológicas }\end{array}$ & 1) & $\begin{array}{l}\text { Mayor predominio femenino } \\
\text { Estable en el tiempo } \\
\text { Respuesta a la medicación estimulante, mejor respuesta a dosis bajas. } \\
\text { complicaciones perinatales y postnatales menos frecuentes. }\end{array}$ \\
\hline
\end{tabular}




\subsection{RESUMEN}

La definición del trastorno que hoy conocemos como TDAH ha tenido una lenta elaboración. Podemos hablar, de hecho, de un largo proceso de definición. Las primeras descripciones de problemas de atención ya pueden identificarse en los escritos de Crichton en 1789. Sin embargo, la historia del trastorno propiamente dicho comenzó en el siglo XX. Desde entonces el foco de atención fue cambiando, situándose sucesivamente sobre los problemas de comportamiento, la hiperactividad y los problemas de atención. Still se centró en el funcionamiento de niños de inteligencia normal con problemas de control del comportamiento, impulsividad y baja atención. La epidemia de encefalitis de 1917-1918 puso en primer plano los problemas de hiperactividad, distraibilidad y mal comportamiento de niños afectados por la infección. Kranner y Pollnow diferenciaron las secuelas de la encefalitis de otro cuadro definido por una acusada inquietud motora. Douglas puso en primer plano los problemas de atención. Los cambios en las visiones del trastorno y en los síntomas considerados primarios tuvieron reflejo en cambios correspondientes en los criterios utilizados para diagnosticarlo.

Desde las primeras descripciones estuvo presente la idea de un origen orgánico del cuadro. Still habló de problemas cerebrales en la primera infancia. Tredgold atribuyó el cuadro a la herencia y daños cerebrales durante el parto. La aparición de los síntomas en niños que habían padecido encefalitis reforzó la idea de que los problemas tenían su origen en lesiones cerebrales. Las dificultades para constatar tales lesiones llevaron a postular el concepto de daño cerebral mínimo y, posteriormente, disfunción cerebral mínima. Por otra parte, el descubrimiento de los efectos de los psicoestimulantes impulsó una reflexión sobre otro tipo de anomalía cerebral, no estructural, sino neuroquímico. 
Utilidad de la cartografía cerebral en el diagnóstico del TDAH

Visto retrospectivamente, el proceso de definición del trastorno sugiere la existencia de un cuadro complejo, con tres grupos de síntomas (atención, impulsividad, hiperactividad) y de origen orgánico, sea por lesión estructural o por fallos neuroquímicos. 
Capítulo 2. Características del niño con TDAH

CAPITULO 2: CARACTERISTICAS DEL NIÑO CON TDAH 
Utilidad de la cartografía cerebral en el diagnóstico del TDAH 


\section{INTRODUCCIÓN}

El TDAH se define por tres núcleos sintomáticos: la impulsividad, el déficit de atención y la hiperactividad-impulsividad. Las combinaciones de los tres núcleos dan como resultado una gran diversidad de presentaciones del cuadro. En este capítulo se describirán los problemas más comunes del trastorno agrupados en los siguientes perfiles: cognitivo y comportamental, neuropsicológico, neuroanatómico, neurofisiológico y neuroquímico.

\subsection{PERFIL COGNITIVO Y COMPORTAMENTAL}

En este primer perfil descriptivo agrupamos las manifestaciones cognitivas y comportamentales, esto es, por una parte las características del procesamiento y elaboración de la información y desempeño cognitivo, y, por otra parte, la sintomatología comportamental más común en el trastorno.

Según Orjales (1998) las dificultades cognitivas más comunes son los problemas de atención sostenida, que implican la forma en que se mantiene la atención durante un periodo de tiempo. Los niños con TDAH tienen peor rendimiento en las pruebas largas, al fluctuar el grado de atención durante periodos largos de tiempo. También tienen dificultad en procesar varios estímulos de forma simultánea, con problemas en la atención focalizada, que permite al niño discriminar de entre los distintos estímulos que recibe aquellos que pueden ser más relevantes para realizar la tarea. 
En el niño con TDAH aparecen problemas a la hora de adaptar una tarea a nuevas consignas y que mantenga un buen rendimiento cuando la tarea es compleja o más aburrida. El rendimiento disminuye al incrementar el número de estímulos irrelevantes presentes en la tarea asignada. Esto provoca dificultades para distinguir los estímulos relevantes de los irrelevantes (Orjales, 1998).

Los niños con TDAH tienen dificultades a la hora de atender a estímulos que aparecen con una frecuencia lenta: cometen más errores cuando el estímulo aparece de forma lenta. Otra dificultad es la que tienen para aprender y recordar lo aprendido por procesar la información de manera más superficial. Es decir, cuando la información ha sido asimilada sin ningún tipo de aprendizaje significativo y durante un periodo largo de tiempo, o cuando el niño no establece estrategias que le permiten relacionar la información que quiere recordar.

Otra de las funciones afectadas más a menudo en el TDAH es la memoria de trabajo verbal. La memoria es un conjunto de funciones que puede implicar acontecimientos desde los más recientes hasta los más lejanos. El termino memoria de trabajo incluye varios tipos de memoria, que van desde la memoria inmediata, a corto plazo, hasta la más compleja y amplia disponible para el discurso. Lezak (1995) propuso un modelo de memoria declarativa que implica el registro, almacenamiento a corto plazo y la memoria a largo plazo, comprendiendo cada uno de ellos subfases con diferentes características en diferentes modalidades. Aunque existen componentes de la memoria para todos los sentidos, los más relevantes son la memoria visual y la auditiva (Quinlan, 2003).

El registro o almacenamiento sensorial inmediato a corto plazo, tiene una capacidad limitada e interactúa junto con los mecanismos afectivos y de dirección de la atención para el registro de elementos mnemónicos. La memoria inmediata, la primera etapa de la memoria a corto plazo, puede denominarse el "campo de atención" (Lezak, 1995). Es un sistema de capacidad limitada (Watkins, 1974) y típicamente dura unos 30 segundos. La memoria de 
trabajo activa habitualmente dura de unos 30 segundos a unos pocos minutos. Esta memoria de trabajo funciona manteniendo información en la mente y utilizándola para guiar el comportamiento. El traslado a la memoria a largo plazo sigue un número de fases, incluyendo la consolidación, el almacenamiento a largo plazo y la recuperación (Quinlan, 2003).

En algunos niños con TDAH todos los aspectos de la memoria pueden verse afectados, en otros la memoria a largo y a corto plazo puede estar intacta, pero alterada la memoria de trabajo, que definimos como la capacidad para recordar desde un minuto hasta un día, para mantener la concentración en una actividad mientras se atiende a otra y para recuperar la información aprendida previamente. Algunos son capaces de desenvolverse correctamente con fijaciones breves e intervalos cortos antes de recordar, pero sin embargo son incapaces de recordar los detalles más elementales de interacciones sociales 5 minutos después de haber sucedido (Quinlan, 2003).

Estos niños utilizan para aprender estrategias simples, propias de niños normales pero mucho más pequeños y tienen una mayor sensibilidad a las variaciones del contexto o del ambiente de trabajo. Este rendimiento es más sensible a las modificaciones del entorno y en el plano cognitivo se observa que cometen más errores, dispersándose con la información irrelevante. Mantienen estilos de procesamiento cognitivos inadecuados para el aprendizaje escolar, que pueden dificultar el aprendizaje y la percepción del mundo que les rodea.

Orjales (1998) describe los estilos cognitivos según tres dimensiones:

- Si poseen un estilo cognitivo impulsivo o reflexivo.

- Si poseen un estilo perceptivo dependiente de campo o independiente de campo.

- $\quad$ Si poseen flexibilidad o rigidez cognitiva.

El primer estilo cognitivo, el estilo impulsivo o reflexivo, hace referencia a la impulsividad cognitiva, que implica rapidez, inexactitud y pobreza en los procesos de 
percepción y el posterior análisis de información que los niños con TDAH hacen del medio que les rodea. En situaciones de preguntas, o de demanda, muestran un desarrollo lento en el control de la impulsividad, responden antes de que se termine la pregunta, y adelantan la respuesta antes de saber en su totalidad el contenido de la misma.

La impulsividad cognitiva, que dificulta el procesamiento y análisis de la información, es común en el desarrollo de todos los niños. Sin embargo, en los niños con TDAH la evolución es más lenta y el problema persiste durante años. Aplican menor número y variedad de estrategias de solución de problemas y establecen como primera opción el ensayo-error. En el extremo opuesto de esta dimensión estaría el estilo reflexivo, donde predomina el análisis, y verificación de las diferentes alternativas de respuesta antes de dar con la respuesta correcta.

Con respecto a la segunda dimensión, el estilo perceptivo hace referencia a la presencia o no de una independencia o dependencia de campo. Orjales (1998) describe este proceso como la capacidad que tiene el niño para percibir independientemente de la organización del campo perceptivo, una parte del campo visual como un todo, o como parte aparte de este mismo campo perceptivo. Se observa que estos niños tienen dificultades para evaluarse correctamente, perciben la información de manera más global y mucho menos analítica, no suelen usar estrategias de contraste de hipótesis y utilizan más las estrategias de ensayo y error. Muestran menor rendimiento en codificación, decodificación y retención de la información. Su procesamiento es más dependiente de campo y evoluciona hasta un grado de independencia a partir de la cual algunos desarrollarán independencia de campo y otros, dependencia de campo. Esta particularidad puede ser observada cuando el niño elabora el test de las figuras enmascaradas (Witkin, 1982). Este estilo cognitivo también tiene implicaciones en el momento de organizar la información, teniendo especial dificultad en organizar y discriminar la información relevante de la información secundaria. 
La tercera dimensión, flexibilidad versus rigidez cognitiva en el procesamiento de la información, haría referencia a la habilidad para cambiar rápidamente de acción o de pensamiento. Estos niños tienen problemas a la hora de frenar una respuesta activada, o ejecutar la respuesta alternativa más adecuada a la situación presente. Su pensamiento puede resultar caótico y desordenado, con la necesidad de más pautas de organización del exterior, con un seguimiento y refuerzo continuado.

Resumiendo el perfil cognitivo, los niños con TDAH se caracterizan por problemas de atención, actuación impulsiva, dependencia de campo, baja capacidad analítica y escasa flexibilidad cognitiva (Orjales, 1998).

Con respecto al perfil conductual, tienen más problemas de conducta cuando la información es repetitiva que cuando es novedosa. La conducta inatenta se manifiesta por las siguientes características:

- $\quad$ No termina las tareas que empieza

- $\quad$ Comete muchos errores.

- $\quad$ No se centra en los juegos.

- Muchas veces parece no escuchar cuando se le habla.

- $\quad$ Tiene dificultades para organizarse.

- $\quad$ Evita las tareas que requieren esfuerzo.

- $\quad$ Muy a menudo pierde cosas que necesita.

- $\quad$ Se distrae con cualquier cosa.

- $\quad$ Es muy descuidado en las actividades que realiza.

Estas conductas provocan desmotivación por la tarea y una mayor dificultad para procesar los estímulos. Los niños con TDAH, se desmotivan con una gran facilidad porque tienen que mantener con mayor esfuerzo su atención. 
Otra conducta muy característica presente en estos niños, según Orjales (1998), es la conducta hiperactiva y la falta de autocontrol. Esto se manifiesta con una excesiva actividad motora que sobrepasa los límites normales con respecto a su edad y a su nivel madurativo. Implica la necesidad de moverse constantemente y un marcado déficit en el autocontrol tanto corporal como emocional.

Las conductas hiperactivas más frecuentemente observadas son:

- $\quad$ Movimientos constantes de manos y pies.

- Se levanta constantemente

- $\quad$ Corretea por todos los lados.

- Le cuesta jugar a actividades tranquilas.

- $\quad$ Está activado como si tuviera un motor.

- $\quad$ Habla en exceso.

Hay que tener en cuenta, que el desarrollo de los niños sin TDAH evoluciona desde conductas típicamente hiperactivas hasta conductas normativas. Los niños con TDAH no siguen esta evolución madurativa y los síntomas hiperactivos se mantienen, interfiriendo su desarrollo.

La conducta impulsiva en situaciones que producen una satisfacción inmediata se relaciona significativamente con el grado de tolerancia a la frustración. Carece de la reflexividad y madurez suficiente para analizar eficazmente una situación real o hipotética, con lo cual, su conducta resulta normalmente inmadura e inadecuada. En particular:

- $\quad$ Se precipita en responder antes de que se hayan completado las preguntas.

- $\quad$ Tiene dificultades para guardar turno.

- $\quad$ Suele interrumpir o se inmiscuye en las actividades de otros, se entromete en conversaciones o juegos. 
Estas conductas impulsivas, junto con la falta de conciencia del riesgo, reducen la capacidad para analizarlo y les hace más propensos a tener accidentes.

En muchos casos el mal comportamiento es frecuente, siendo niños más desobedientes, con marcadas dificultades en aceptar la autoridad y los límites a su comportamiento. Cuando el problema aparece en edad temprana se hace urgente el establecimiento de una intervención en autocontrol y en el asesoramiento educativo a los padres, para el conocimiento de técnicas y estrategias que sirvan para controlar y monitorizar estas conductas desobedientes y desafiantes y así establecer los límites apropiados, para que el niño los conozca y actué en consecuencia (Orjales, 1998).

\subsection{PERFIL NEUROPSICOLÓGICO}

Más recientemente, la investigación ha querido explicar cómo un déficit cognitivo podría dar lugar a las características conductuales del trastorno. Aunque este trastorno lleva implícito un déficit atencional, la investigación no apoya que éste sea primario y explique las manifestaciones comportamentales (Pennigton, 1991).

Los trabajos de Conners (1986) fueron centrales en el estudio del fenotipo neuropsicológico del trastorno al distinguir seis subtipos de niños hiperactivos. Concluyó que la hiperactividad refleja un déficit de inhibición de conducta motriz. Uno de los subtipos fue denominado "disfunción del lóbulo frontal” y su perfil coincide con las apreciaciones de los trabajos de Douglas (1988).

Capdevila-Brophy y cols. (2005) señalan que los patrones neuropsicológicos del trastorno son variables y los déficits cognitivos más frecuentes abarcan un amplio espectro de habilidades que, aunque aparentemente son muy distintas, tienen en común ser consideradas funciones ejecutivas (FE). Tal como señala Barkley (2006), es un trastorno de los lóbulos 
frontales y prefrontales localizadas en zona orbitofrontal, ganglios basales y sistema límbico. El córtex orbitofrontal media en la respuesta retardada y regula así diversas capacidades cognitivas. Estas alteraciones están asociadas con el funcionamiento frontal, con la autorregulación y funciones ejecutivas, tales como la fluidez verbal, la impulsividad, la pérdida de la inhibición y manteniendo de la atención, así como la organización y monitorización de la conducta en estos niños (Miranda y cols, 2003).

El déficit primario de este trastorno está vinculado a las disfunciones ejecutivas, hipótesis propuesta por varios autores (Barkley, 1987, 2006; Gualteri, 1995; Pennigton, 1991; Stuss y cols., 1986). Su manifestación en estos niños incluye inflexibilidad cognitiva, incapacidad para desarrollar un plan de acción y una meta, mantener este plan en la mente y llevarlo a cabo con la ayuda de planificación (Capdevila-Brophy y cols., 2005).

Presentan una respuesta ineficaz ante estímulos, dificultades en los pasos necesarios para llevar a cabo una respuesta eficaz. Tales observaciones justificarían la dificultad que tienen estos niños de aprender de sus errores y la previsión a la hora de dar respuestas ante estímulos nuevos, así como la dificultad para aprender observando a otros niños con un estilo social adecuado, donde tienen que adscribirse a reglas sociales establecidas.

Por su relevancia, más adelante dedicaremos un capítulo a las funciones ejecutivas.

\subsection{PERFIL NEUROANATÓMICO Y DE NEUROIMAGEN}

La evaluación anatómica del trastorno junto con el empleo de nuevas tecnologías, son las principales armas tecnológicas para examinar el cerebro de los niños. Ejemplos de esta tecnología son la resonancia magnética (RM), la tomografía por emisión de positrones (PET), la tomografía por emisión de fotón único (SPECT) y la resonancia magnética funcional 
(RMf). Las técnicas de imagen cerebral permiten hacer evaluaciones directas de la estructura y de la función cerebral, por lo que son ideales para el estudio del TDAH.

Los estudios genéticos apoyan la hipótesis de que el TDAH tiene una base biológica. Con la aplicación de las nuevas técnicas de imagen cerebral se ha avanzado hacia la identificación de los sustratos neuroanatómicos de este trastorno. Inicialmente se propuso que existía una alteración en el funcionamiento de algunas estructuras, entre las que se cuentan los circuitos frontales y límbicos. Esta es la que se denominó hipótesis fronto-límbica del TDAH. No obstante, los estudios realizados desde el punto de vista de diferentes disciplinas, tales como la neuropsicología, la neuroimagen y los estudios neuroquímicos, sugieren que aunque esta hipótesis sea correcta, la neurobiología de este padecimiento es aún más compleja (Almeida, 2005).

Dada la complejidad de los circuitos prefrontales, aún no ha quedado claro si las anomalías prefrontales del TDAH se deben a "lesiones" en la neocorteza prefrontal y/o en las estructuras subcorticales que están interconectadas con esta. Por esta razón y tal como señala Almeida (2005), es más apropiado referirse a la alteración funcional del TDAH como una alteración de las estructuras fronto- subcorticales.

\subsubsection{ANORMALIDADES NEUROANATÓMICAS}

El cerebro de los niños con TDAH es significativamente más pequeño en promedio a través de la infancia y la adolescencia, cuando se compara con los cerebros de niños normales sanos (Castellanos y cols, 2002; Hill y cols, 2003). Además de esta disminución global del volumen, existe evidencia, aunque más controvertida, que sustenta la alteración de un circuito especifico que se implicaría en los síntomas de este trastorno. Por lo menos en niños varones este circuito parece incluir regiones prefrontales derechas del cerebro, ganglios basales, los 
hemisferios cerebelosos y una subregión del vermis cerebeloso. Finalmente, la distribución de la sustancia gris (SG) y la sustancia blanca (SB) podría alterarse también en el TDAH (Castellanos y cols, 2004).

\subsubsection{DISMINUCION DEL VOLUMEN CEREBRAL TOTAL}

En la mayoría de los estudios que han investigado sobre el volumen cerebral total en el TDAH, se observa una reducción del volumen total en niños con este trastorno, comparados con controles pareados por edad y sexo. En el metaanalisis realizado por Castellanos y cols. (2004) se obtuvo un efecto total altamente significativo ( $Z=22,16$; IC: 95\%: 11,23-33,09). Estos autores concluyen que los volúmenes totales del cerebro de los niños y adolescentes con TDAH, como promedio, incorporando todos los estudios actuales, son $2,7 \%$ más pequeños que los controles pareados por edad (ver tabla 3 ).

\subsubsection{2. ÁREAS PREFRONTALES DEL CEREBRO}

Las hipótesis sobre los sustratos anatómicos de este trastorno, se han enfocado generalmente en el papel que desempeña la corteza prefrontal (CPF). Se sabe que la CPF está implicada en el funcionamiento ejecutivo. Normalmente la CPF derecha es ligeramente mayor que la izquierda (Weinberger y cols, 1982). Sin embargo, esta región es más simétrica en el TDAH (Castellanos y cols, 1996; Hynd y cols, 1990; Reiss y cols, 1996; Shaywitz y cols, 1983).

Casey y cols. (1997) encuentran disminución del tamaño de la CPF derecha, correlacionándola con problemas en la inhibición de respuestas en niños con este trastorno. Sin embargo, las dificultades estadísticas inherentes al estudio de las asimetrías cerebrales 
previamente expuestas, deben tenerse en cuenta al analizar estos resultados (Castellanos y cols, 2004).

Mientras los resultados anteriormente mencionados examinaron en general las diferencias volumétricas de la CPF, estudios recientes han buscado diferencias en el volumen de la SG y la SB en la CPF. Los estudios encuentran reducción de la SG y de la SB en la CPF derecha (Filipek y cols, 1997; Overmeyer y cols, 2001). Sin embargo, Kates y cols. (2002) encuentran que esta reducción en volumen se limitaba a la CPF izquierda, con disminución de la SG en ambos hemisferios, pero mayor en el derecho. Estos últimos hallazgos los confirmaron Mostofsky y cols. (2002), encontrando que esta reducción también se encontraba en la CFP izquierda, con disminución de la SG en ambos hemisferios, pero mayor en el derecho.

\subsubsection{GANGLIOS BASALES}

Al igual que la CPF, el núcleo caudado y sus circuitos se han asociado con este trastorno durante mucho tiempo (Pontius, 1973). El núcleo caudado y el putamen sirven como punto de entrada a los GB; anormalidades en estas estructuras se han encontrado en este trastorno. Algunos investigadores han encontrado diferencias volumétricas y la mayoría de los estudios constatan pérdida de la asimetría (Hynd y cols., 1990, 1993; Mataró y cols, 1993). Todavía no queda claro si el núcleo caudado es normalmente asimétrico y, si esto es así, si ésta asimetría normalmente favorece al lado derecho o al izquierdo (Castellanos y cols, 2002).

El putamen es una región de los GB que se asocia con las regiones motoras primarias y suplementarias que pueden contribuir a los síntomas motores del TDAH. Los estudios volumétricos del putamen han mostrado también resultados igualmente ambiguos. Los 
investigadores que han examinado los volúmenes del putamen como regiones de interés, no han encontrado diferencias significativas (Aylward y cols, 1996; Castellanos y cols, 1996).

Teicher y cols (2000) mediante un estudio con imágenes funcionales encontraron una disminución del flujo cerebral en el putamen en niños varones con TDAH de predominio hiperactivo, comparados con niños con TDAH que tenían un nivel de actividad similar a los controles. Lesiones del putamen como las descritas anteriormente se asocian también con una mayor posibilidad de TDAH (Castellanos, 2004).

Con respecto a la investigación neuroanatómica del globo pálido, que recibe información a partir del núcleo caudado y del putamen, se ha encontrado más pequeño en niños varones con TDAH (Aylward y cols, 1996; Castellanos y cols, 1996).

\subsubsection{CEREBELO}

Estructura asociada con la coordinación motora de los movimientos, aunque los estudios funcionales de neuroimagen han mostrado claramente la participación de esta estructura en funciones no motoras (Allen y cols, 1997; De Zubicaray y cols, 2000; Desmond y cols, 1998; Rao y cols, 1997; Thomas y cols, 1999; Tracy y cols, 2000). Estudios con RM del cerebelo en niños con TDAH han mostrado que los volúmenes de los hemisferios cerebelosos son más pequeños y que estas diferencias se mantienen a través de la adolescencia (Castellanos y cols, 1996, 2002). Anderson y cols (2002) asocian a los hemisferios cerebelosos y el vermis cerebeloso posteroinferior como nuevas incorporaciones científicas en las hipótesis de la fisiopatología del TDAH. 
Tabla 3. Metanálisis del volumen total cerebral en el TDAH, Castellanos y cols., 2004)

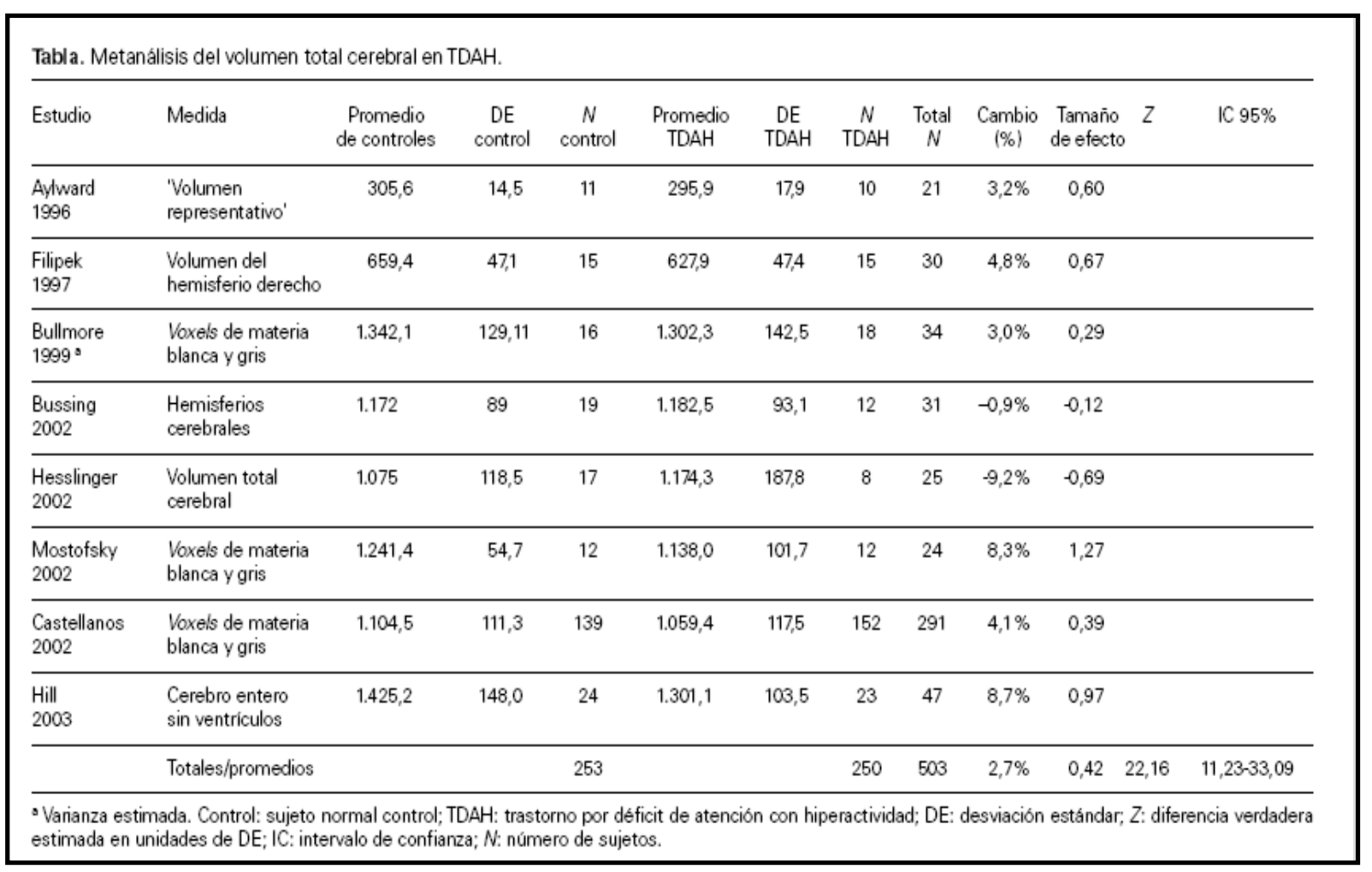

Tabla 4. Resumen de los hallazgos anatómicos en el TDAH y las características observables en neuroimagen (Castellanos y col., 2004; Popper y West ,2005)

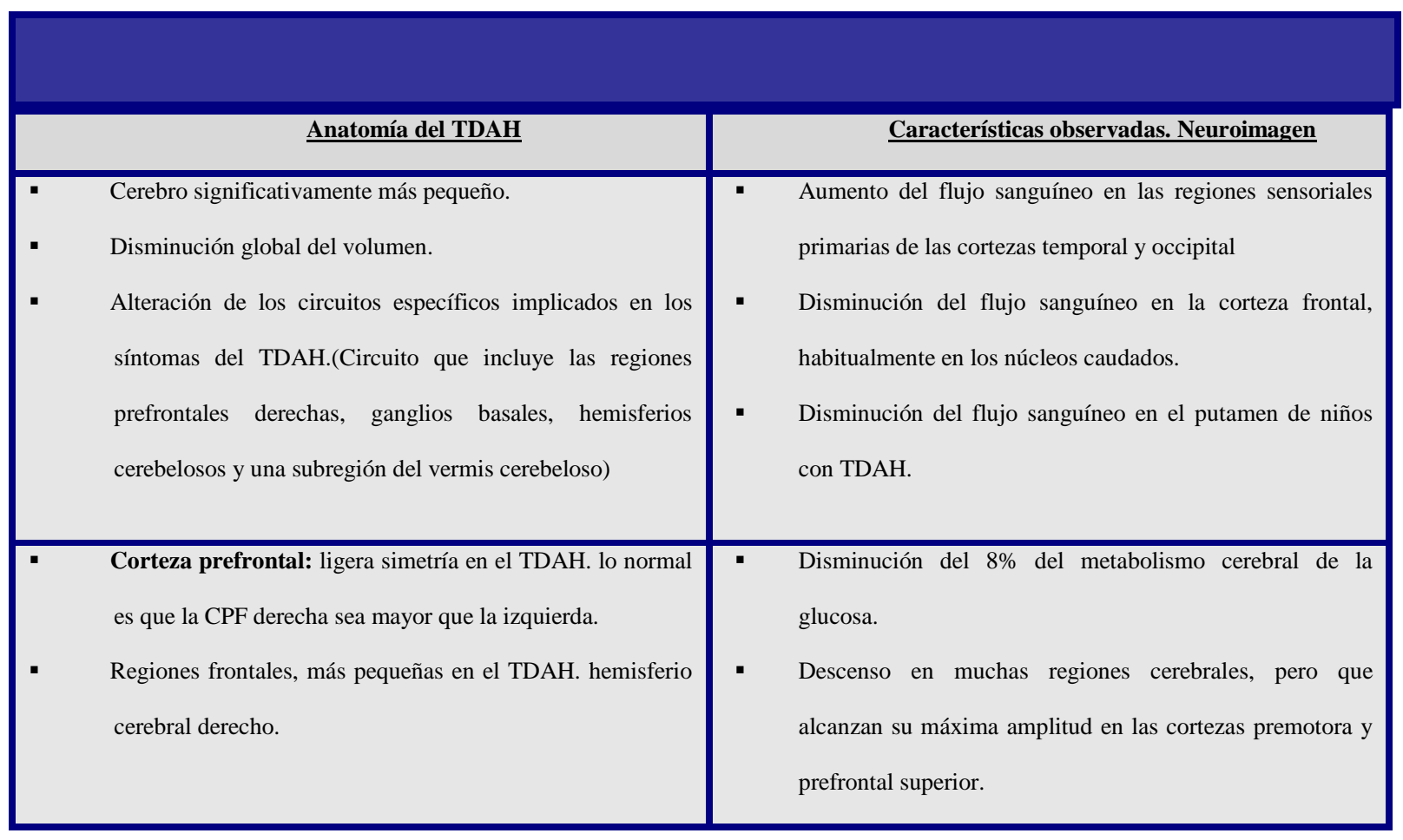




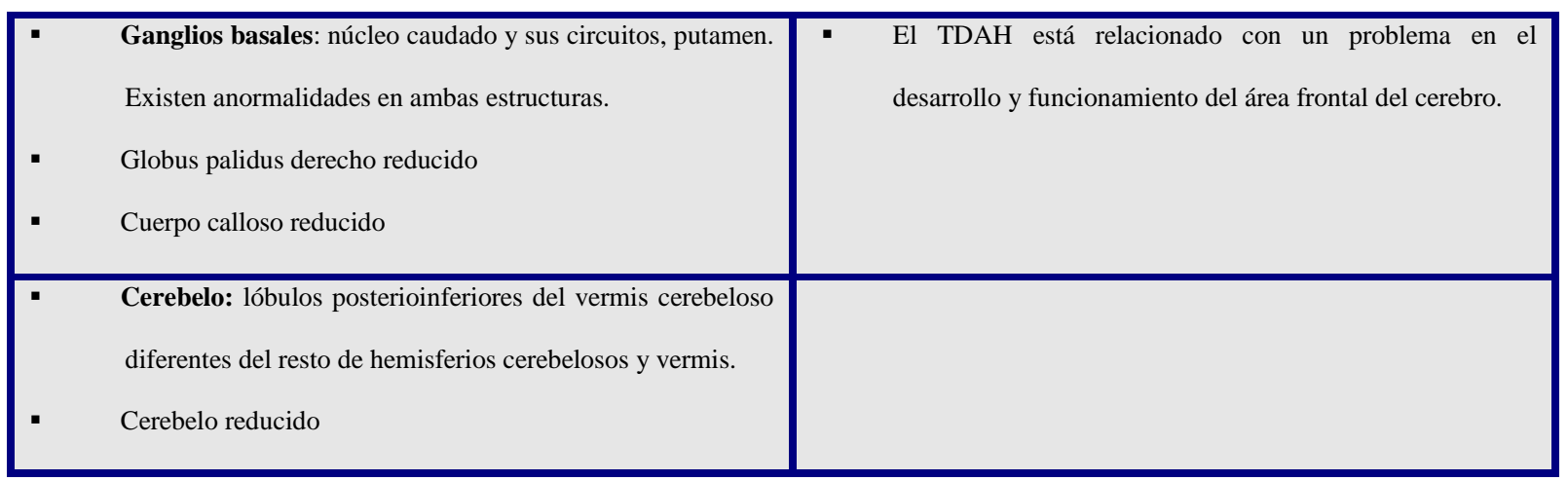

\subsection{PERFIL NEUROFISIOLÓGICO}

En el estudio del TDAH se utilizan principalmente cuatro técnicas neurofisiológicas; el electroencefalograma convencional (EEG), la cartografía cerebral (EEGq) o EEG cuantificado, los potenciales evocados cognitivos (PE) y el Polisomnograma (PSG). En el momento actual, la tecnología dominante se centra en el registro, procesamiento y análisis de las señales bioeléctricas del sistema nervioso, incluyéndose también aquellas otras técnicas que permiten el análisis cuantitativo de variables neurobiológicas de aplicación clínica.

Con el EEG convencional se obtiene el registro de la actividad eléctrica generada por las células nerviosas (sumación de potenciales postsinápticos de las neuronas del córtex). En el registro EEG se pueden observar cuatro tipos de ondas cerebrales, que son las ondas alfa, beta, theta y delta. La actividad alfa se registra en zona occipital y está presente en vigila o estado de alerta, en periodos de relajación, y tal como exponen Parra y cols (2002), muestra reactividad típica a la apertura de los ojos. Esta actividad tiene una frecuencia entre $8 \mathrm{~Hz}$ y 12 Hz. En el niño hay un aumento progresivo de la actividad alfa en vigilia a partir de los cuatro años de edad. En situaciones normativas, se presenta una asimetría del ritmo alfa, con mayor amplitud en el hemisferio derecho.

Con respecto a la actividad beta, ésta actividad está presente cuando existe una demanda cognitiva y el sujeto está concentrado. Tiene una oscilación de 13 a $18 \mathrm{~Hz}$. Esta 
actividad, tal como señalan Godoy y cols (2002), también puede mostrar asimetrías, con una distribución frontocentral y puede tener reactividad ante estímulos táctiles y actividad motora de las extremidades contralaterales.

El ritmo Theta tiene oscilaciones entre 4 a $7 \mathrm{~Hz}$, aparece durante la somnolencia en adultos jóvenes y está presente en estado de vigilia en niños menores de seis años.

La onda delta, menor de $4 \mathrm{~Hz}$, aparece en sueño profundo y está presente en los recién nacidos.

Con la EEGq se puede obtener una visión topográfica de la distribución espectral de las ondas cerebrales presentes en estos niños. Según Idiazábal (2005), con el EEGq se puede descomponer en bandas de frecuencia la actividad bioeléctrica cerebral, digitalizarla y compararla con valores normativos.

Los estudios neurofisiológicos muestran que los niños con este trastorno difieren en su susceptibilidad de repuesta vegetativa con respecto a los que no sufren el trastorno, al presentar más o menos reactividad que éstos, ya sea en estado de reposo tónico o en respuesta a situaciones nuevas.

Aunque los EEG clínicos habituales se interpretan como normales en la mayoría de los pacientes con este trastorno, en la cuantificación de los datos del EEG o EEGq, se ha observado que el $93 \%$ de los niños pueden calificarse como de hiperarousal (aumento de la actividad en zona frontal) o hipoarousal (enlentecimiento en zona frontal) con respecto a lo normal (Chabot y Serfontein, 1996). Este hallazgo sugiere que el trastorno engloba ambas situaciones de hiperarousal e hipoarousal (en diferentes individuos) y apoya la idea que considera el trastorno como una alteración, más que un retraso en el desarrollo (Popper y West, 2000).

Con respecto a los potenciales evocados (ondas eléctricas relacionadas con eventos), en este trastorno presentan una amplitud de onda más pequeña y una latencia más prolongada 
en relación con lo normal. Las respuestas iniciales son inconstantes entre los diferentes estudios, pero suelen estar en rangos normales, lo cual sugiere que la estimulación mental para la información que se recibe es normal. La amplitud es generalmente más pequeña, excepto en los potenciales evocados visuales. En este trastorno se observa más negatividad de lo normal en ondas lentas (700-900 mseg) a nivel de línea media occipital. En comparación con los individuos con este trastorno no agresivos, los que presentan el trastorno con carácter agresivo tienen más negatividad frontocentral (ondas lentas de 640-900 mseg), y en las regiones parietales predomina la negatividad en el lado derecho, en comparación con el izquierdo.

Al emplear estimulantes, los potenciales evocados muestran un aumento normalizador en la pequeña amplitud de P3, lo que se acompaña de una mejoría en la precisión y en los tiempos de reacción al realizar una tarea. Existe un enlentecimiento ulterior en la latencia de la respuesta P3b frente al aumento en la exigencia de memorizar. En los picos iniciales probablemente no hay cambios en los primeros (N1, P1) pero N2 aumenta la amplitud, especialmente en la región frontal. Se han propuesto algunas características para distinguir los pacientes que responden a los estimulantes de los que no responden. Aunque ambos tienen una amplitud similar P3b antes de la medicación, dicha amplitud parece incrementarse en mayor grado en los que no responden a los estimulantes.

Estos hallazgos neurofisiológicos, parcialmente discordantes, no se prestan a fácil resumen, aunque el TDAH parece englobar un trastorno del estado de activación (arousal) además de una deficiencia en la inhibición de respuestas. Pueden observarse dos clases principales de activación en diferentes pacientes. El hiperarousal y el hipoarousal, ambos en comparación con el estado de activación normal, ligadas presumiblemente a una reactividad vegetativa respectivamente elevada y escasa, podrían representar dos subtipos de trastorno. Ambos subtipos parecen asociarse con anomalías particulares destacadas en la región frontal. 
Una anomalía en la corteza frontal derecha, relacionada con trastornos en la atención y en el procesamiento de la información (pequeña amplitud de la P300) se acompaña de menor eficacia de los estimulantes en algunos pacientes. Sin embargo los pacientes que no responden a los estimulantes pueden presentar una normalización paradójicamente menor de la pequeña amplitud de la P3 en este trastorno, en comparación a los que sí que responden a los estimulantes. Los mecanismos que intervienen en la preparación (o estimulación) para la información que se recibe (lo que corresponde a la forma casi normal de los potenciales evocados iniciales de respuesta) parecen hallarse intactos en este trastorno y no se modifican con los estimulantes.

Los estudios realizados en la actualidad sobre el sueño señalan que los niños con este trastorno tienen más problemas del sueño comparándolos con niños normales. (Corkum y cols, 1998; Greenhill y cols, 1983). Sin embargo, la mayoría de los estudios sobre el sueño y el TDAH se han basado en cuestionarios a padres y son pocos los estudios que han realizado valoraciones objetivas del sueño (Platon y cols, 1999; Palm y cols, 1992; Busby y cols, 1981; Greenhill y cols, 2002; Gruber y cols, 200). Aunque son prevalentes los informes subjetivos de alteraciones en niños con este trastorno, la verificación objetiva es menos robusta. La naturaleza exacta de los problemas de sueño en estos niños está todavía por determinar, factores como grupos de diagnóstico poco definidos, pequeño tamaño muestral, pocos estudios y limitaciones de procedimiento y metodología hacen difícil establecer la relación entre el TDAH y trastornos del sueño definidos (Corkum y cols, 1998).

Bernal la fuente y cols (2002), con una muestra de 48 niños con TDAH, subtipo inatento, predominio hiperactivo y combinado, y grupo control, registran por medio del Polisomnograma las posibles alteraciones en el sueño y encuentran diferencias en el patrón de sueño de los niños con TDAH, en comparación con el grupo control, sobre todo en cinco parámetros del sueño. Encuentran que los niños con TDAH tienen una disminución de la 
eficiencia del sueño, un aumento del número de los minutos que están despiertos durante el sueño, un aumento del porcentaje de fase 3 del sueño, un aumento del porcentaje de sueño lento y una disminución del porcentaje del sueño REM. También observan que en un elevado porcentaje de niños con TDAH existen paroxismos epileptiformes durante el sueño. Estos hallazgos indican inestabilidad del sueño-vigilia en los niños con TDAH, que concuerdan con los datos que aportan Platon y cols (1999) de considerar al TDAH como una alteración en la regulación del Arousal.

En las siguientes tablas (Tabla 5 y Tabla 6) se resumen los principales hallazgos sobre los parámetros de sueño y sus características polisomnográficas. Se observan diferencias significativas con respecto al grupo de edad con TDAH y el grupo normal. Se establecen grupos de comparación con respecto a los rangos de edad.

Hay diferencias neurofisiológicas en comparación con los rangos de edad, que oscilan desde los 6 a los 7 años, el rango de edad de los 8 a los 9 años, de los 10 a los 11 años y de los 12 a los 13 años.

Tabla 5. Parámetros de sueño en niños normales y con TDAH. (Bernal-La Fuente y cols 2002).

\begin{tabular}{|c|c|c|c|c|c|c|c|c|}
\hline \multirow[b]{2}{*}{$\begin{array}{l}\text { Tiempo total de } \\
\text { registro (TTR) }\end{array}$} & \multicolumn{2}{|c|}{$\begin{array}{l}\text { De } 6 \text { a } 7 \text { años } \\
\text { Control }(n=9) \\
\text { TDAH }(n=15)\end{array}$} & \multicolumn{2}{|c|}{$\begin{array}{c}\text { De } 8 \text { a } 9 \text { años } \\
\text { Control }(n=14) \\
\text { TDA.H }(n=10)\end{array}$} & \multicolumn{2}{|c|}{$\begin{array}{c}\text { De } 10 \text { a } 11 \text { años } \\
\text { Control }(n=20) \\
\text { TDAH }(n=10)\end{array}$} & \multicolumn{2}{|c|}{$\begin{array}{l}\text { De } 12 \text { a } 13 \text { años } \\
\text { Control }(n=27) \\
\text { TDAH }(n=9)\end{array}$} \\
\hline & $\begin{array}{l}\text { Control: } 579 \\
\text { TDAH: } 432\end{array}$ & $p<0,05$ & $\begin{array}{l}\text { Control: } 543,3 \\
\text { TDAH: } 414,80\end{array}$ & $p<0,05$ & $\begin{array}{l}\text { Control: } 490,5 \\
\text { TDAH: } 436,10\end{array}$ & $p=0,007$ & $\begin{array}{l}\text { Contrd: } 478,3 \\
\text { TDAH: } 442,67\end{array}$ & $p=0,023$ \\
\hline $\begin{array}{l}\text { Latencia de } \\
\text { sueño (min) }\end{array}$ & $\begin{array}{l}\text { Control: } 18,4 \\
\text { TDAH: } 18,5\end{array}$ & $p=0,9$ & $\begin{array}{l}\text { Control: } 24,6 \\
\text { TDAH: } 28,10\end{array}$ & $p=0,57$ & $\begin{array}{l}\text { Control: } 19,5 \\
\text { TDAH: } 26,40\end{array}$ & $p=0,37$ & $\begin{array}{l}\text { Contrd: } 20,3 \\
\text { TDAH: } 25,44\end{array}$ & $p=0,32$ \\
\hline $\begin{array}{l}\text { Despertares } \\
\text { intermitentes (min) }\end{array}$ & $\begin{array}{l}\text { Control: } 8,20 \\
\text { TDAH: } 38,53\end{array}$ & $p=0,004$ & $\begin{array}{l}\text { Control: } 4,3 \\
\text { TDAH: } 29,8\end{array}$ & $p=0,041$ & $\begin{array}{l}\text { Control: } 3,7 \\
\text { TDAH: } 65,30\end{array}$ & $p=0,006$ & $\begin{array}{l}\text { Contrd: } 5,6 \\
\text { TDAH: } 21,56\end{array}$ & $p=0,056$ \\
\hline $\begin{array}{l}\text { Tiempo total de } \\
\text { sueño (TTS) (min) }\end{array}$ & $\begin{array}{l}\text { Control: } 546,6 \\
\text { TDAH: } 374,73\end{array}$ & $p<0,05$ & $\begin{array}{l}\text { Control: } 513,7 \\
\text { TDAH: } 363,6\end{array}$ & $p<0,05$ & $\begin{array}{l}\text { Control: } 467,2 \\
\text { TDAH: } 351,10\end{array}$ & $p=0,001$ & $\begin{array}{l}\text { Contrd: } 451,1 \\
\text { TDAH: } 395,67\end{array}$ & $p=0,003$ \\
\hline $\begin{array}{l}\text { Eficiencia de sueño } \\
(\text { TTS } / T T R \times 100 \text { ) }\end{array}$ & $\begin{array}{l}\text { Control: } 94,5 \\
\text { TDAH: } 86,76\end{array}$ & $p=0,002$ & $\begin{array}{l}\text { Control: } 94,7 \\
\text { TDAH: } 86,16\end{array}$ & $p=0,019$ & $\begin{array}{l}\text { Control: } 95,4 \\
\text { TDAH: } 78,21\end{array}$ & $p=0,002$ & $\begin{array}{l}\text { Contrd: } 94,4 \\
\text { TDAH: } 89,50\end{array}$ & $p=0,048$ \\
\hline Fase 1 (\%) & $\begin{array}{l}\text { Control: } 7,70 \\
\text { TDA.H: } 2,7\end{array}$ & $p<0,05$ & $\begin{array}{l}\text { Control: } 7,70 \\
\text { TDAH: } 4,35\end{array}$ & $p=0,040$ & $\begin{array}{l}\text { Control: } 6,9 \\
\text { TDAH: } 4,27\end{array}$ & $p=0,062$ & $\begin{array}{l}\text { Contro: } 8,1 \\
\text { TDAH: } 3,67\end{array}$ & $p=0,001$ \\
\hline Fase 2 (\%) & $\begin{array}{l}\text { Control: } 47,20 \\
\text { TDAH: } 43,71\end{array}$ & $p=0,24$ & $\begin{array}{l}\text { Control: } 48,3 \\
\text { TDAH: } 49,72\end{array}$ & $p=0,64$ & $\begin{array}{l}\text { Control: } 52 \\
\text { TDAH: } 35,64\end{array}$ & $p=0,001$ & $\begin{array}{l}\text { Contrd: } 50,5 \\
\text { TDAH: } 48,13\end{array}$ & $p=0,52$ \\
\hline Fase $3(\%)$ & $\begin{array}{l}\text { Control: } 6,30 \\
\text { TDAH: } 17,85\end{array}$ & $p<0,05$ & $\begin{array}{l}\text { Control: } 6,5 \\
\text { TDAH: } 17\end{array}$ & $p<0,05$ & $\begin{array}{l}\text { Control: } 7 \\
\text { TDAH: } 20,59\end{array}$ & $p=0,001$ & $\begin{array}{l}\text { Contrd: } 8,3 \\
\text { TDAH: } 15,07\end{array}$ & $p=0,07$ \\
\hline Fase 4 (\%) & $\begin{array}{l}\text { Control: } 17,60 \\
\text { TDAH: } 21,74\end{array}$ & $p: 0,124$ & $\begin{array}{l}\text { Control: } 15,3 \\
\text { TDAH: } 12,47\end{array}$ & $p=0,253$ & $\begin{array}{l}\text { Control: } 14 \\
\text { TDAH: } 20\end{array}$ & $p=0,092$ & $\begin{array}{l}\text { Contrd: } 12,6 \\
\text { TDAH: } 15,05\end{array}$ & $p=0,10$ \\
\hline Total sueño lento $[\%]$ & $\begin{array}{l}\text { Control: } 24 \\
\text { TDAH: } 37,42\end{array}$ & $p=0,004$ & $\begin{array}{l}\text { Control: } 21,8 \\
\text { TDAH: } 29,50\end{array}$ & $p=0,013$ & $\begin{array}{l}\text { Control: } 21 \\
\text { TDAH: } 40,59\end{array}$ & $P<0,05$ & $\begin{array}{l}\text { Contrd: } 20,9 \\
\text { TDAH: } 30,13\end{array}$ & $p=0,043$ \\
\hline
\end{tabular}


Tabla 6. Parámetros de sueño.

\begin{tabular}{|c|c|c|c|c|c|c|c|c|}
\hline \multirow[b]{2}{*}{$\begin{array}{l}\text { Tiempo total } \\
\text { de registro (TTR) }\end{array}$} & \multicolumn{2}{|c|}{$\begin{array}{c}\text { Do } 6 \text { a } 7 \text { años } \\
\text { DA }(n=9) \\
C(n=5)\end{array}$} & \multicolumn{2}{|c|}{$\begin{array}{c}\text { De 8 a } 9 \text { años } \\
D A(n=4) \\
C(n=5)\end{array}$} & \multicolumn{2}{|c|}{$\begin{array}{c}\mathrm{De} 10 \text { a } 11 \text { años } \\
\mathrm{DA}(\mathrm{in}=6) \\
\mathrm{C}(\mathrm{n}=3)\end{array}$} & \multicolumn{2}{|c|}{$\begin{array}{c}\text { De } 12 \text { a } 13 \text { arios } \\
D A(n=5) \\
C(n=4)\end{array}$} \\
\hline & $\begin{array}{l}\mathrm{DA}: 436,56 \\
\text { C: } 416\end{array}$ & $p=0,74$ & $\begin{array}{l}\text { DA: } 446,25 \\
C: 399,40\end{array}$ & $p=0,18$ & $\begin{array}{l}\text { DA: } 437,83 \\
\text { C: } 429,67\end{array}$ & $p=0,15$ & $\begin{array}{l}\text { DA: } 442 \\
\text { C: } 443,50\end{array}$ & $p=0,19$ \\
\hline $\begin{array}{l}\text { Latencia do } \\
\text { sueño (min) }\end{array}$ & $\begin{array}{l}\text { DA: } 17 \\
\text { C: } 22,40\end{array}$ & $p=0,06$ & $\begin{array}{l}\text { DA: } 20,75 \\
\text { C: } 32,20\end{array}$ & $p=0,29$ & $\begin{array}{l}\text { DA: } 27 \\
\text { C: } 28,33\end{array}$ & $P=0,33$ & $\begin{array}{l}\text { DA: } 20,80 \\
\text { C: } 31,21\end{array}$ & $p=0,41$ \\
\hline $\begin{array}{l}\text { Tiempo total } \\
\text { de sueño (TT) (min) }\end{array}$ & $\begin{array}{l}\text { DA: } 385,99 \\
\text { C: } 339,40\end{array}$ & $p=0,63$ & $\begin{array}{l}\text { DA: } 389,25 \\
\text { C: } 354,40\end{array}$ & $p=0,15$ & $\begin{array}{l}\text { DA: } 381 \\
\text { C: } 285,33\end{array}$ & $p=0,22$ & $\begin{array}{l}\text { DA: } 392 \\
\text { C: } 400,25\end{array}$ & $p=0,68$ \\
\hline $\begin{array}{l}\text { Eficiencia de sueño } \\
\text { (TTS } / \text { TTR } \times 100 \text { ) }\end{array}$ & $\begin{array}{l}\text { DA: } 89,42 \\
\text { C: } 81,69\end{array}$ & $P=0,49$ & $\begin{array}{l}\text { DA: } 87,28 \\
\text { C: } 85,72\end{array}$ & $p=0,014$ & $\begin{array}{l}\text { DA: } 83,20 \\
\text { C: } 66,6\end{array}$ & $P=0,92$ & $\begin{array}{l}\text { DA: } 88,91 \\
\text { C: } 90,23\end{array}$ & $p=0,63$ \\
\hline Fase $1[\%]$ & $\begin{array}{l}\mathrm{DA}: 3,28 \\
\mathrm{C}: 2,10\end{array}$ & $P=0,29$ & $\begin{array}{l}\mathrm{DA}: 5,57 \\
\mathrm{C}: 2,89\end{array}$ & $p=0,52$ & $\begin{array}{l}\mathrm{DA}: 2,66 \\
\mathrm{C}: 8,36\end{array}$ & $P=0,02$ & $\begin{array}{l}\mathrm{DA}: 3,71 \\
\mathrm{C}: 3,61\end{array}$ & $p=0,41$ \\
\hline Fase $2(\%)$ & $\begin{array}{l}\text { DA: } 47,46 \\
\text { C: } 38,60\end{array}$ & $p=0,70$ & $\begin{array}{l}\text { DA: } 50,65 \\
C: 50,07\end{array}$ & $p=0,02$ & $\begin{array}{l}\text { DA: } 31,87 \\
\text { C: } 40,40\end{array}$ & $p=0,94$ & $\begin{array}{l}\text { DA: } 45,94 \\
\text { C: } 50,86\end{array}$ & $p=0,55$ \\
\hline Fase $3[\%]$ & $\begin{array}{l}\text { DA: } 16,00 \\
\text { C: } 20,72\end{array}$ & $p=0,54$ & $\begin{array}{l}\text { DA: } 15,78 \\
\text { C: } 17,66\end{array}$ & $p=0,46$ & $\begin{array}{l}\text { DA: } 24,40 \\
\text { C: } 13,70\end{array}$ & $P=0,58$ & $\begin{array}{l}\text { DA: } 18,99 \\
\text { C: } 10,18\end{array}$ & $p=0,06$ \\
\hline Fase $4[\%]$ & $\begin{array}{l}\text { DA: } 19,26 \\
\text { C: } 25,71\end{array}$ & $p=: 0,55$ & $\begin{array}{l}\text { DA: } 14,65 \\
\text { C: } 8,7\end{array}$ & $p=0,12$ & $\begin{array}{l}\text { DA: } 18,33 \\
\text { C: } 25,4\end{array}$ & $p=0,67$ & $\begin{array}{l}\text { DA: } 15,03 \\
\text { C: } 15,07\end{array}$ & $p=0,05$ \\
\hline Total sueño lento (96) & $\begin{array}{l}\text { DA: } 35,27 \\
\text { C: } 39,90\end{array}$ & $p=0,46$ & $\begin{array}{l}\text { DA: } 30,44 \\
\text { C: } 26,39\end{array}$ & $p=0,33$ & $\begin{array}{l}\text { DA: } 42,73 \\
\text { C: } 39,10\end{array}$ & $p=0,16$ & $\begin{array}{l}\text { DA: } 34,02 \\
\text { C: } 25\end{array}$ & $p=0,10$ \\
\hline Latencia REM & $\begin{array}{l}\text { DA: } 161,83 \\
\text { C: } 149,80\end{array}$ & $p=0,74$ & $\begin{array}{l}\text { DA: } 156 \\
\text { C: } 157,60\end{array}$ & $p=0,27$ & $\begin{array}{l}\text { DA: } 182,67 \\
\text { C: } 272,67\end{array}$ & $p=0,23$ & $\begin{array}{l}\text { DA: } 169,2 \\
\text { C: } 147\end{array}$ & $p=0,63$ \\
\hline $\begin{array}{l}\text { Tiempo total } \\
\text { sueño REM (min) }\end{array}$ & $\begin{array}{l}\text { DA: } 59,22 \\
\text { C: } 48,80\end{array}$ & $p=0,12$ & $\begin{array}{l}\text { DA: } 52,75 \\
C: 61,40 \\
\end{array}$ & $p=0,54$ & $\begin{array}{l}\text { DA: } 52 \\
\text { C: } 35,67\end{array}$ & $p=0,33$ & $\begin{array}{l}\text { DA: } 62,20 \\
C: 83,50 \\
\end{array}$ & $p=0,013$ \\
\hline Porcentaje sueño REM & $\begin{array}{l}\text { DA: } 15,18 \\
\text { C: } 14,22\end{array}$ & $p=0,17$ & $\begin{array}{l}\text { DA: } 13,31 \\
\text { C: } 17,34\end{array}$ & $p=0,61$ & $\begin{array}{l}\text { DA: } 14 \\
\text { C: } 12,39\end{array}$ & $p=0,39$ & $\begin{array}{l}\text { DA: } \\
C: 20,23\end{array}$ & $p=0,00$ \\
\hline Número fases REM & $\begin{array}{l}\mathrm{DA}: 3,33 \\
\mathrm{C:} 5\end{array}$ & $P=0,86$ & $\begin{array}{l}\mathrm{DA}: 4 \\
C: 5\end{array}$ & $p=0,91$ & $\begin{array}{l}\text { DA: } 2,67 \\
C: 3\end{array}$ & $P=0,79$ & $\begin{array}{l}\mathrm{DA}: 5 \\
\mathrm{C}: 4\end{array}$ & $p=0,9$ \\
\hline
\end{tabular}

Estos resultados (Tabla 5 y Tabla 6) con respecto a la arquitectura del sueño, son científicamente menores, pero desde el punto de vista clínico no lo son por la enorme repercusión que tiene el sueño sobre la recuperación de la corteza prefrontal. (Bernal- La fuente y cols, 2004). El estudio polisomnográfico es muy importante para el posterior tratamiento diagnóstico y terapéutico de niños con sospecha de TDAH.

Se puede concluir que el sueño de los niños con TDAH no presenta grandes alteraciones en su arquitectura que indique la existencia de un foco lesivo. Las alteraciones encontradas no parecen indicar que exista una alteración de los mecanismos que regulan el sueño. 


\subsection{PERFIL NEUROQUIMICO}

Las descripciones de los circuitos neuroanatómicos asociados al trastorno se organizó previamente por la hipótesis de las catecolaminas, con el desarrollo posterior de la hipótesis de la alteración de la dopamina y la norepinefrina como neurotransmisores principales (Castellanos y cols, 1997; Pliszka y cols, 1996; Roth y cols, 1995). Posteriormente, la hipótesis del neurotransmisor dopaminérgico se ha sometido a numerosas revisiones a lo largo de los años. En la actualidad se insiste mayoritariamente en el papel que ejercen la dopamina, la noradrenalina, la serotonina, el ácido aminobutírico (GABA) y el glutamato en la corteza prefrontal y en el núcleo caudado, con menor intervención de la noradrenalina y la acetilcolina.

Ésta hipótesis vendría respaldada por la eficacia de la terapia farmacológica y el papel de los psicoestimulantes, que tienen un papel principal en la intervención sobre determinados síntomas del TDAH, al actuar sobre los receptores dopaminérgicos bloqueando los receptores de dopamina (Popper y West, 2000).

Tal como señala Brown (2006), las investigaciones realizadas sobre los aspectos neuroquímicos del TDAH muestran que la producción de dopamina y noradrenalina en pacientes con un diagnóstico de TDAH es normal. En sus cerebros, simplemente no se liberan ni recargan estos neurotransmisores de una forma eficiente en áreas cruciales para las funciones ejecutivas. Estos neurotransmisores no están distribuidos de una forma homogénea por todo el cerebro, sino muy concentrada en unas áreas que son muy importantes para las funciones ejecutivas. En pacientes con TDAH, en estas conexiones no se libera una cantidad suficiente del neurotransmisor, o la cantidad liberada se recarga con demasiada rapidez y es captada de nuevo hacia la célula remitente, mucho antes de que el mensaje eléctrico haya podido ser transportado en su totalidad. Esto implica que muchos de los mensajes que tienen que ser llevados por estas redes de gestión no se trasmiten de una manera adecuada y eficaz. 
Con los medicamentos destinados al tratamiento del TDAH, y en concreto los estimulantes, se consigue que haya más cantidad disponible de dopamina y noradrenalina en los cientos de miles de uniones sinápticas, en el lugar y momento adecuados para el control central de las funciones cerebrales. Éstos no crean ni incrementan la cantidad total de neurotransmisores en el cerebro, pero facilitan su liberación y frenan la captación en las innumerables conexiones de las áreas de gestión, desbloqueando de forma secuencial una serie de puertas químicas para facilitar que la transmisión sea correcta y eficaz. Tal como desarrolla Brown (2006), los resultados de muchos estudios farmacológicos muestran claramente que el TDAH es esencialmente un problema químico, que tiene como consecuencia un deterioro del sistema que sirve de soporte a una comunicación rápida y eficiente dentro del sistema de control cerebral. Este trastorno refleja un deterioro del procesamiento de la dopamina y la noradrenalina que evoluciona desde la infancia a la adolescencia y la edad adulta (Brown, 2006).

\subsection{RESUMEN}

El TDAH aparece como una entidad patológica compleja, que afecta sutilmente al funcionamiento cognitivo y conductual. Para explicarlo, se han propuesto diversas hipótesis sobre la estructura de las áreas prefrontales y áreas subcorticales, alteraciones de volumen cerebral global, de las áreas prefrontales, de la distribución de la sustancia blanca y gris, asimetrías y lesiones del núcleo caudado y putamen, problemas en los hemisferios cerebelosos, alteraciones en las ondas cerebrales, anomalías de sueño y mal funcionamiento del sistema de neurotransmisión. Todo ello sugiere que en el TDAH se combinan alteraciones morfológicas, funcionales y de la conectividad de varios circuitos que intervienen en las funciones ejecutivas (Rubia y cols, 2014). Sin embargo, hasta la fecha no se han identificado 
biomarcadores objetivos del trastorno. Una parte de la dificultad tiene que ver con las limitaciones de las investigaciones, con muestras pequeñas o problemas de diseño. Otra, tiene que ver con la naturaleza del propio trastorno. Al igual que otras condiciones médicas, el TDAH posiblemente sea una condición compleja que no tiene causa única (Van-Wielink, 2005). 
CAPITULO 3. EL TDAH Y LAS FUNCIONES EJECUTIVAS 
Utilidad de la cartografía cerebral en el diagnóstico del TDAH 


\section{INTRODUCCIÓN}

El término funciones ejecutivas (FE) describe un amplio grupo de procesos que implican el desarrollo y monitorización de las destrezas cognitivas necesarias para realizar acciones con un fin determinado. Son las habilidades cognitivas superiores implicadas en el desempeño de nuevas acciones y conductas intencionales. Suponen la formulación de objetivos y toma de decisiones ante situaciones nuevas. Todos estos procesos se activan para verificar si una acción es adecuada a una situación dada. Su desarrollo está vinculado al desarrollo de la corteza prefrontal (Papazian y cols. 2006), que coordina estos procesos, envía y recibe información de la mayoría de las áreas corticales y subcorticales. Una función central de los procesos cognitivos es la de coordinar y controlar la totalidad del sistema cognitivo y asignar los recursos cognitivos en forma apropiada (Grieve y Gnanasekaran, 2009).

Barkley (1998) define las funciones ejecutivas como actividades mentales que permiten planificar, organizar, guiar, revisar, regular y evaluar el comportamiento necesario para obtener metas. Ayudan a resolver los problemas internos y externos. Los problemas internos son el resultado de la representación mental de actividades creativas y conflictos de interacción social, comunicativos, afectivos, motivacionales nuevos y repetitivos. Los problemas externos son el resultado de la relación entre el sujeto y su entorno. La meta de las funciones ejecutivas, es la de solucionar estos problemas de una manera efectiva y eficaz para satisfacer las demandas del medio y del sujeto. A fin de solucionar futuros problemas, las FE inhiben otros problemas internos y externos irrelevantes y activan el estado de alerta del 
sistema atencional selectivo y sostenido durante y antes de tomar una decisión $\mathrm{y}$ posteriormente realizar una acción. Se informa si el problema es nuevo o si por el contrario ya ha sucedido con anterioridad y se establecen las estrategias de solución y sus posibles resultados. Se busca la información almacenada en la memoria remota y reciente. Si el problema es nuevo, se vale de la información almacenada en la memoria verbal y no verbal, analizando las consecuencias de resultados de acciones previas similares y tomando en consideración riesgos contra beneficios. Posteriormente se elabora un plan de actuación, se toma una decisión y se actúa internamente o externamente (Barkley y cols, 1997; Papazian y cols, 2006; Tirapu-Ustarroz y cols, 2002).

Todos estos procesos mentales que conforman las FE, se realizan de una manera automática a fin de evitar errores tanto en tiempo como en espacio y proporcionando una autoevaluación posterior que asegura que las órdenes se han cumplido con exactitud y los resultados son autoanalizados. Se podría hablar de que estas funciones tienen la capacidad de filtrar la interferencia, el control de las conductas dirigidas a una meta, la habilidad de anticipar las consecuencias de la conducta y la flexibilidad; también incluye la moralidad, la conducta ética y la autoconciencia (Ardila y Roselli, 2007).

La definición conceptual de este sistema funcional, tanto en el adulto como en el niño, pero especialmente en este último, y el establecimiento de las adquisiciones que marcan los hitos de su desarrollo en las primeras décadas de la vida, no están exentos de dificultades (Sánchez-Carpintero y cols, 2001).

Su correcta evolución madurativa nos asegura una correcta monitorización del comportamiento hacia un futuro en concreto. Tal como señala Papazian y cols (2006), la adquisición de las FE muestra un comienzo alrededor de los 12 meses de edad y a partir de ahí se desarrolla lentamente, con dos picos a los 4 y a los 18 años, se estabiliza posteriormente y declina en la vejez, formando una curva de U invertida. Se relaciona con el 
desarrollo de la corteza prefrontal. El aumento del volumen de la CPF es lento hasta la edad de 8 años y rápido entre los 8 y los 14 años de edad (Papazian y cols, 2006).

\subsection{EL MODELO EXPLICATIVO DE RUSSELL BARKLEY (1997): EL MODELO DE AUTORREGULACIÓN}

Russell Barkley (1997) consideraba que el problema principal de los niños con hiperactividad es un déficit en la inhibición conductual, relacionado con la disfunción del sistema ejecutivo anteriormente descrito (Barkley, 1997). Esta teoría evolucionó hacia el concepto de autorregulación. Este modelo, según Servera-Barceló (2005), se basa en el análisis de las interrelaciones entre la inhibición conductual, las funciones ejecutivas y la autorregulación. Las FE permiten autorregular el comportamiento para poder hacer lo que nos proponemos hacer. Estos constructos psicológicos tienen su base neurológica situada principalmente en córtex prefrontal, como estructura anatómica diana.

Los procesos de inhibición conductual implican tres procesos interrelacionados (Figura 1)

1) La capacidad para inhibir respuestas prepotentes.

2) La capacidad para detener patrones de respuesta habituales y permitir una demora en la toma de decisión.

3) La capacidad para proteger este periodo de demora y el establecimiento de respuestas autodirigidas que acontecen en él de las interrupciones que derivan de eventos y respuestas competitivas (control de la interferencia). 
El niño con TDAH tiene serios problemas para inhibir tanto las respuestas asociadas al refuerzo positivo, por las cuales obtiene una recompensa, como las respuestas asociadas a una consecuencia negativa, en la cual el niño evita un estímulo o actividad desagradable.

El desarrollo de la autorregulación propuesta por Barkley, empieza tanto con la inhibición de las respuestas inadecuadas como la de los patrones de respuesta habituales que llegan en un momento en el que se muestran ineficaces (Barkley, 1998; Servera- Barceló, 2005). Cuando el niño es capaz de ejercer control motor sobre sus acciones y establecer periodos de demora, en los que evalúa la conveniencia o no de una u otra conducta, madura la autorregulación. En el momento en el cual el niño es capaz de introducir periodos de demora en la toma de decisiones, es especialmente importante que éstos estén protegidos de las interrupciones en interferencias que puedan derivar tanto de estímulos ambientales como estímulos interoceptivos.

La autorregulación, tal como la define Barkley (1998), es la respuesta o cadena de respuestas del sujeto que alteran la probabilidad de que ocurra una respuesta que normalmente sigue a un evento y que además altera a largo plazo la probabilidad de sus consecuencias asociadas.

Las funciones ejecutivas implicadas en la autorregulación, hacen referencia a aquellas acciones autodirigidas del individuo. Las cuatro funciones ejecutivas del modelo de Barkley (1998) son:

1) La memoria de trabajo no verbal.

2) La memoria de trabajo verbal (o el habla internalizada)

3) El autocontrol de la activación, la motivación y el afecto.

4) La reconstitución.

Estas funciones, según Servera-Barceló (2005), tienen como objetivo internalizar las conductas para anticipar cambios en el futuro y así, maximizar a largo plazo los beneficios 
del individuo. Suponen la maduración de patrones de conducta manifiestos. Por ejemplo, la memoria de trabajo no verbal interioriza las actividades sensoriomotoras, y permite mantener internamente representada la información que se utilizará para controlar la emisión de respuestas contingentes a un evento. La memoria de trabajo verbal interioriza el habla, hace alusión al proceso por el cual esta estructura se pone al servicio del pensamiento a través del lenguaje. El autocontrol controla la activación/ motivación/ afecto/ emoción. Estos procesos sitúan al individuo en el control del tono afectivo presente en la acción cognitiva dirigida a un objetivo, la capacidad para activar cargas afectivas asociadas a las memorias de trabajo. Por último, la reconstitución, hace referencia a la internalización del juego. Es la capacidad del lenguaje para representar objetos, acciones y propiedades que existen en el medio. Es la capacidad de deducción que consta del análisis de los comportamientos observados y la posterior deducción a partir de estos comportamientos que no hayan sido previamente aprendidos mediante la experiencia (Van-Wielink, 2005).

Barkley (1998) propone que esta función se expresa por un proceso de análisis y otro proceso de síntesis. Por la habilidad de separar las secuencias conductuales en sus unidades y por la capacidad para combinar diversos elementos de distintas secuencias para construir otras nuevas. La organización de estas funciones ejecutivas y el correcto equilibrio, conlleva a la puesta en funcionamiento de las conductas propositivas e intencionales orientadas a la consecución de un objetivo. Barkley, partiendo de estos conceptos, expone una posible vía de maduración de las funciones ejecutivas, con el posterior desarrollo de la inhibición conductual y la autorregulación (Barkley, 1998; Servera-Barceló, 2005).

Lo que primero comenzaría a desarrollarse sería la capacidad inhibitoria, desarrollándose en paralelo con la memoria de trabajo no verbal. Seguidamente, vendría la progresiva internalización del afecto y la motivación, estrechamente relacionada con la 
internalización del habla. Finalmente, el último elemento a desarrollarse, sería la internalización del juego, es decir, la reconstitución.

Este modelo hipotético, enfatiza la comprensión del TDAH a través de la conducta encubierta, privada y autodirigida. Establece una estructura jerárquica en donde las funciones ejecutivas dependen de la inhibición conductual y la interacción entre ambas tiene como consecuencia el desarrollo de la autorregulación y el control motor. Este control motor se refiere al número de conductas que se ponen en marcha para conseguir la meta en un proceso de autorregulación. Dentro del control motor, se hace referencia a dos capacidades enfocadas a las acciones a desarrollar en concreto. Dichas capacidades son la fluencia, que permite la capacidad para generar conductas novedosas y creativas en el momento en que se necesitan y, por otro lado, la sintaxis que facilita la capacidad para reconstruir y representar internamente la información del medio (Barkley, 1997; Servera-Barceló, 2005).

\subsection{EL PATRON TDAH APLICADO AL MODELO TEORICO DE RUSSELL BARKLEY}

La alteración de las funciones ejecutivas en los niños con TDAH (figura 1), tendría como consecuencia la presencia de déficit en la memoria de trabajo, mal funcionamiento en la internalización del habla, inmadurez en el control del afecto, la motivación, la activación y una reconstitución dañada. Los niños con TDAH presentan dificultades en la regulación del control motor, reducción en la capacidad de control de la fluencia y la sintaxis. Esto implicaría una seria dificultad para desarrollar conductas orientadas hacia un objetivo, con reducida capacidad de persistencia, graves dificultades en la monitorización de su conducta y en su activación emocional. Estos niños son muy insensibles al feedback de proceso y como resultado, están más afectados por las cuestiones irrelevantes de la tarea y tienen grandes 
dificultades organizativas y muestran menos creatividad. Tienen dificultades en el mantenimiento de atención sostenida, suficientemente documentado en el TDAH. Cometen errores por omisión en las pruebas psicométricas diseñadas para estas cuestiones (figura 2) (Arán y Mias, 2009; Brown, 2001, 2006).

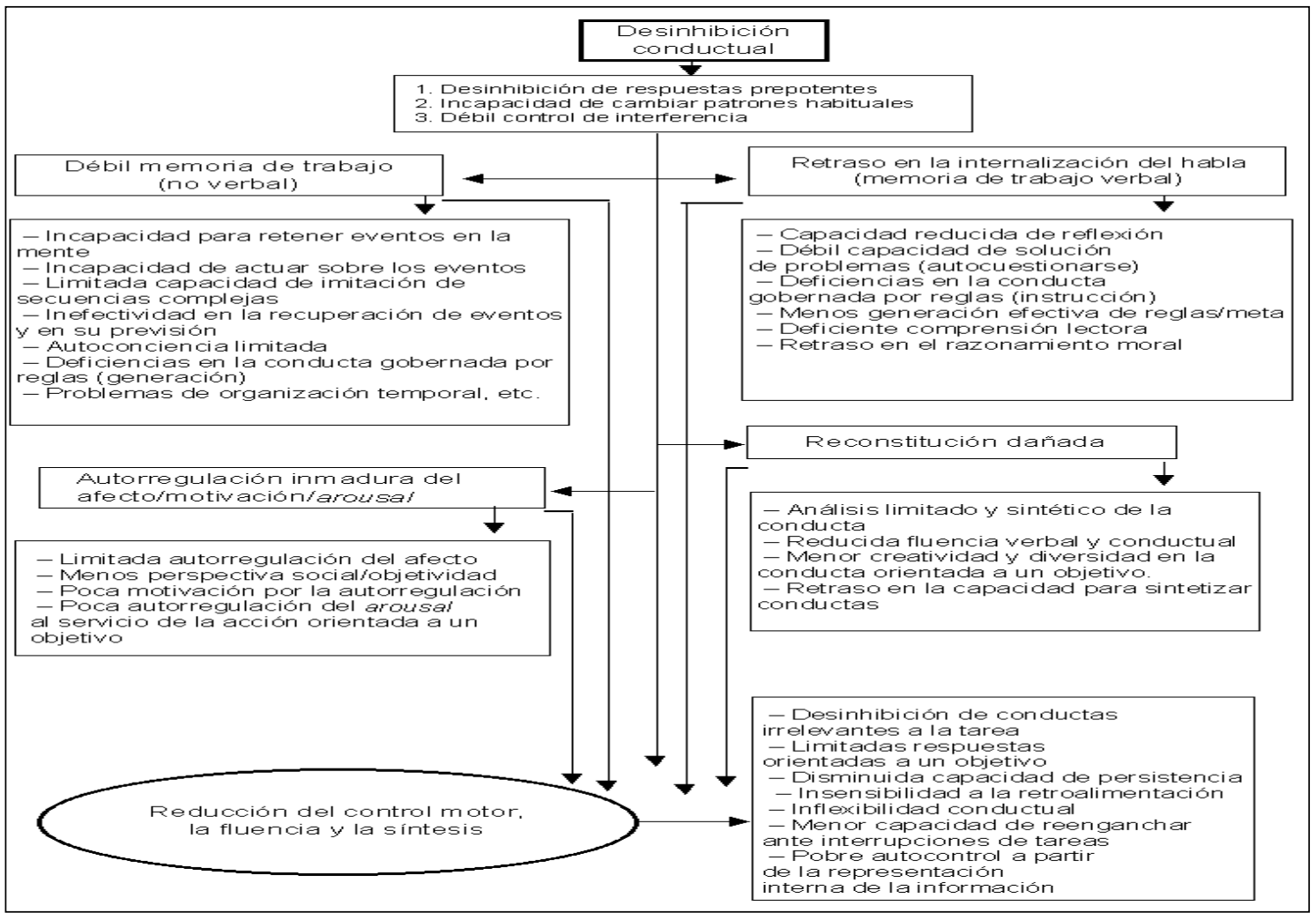

Figura 1 Características del TDAH a partir del modelo de autorregulación de Russell Barkley (1998) (Serverá-Barcelo, 2005).

\begin{tabular}{|c|c|c|c|c|c|}
\hline \multirow[b]{2}{*}{$\begin{array}{l}\text { Organización, } \\
\text { establecimiento } \\
\text { de prioridades. } \\
\text { activación para } \\
\text { trabajar. }\end{array}$} & \multicolumn{4}{|c|}{$\begin{array}{l}\text { Funciones ejecutivas. } \\
\text { Actúan varias en combinaciones }\end{array}$} & \\
\hline & $\begin{array}{c}\text { Atención } \\
\text { mantenimiento } \\
\text { desplazamiento } \\
\text { de la atención } \\
\text { hacia tareas }\end{array}$ & $\begin{array}{c}\text { Regulación } \\
\text { estado } \\
\text { de alerta } \\
\text { mantenimiento } \\
\text { del esfuerzo } \\
\text { velocidad }\end{array}$ & $\begin{array}{c}\text { Control de la } \\
\text { Frustración } \\
\text { y } \\
\text { Modulación } \\
\text { de las } \\
\text { emociones. }\end{array}$ & $\begin{array}{l}\text { Uso de la } \\
\text { memoria de } \\
\text { trabajo } \\
\text { y } \\
\text { acceso a los } \\
\text { recuerdos. }\end{array}$ & $\begin{array}{c}\text { Observación } \\
\text { y } \\
\text { acción } \\
\text { auto- } \\
\text { reguladora. }\end{array}$ \\
\hline Activación & Concentración & Esfuerzo & Emoción & Memoria & Acción \\
\hline
\end{tabular}

Figura 2 Alteración de las funciones ejecutivas en el TDAH (Brown, 2001; Brown, 2006) 


\subsection{RESUMEN}

La disfunción ejecutiva no es exclusiva del TDAH, pero tiene influencias negativas más potentes de las que ocasiona en otros trastornos (Willcutt y cols, 2008). Estos déficits ejecutivos están afectando, sobre todo, a los procesos de inhibición y memoria de trabajo y correlacionan significativamente con las manifestaciones de inatención, pero no con la sintomatología de hiperactividad/ impulsividad (Doyle, 2006; Martel, 2006).

Según Barkley (1998) y Servera-Barceló (2005) este modelo, aplicado al TDAH, hace más referencia a un trastorno de la ejecución que a un trastorno de habilidad o de capacidad. La dificultad del TDAH no radica en no saber qué hacer y cómo hacerlo, sino en cuándo o dónde hacerlo. Los niños con TDAH, en líneas generales, tienen un nivel intelectual y de procesamiento de la información dentro de los parámetros de la normalidad. Su aprendizaje, tanto académico, social o comportamental se va desarrollando, aunque mucho más lento que los niños sin este trastorno del neurodesarrollo. Necesitan la tutela de alguien que les guíe para que puedan poner en marcha estas habilidades adquiridas. Sin esta monitorización constante, estos niños no las utilizan o lo hacen de un modo muy desorganizado.

Servera- Barceló (2005) concluye que el factor tiempo es determinante en estos niños, ya que la capacidad cognitiva más deteriorada es la percepción del tiempo, la imposibilidad de prescindir del aquí y el ahora. Al no tener en cuenta las consecuencias del pasado, y no tener capacidad de predicción de lo que pueda acontecer en un futuro, tienen muy disminuida su conciencia de responsabilidad. Además, el niño con TDAH calcula mal el esfuerzo y la dedicación que requieren las tareas de procesamiento secuencial. En definitiva, están seriamente afectadas la capacidad organizativa, planificadora y de control de la actuación. 
CAPITULO 4. HISTORIA DEL DESARROLLO DE LA ELECTROENCEFALOGRAFIA 
Utilidad de la cartografía cerebral en el diagnóstico del TDAH 


\subsection{HISTORIA DEL DESARROLLO DEL EEG}

Los primeros estudios sobre los ritmos eléctricos del cerebro en animales se remontan al año 1770, cuando el italiano Luigi Galvani publica sus resultados sobre la actividad cerebral animal. Este científico demuestra la existencia de actividad eléctrica cerebral en animales, pero sus observaciones no tuvieron demasiado impacto al igual que los estudios realizados por Frederick Von Humboldt en 1797 y Carlo Matteucci en 1830 (Palacios, 2002). Esto en parte, se debe a la influencia de Volta, que consideraba que los hallazgos descubiertos, se debían al efecto ocasionado por un estímulo eléctrico proveniente de la batería sobre dos metales disímiles.

Posteriormente, entre 1848 y 1849, Emil du Bois Raymond se interesó por el fenómeno eléctrico intrínseco en el funcionamiento de los nervios y músculos. En sus "Investigaciones sobre actividad eléctrica cerebral" describe el registro de potenciales del músculo sobre la piel y establece las bases de la electromiografía clínica (Goldesohn, 1993).

Las primeras descripciones de la actividad eléctrica en cerebros de animales fueron realizadas por el fisiólogo inglés Richard Caton, interesado por los estudios realizados por Raymond e influenciado por Edouard Hitzig y Gustav Theodor Fritsch, quienes habían demostrado la evidencia de respuestas motoras locales después de realizar estimulación eléctrica en varias áreas de los cerebros de perros, sosteniendo la hipótesis de que los estímulos periféricos podían evocar respuestas eléctricas focales. Dichos autores llegaron a producir convulsiones en los perros después de aplicar sobre el cráneo intensos estímulos eléctricos. Caton, conocedor de estas investigaciones, sostuvo la hipótesis de que los 
estímulos periféricos podían evocar respuestas eléctricas cerebrales focales. Dicha hipótesis le permitió obtener financiación de la Asociación Británica de Medicina para realizar estudios experimentales sobre actividad eléctrica cerebral. Los resultados se publicaron en el British Medical Journal en 1875. En este trabajo comparó su trabajo con el que había realizado algunos años antes el neurocirujano inglés David Ferrier, que demostró en perros respuestas motoras discretas y locales tras recibir estimulación cortical (Palacios, 2002). Caton fue el primero en observar actividad eléctrica cerebral continua y espontánea, refiriéndose a ésta como "Corrientes eléctricas en la Sustancia gris"

Aproximada quince años después de los hallazgos de Caton, Adolf Beck junto a su mentor Cybulsky, inspirados por los trabajos de Hitzig y Fritsch, realizaron nuevas propuestas para intentar otros métodos de localización funcional en el cerebro. Debe advertirse que ninguno de los investigadores conocía el trabajo previo realizado por Richard Caton. En su tesis doctoral, realizada en 1891, Beck hipotetizaba sobre la presencia de corrientes eléctricas en el cerebro y en la médula espinal y en el caso de que así fuese, que éstas corrientes tuvieran modificaciones durante la actividad. Aunque ya existían galvanómetros desde que Caton realizara sus experimentos, el equipo de medición de frecuencias de respuesta que utilizaron Beck y Cybulsky no permitía reconocer espigas epileptiformes y la amplificación de la señal apenas permitía registrar actividad electroencefalográfica colocando electrodos sobre la corteza cerebral. La tesis de Beck describe la presencia de potenciales evocados visuales y la supresión de la actividad continua de fondo al aplicar diferentes estímulos sensoriales (Palacios, 2002).

A su vez, el vienés Fleich Von Marxow confirmó la actividad eléctrica rítmica recogida sobre la superficie cerebral de perros, mediante electrodos impolarizables y describe la desaparición de esta actividad eléctrica cuando se administraba anestesia cloroformiza profunda (Palacios, 2002). 
A comienzos de este siglo, los rusos Pavel Kaufman y Pradvich Neminski fueron los primeros en establecer que los potenciales eléctricos cerebrales se podían recoger a través del cráneo intacto. Estos autores realizaron experimentos con perros, a los que se les realizaron craneotomias, y, con electrodos colocados sobre la corteza cerebral, registraron actividad cerebral electroencefalográfica epileptiforme (Palacios, 2002).

Posteriormente, Neminski, utilizando un galvanómetro de cuerda, observó por primera vez la presencia de distintos ritmos cerebrales captados en cerebros de perros, diferenciados de acuerdo con su frecuencia (10, 15, 20, 32 ciclos por segundo), bautizando dichas oscilaciones en el término "Electrocerebrograma".

Sin embargo, el padre del EEG en humanos, fue sin duda Hans Berger, jefe de la unidad de Psiquiatría de la Universidad de Jena, quien en 1902 comenzó con una prolongada serie de estudios, aunque siendo el primer registro documentado es el efectuado el 6 de Julio de 1924 en un joven de 17 años. En él registró las oscilaciones rítmicas cerebrales a través de un orificio provocado por una trepanación descomprensiva utilizando un galvanómetro de cuerda. Berger observó que obtenía mayor éxito al registrar cráneos que habían sufrido lesiones y que tenían defectos entre el cuero cabelludo y en el cerebro. Utilizó diferentes tipos de electrodos (agujas de zinc, platino, pomo y de otros materiales) colocados en o sobre el cuero cabelludo. Los mejores resultados fueron obtenidos cuando se fijaban en zona frontal y en zona occipital (Palacios, 2002).

Berger, desde muy temprano, quiso estudiar las relaciones entre los procesos mentales y los procesos cerebrales. Estaba convencido de que la relación mente-cuerpo no era tan distante y existían procesos que unían de manera muy cercana al uno con el otro. El resultado más importante de sus inquietudes y de los estudios que llevó a cabo, fue el descubrimiento del electroencefalograma (EEG). 
Inicialmente, Berger disponía de una pobre preparación para la investigación que pretendía llevar a cabo. Tenía poca experiencia como neurofisiólogo y sus conocimientos electromecánicos eran limitados. Utilizó galvanómetros de cuerda relativamente primitivos, destinados a registrar potenciales de mucho mayor voltaje, como el electrocardiograma (ECG). Sus primeros intentos en registrar la actividad bioeléctrica cerebral fueron un fracaso, pero progresivamente logró mejorar. Se sabe que intentó entre el 1902 y el 1910 reproducirlos en diferentes animales, pero falló en su cometido (Goldesohn, 1993, Stevens, 1971).

Para realizar el registro electroencefalográfico en humanos, Berger utilizaba electrodos de aguja y un galvanómetro de cuerda con un espejo en el que se reflejaba la luz, que a su vez permitía la exposición en un papel fotográfico de bromuro de plata que se movía a $3 \mathrm{~cm}$ por segundo, la misma velocidad que se utiliza en los registros actuales. Durante los siguientes años, acumuló varios registros electroencefalográficos de individuos con cráneos intactos, incluyendo 73 trazados de su hijo Klaus (Palacios, 2002).

En 1929 publicó su histórico artículo llamado “Actividad eléctrica cerebral” y entre ese año y el 1938 publicó en los “Archiv Fur Und Nerven Kranheiten” una serie de trabajos en los cuales se realizan las primeras descripciones de los ritmos cerebrales en humanos y sus modificaciones en condiciones fisiológicas y patológicas. Berger bautizó a sus registros con el nombre de Electroencefalograma, que reemplazó al de electrocerebrograma propuesto previamente por Neminski. A pesar de ser consciente de la importancia del descubrimiento, Berger esperó cinco años para publicar sus resultados (Palacios, 2002).

En 1930, Berger realizó 1133 registros en 76 personas y preparó un segundo informe. Designó con letras del alfabeto griego los dos tipos de ondas que había observado desde el principio en los trazados realizados en seres humanos. Las de mayor voltaje y menor frecuencia fueron denominadas ondas alfa $(\alpha)$ y las de menor voltaje y mayor frecuencia, las 
denominó ondas beta $(\beta)$. En 1931, registró por primera vez actividad de punta-onda, observando la frecuencia con la que se observaba actividad electroencefalográfica anormal en pacientes con epilepsia.

Los trabajos de Berger fueron recibidos con escepticismo en el ambiente médico, hasta que en 1934, el prestigioso fisiólogo ingles ED Adrian y su colega HC Matthews confirmaron sus observaciones, utilizando amplificadores termoiónicos, demostrando la presencia de ondas alfa en región occipital denominando a dicha actividad como " Ritmo de Berger”. A su vez, Herbert Jasper, corroboró los hallazgos obtenidos por Berger, publicándolo sólo dos meses después de la publicación de Adrian en la revista "Science” en el año 1935. Jasper y Hunter, posteriormente lograron realizar con una sola cámara, un registro simultaneo del EEG y de la actividad del paciente, mediante un ingenioso sistema de espejos colocados sobre el paciente y sobre el trazado electroencefalográfico (Palacios, 2002). El primer registro de actividad cerebral colocando los electrodos sobre la corteza cerebral (electrocorticografía) y no la superficie craneal, fue llevado a cabo por Forester y Alternburger en 1935.

Entre los años 1935 y 1937 Jasper, Grass, F.A Gibbs, E. L Gibbs, David, Lennox y Walter, confirmaron el valor de este procedimiento, introduciéndolo en investigación y en la práctica clínica, especialmente en el campo de la epilepsia, convirtiendo el EEG en el método rutinario en la práctica clínica hospitalaria. Sobre estas fechas, Loomis y sus colaboradores registraron cambios electroencefalográficos durante el sueño. (Tejeiro, 2005). En el 1938, aumentaron los esfuerzos en registrar electroencefalogramas durante eventos ictales, mostrando imágenes en movimiento sincronizadas con el trazado electroencefalográfico. En 1965 los transistores, que habían sido inventados en 1947, reemplazaron a los amplificadores con tubos de vacío en los electroencefalógrafos, logrando un mejor registro gráfico. Los 
mismos transistores hicieron posible, el manejo computerizado de todos los aspectos de la electroencefalografía.

Posteriormente, los trabajos de Berger fueron publicados en ingles por Peter Gloor en 1969, en su libro titulado Hans Berger in the Electroencephalogram of the Man. Dicha obra incluye una excelente biografía del científico alemán (Palacios, 2002). En 1976, Andersen y Andersen, formularon la hipótesis según la cual, el funcionamiento indefinido de los núcleos talámicos como circuitos oscilantes, originaría actividad EEG rítmica.

\subsection{DESARROLLO DE LOS MÉTODOS CUANTITATIVOS EN EL EEG: DEL EEG AL EEG CUANTITATIVO O CARTOGRAFÍA CEREBRAL (EEGq)}

Desde el descubrimiento del EEG por Hans Berger en 1929, muchos han investigado el registro EEG bajo diferentes condiciones y en diferentes trastornos tanto neurológicos como trastornos psiquiátricos. En los registros iniciales, el EEG era principalmente inspeccionado visualmente. Posteriormente, el perfeccionamiento de los equipos de registro, permitieron otros abordajes (Arns y cols, 2011). Con la ayuda de diferentes instrumentos matemáticos, se consigue el registro más fino de la señal eléctrica obtenida en el EEG. Cabe destacar las primeras aplicaciones del análisis de Fourier al EEG por Dietsch en 1932, representando este avance un paso importante en el estudio de la actividad eléctrica cerebral.

En este sentido e históricamente, tal como señalan Oller y Ortiz (1987), deben mencionarse una serie de intentos realizados en los últimos 25 años. Inicialmente, cabe destacar, los trabajos de Walter y Shipton en 1951, que desarrollan el denominado toposcopio, el cual podía representar las modificaciones de la señal del EEG sobre el cráneo. Posteriormente, en 1955, Remond desarrolló mapas espacio-temporales mediante un montaje 
de electrodos colocados en línea. A su vez, Cooley y Tukey, en 1965 realizan el análisis espectral del EEG por medio de la aplicación del algoritmo de Fourier (Tejeiro, 2005). En 1976, la aparición de los miniordenadores de bajo coste y alta velocidad, permitió el desarrollo de programas más potentes, especializados en realizar la trasformada de Fourier, aplicándola a las señales neuroeléctricas (Cooley y Tukey, 1965; Oller y Ortiz, 1987). En Estados Unidos, el grupo liderado por Ross Adey, del Instituto de Investigación Cerebral de UCLA, entre el periodo de 1961 hasta e1974, desarrollaron el EEG cuantitativo o EEGq. Estos investigadores, comenzaron a utilizar metodología digital en el análisis EEG, con la producción de mapas cerebrales y desarrollaron la primera base de datos normativa de los mapas cerebrales (Arns y cols, 2011). En 1967, Adey y Walter, utilizaron una forma de visualización gráfica del espectro de potencia del EEG, basada en los contornos espectrales de isopotencia para el análisis de los registros EEG de los tripulantes del vuelo espacial Géminis (Oller y Ortiz, 1987). Posteriormente, Lehman (1971) publicó "Los mapas de actividad alfa", registrados mediante derivaciones múltiples. A su vez, Bostem, en 1975 utilizó metodología sinóptica de representación, con similares objetivos (Oller y Ortiz, 1987). En 1978, Ragot y Remond, consiguen representar el primer mapa EEG de la superficie del cuero cabelludo, llegando a una distribución en toda la superficie, obteniendo mapas espaciotemporales del EEG.

Gracias a este desarrollo matemático, aplicando la transformada de Fourier, se consiguió el espectro de potencia del EEG en las diferentes bandas de frecuencia, obteniendo en tiempo real, mapas de actividad eléctrica cerebral.

Posteriormente al desarrollo de esta metodología, Cooley y Tukey, Duffy, Burchfield y Lombroso, (1979) presentaron un nuevo sistema de análisis de la actividad del EEG denominándola "Brain Electrical Activity Mapping”. Esta metodología se ha ido utilizando con otras técnicas neurofisiológicas como los potenciales evocados (en adelante PE) 
Cabe destacar los trabajos realizados por Duffy y Lombroso (1979), que desarrollaron programas de Cartografía Cerebral en tiempo real y presentaron por primera vez, la comparación de los mapas de actividad cerebral como complemento de la Tomografía Axial Computerizada (en adelante TAC) (Oller y Ortiz, 1987). Estos autores, señalan que así como el examen realizado con la TAC que permite detectar procesos lesionales cerebrales, con mucha más exactitud que el registro EEG, este último, junto con los PE, quedan como herramientas diagnósticas fundamentales para los procesos cerebrales, no necesariamente lesionales. Duffy y Lombroso, (1979) concluyeron que la culminación de la cartografía espectral o mapas de actividad eléctrica evocada como técnicas de neuroimagen funcional, podían permitir en un futuro realizar una valoración funcional de una lesión, ya demostrada por técnicas de neuroimagen estructural. Dicho de otro modo: con la QEEG o mapas de actividad eléctrica, se puede obtener una valoración de anomalías funcionales (Oller y Ortiz, 1987).

\subsection{RESUMEN}

La investigación de la actividad eléctrica del cerebro tiene una historia relativamente corta y estrechamente relacionada con los desarrollos tecnológicos. Comenzó con observaciones sobre la actividad eléctrica del cerebro y músculos de los animales, recogida directamente en la corteza cerebral. Posteriormente se aplicó a seres humanos con heridas craneales y, ya en el siglo XX, comenzaron los registros a través de los huesos del cráneo. Berger describió de las distintas ondas cerebrales, propuso que existían relaciones entre procesos mentales y actividad eléctrica del cerebro, y creó lo que hoy conocemos como EEG. La matematización del análisis de la señal mediante la transformada de Fourier y el registro simultáneo mediante varios electrodos en distintas áreas del cráneo, permitieron obtener 
registros de mayor calidad, que se aplicaron con éxito al estudio de la epilepsia, los procesos del sueño y la detección de lesiones cerebrales. De este modo, el EEG se convirtió en una herramienta de uso común en la práctica clínica. El progreso técnico en el registro y análisis de la señal eléctrica a lo largo de los últimos años ha traído nuevas posibilidades, en particular los estudios de correlación con técnicas de imagen estructural (TAC), los mapas cerebrales y la formación de bases de datos normativas, que permiten comparar los resultados de la exploración de un sujeto con los de su grupo de referencia. 
Utilidad de la cartografía cerebral en el diagnóstico del TDAH 
CAPITULO 5. ASPECTOS TÉCNICOS DEL EEG Y LA EEGq 
Utilidad de la cartografía cerebral en el diagnóstico del TDAH 


\subsection{REGISTRO EEG}

El EEG es una de las exploraciones neurofisiológicas de uso más extendido en la práctica médica actual. Como se ha expuesto en el capítulo anterior, consiste en el registro de la actividad eléctrica del cerebro empleando electrodos colocados generalmente sobre el cuero cabelludo. La actividad eléctrica cerebral tiene su origen en las corrientes iónicas derivadas de los diversos procesos bioquímicas que acontecen a nivel celular (FernándezTorre, 2001).

La señal de EEG es generada básicamente por la suma de actividad eléctrica de distintas poblaciones neuronales, las cuales pueden generar potenciales eléctricos y magnéticos, que pueden ser registrados a cierta distancia de sus fuentes de producción mediante electrodos en el cuero cabelludo (EEG de superficie). Ésta exploración neurofisiológica se basa en el registro de la actividad bioeléctrica cerebral en condiciones basales de reposo, en vigilia o sueño, y durante diversas activaciones (habitualmente hiperventilación y estimulación luminosa intermitente). La duración total aproximada de la prueba es de unos 20- 30 minutos.

\subsubsection{COLOCACION DE LOS ELECTRODOS}

Los electrodos pueden ser situados en cualquier lugar del cuero cabelludo que se desee. En los primeros registros, cuando comenzaba la Electroencefalografía clínica, no había puntos establecidos de colocación de los electrodos. Pronto se observó que este modo de 
proceder no era apropiado, pues si se variaba la posición de los electrodos, variaba el registro que se obtenía. En esas condiciones no se podía comparar dos registros de un mismo paciente. Este es el problema de la localización imprecisa de electrodos. Para subsanarlo, los laboratorios de neurofisiología definieron estándares para la colocación de electrodos. De este modo se podían comparar diversos EEG de un mismo paciente y estudiar los cambios existentes (Tejeiro, 2005).

Aunque la definición de estándares de localización solucionó el problema de la comparación de registros realizados en cada centro, la falta de un estándar común plantó un nuevo problema. Si en un laboratorio de neurofisiología se adoptaba una disposición fija de los electrodos, pero esta no coincidía con la adoptada por otros centros de estudio, la experiencia de un laboratorio no podía ser transmitida a otro laboratorio. Para solucionar este problema se creó un sistema internacional de colocación de electrodos. A partir de este momento las experiencias de un equipo EEG pudieron ser trasladadas de manera fidedigna a otros equipos EEG. La Federación Internacional de Sociedades de Electroencefalografía y Neurofisiología Clínica (1958) desarrolló el sistema 10-20, sistema congruente, que unifica la nomenclatura y localización de los electrodos y permite comparar y compartir los hallazgos electrográficos.

Entre las ventajas que ofrece este sistema, cabe destacar que constituye un formato estándar aceptado internacionalmente para situar los electrodos sobre el cuero cabelludo; existe una correlación anatómica demostrada para cada electrodo, es invariable en todos los pacientes y la separación de los electrodos es uniforme, asegurando poder comparar diversas áreas cerebrales; la denominación de los electrodos y sus localizaciones correspondientes es idéntica en todos los idiomas y se efectúa en términos anatómicos relacionados con el área cerebral cuya actividad registra; permite comparar los datos obtenidos de diversos EEG de uno o distintos pacientes obtenidos en el mismo o distinto laboratorio; finalmente, es un 
sistema flexible, que obtiene un adecuado estudio de las áreas cerebrales y permite modificaciones de los electrodos (en número o en situación sobre el cuero cabelludo) de acuerdo con la circunstancias de cada paciente (neonato, paciente con lesiones de cuero cabelludo, deformaciones, etc.) (Tejeiro, 2005).

La terminología es sencilla. Las iniciales F, C, P, O, T y Fp, corresponden las diferentes zonas anatómicas de colocación de electrodos: zona frontal $(\mathrm{F})$, zona central $(\mathrm{C})$ zona parietal $(\mathrm{P})$, zona occipital $(\mathrm{O})$, zona temporal $(\mathrm{T})$, y zona frontopolar $(\mathrm{Fp})$. Los números que acompañan a las iniciales hacen referencia al hemisferio cerebral. Los impares hacen referencia al izquierdo y los pares hacen referencia al derecho. El sufijo z, designa a los electrodos situados en la línea media (Iriarte, 2011).

Los electrodos utilizados en el registro EEG se designan por su localización y se asocian a coordenadas espaciales que permiten obtener mapas tridimensionales. Además del EEG, puede ser necesario tener en cuenta otros parámetros, como sucede en el polisomnograma, que registra además del EEG, el Electrocardiograma, el Electrooculograma y la Electromiografía. Además puede ser necesario conocer la saturación de oxígeno y los movimientos respiratorios por medio de bandas de flujo.

Tabla 7 Sistema internacional colocación electrodos 10-20 (Tejeiro, 2005)

\begin{tabular}{c|c|c|c} 
Fp1 & 1 & O2 & 10 \\
\hline Fp2 & 2 & F7 & 11 \\
\hline F3 & 3 & F8 & 12 \\
\hline F4 & 4 & T3 & 13 \\
\hline C3 & 5 & T4 & 14 \\
\hline C4 & 6 & T5 & 15 \\
\hline P3 & 7 & T6 & 16 \\
\hline P4 & 8 & A1 & 17 \\
\hline 01 & 9 & A2 & 18
\end{tabular}




\subsubsection{DERIVACIONES}

El método de amplificación diferencial utilizado en los registros EEG, impide determinar el potencial absoluto de un electrodo aislado. Por este motivo, es necesario utilizar múltiples combinaciones de electrodos durante el trazado para estimar la actividad de un electrodo aislado. El término derivación hace referencia al registro obtenido cuando un par de electrodos se conectan a cada canal de amplificación (amplificador diferencial). En cada derivación se registra un potencial eléctrico relativo, siendo éste la diferencia de potencial entre las entradas 1 y 2 del amplificador. La combinación de derivaciones constituye el montaje, y el número de derivaciones en un montaje vendrá dado por el número de canales de amplificación de que disponga el electroencefalógrafo (Tejeiro, 2005).

Hasta hace relativamente poco los instrumentos de registro de más uso eran aparatos de 8 y 16 canales, siendo el de 16 canales de amplificación en que se solía utilizar con mayor frecuencia. Actualmente, y gracias al desarrollo de los EEG digitales, se utilizan un número superior de canales, permitiendo el registro simultáneo de un mayor número de lugares en el registro.

\subsubsection{TIPOS DE MONTAJES EN EL EEG}

Existen dos tipos de montajes: los montajes referenciales y los montajes bipolares. Con respecto a los montajes referenciales, los electrodos exploradores ocupan la posición 1 del amplificador respectivo, mientras que la posición 2 es ocupada por un electrodo que se conecta a un punto teóricamente inactivo común para todos los canales. En la práctica no existe un punto inactivo o indiferente (potencial 0) en el organismo, ya que cualquier potencial es transmitido al resto del cuerpo y a electrodos 
Todo sistema de registro, debe disponer de montajes de reformateo preparados tanto para ser monopolares (que comparan cada electrodo con una referencia común) como para ser un montaje bipolar (en cada canal se comparan electrodos vecinos). Ésta organización de los canales debe ordenarse de adelante a atrás y de izquierda a derecha (Iriarte, 2001).

La particular disposición de un determinado número de derivaciones representadas simultáneamente en un registro constituye un montaje, la actividad de cada derivación requiere un canal aparte de la amplificación y se registra sobre papel o digitalmente. Dada la gran amplificación necesaria para visualizar la actividad EEG, los instrumentos utilizados para el registro, son especialmente sensibles y requieren un manejo cuidadosamente desarrollado.

Con el EEG se obtiene una representación gráfica en el tiempo de la distribución de las diferencias de potencial eléctrico entre los electrodos aplicados (o a veces entre un electrodo y una referencia matemática) sobre las distintas zonas del cuero cabelludo. Con el registro EEG se pretende estudiar campos eléctricos complejos que cambian continuamente a lo largo del tiempo.

Entre las derivaciones más empleadas en el registro EEG, Fernández-Torre (2001) destaca los siguientes: (Tabla 5.2)

1) Derivación de referencia común: Este método emplea la diferencia de potencial eléctrico entre cada uno de los electrodos de registro y un electrodo de referencia común. En los registros con referencia común el electrodo de referencia siempre se conecta en el amplificador diferencial al terminal de entrada 2 (input 2). El electrodo de referencia ideal es el más inactivo posible. De este modo, es más factible seleccionar la referencia más inactiva respecto a una alteración específica del EEG que tiene una distribución determinada. (Fernández-Torre, 2001). En general, el montaje referencial común, es ideal 
para observar potenciales de amplia difusión sobre el cuero cabelludo (Tejeiro 2005).

2) Derivación de referencia común al promedio de los electrodos: Este sistema utiliza una referencia artificial, que representa el promedio de la actividad de todos los electrodos del registro. Una propiedad matemática de la media de un numero de observaciones es que la suma de las diferencias entre cada observación y la media es 0 y, en consecuencia, un número determinado de canales mostrarán una deflexión negativa y otros una deflexión positiva, pero la suma de las deflexiones tiene que ser 0 (Fernández-Torre, 2001). Con esta combinación se produce mayor atenuación de potencial de amplia difusión que con un registro de referencia común (Tejeiro, 2005).

3) Derivación bipolar: Cuando el número de canales disponibles es limitado, el uso de un método de derivación bipolar es particularmente recomendable. Este sistema de derivación conecta pares de electrodos, de tal manera que representa la diferencia de potencial eléctrico entre cada electrodo y los electrodos circundantes o cercanos al mismo.

\subsubsection{SEÑAL DE CALIBRACIÓN}

La calibración consiste en conocer qué magnitud y tipo de señal da el sistema en cada canal, para valorar el estado de los amplificadores y el sistema de digitalización. Por ello es importante que antes de cada registro se calibre el equipo, asignando la misma señal a cada canal de los amplificadores, y el sistema de registro para reproducir lo que genera cada entrada con esa señal. Así se comprueba que la calibración es adecuada, ya que todos los canales dan la misma señal (Iriarte, 2011). 
Todos los instrumentos de registro disponen de una batería que es capaz de enviar una señal eléctrica, de voltaje conocido, simultáneamente en las dos entradas de cada canal del aparato. Esta señal de calibración es una onda cuadrada que suministra datos sobre la mayoría de las características del amplificador. La distorsión producida por el amplificador (sensibilidad, filtros de frecuencia) hace que la onda cuadrada se presente de forma distinta (Tejeiro, 2005).

\subsection{TÉCNICA Y METODOLOGIA DEL EEGQ: ASPECTOS PRÁCTICOS}

Por medio del EEGq se consigue crear mapas de actividad eléctrica cerebral, basándose en el análisis de la actividad de base neurofisiológica en cada una de las áreas cerebrales, cuantificando la energía que corresponde a las diferentes bandas de frecuencia de la señal del EEG, aportando su representación gráfica en forma de mapas (Oller y Ortiz, 1987).

En la configuración de las diferentes bandas de frecuencia, la señal eléctrica se ha diferenciado en ritmos específicos caracterizados por el registro de actividad delta $\left(1^{\prime} 5-<4\right.$ $\mathrm{Hz})$, actividad Theta $(4-<8 \mathrm{~Hz})$ actividad alfa $(8-13 \mathrm{~Hz})$ y actividad beta $(>13 \mathrm{~Hz})$. A su vez, dentro de los parámetros utilizados en la obtención de los datos de la QEEG, cabe destacar los siguientes (tabla 9).

1) Potencia absoluta de las bandas de frecuencia: La potencia absoluta, hace referencia al índice que cuantifica la cantidad de energía en una de las bandas de frecuencia determinada y en un punto determinado de la superficie craneal. La potencia absoluta, queda configurada como los resultados extraídos de cada electrodo en cada banda (Total $\mu \mathrm{V}^{2}$ ) (Hughes y John, 1999). 
2) Potencia relativa de las bandas de frecuencia: Es el porcentaje de actividad de una banda de frecuencia y su distribución topográfica.

3) La coherencia interhemisférica: Indica el grado de sincronismo entre ambos hemisferios, siendo la medida de sincronización de la actividad entre dos canales (Hughes y John, 1999).

4) La coherencia intrahemisférica: Hace referencia a la suma de la sincronización de los eventos eléctricos entre las correspondientes regiones cerebrales dentro de cada hemisferio.

5) La asimetría interhemisférica: Es la diferencia de energía entre ambos hemisferios.

Cada uno de estos parámetros describe aspectos independientes de la actividad bioeléctrica cerebral y son sensibles a los cambios psicofísicos del paciente y a la presencia de determinadas enfermedades.

En la actualidad los servicios de Salud mental van valorando positivamente los datos que les pueden proporcionar el estudio neurofisiológico de los diferentes trastornos mentales. Según Herrero (1981), la primera función del EEG en un enfermo mental es saber si los síntomas psiquiátricos pueden ser relacionados con una etiología orgánica. En este caso, el registro EEG tiene como misión fundamental valorar el componente orgánico de la sintomatología.

Con el EEGq se obtienen mapas de actividad eléctrica cerebral, basados en el análisis de la actividad de base electroencefalográfica, en cada una de las áreas cerebrales, cuantificando la energía que corresponde a las diferentes bandas de las frecuencias de la señal EEG, con representación gráfica en forma de mapas (Oller y Ortiz, 1987). 


\subsubsection{MÉTODOS DE ANÁLISIS}

Para analizar la señal de base del EEG disponemos de métodos de análisis. El primero, es el análisis en el dominio de tiempo y el segundo, el análisis en el dominio de la frecuencia o análisis espectral.

\section{Análisis en el dominio de tiempo:}

Técnicas que tienen en común el reconocimiento de cada una de las ondas y su clasificación en las bandas de frecuencia (alfa, theta, beta y delta), siendo posible calcular el porcentaje de tiempo ocupado por cada una de las bandas de frecuencia en un segmento de señal EEG.

El método más simple se basa en el número de cruces por 0, es decir, el número de veces que la señal o la onda atraviesa la línea isoeléctrica y el cálculo del intervalo entre 2 cruces por 0 consecutivos en forma de un análisis de periodo. Cada onda es así reconocida y clasificada como una onda, delta, theta, alfa o beta. Itil, (1975) utiliza este método en psiquiatría y en psicofarmacología (Burch y cols).

2. Análisis en el dominio de la frecuencia o análisis espectral:

A diferencia del análisis en el dominio del tiempo, el análisis en el dominio de la frecuencia, o análisis espectral, no aporta la dimensión temporal de la sucesión de las ondas, pero es una excelente técnica para la cuantificación estadística de la actividad de base del EEG y su uso es actualmente generalizado, particularmente en Farmacología (Oller y Ortiz, 1987). 


\subsection{METODOLOGIA DE LOS MAPAS DE ACTIVIDAD ELECTRICA CEREBRAL}

Por medio de la transformada rápida de Fourier de la señal EEG, se consigue conocer la distribución de la potencia contenida la señal y en función de las frecuencias de las ondas que la componen.

Las señales EEG son recogidas por medio de la colocación de 16 electrodos, los cuales se hallan distribuidos sobre el cráneo, siguiendo el sistema internacional de Jasper denominada 10/20, mostrando la representación de la actividad eléctrica cerebral en forma de mapas.

Tal como señalan Oller y Ortiz, no todos los autores utilizan esta distribución de electrodos, siendo variable de unos a otros, en función de los requerimientos que precisen para el objetivo planteado. Así, por ejemplo, cuando se trata de efectuar mapas de actividad eléctrica cerebral del lóbulo temporal, autores como Nuwer (1986) distribuyen estos electrodos en una zona concreta del cuero cabelludo correspondiente. A continuación, las señales digitalizadas son sometidas a una transformada rápida de Fourier. Para cada electrodo se calcula el espectro de potencia que oscila entre 0 y $30 \mathrm{~Hz}$ por regla general, si bien algunos autores proponen anchos de banda superiores. En función del ancho de banda a estudiar, la conversión analógica/digital se realizará de acuerdo al teorema de Shannon, por el que la frecuencia de muestreo tiene que ser como mínimo el doble de la frecuencia máxima de la señal estudiada (Oller y Ortiz, 1987).

Diferentes sistemas de cartografía efectúan su representación en base al promedio de épocas de un segundo al menos, si bien otros aparatos más sofisticados efectúan el análisis en auténtico tiempo real, obteniendo imágenes sucesivas inmediatas de la evolución de la actividad cerebral del EEG o de los potenciales evocados. Estas imágenes sucesivas 
inmediatas unas a otras se denominan "cartooning” permitiendo una visión consecutiva de las modificaciones de la actividad cerebral en el curso del tiempo (Oller y Ortiz, 1987).

Otros instrumentos, tal como señalan Oller y Ortiz (1987), permiten, a través del promediado del espectro de potencia en forma sucesiva, la representación ya sea en valores de potencia absoluta, potencia relativa o proporciones entre diferentes bandas o entre el total de energía y una banda específica, modificable a voluntad del clínico, observar las características del EEG. Estos autores plantean los primeros temas de discusión en torno a la elaboración de los mapas de actividad cerebral (EEGq) y en concreto exponen tres temas a debatir:

\section{Los electrodos de referencia}

2. Los mapas de significación probabilística

3. Los sistemas de interpolación.

Con respecto a los electrodos de referencia, todos los registros electroencefalográficos que se utilizan para construcción de mapas de actividad eléctrica cerebral, se efectúan en derivación monopolar, es decir, se basan en el análisis de la diferencia de potencial entre un electrodo activo, situado en el cráneo, con respecto a un electrodo de referencia que puede variar según autores. Este electrodo de referencia ha sido objeto de polémica, al valorarse la influencia de sus características sobre el resultado del mapa o de la cartografía obtenida (Oller y Ortiz, 1987). Autores como Duffy y cols (1986) no encuentran diferencias suficientemente significativas para tener en cuenta dichas alternativas entre electrodos de referencia, llegando a la conclusión de que un montaje monopolar contra referencia media o referencia común seria quizás el más adecuado, especialmente cuando se eliminan del promediado aquellas derivaciones que con mayor frecuencia recogen actividades de origen extracerebral (electrodos frontales frecuentemente artefactados por movimientos oculares o palpebrales) (Duffy, 1986, Oller y Ortiz, 1987). 
Con respecto a la elaboración de mapas de significación probabilística, Oller y Ortiz, hacen referencia al sistema o procedimiento de análisis estadístico de la señal cartográfica obtenida desarrollada por Duffy en 1983, que consiste en la creación de un banco de datos de cartografías de individuos normales de cada una de las edades, en cada frecuencia. Por medio de configuraciones estadísticas como es la puntuación "Z" se puede comparar un determinado individuo con el grupo correspondiente y aportar así un mapa de significación probabilística, en el que en vez de representarse las características cartográficas del individuo en concreto, se representan las características estadísticas que se desvían del grupo control, representándose en desviaciones standards en vez de unidades de potencia (Duffy, 1983, Oller y Ortiz, 1987).

Por último, como tercer tema a tratar, Oller y Ortiz, (1987) hablan de la interpolación, que es el proceso por el cual, una vez registrados los datos en cada uno de los electrodos situados sobre el cuero cabelludo, se obtiene el peso o valor de energía que corresponde a cada uno de los electrodos atribuyendo unos valores de energía en los puntos interelectrodos, en función del inverso del cuadrado de la distancia de cada punto entre electrodos a uno o varios electrodos determinados. Estos autores hablan de varios métodos de interpolación. En primer lugar estaría la interpolación en cuadriláteros, que aporta un valor a cada uno de los puntos entre electrodos en función del valor de la energía que corresponde a los cuatro electrodos entre los que está comprendido. Otro método útil es la triangulación, que sería similar al anterior y que tiene como base el triángulo de electrodos y un valor que viene determinado por los parámetros asociados a todos y cada uno de los electrodos. La energía asignada con respecto a dicho punto a interpolar y el electrodo cuyo valor en energía se toma en consideración, teniendo en cuenta la distancia de cada punto a interpolar con respecto a todo el resto de electrodos. 
Una vez realizados todos estos procedimientos, se llega a la representación del mapa de actividad eléctrica cerebral, en valores numéricos en microvoltios cuadrados $\left(\mathrm{Mv}^{2}\right)$ en cada área explorada en cada una de las bandas de frecuencia analizada y representada en forma de escala de colores con unos niveles de gradiente (Oller y Ortiz, 1987).

Tabla 8 Propiedades de los distintos métodos de derivación. (Binnie, 1982; Gil-Nagel y cols ,2001)

\begin{tabular}{|c|c|c|c|c|}
\hline & Bipolar & Referencia común & $\begin{array}{l}\text { Referencia común } \\
\text { promedio }\end{array}$ & Referencia origen \\
\hline Principio & $\begin{array}{l}\text { Diferencias entre } \\
\text { electrodos } \\
\text { circundantes }\end{array}$ & $\begin{array}{l}\text { Diferencias entre cada } \\
\text { electrodo y una } \\
\text { referencia común. } \\
\text { Localización por } \\
\text { amplitud }\end{array}$ & $\begin{array}{l}\text { Diferencia entre cada } \\
\text { electrodo y el } \\
\text { promedio. } \\
\text { Localización por } \\
\text { amplitud y fase }\end{array}$ & $\begin{array}{l}\text { Diferencias entre } \\
\text { cada electrodo y una } \\
\text { referencia local: } \\
\text { localización por } \\
\text { amplitud }\end{array}$ \\
\hline $\begin{array}{c}\text { Actividad } \\
\text { focal }\end{array}$ & $\begin{array}{l}\text { Buena detección y } \\
\text { localización }\end{array}$ & $\begin{array}{l}\text { Buena detección y } \\
\text { localización }\end{array}$ & $\begin{array}{l}\text { Buena detección y } \\
\text { fácil localización }\end{array}$ & $\begin{array}{l}\text { Buena detección y } \\
\text { localización }\end{array}$ \\
\hline $\begin{array}{l}\text { Actividad baja } \\
\text { amplitud } \\
\text { difusa }\end{array}$ & Escasa detección & $\begin{array}{l}\text { Buena detección y } \\
\text { localización }\end{array}$ & $\begin{array}{l}\text { Adecuada detección } \\
\text { y localización }\end{array}$ & Escasa detección \\
\hline Asimetrías & Poco fiable & Bueno & Bueno & Bueno \\
\hline Forma & $\begin{array}{l}\text { Adecuado si la } \\
\text { actividad focal es } \\
\text { estable }\end{array}$ & Bueno & $\begin{array}{l}\text { Bueno, excepto } \\
\text { actividad difusa y } \\
\text { transitoria }\end{array}$ & Intermedia \\
\hline Artefactos & $\begin{array}{l}\text { Fácil } \\
\text { identificación }\end{array}$ & Fácil identificación & $\begin{array}{l}\text { Afecta a todos los } \\
\text { canales }\end{array}$ & $\begin{array}{l}\text { Afecta a varios } \\
\text { canales }\end{array}$ \\
\hline $\begin{array}{l}\text { Actividad de } \\
\text { fondo }\end{array}$ & Buena panorámica & Buena panorámica & Difícil & Buena panorámica \\
\hline Indicaciones & $\begin{array}{l}\text { Panorámica } \\
\text { general, localizar } \\
\text { la actividad focal } \\
\text { estable }\end{array}$ & $\begin{array}{l}\text { Asimetrías, actividad } \\
\text { difusa, focal y } \\
\text { transitoria }\end{array}$ & $\begin{array}{l}\text { Como referencia } \\
\text { común, pero menos } \\
\text { exacto }\end{array}$ & $\begin{array}{l}\text { Como referencia } \\
\text { común promedio, } \\
\text { mejor para actividad } \\
\text { focal }\end{array}$ \\
\hline
\end{tabular}


Tabla 9. Características técnicas de la QEEG (Cabanyes-Trufino, 2004).

\begin{tabular}{|c|l|}
\hline Potencia relativa & $\begin{array}{c}\text { Definición } \\
\text { (\% de actividad de una banda de frecuencia y su distribución topográfica }\end{array}$ \\
\hline Potencia absoluta & Índice de la cantidad de energía existente en una banda de frecuencia \\
& (Azul, verde, rojo). \\
\hline Coherencia interhemisférica & Sincronía entre ambos hemisferios. \\
\hline Asimetría interhemisférica & Diferencia de energía entre ambos hemisferios. \\
\hline
\end{tabular}

\subsection{RESUMEN}

El EEG es una de las exploraciones neurofisiológicas de uso más extendido en la práctica médica. Se basa en el registro de la actividad bioeléctrica cerebral en condiciones basales de reposo, en vigilia o sueño, y durante diversas activaciones. La duración total aproximada de la prueba es de unos 20-30 minutos. En la actualidad se ha alcanzado un alto grado de estandarización de los procedimientos de registro y definición de los parámetros que describen la actividad bioeléctrica cerebral. La cartografía cerebral, a su vez, representa un nuevo paso en el análisis de la actividad neurofisiológica en cada una de las áreas cerebrales, representada en mapas. Se trata de una herramienta de gran flexibilidad metodológica y analítica, que ha hecho posibles análisis precisos de las modificaciones de la actividad cerebral en el curso del tiempo o mapas en los que se representan las características cartográficas del individuo en relación a un grupo normativo. 
CAPITULO 6. MODELOS NEUROFISIOLÓGICOS EN EL TDAH 
Utilidad de la cartografía cerebral en el diagnóstico del TDAH 


\subsection{HISTORIA DE LA INVESTIGACIÓN CIN EL EEG EN EL TDAH. REGISTRO EEG}

Todos los estudios iniciales utilizaron la inspección visual del registro en papel del EEG. En la mayoría se observan alteraciones entre los grupos clínicos y los grupos controles, más allá de subrayar la naturaleza exacta de estas anormalidades en el EEG (Barry y cols, 2003). La primera investigación que describe hallazgos EEG en niños con disfunción cerebral mínima, (MBD) fue realizada por Jasper, Solomon y Bradley (1938). Estos autores ya hablaban de lo que actualmente se conoce como "Enlentecimiento frontal del EEG" (Arns y cols, 2011). Jasper y cols (1938) realizaron el análisis en base a tres tipos de clusters de síntomas: 1) predominio hiperactivo e impulsivo, 2) grupo con predominio de inmadurez emocional, 3) grupo con comportamiento delictivo. Encuentra en aproximadamente la mitad de la muestra anormalidades en el EEG, que consistieron en un incremento de actividad de onda lenta (2-6 Hz) en zona frontal (Barry y cols, 2003).

Posteriormente, Lindsley y Cutts (1940) compararon el registro EEG de 50 niños identificados por sus padres como niños con trastornos de comportamiento, con el registro de 36 niños sin dificultades de comportamiento. Encontraron alteraciones en el EEG, consistentes en actividad 2-5 Hz en los niños con problemas de comportamiento. Kennard (1949) trabajó con una muestra de 131 niños con varios trastornos de comportamiento, encontrando alteraciones en el EEG en el 60\% de los sujetos. Cohn y Nardini (1958) 
relacionaron el comportamiento agresivo con la actividad lenta bi-occipital. Anderson (1963) investigó a 30 niños de edades comprendidas entre los 8-12 años con comportamiento hiperquinético, y encontró tanto anormalidades focales como anormalidades focales inespecíficas. Capute y cols. (1968) estudiaron a 106 niños con daño cerebral mínimo de edades entre los 2 a los 16 años. Estos autores encontraron que la mitad de los niños de la muestra mostraron anormalidades, que consistieron en alteraciones en el EEG; 45 niños presentaron ligeras a moderadas anormalidades, 8 niños obtuvieron grandes alteraciones EEG y 14 de estos niños, mostraron alteraciones focales. Estas anormalidades totales encontradas en el EEG consistieron en un incremento de actividad de onda lenta bilateral en regiones posteriores (Capute y cols, 1968).

En este mismo año, Stevens y cols (1968) correlacionaron diferentes anormalidades EEG con perfiles comportamentales y encontraron que el enlentecimiento de las frecuencias del EEG en zona occipital estaba relacionada con la presencia de hiperactividad, dificultades emocionales y pobre discriminación figura-fondo. (Arns y cols, 2011). Wilker y cols. (1970) compararon a niños hiperactivos y con comportamiento agresivo, con niños no hiperactivos y registraron más actividad de onda lenta y más descargas transitorias en el EEG de estos niños hiperactivos que los niños no hiperactivos.

En contraste con estos resultados, según Arns y cols (2011) casi ninguno de los recientes estudios, salvo el realizado por Stevens en 1968, demuestra la clara relación que existe entre el enlentecimiento de la frecuencia alfa y las alteraciones comportamentales que se observan en la hiperactividad. Steriade y cols apuntan que la actividad theta podría disminuir la velocidad de onda alfa, sugiriendo que quizás el exceso de actividad theta a menudo observado, consista en la presencia de ambos tipos de onda, tanto una actividad alfa enlentecida y un exceso real de actividad lenta (Steriade y cols, 1990). 


\section{2. ESTUDIOS CUANTITATIVOS DEL EEG: DEL EEG A LA EEGq}

El paso de la tecnología cuantitativa del EEG a la cartografía cerebral (EEGq) ha permitido observar un incremento de actividad en las bandas theta y delta (Barry y cols, 2003). Los parámetros neurofisiológicos de la EEGq utilizados en el estudio del TDAH son:

1. Potencia absoluta y Potencia relativa

2. Amplitud de onda

3. Frecuencia media

4. Porcentaje de tiempo presente de la onda

5. Coherencia EEG de la onda entre regiones

6. Análisis de frecuencia de la onda dominante y onda subordinada.

7. Ratio entre bandas de frecuencia.

La potencia absoluta es un índice de la cantidad de energía existente en una banda de frecuencia determinada y en un punto concreto de la superficie craneal. La potencia relativa hace referencia al porcentaje de actividad de una banda de frecuencia y su distribución topográfica. Es una medida que, bajo la condición de ojos cerrados en situación de reposo, muestra una buena fiabilidad test-restest (Barry y cols, 2003; John y cols, 1980). La potencia absoluta y la potencia relativa proporcionan una fácil interpretación y un método fiable para cuantificar cambios en el EEG bajo diferentes condiciones, así como diferencias entre grupos clínicos y grupos control (Barry y cols, 2003).

Dykam y cols (1982) usaron análisis de componentes para investigar las diferencias EEG entre 4 grupos: 1) Grupo hiperactivo, 2) grupo dificultades de aprendizaje, 3) grupo hiperactivo-dificultades de aprendizaje, o grupo mixto y 4) grupo control. Encontraron que el grupo hiperactivo obtuvo resultados más bajos que el grupo control, en particular actividad en banda theta y alfa de 7 a $10 \mathrm{~Hz}$ y una actividad de $16-20 \mathrm{~Hz}$ de actividad beta. 
Posteriormente, Callaway y cols (1983) compararon por medio de los PE y la EEGq un grupo de 18 niños sin patología y otros 18 niños con TDAH. Realizaron un registro EEG de tres electrodos colocados en zona posterior, en condición de registro de ojos abiertos y ojos cerrados en situación de reposo. Según sus resultados, el grupo TDAH muestra baja potencia absoluta en banda alfa y banda beta con respecto al grupo control (Barry y cols, 2003).

Satterfield y cols (1984) realizaron un estudio longitudinal de 138 niños con TDAH. Encontraron que a medida que aumentaba la edad de los sujetos, la potencia absoluta del EEG decrecía más rápido en los sujetos del grupo control que en el grupo de los chicos TDAH (Barry y cols, 2003).

Chabot y Serfontein (1996) describen diferencias EEG en 407 niños diagnosticados de TDAH con predominio déficit de atención (TDA), comparados con una muestra de 310 niños sin patología. Estos autores observaron que los niños TDA muestran un incremento en la potencia absoluta y relativa para la banda theta, predominante en zonas frontales y en la mitad de la zona frontal. Además, encuentran una ligera elevación de alfa relativa y un difuso decremento en las frecuencias medias para las bandas alfa y beta con respecto al grupo sin patología.

Lazzaro y cols (1998) investigaron las diferencias EEG entre 26 adolescentes varones diagnosticados de TDAH según criterios DSM-IV y un grupo control de 26 adolescentes sin diagnóstico. El registro se llevó a cabo bajo condición de ojos cerrados en situación de reposo. Según sus resultados, el grupo TDA obtiene un incremento en la potencia absoluta para actividad alfa y theta en regiones frontales y reducción de la potencia relativa para actividad beta en zona posterior.

Otro estudio importante es el realizado por Clarke y cols (1998). Se trata del primer estudio de las diferencias EEG entre niños con distintos diagnósticos DSM-IV. Compara 20 
niños con TDA y 20 niños con TDAH tipo combinado y 20 niños sin patología como grupo control. El registro se llevó a cabo en situación de reposo y bajo la condición de ojos cerrados. Según sus resultados, los niños con TDAH tipo combinado muestran incremento en poder absoluto y relativo sobre toda la zona del registro en bandas theta y reducción de la potencia relativa en banda beta y alfa. También observaron incremento de la potencia relativa en banda delta en región posterior, que permitieron discriminar a los tres grupos experimentales. En otro estudio de seguimiento, (Clarke y cols., 1998), con una amplia muestra de sujetos y un amplio rango de medidas, encuentran que los niños TDAH obtuvieron incrementos en la potencia absoluta y relativa en banda theta y un decremento en la potencia relativa en banda alfa y beta, lo que permitió diferenciar los TDAH combinado de los TDAH predominio inatento. Estos resultados muestran que los efectos en la potencia relativa fueron más estables que los efectos que se obtuvieron en los resultados sobre la potencia absoluta.

Boutros y cols (2005), en un meta-análisis que reúne a más de 1100 sujetos con TDAH y TDA, concluyen que el incremento de actividad lenta theta y theta relativo en el TDAH es el hallazgo más robusto para la obtención de un biomarcador EEG del TDAH.

Otro parámetro útil en investigación es la ratio o proporción entre las diferentes bandas de frecuencia. Permite evaluar los cambios en el EEG debidos a procesos madurativos cerebrales, arousal cortical o grado de activación (Lubar, 1991; Matousek y Peterson, 1973). La mayoría de los estudios en TDAH, han utilizado la ratio theta/beta y theta/ alfa. Ambas medidas han demostrado ser útiles para diferenciar entre pacientes TDAH y sujetos control sin patología (Clarke, 2001, 2002; Janzen y cols, 1995; Lubar, 1991; Matousek y cols, 1984, Monastra, 1999, 2001; Ricardo- Gardell, 2006).

Matousek y cols (1984) encontraron que la ratio theta/alfa permitía diferenciar entre niños con trastorno cerebral mínimo (MBD), TDAH tipo inatento y grupo control sin 
patología. Lubar (1991) desarrolló el concepto de la ratio theta/beta y observó que este índice discriminaba a niños sin patología y niños con TDA. Obtuvo la ratio de las bandas theta/beta en 25 niños con TDAH y 27 niños de un grupo control sin patología, con un registro realizado durante una prueba de dibujo. Encontró que la ratio del grupo TDAH era mayor que la del grupo control en todas las áreas del registro, con una gran diferenciación en la zona frontal (Lubar, 1991).

Esta medida fue investigada posteriormente por otros autores, destacando el trabajo de réplica de Monastra (1999). Realizó un estudio multicentro con 482 sujetos, obteniendo el registro con un único electrodo en $\mathrm{Cz}$. Según sus resultados, la ratio theta/beta discrimina sujetos con TDAH y sujetos normales con una precisión del 88\% (Monastra, 1999). Otro estudio importante es el de Janzen y cols (1995), que encontraron que la ratio theta/beta de los niños TDAH era más elevada que la de un grupo control. Uclés y Lorente (1996) encontraron que niños con TDAH inatento, diagnosticado según criterios DSM-III-R, obtuvieron una ratio en zona occipital superior a la del grupo control durante el registro en situación de reposo con los ojos cerrados. Estos datos, según estos autores, muestran que la reducción de actividad alfa quedaría explicada por la presencia de un déficit localizado en los sistemas córtico-corticales o en los sistemas talámico-corticales, siendo éste hallazgo la hipótesis más plausible para explicar el retraso madurativo.

Clarke $(2001,2002)$ encontró que la ratio theta/alfa puede servir para diferenciar entre grupos de niños con y sin TDAH. Encontró diferencias entre TDAH inatento versus TDAH combinado y entre TDAH inatento y TDAH inatento con trastorno de la lectura. Lansbergen, Arns, Van Dongen- Boomsma, Spronk y Buitelaar (no publicado), basándose en el estudio previo de Klimesch (1999) sobre oscilaciones de la actividad alfa y theta durante procesos cognitivos, calculan la ratio theta/ beta en un grupo de 49 niños con TDAH y 49 niños en el grupo control, emparejados usando ambas frecuencias mixtas $y$ frecuencias EEG 
individualizadas. Demuestran una significativa desviación de la ratio theta/beta que únicamente se encuentra en las frecuencias EEG mixtas. No hubo diferencias significativas en las frecuencias individualizadas del EEG.

Resumiendo, de los anteriores estudios puede concluirse que la ratio theta/beta y la presencia de un exceso de actividad theta puede discriminar niños con TDAH y niños de un grupo control sano. Sin embargo, es posible que no sea una medida específica, puesto que se incluyen diferentes subtipos de TDAH (Arns y cols, 2011).

Respecto a los estudios llevados sobre la coherencia, o la actividad EEG entre dos señales en una banda de frecuencia dada, proporciona información sobre la actividad cerebral y en concreto sobre las asociaciones córtico-corticales, obteniendo la sincronía entre ambos hemisferios (Thatcher y cols, 1986). Chabot y Serfontein (1996), sobre una muestra mixta de TDAH y TDA, algunos también con trastornos de aprendizaje, encuentran que el TDAH se asocia a una hipercoherencia interhemisférica e intrahemisférica en regiones centrales y en zona frontal. También observaron reducción de la coherencia en zona parietal. Chabot (1999) estudia la coherencia pre-medicación en un grupo de sujetos estudiados en anteriores investigaciones. Encuentra incremento de la coherencia interhemisférica, particularmente en banda theta y alfa e incremento de la coherencia intrahemisférica bilateral en las regiones fronto-temporales. En otro estudio sobre la coherencia, Barry y cols (2002) encuentran que niños TDAH obtuvieron coherencias intrahemisféricas elevadas y una distancia más corta entre electrodos en la banda theta, así como una reducción lateralizada en las bandas theta y alfa. A nivel frontal, se observó en los niños con TDAH una elevada coherencia interhemisférica en bandas delta y theta y disminución de coherencia en banda alfa. La reducción de coherencia en banda alfa se encontró en regiones temporales. Barry y cols (2002) destacan la presencia de un aumento de la coherencia en banda theta en regiones central-parietal- occipital, aunque, de forma aparente. Estas anomalías fueron más notorias en 
el grupo de los niños con TDAH de tipo combinado que en los niños con TDAH de tipología inatenta. Es importante señalar que Barry (2007) en una posterior investigación, que compara la coherencia entre TDAH inatento y TDAH combinado versus el grupo control, no encontró ninguno de los efectos en coherencia previamente descritos.

\subsection{MODELO EEG-VIGILANCIA}

Diferentes autores han centrado su investigación en torno a la vigilancia y su regulación, como mecanismo flexible de adaptación ante las necesidades internas o externas de estimulación y requisito necesario para el funcionamiento del organismo. La vigilancia se adapta a las demandas externas, asegurando un nivel alto de alerta en situaciones de peligro y disminuyendo este nivel de alerta ante demandas menos exigentes. Además, la interacción entre el entorno y la regulación de la vigilancia también actuaría evitando determinados niveles de estimulación (Arns y cols, 2011).

Tal como señalan Bente, Ulrich y Frick (1964, 1986), el entorno activamente buscado por una persona puede también depender de la regulación de la vigilancia. Si la capacidad del cerebro para mantener un alto nivel de vigilancia está reducida, ésta persona normalmente se sentirá somnolienta y por lo tanto buscará un entorno con baja estimulación externa y una oportunidad para dormir. Sin embargo, bajo ciertas circunstancias, como una regulación inestable de la vigilancia, ésta podría también inducir patrones comportamentales compensatorios, denominados "conductas autoestabilizadoras de la vigilancia". Esta conducta se observaría en la hiperactividad, donde la búsqueda de sensaciones y otros patrones comportamentales tendrían como finalidad la adquisición de un entorno altamente estimular.

Al incrementar la estimulación externa, se contrarrestaría el bajo nivel de vigilancia y se lograría una situación estable (Arns y cols, 2011). 


\subsubsection{EEG VIGILANCIA-ALGORITMO VIGALL}

En paralelo con la transición de la vigilia a un sueño profundo, el cerebro humano toma diferentes estados globales de funcionamiento (figura 3). Estos estados funcionales se reflejan en la composición y topografía espectral del EEG y es denominado estado de vigilancia (Arns y cols, 2011). Estos estados corresponden a diferentes estados de alerta con sus correspondientes estados comportamentales. Pueden ser separados durante la transición de un estado de conciencia relajada a un estado de ensoñación con inicio de las fases del sueño.

Varios autores (Bente y cols, 1964; Frick, 1986; Klimesch, 1999; Loomis y cols., 1937; Roth, 1961) describen clasificaciones de los estados de vigilancia, que comienzan con la conciencia activa y se suceden hasta llegar al inicio de las fases del sueño. Estos autores, se basan en la observación de los fenómenos EEG bajo la condición de ojos cerrados siguiendo un continuo de seis estados.

Para obtener estos estados se realiza un algoritmo computerizado que separa los diferentes estados de vigilancia EEG y crea los subsiguientes segmentos. La primera versión del algoritmo "VIGALL" se basó en la transformada de Fourier derivada de la extracción de las cuatro principales frecuencias EEG (Alfa, beta, theta, delta) durante dos segundos del registro continuo en diferentes sitios del registro. Una segunda versión mejorada del algoritmo se tomó de la tomografía magnética cerebral de baja resolución (LORETA), desde diferentes regiones de interés (Arns y cols, 2011).

Estos seis fenómenos EEG se describen de la siguiente manera. Inicialmente aparece actividad alfa bajo la condición ojos cerrados con una frecuencia de 8-12 Hz en zona occipital. Esta oscilación ha sido descrita como "Idling rhythm" porque marca un estado de conciencia relajada correspondiente al estado A1 (Bente, 1964, Niedermeyer, 1997, Loomis, 1937). Se observa actividad alfa en zona anterior, incrementada después de varios minutos de 
conciencia relajada. Este fenómeno es observado cuando se produce la ensoñación. El punto máximo de frecuencia alfa muestra un ligero decremento y corresponde a un estado de vigilancia A2 y A3 (Bente, 1964; Broughton y Hasan, 1995; Connemann y cols, 2005; de Gennaro, Ferrara, Curcio y Cristiani, 2001; Loomis, 1937). A continuación aparece bajo voltaje EEG, que se incrementa durante el estado de baja vigilancia. La actividad alfa desaparece y la actividad beta aumenta. Este patrón EEG corresponde a un estado de vigilancia B1 y es similar al registro EEG que se produce durante una intensa actividad mental y bajo la condición de ojos abiertos (de Gennaro, Ferrara y Bertini, 2001; Merica y Fortune, 2004; Roth, 1961; Tanaka, Hayashi y Hori, 1996, 1997). A continuación, aparece actividad delta y theta, observada en paralelo con la presencia de una ensoñación subjetiva, correspondiendo al estado de vigilancia B2 y B3 (Roth, 1961; Strijkstra y cols, 2003; Tanaka y cols, 1996, 1997). Finalmente aparece la presencia de complejos K y husos del sueño marcando el inicio del sueño (Cash y cols, 2009, de Gennaro y Ferrara, 2004, Tanaka y cols, 1997).

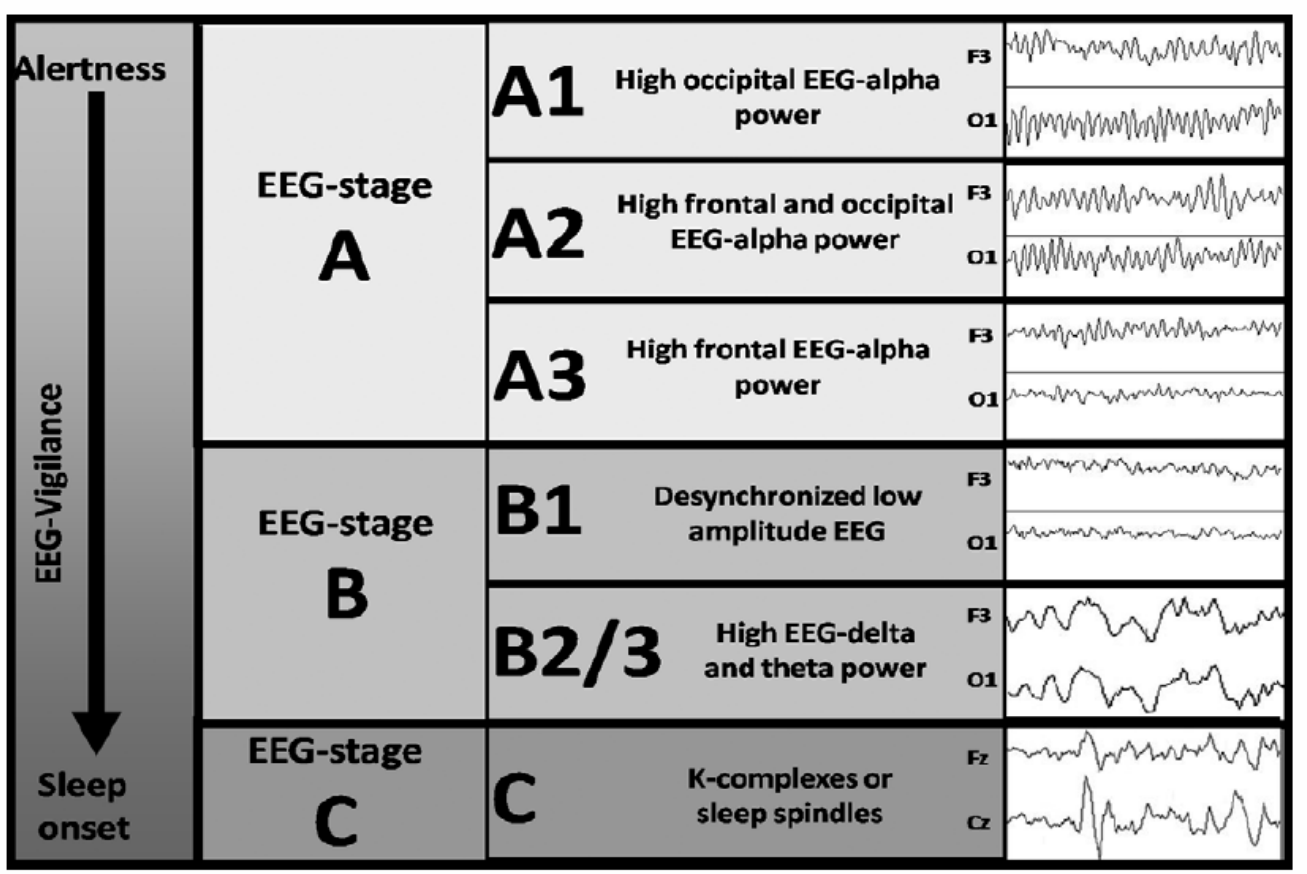

Figura 3. EEG vigilancia dentro de un continuo de alto y bajo nivel de vigilancia. (Arns y cols, 2011). 


\subsubsection{MODELO EEG -VIGILANCIA EN EL TDAH}

La teoría de la regulación inestable de la vigilancia en el TDAH se basa en que el trastorno se asocia con la presencia de somnolencia y una disminución en valores de la latencia media del sueño, medida a través del test de latencia múltiple del sueño (TLMS) (Golan y cols, 2004). Existiría una evidencia empírica que indicaría que determinados trastornos que a la calidad del sueño (síndrome de las piernas inquietas, movimientos periódicos de las extremidades) se asocian con el TDAH pediátrico o con el incremento de la severidad del TDAH (Chervin y cols, 2002). Estos datos sugieren como factor patogénico en el TDAH un estado de vigilancia lábil o inestable (déficits en atención sostenida, distractibilidad), mientras que otros síntomas clínicos (hiperactividad, búsqueda de sensaciones) podrían ser interpretados como un síndrome de vigilancia estabilizadora (Arns y cols, 2011).

En otros estudios, Sanders y cols, (2008), usando los mismos datos que Arns y cols, (2011), encuentran que la regulación de la vigilancia EEG estuvo directamente asociada en niños con TDAH y su relación con la efectividad de la medicación estimulante. Los resultados muestran que los niños con TDAH pasan significativamente menos tiempo en estados de vigilia A1 y más tiempo en estados de vigilancia A2 que el grupo control. Estos datos sugieren que los niños con TDAH muestran un bajo nivel de vigilancia-EEG. Estos autores también demuestran que los niños con TDAH mostraron cambios entre diferentes estados de vigilancia más a menudo que el grupo control (Sanders y cols, 2008).

\subsection{TDAH Y TRASTORNOS DEL SUEÑO-AROUSAL}

Brown y Mc Mullen (1997) revisan las investigaciones sobre las alteraciones en el sueño y arousal en población con TDAH. Las principales consisten en dificultades en 
quedarse dormidos, dificultades en despertarse, dificultades en mantener la alerta diaria y otras anormalidades adicionales en el sueño. Estos autores plantean posibles explicaciones de estas alteraciones. La primera consiste en la dificultad para quedarse dormido, siendo éste trastorno no específico del TDAH, existiendo una gran variabilidad sintomática debido a varios factores. Para algunos pacientes puede ser solamente la falta de una adecuada rutina para ir reduciendo gradualmente el nivel de actividad al irse a dormir. En otros casos puede haber patrones ineficaces o inconsistentes de los refuerzos para irse a dormir. Otra posible explicación que dan estos autores, es la observada en pacientes con TDAH inatento. Éstos pacientes afirman sentirse con más energía por la noche y más predispuestos a realizar su trabajo o actividades que por la mañana. En estos casos se podría tratar de un incremento nocturno de la alerta. Todas estas descripciones podrían explicar la dificultad que muestran ciertos pacientes en mantener y regular la alerta diaria. (Brown y Mc Mullen, 1997).

Ball y cols., (1997) observaron que más del 50\% de niños con TDAH tienen dificultades para quedarse dormidos. Stein (1999) concluye que los trastornos del sueño de grado moderado ocurren al menos una vez a la semana en cerca del $20 \%$ de los niños con TDAH, comparados con el 13,3\% de la muestra de pacientes psiquiátricos del grupo control y un $6,2 \%$ de los pacientes pediátricos controles. Tal como señalan estos autores, actualmente no queda clara la relación entre estos problemas y la fisiopatología del TDAH

Dalh describe el sueño y el arousal como un extremo de un continuo, donde el sueño sería la disminución de la vigila y respuesta al ambiente, y, en el otro extremo del continuo, estaría un estado de alta respuesta que sería la vigilancia (Dalh, 1995, 1996). Considera que existe una fuerte relación entre el control del sueño y la regulación del ánimo y conducta.

Los problemas de regulación del sueño y el arousal aparecen como factor importante presente en los TDAH de predominio inatento. Los hallazgos que se observan en estos pacientes, así como sus manifestaciones clínicas, muestran una gran variabilidad y dado las 
actuales clasificaciones del TDA hablarían de una disfunción de los circuitos frontalsubcortical encargados de regular la dopamina, donde el tratamiento farmacológico por medio de la medicación estimulante puede mejorar la regulación de la disfunción vigiliasueño.

\subsection{FENOTIPOS EEG}

El enfoque propuesto sobre grupos EEG y grupos EEGq considera el fenotipo como el paso intermedio entre los factores genéticos y comportamentales. Gunkelman y cols (2005) propusieron que los fenotipos basados en el EEG son estados semiestables de una función neurofisiológica, que podrían ser identificados a partir de las ondas del EEG. A diferencia de los criterios de la DSM, estos fenotipos han sido observados para predecir la respuesta individual al tratamiento mediante neurorrehabilitación o tratamiento farmacológico (Arns y cols, 2011).

Jonhnstone y cols, (Jonhnstone y cols, 2008) demuestran la presencia de patrones EEG identificables con una buena fiabilidad inter-ratio, tanto en población sana como en población con TDAH.

La evidencia de la existencia de un alto grado de heredabilidad de fenotipos alfa EEG presentes en estudios de familias de una amplia muestra (Elhers y cols, 2010) muestra la tendencia a clasificar los trastornos como subtipos de un trastorno específico, donde estos subtipos se asocian a varios patrones EEG (Arns y cols, 2005). Sin embargo, la evidencia de la presencia de un enlace genes-localización cromosómica todavía es limitada (Elhers y cols, 2010).

A través de la agrupación en clusters de estos patrones EEG, siendo delimitados como subtipos, puede aumentar el conocimiento práctico de cómo responderá el paciente en la 
terapia. Cabe destacar que esta semiología todavía permanece sujeta a los criterios diagnósticos de la DSM-IV.

En anteriores investigaciones que incluyeron el análisis estadísticos del EEG, se documentan grupos de EEG y de EEGq en población psiquiátrica (John y cols, 1992). Estos autores consideran que se trata de índices fiables de la función cerebral, que pueden ayudar a predecir la respuesta al tratamiento tanto farmacológico como con el tratamiento con neurorrehabilitación.

\subsubsection{PRINCIPALES FENOTIPOS EEG}

Varios autores (Arns y cols, 2008; Gunkelman, Breteler y Spronk, 2008; Jonhnstone y cols, 2005) describen fenotipos EEG en niños con TDAH. Cada fenotipo se caracteriza por un fenómeno neurofisiológico. Los principales son:

1. Pico bajo de frecuencia alfa: Pico de frecuencia alfa, consistente en baja actividad alfa (menor de 9 Hz). Localizado en Pz (Niedermeyer y Lopes da Silva, 1998).

2. Pico alto de frecuencia alfa: frecuencia mayor de $11 \mathrm{~Hz}$, localizada en $\mathrm{Pz}$, actividad rápida de frecuencia alfa.

3. Alfa frontal: incremento actividad alfa $(8-12 \mathrm{~Hz}$ o bajo rango de frecuencia para edades más tempranas) en zona frontal.

4. Persistente actividad alfa con ojos abiertos: Decremento de la potencia de actividad alfa inferior al 50\% de decremento en condición de ojos abiertos cuando se compara con la condición del registro en ojos cerrados. Localizado en Pz.

5. Exceso actividad alfa en zona temporal: Clara presencia de actividad alfa en uno de los registros en zona temporal (T3, T4, T5 y T6). En el registro EEG la 
presencia de alfa ocurre en zona temporal, independiente de la zona occipital o de actividad alfa en zona parietal.

6. Salvas de actividad beta frontal: Aparición al menos en 1 ó 2 ocasiones, de salvas de actividad beta superior a $20 \mathrm{mV}$ y frecuencia mayor de $14 \mathrm{~Hz}$, teniendo el cuenta la definición que propone Niedermeyer y Lopes da Silva (1998).

7. Enlentecimiento frontal: Presencia de actividad lenta. Este fenotipo es a menudo descrito como theta frontal (exceso de actividad 4-7 Hz). Se asocia a alteraciones en lóbulo frontal.

8. Bajo voltaje: Este fenotipo se caracteriza porque la potencia absoluta EEG en todas las frecuencias está reducida, esto es, aparece decremento significativo en la mayoría de las bandas de frecuencias, (delta, theta, alfa y beta). Se conoce como de baja magnitud.

9. Anormalidades focales: Actividad focal lenta.

10. Actividad mixta lenta y rápida: Incremento actividad lenta, pérdida de organización de la actividad alfa, incremento de actividad beta.

11. Actividad epileptiforme: Actividad punta onda transitoria. EEG paroxístico.

\subsection{MODELOS EXPLICATIVOS TDAH BASADOS EN EL EEG y la EEGq}

\subsubsection{LA PERSPECTIVA DEL RETRASO MADURATIVO}

Se establecen dos principales modelos de TDAH (TDA) en base a los registros EEG. El primero es el modelo del retraso madurativo y el segundo modelo es de la disfunción del SNC. 
Por retraso en la maduración se entiende la presencia de hallazgos electroencefalográficos anormales que podrían ser normales en un niño de menor edad cronológica. Éste retraso madurativo, tiende a desaparecer con la edad (Harmony y cols, 1995; Ricardo-Gardell, 2006).

Kinsbourne (1973) propone que el TDAH (TDA) resulta de un retraso en el desarrollo del SNC. Estos niños presentarían un nivel madurativo de su SNC inapropiado para su edad, propio de niños más pequeños. Desde una perspectiva neurofisiológica, este modelo requiere que las medidas EEG de niños con TDAH se correspondan con la de niños más pequeños.

Satterfield y cols. (1973) encontraron que los niños hiperactivos que respondían mejor a la medicación mostraban en el EEG un incremento de actividad onda lenta, mayores latencias y más bajas amplitudes en la respuesta de los PE. Estos resultados respaldarían la existencia de un retraso madurativo, más allá de considerar la presencia de algún tipo de daño cerebral (Satterfield y cols, 1973).

Posteriormente, en un estudio EEG transcultural, Matsuura (1993), con una muestra de niños con trastorno oposicionista desafiante y niños con TDAH (TDA), encontró que el grupo TDAH (TDA) obtuvo mayor amplitud media de actividad delta, mayor porcentaje de actividad delta y theta lenta y más bajo porcentaje de actividad alfa que el grupo control. A su vez, se calculó la edad hipotética EEG para el grupo TDAH utilizando los procedimientos matemáticos de John y cols (1987), concluyendo que los niños TDAH mostraban un retraso madurativo en el funcionamiento cerebral.

Clarke interpretó sus resultados sobre el retraso madurativo en base a una muestra de niños TDAH (TDA) en los que se observó la presencia de un aumento de actividad theta y reducción de actividad beta (Clarke, 1998).

Apoyando esta teoría, Lazzaro y cols (1998), estudiando una muestra de adolescentes con TDAH (TDA), también encontraron aumento de la potencia absoluta en banda theta y 
alfa en región frontal y reducción de actividad beta en regiones posteriores, interpretando tales resultados como retraso madurativo.

Considerando los resultados anteriores, se observa un problema importante en el modelo del retraso madurativo, y es que el TDAH también se encuentra en la población adulta. El modelo, al no tener en cuenta este hecho, sería incompleto (Bellack y Black, 1992; Ricardo-Gardell, 2006).

\subsubsection{LOS CLUSTER-EEG Y LA DISFUNCION DEL SNC}

Para subsanar la limitación que conlleva sólo tener en cuenta la variable madurativa como explicación plausible del TDAH, la investigación se ha centrado en considerar la presencia de una posible disfunción del SNC como explicación real del trastorno, más que en el perfil conductual (Ricardo-Gardell, 2006). Tal como expone John (1987), en la desviación del desarrollo del SNC o disfunción del SNC, existen patrones electroencefalográficos anómalos que no serían normales a ninguna edad, siendo esta alteración permanente y asociada, por lo tanto, a una disfunción del SNC (Barry, 2003, Ricardo-Gardell, 2006).

Clarke y cols (2002) realizan un análisis de clusters de los resultados que obtienen en el EEG en una muestra de TDAH de tipo inatento y combinado, describiendo diversos subgrupos electroencefalográficos. No hablan de perfiles EEG para el tipo TDAH predominio hiperactivo- impulsivo. Describen tres perfiles EEG en niños TDAH.

1. Perfil de niños con hipoalerta cortical: Caracterizado por incremento de alta amplitud de actividad theta y decremento de actividad delta y beta, incremento del poder total, incremento de la ratio theta/beta y decremento del poder relativo en banda delta y beta sobre todas las regiones. 
2. Perfil de niños con retraso madurativo: Caracterizado por incremento de actividad de onda lenta y deficiencias en actividad de onda rápida. Esto supondría un retraso en la maduración de la actividad eléctrica cortical. Ambos resultados se encontraron en el TDAH mixto y el TDAH de predominio inatento.

3. Perfil de niños con hiperalerta cortical: Grupo con exceso de actividad beta. Es un perfil encontrado mayoritariamente en el TDAH de tipología mixta.

\subsection{EL EEG COMO HERRAMIENTA DIAGNÓSTICA EN EL TDAH. PRE- DICCIÓN DE LA RESPUESTA AL TRATAMIENTO FARMACOLÓGICO EN EL TDAH}

Desde las primeras investigaciones que utilizaron el EEG como herramienta valorativa en el TDAH se planteó la posibilidad de predecir el efecto de la medicación estudiando la normalización del trazado del EEG. Satterfield y cols (1973) fueron los primeros en investigar el uso potencial del EEG en la predicción de los resultados obtenidos con la medicación estimulante. Estos autores encontraron que los niños con un exceso de actividad onda lenta y una larga amplitud de respuesta en los potenciales evocados (PE), respondían mejor al tratamiento farmacológico. Concluyeron que un EEG anómalo podría ser considerado predictor de una respuesta positiva al tratamiento farmacológico (Chabot y cols, 2001).

Chabot y cols. (2001) sugieren que tanto los niños con TDAH como los TDAH con predominio déficit de atención que muestran un exceso de alfa relativo o potencia total en banda beta, muestran alteraciones comportamentales, mientras que el exceso de potencia relativa de theta predice una baja respuesta y una alta probabilidad de respuesta negativa al 
tratamiento farmacológico con estimulantes. Según estos autores, estos niños presentarían un exceso generalizado de potencia absoluta y potencia relativa de onda theta, decremento de la frecuencia media de actividad alfa y una hipercoherencia frontal de actividad theta.

Con respecto al perfil neurofisiológico de niños con respuesta positiva al tratamiento farmacológico, se observa que su perfil responde a la presencia de incremento de la ratio theta/beta e incremento de actividad theta (Clarke, 2003). Sin embargo, se demuestra que también la presencia de un exceso de actividad beta predice la eficacia en el tratamiento farmacológico (Hermens, 2005).

Arns y cols (2010) separa el grupo de la onda lenta frontal del grupo de frecuencia lenta alfa. Según estos resultados, el grupo lento frontal responde positivamente al tratamiento farmacológico mientras que el grupo con frecuencia lenta alfa no responden al tratamiento. Esto podría ser debido a un factor de confusión en las investigaciones sobre respuesta al tratamiento, pues la mayoría de las investigaciones realizadas sobre la respuesta al tratamiento mezclan actividad theta frontal con frecuencia lenta alfa.

\subsection{RESUMEN}

El EEG ha demostrado ser útil para discriminar diversos cuadros psicopatológicos, aunque la naturaleza de las diferencias observadas sigue siendo objeto de discusión. Los resultados más frecuentemente obtenido en niños con hiperquinesia son enlentecimientos en diversas áreas y anomalías focales. Utilizando el EEGq se ha podido discriminar sujetos control y cuadros de hiperactividad, dificultades de aprendizaje y subtipos de TDAH. Se han encontrado alteraciones en la banda theta y alfa, diferencias en potencia absoluta y relativa, en coherencia y, en especial, en la ratio theta/alfa. Las técnicas neurofisiológicas también han 
sido útiles para investigar las anomalías de la activación o vigilancia y trastornos del sueño en niños con TDAH. Más recientemente, se han propuesto fenotipos EEG.

En la actualidad persisten varios problemas para integrar en una teoría consistente los hallazgos neurofisiológicos de los diferentes estudios. Uno se refiere a la variación de criterios diagnósticos a lo largo de los años, que dificulta la comparación de resultados de estudios de distintas épocas. Otro se refiere a la tecnología utilizada. Los resultados obtenidos con dispositivos y procedimientos de registro clásicos valoran parámetros diferentes de los utilizados en estudios con EEGq y otras técnicas de registro. A pesar de estas dificultades, los registros neurofisiológicos han mostrado de modo contínuo su capacidad para diferenciar grupos psicopatológicos y parecen llamados a jugar un papel cada vez mayor en la caracterización y diagnóstico del TDAH. 
CAPITULO 7. INSTRUMENTOS DE EVALUACION DEL TDAH 
Utilidad de la cartografía cerebral en el diagnóstico del TDAH 


\section{INTRODUCCIÓN}

En la actualidad el diagnóstico del TDAH se basa en la identificación de los síntomas a partir de las informaciones que se obtienen del propio paciente, de sus familiares y también de los profesores. Este procedimiento es poco preciso, subjetivo y favorece la confusión del cuadro con otras patologías. Por ello es importante descartar otras alteraciones que comparten sintomatología pero necesitan otro tratamiento y otro tipo de intervenciones (Van-Wielink, 2005).

En este capítulo se revisarán los principales instrumentos de evaluación en el TDAH, criterios diagnósticos diferenciales y directrices de evaluación psicológica y neuropediátrica de los niños con TDAH.

\subsection{GENERALIDADES}

Sasot (2003) explica que muchas familias que consultan sobre este trastorno trasmiten la sensación de no "resistir" más. Por este motivo, evaluar la hiperactividad requiere una cuidada metodología de entrevista. Es importante, empatizar con la familia, no dirigir la entrevista y siempre iniciarla de forma abierta, evitando dirigismos. Es importante que los padres expresen sus preocupaciones y expongan ejemplos de cómo es el día a día con sus hijos. También hay que observar cómo se expresan en las primeras visitas y observar desde la primera consulta el comportamiento del niño. 
Sasot (2003) señala la importancia de averiguar la edad de aparición de la sintomatología y si ésta tuvo un inicio precoz. Es frecuente que estos niños pasaran por una etapa de lactancia conflictiva, que presentaran alteraciones del sueño, llanto frecuente y cólicos del lactante. Hay algunas madres que refieren que durante la gestación el bebé ya presentaba movimientos excesivos en comparación con otros embarazos. Lo más frecuente es que se trate de bebés activos en la cuna, que duermen poco y lloran mucho. Aproximadamente $1 / 3$ de las madres de los niños con TDAH en edad escolar refieren que el niño comenzó a presentar dificultades desde el primer año de vida, y las dificultades aumentaron cuando comenzó la deambulación.

Para efectuar el diagnóstico los síntomas deben tener una duración mínima de seis meses y manifestarse en más de un ámbito, esto es, no sólo en el ámbito familiar sino también en el escolar (Sasot, 2003). Es importante conocer la capacidad de atención y de control de la impulsividad. Por ello, la entrevista debe estructurarse como una exploración sistemática de los criterios diagnósticos y, posteriormente, recoger la información necesaria para descartar otros problemas diferentes del TDAH.

En la planificación del tratamiento se tendrán en cuenta los datos obtenidos en la evaluación neurológica, realizada en la consulta de neuropediatría, y los datos de la unidad de psicología y psiquiatría infanto-juvenil. Los datos de estas evaluaciones son importantes para discriminar comportamientos evolutivamente normales, trastornos médicos, del desarrollo, emocionales o conductuales.

\subsection{EVALUACION NEUROPEDIATRICA}

La exploración neuropediátrica del niño no tiene como finalidad realizar el diagnóstico. Es bien conocido que el diagnóstico se realiza mediante la historia clínica (Van- 
Wielink, 2005). Sin embargo, la evaluación neuropediátrica tiene un gran valor para conocer el estado general de salud del niño y si puede existir alguna contraindicación a la hora de una posible administración de medicamentos. Se sabe que el tratamiento farmacológico puede generar diferentes efectos secundarios. Los estimulantes aumentan la presión arterial y pueden causar pérdida de apetito, por lo que se valorará la curva de crecimiento/peso/talla y su evolución. A su vez, los antidepresivos tricíclicos pueden alterar la función cardiovascular, por lo que es recomendable realizar una valoración cardiológica tanto preventiva como de seguimiento, que permita detectar posibles alteraciones.

En la evaluación neurológica infantil también se descartan otras condiciones con síntomas semejantes a los del TDAH, como el hipotiroidismo o la intoxicación por plomo. Para ello se realizará una bioquímica completa, incluyendo biométrica hemática, función hepática, función tiroidea y nivel de plomo en sangre (Van-Wielink, 2005). Se deben explorar los signos neurológicos menores o "Soft signs", alteraciones en la motricidad fina o en la motricidad gruesa, coordinación estática, coordinación dinámica de la mano, coordinación dinámica general, rapidez de movimientos, movimientos simultáneos, coordinación de movimientos alternativos rápidos y ausencia de sincinesias. También es recomendable evaluar la direccionalidad, orientación izquierda-derecha y la orientación sobre sí mismo (Alcaina y cols., 2000).

En cuanto a la evaluación del estado mental del niño, Sasot (2005) propone tener en cuenta los siguientes elementos: estado de conciencia, estado de ánimo, inteligencia, memoria inmediata, capacidad de atención (selectiva, sostenida y alternante) y control ejecutivo. Además, se debe observar el lenguaje expresivo, cómo se expresa el niño, el lenguaje receptivo, si entiende lo que le podemos decir y si comprende las explicaciones de la clase.

La motricidad puede valorarse observando al niño en la consulta. Se debe observar la simetría de la marcha, la seguridad, la base de sustentación, la simetría del balanceo de los 
brazos al andar y los movimientos de la mano. También es importante valorar el tono muscular, la posible hipotonía o hipertonía, si se observan asimetrías con los brazos extendidos, manos abiertas con las palmas hacia arriba y con los ojos cerrados. El test dedo del explorador-nariz del paciente permite evidenciar posible disimetría o temblor.

La exploración neurológica debe considerar la presencia, intensidad y simetría de los reflejos rotuliano, aquíleo, y cutáneo-plantar. También hay que valorar posibles déficits sensoriales, alteraciones en la percepción visomotora o en la discriminación auditiva, déficits nutricionales, y otros problemas neurológicos como traumatismos, infecciones del SNC, trastornos neuroexpansivos o neurodegenerativos (Sasot, 2003). Hay que excluir posibles trastornos neuropsicomadurativos, trastornos del aprendizaje, sobredotación o la presencia de déficits cognitivos u otros trastornos del neurodesarrollo.

\subsection{EVALUACION PSICOPATOLÓGICA}

Según Van-Wielink (2005) la participación de especialistas en psicopatología es imprescindible para un correcto diagnóstico y tratamiento. El proceso de evaluación debe incluir los siguientes aspectos:

1) Entrevista completa con los adultos que están al cuidado del niño.

2) Evaluación de las funciones cognoscitivas.

3) Evaluación general del estado médico y neurológico del niño.

4) Evaluación de las habilidades y logros académicos del niño.

5) Uso de escalas de síntomas conductuales para padres y profesores.

6) Informes psicopedagógicos.

La entrevista completa con los adultos que están al cuidado del niño, generalmente los padres, suele ser la fuente de información más importante. Los datos que proporcionan 
permiten conocer la historia del neurodesarrollo del niño, fundamental en el proceso diagnóstico (Van-Wielink, 2005). Además, suele pedírseles que cumplimenten algún cuestionario de valoración de síntomas en el ámbito familiar. Uno de los más utilizados es el de Conners, que también puede aplicarse en el medio escolar. Más adelante tendremos ocasión de analizarlo.

Van-Wielink (2005) señala varias cuestiones que hay que tener en cuenta en la evaluación del estado de las funciones cognitivas:

1) El psicólogo no debe esperar ver los síntomas del trastorno en la consulta. Los niños con TDAH pueden tener un aceptable autocontrol en situaciones especiales, como puede ser la consulta, y comportarse correctamente. En situaciones menos novedosas o con otras exigencias, sin embargo, su comportamiento puede ser alborotador y desordenado. Por este motivo es necesario estudiar el comportamiento en varias consultas sucesivas y en diferentes situaciones. Además de observar el comportamiento del niño durante la entrevista con sus padres, se debe realizar una entrevista directa con el niño, que incluya pruebas de atención (De la Gándara y cols, 2006).

2) La evaluación mental debe permitir descartar otros problemas psicopatológicos. Hay que obtener información del funcionamiento conductual y emocional del niño en la escuela, en su casa y con sus amigos.

La evaluación cognoscitiva debe incluir la aplicación de diversas escalas o tests. Es recomendable estudiar el nivel de inteligencia, la capacidad de atención, la personalidad y, en algunos casos hacer pruebas simples de lectura y de escritura También son útiles las observaciones con registros o sistemas de información realizados en el hogar y el centro escolar por padres y educadores (De la Gándara y cols, 2006). 


\subsubsection{EL DIAGNOSTICO DIFERENCIAL}

Los problemas de atención, impulsividad e inquietud que caracterizan al TDAH pueden aparecer en otras condiciones psicopatológicas o durante fases del desarrollo normal. Por este motivo el diagnóstico diferencial es una parte fundamental de la valoración de posibles cuadros de TDAH. Distinguiremos tres tipos de situación: confusión entre comportamientos evolutivamente normales y TDAH, síntomas debidos a problemas ambientales y síntomas de otras patologías (De la Gándara y cols., 2006).

La confusión entre comportamientos evolutivamente normales y síntomas de TDAH es frecuente en niños menores de cuatro o cinco años. Los niños de esas edades atraviesan períodos de gran actividad física, cambios constantes de interés y baja obediencia a las órdenes. Los padres pueden tener dificultades para diferenciar estos períodos evolutivos y síntomas de TDAH (Bielsa y cols, 2003).

También los problemas ambientales pueden provocar síntomas semejantes a los del TDAH. De la Gándara y cols. (2006) los agrupan del siguiente modo:

1) Ambiente familiar que no favorece el aprendizaje adecuado.

2) Exigencia escolar excesiva o inferior a la capacidad del niño.

3) Mal funcionamiento familiar o malos hábitos de los padres.

4) Abuso o negligencia del niño.

5) Enfermedades psíquicas de los padres.

Otra situación frecuente son las consultas por el comportamiento en el aula o el hogar de niños con problemas de lenguaje, aprendizaje o inteligencia límite o superior. En estos casos el comportamiento inquieto o desatento puede ser consecuencia del aburrimiento y falta de motivación consiguiente al fracaso reiterado para realizar las tareas escolares, o de la falta de interés por una situación poco gratificante. A diferencia de los síntomas del TDAH, el 
problema sólo aparece en situaciones relacionadas con la actividad escolar, al menos en edades tempranas. La solución sería la ayuda especializada.

También pueden aparecer síntomas semejantes a los del TDAH en el curso de un trastorno adaptativo. En este caso, sin embargo, se puede constatar que el cuadro comienza en un momento definido, como consecuencia de un agente estresante identificable. Un caso particular de problema adaptativo son los niños de familias en situación de conflicto, que pueden presentar problemas de interacción social, dificultades para establecer relaciones profundas o para admitir guía de los adultos. En estos casos es frecuente observar grandes variaciones en la actividad y desarrollo de intereses, así como en el estado de ánimo, que puede dar lugar a comportamientos impulsivos, ensimismamiento y falta de atención. Sin embargo, el origen de los síntomas tiene que ver con los problemas relacionados con la situación estresante y no con un déficit propio del niño.

Los límites entre TDAH y otros problemas de salud no siempre son claros. Bielsa y cols (2003) ofrecen la siguiente clasificación:

1) Causas físicas de distracción, tales como alteraciones visuales o auditivas, insomnio, enfermedades crónicas o tics.

2) Cuadros de ansiedad excesiva, depresión, trastornos bipolares o estrés postraumático. La inquietud, dificultades de concentración e irritabilidad, característicos del TDAH, forman parte de los síntomas de ansiedad y depresión en niños y pueden aparecer en problemas de estrés postraumático. En cuadros bipolares puede aparecer excesiva actividad, comportamiento impulsivo y razonamiento disminuido.

3) Trastornos de comportamiento y negativismo desafiante.

Es importante destacar que los problemas anteriores pueden aparecer asociados a cuadros de TDAH, unas veces de modo comórbido y otras como efecto 
secundario del trastorno. En ocasiones el diagnóstico diferencial plantea grandes dificultades.

\subsubsection{INSTRUMENTOS DE EVALUACIÓN}

Existen una gran variedad de pruebas útiles en la evaluación del TDAH. Podemos agruparlas en cuatro categorías: entrevistas estructuradas, inventarios, tests psicométricos de funcionamiento cognitivo y tests de valoración de los síntomas del TDAH. En conjunto constituyen un arsenal útil para la exploración objetiva de los déficits y progresos a lo largo del tratamiento. Los tests y pruebas psicométricas, en particular, proporcionan al clínico datos válidos para emitir un juicio sobre los síntomas y el nivel de alteración de forma objetiva, cuantificable y fiable (Quinlan, 2003).

\subsubsection{INSTRUMENTOS DE ENTREVISTA}

La primera herramienta para obtener información en consulta es la entrevista. $\mathrm{Su}$ utilidad es doble. Por una parte, permite recabar información directamente, a partir de las respuestas del paciente a las preguntas. Por otra, permite observar su funcionamiento mientras se realiza la consulta. En el caso de niños y adolescentes con TDAH estas dos funciones están parcialmente disociadas. La información se obtiene principalmente a través de los padres y se complementa con observaciones de los profesores. En cuanto a la observación del comportamiento del menor, hay que recordar lo anteriormente señalado: muchos niños y adolescentes son capaces de mantener la atención y la concentración durante una entrevista y es posible que el clínico no pueda observar directamente el funcionamiento alterado (AACAP, 1997). 
Se trate de un adulto o un niño, es recomendable utilizar entrevistas estructuradas o semiestructuradas (p.ej., APA, 2000; Barkley, 1998; Brown, 1996). La valoración en consulta de un cuadro de TDAH puede resultar difícil por la tendencia de los pacientes a desorganizar la situación. Los cambios de tema o respuestas irrelevantes provocados por el déficit de atención, o el comportamiento inquieto, pueden dificultar la obtención de información. Las entrevistas estructuradas y semiestructuradas permiten que la exploración avance de modo ordenado hasta obtener la información necesaria.

El Work Group on Quality Issues de la Academia Americana de Psiquiatría del Niño y el Adolescente (AACAP, 1997) recomienda que la entrevista incluya la elaboración de la historia clínica, incluyendo la historia evolutiva, exploración de los síntomas del TDAH, síntomas de otros trastornos, historia de tratamientos e intervenciones, áreas de funcionamiento satisfactorio, historial médico, historial familiar y evaluación física, incluyendo resultados de exploraciones físicas y tratamientos recientes. La historia familiar incluye antecedentes de TDAH, abuso de sustancias y otros trastornos de conducta en otros miembros de la familia.

Barkley (1998), en su entrevista estructurada para TDAH recoge numerosos signos y síntomas del trastorno. Las áreas clínicas no sólo incluyen los síntomas-criterio de TDAH, sino también numerosos síntomas de atención, hiperactividad e impulsividad que permiten documentar así la gravedad del trastorno.

La entrevista semiestructurada para adolescentes y adultos de Brown (1996) permite obtener información de los síntomas presentes, historia escolar y laboral, historia evolutiva, aspectos de la salud, patrones familiares, tiempo de ocio e historia de tratamientos. Incluye un conjunto de preguntas de detección sistemática y pruebas de seguimiento para trastornos de conducta, así como un inventario administrado mediante entrevista para los síntomas del 
TDAH especificados en el DSM-IV, siendo posible registrar respuestas del paciente, familiares (padres, hermanos o cónyuge) y entrevistador.

La Entrevista Clínica Estructurada del DSM-IV proporciona un modelo de investigación diagnóstica. Sin embargo, el apartado dedicado al TDAH está incompleto, y se utilizan suplementos de la versión para niños del protocolo para trastornos del estado de ánimo y esquizofrenia (Schelude for Affective Disorders and Schizofrenia) para evaluar el TDAH en adolescentes mayores y adultos.

La versión para niños en edad escolar de la versión epidemiológica del K-SADS-E (Orvaschel y Puig-Antich, 1987) es una entrevista estructurada para evaluar trastornos en la infancia. Se han realizado ampliaciones posteriores (K-SADS-LP) para incluir pruebas para valorar posibles TDAH. La entrevista es extensa y, para la mayoría de las situaciones clínicas, demasiado larga, así como lenta en la obtención de informaciones nuevas útiles en muchos pacientes (Quinlan, 2003).

\subsubsection{ESCALAS DE VALORACIÓN}

Las escalas de valoración del trastorno se agrupan en dos categorías: categorías generales o categorías de amplio espectro, que sirven para detectar sistemáticamente trastornos de conducta y escalas específicas para el TDAH. Las escalas de amplio espectro son numerosas y muy variadas (Barkley, 1990; Klens y cols., 1994). Las escalas específicas para el TDAH incluyen una variedad de cuestionarios de autoinformes para padres, para maestros y otras personas significativas. 


\subsubsection{ESCALAS DE VALORACION DE AMPLIO ESPECTRO}

Las escalas de valoración de amplio espectro más utilizadas son:

1) Inventario de conducta infantil de Achenbach Achenbach's Child Behavior Checklist, CBCL, con el formulario de autoinforme adjunto, el Autoinforme juvenil (Achenbach, 1991).

2) Sistema de evaluación conductual para niños BASC o Behavior Assessment System for Children (Reynolds y Kamphaus, 1992).

3) Inventario de síntomas para niños CSI o Child Symptom Inventories, (Gadow y Sprafkin, 1994).

El CBCL y el Autoinforme juvenil proporcionan múltiples escalas resumidas en dos escalas generales: síntomas interiorizados y síntomas exteriorizados. Tres de las escalas son de especial relevancia en el TDAH: La Escala de síntomas de atención, la Escala de síntomas de agresividad y la Escala de síntomas de delincuencia. Se dispone de normas para niños y niñas basadas en importantes muestras nacionales y en muestras específicas. La estructura de las escalas es ligeramente diferente en los dos sexos (Quinlan, 2003).

El CSI (Gadow y Sprafkin, 1994; Gadow y cols, 1995; Sprafkin y Gadow, 1996) han está formado por una serie de escalas aplicables desde la primera infancia hasta la adolescencia. Incluyen múltiples ítems para que los padres y los profesores procedan a la evaluación. Estos ítems corresponden a diferentes categorías diagnósticas. Los autores insisten en que los inventarios son procedimientos preliminares para obtener un diagnostico y no un medio de llevarlo a cabo, subrayando la necesidad de observar cuidadosamente al niño (Quinlan, 2003).

Con respecto al sistema de evaluación conductual para niños, BASC, (Behavior Assessment System for Children) (Reynolds y Kamphaus, 1992) también proporciona un 
sistema integrado de autoinforme, informe de los padres e informe del profesor para un amplio espectro de trastornos emocionales y conductuales en menores de 6 a 18 años de edad.

\subsubsection{ESCALA DE VALORACIÓN ESPECÍFICA DEL TDAH}

El número de escalas específicas para el trastorno es amplio y aumenta rápidamente. Existen formatos para niños, adolescentes y adultos con diferentes contenidos, diferentes niveles de representación de síntomas y diferentes niveles de fundamentación en la investigación. Tanto los formatos para el paciente como para los padres y maestros, son útiles para obtener información sobre el funcionamiento del paciente en diferentes situaciones.

Para niños existen numerosas escalas de valoración aplicables al paciente, maestro y padres. Las más utilizadas en nuestro entorno son las de Conners (1997), para niños de 3 a 17 años de edad. Existen una forma extensa y otra resumida. Otras escalas son las de Barkley (1990; Barkley y cols, 1989), que permiten recoger valoraciones de problemas de hiperactividad-impulsividad, déficit de atención, conducta perturbadora, situaciones en el hogar y el centro escolar, la escala de valoración para profesores de Iowa-Conners (IOWA Conners Teacher Rating Scale), útil para diferenciar la hiperactividad-impulsividad de TND (Loney y Milich, 1982; Pelham y cols, 1989) y las de Brown (1996), que cubren cinco áreas clínicas: Organización y activación para el trabajo, mantenimiento de la atención y concentración, mantenimiento de la energía y el esfuerzo, control de la interferencia afectiva y utilización de la memoria de trabajo y el acceso a los recuerdos.

Las escalas de valoración por sí mismas no pueden proporcionar la información necesaria para emitir un diagnóstico definitivo. Permiten iniciar el proceso diagnóstico y recopilar sistemáticamente información procedente de múltiples fuentes, difícil de obtener mediante entrevistas diagnósticas. La utilización clínica de las escalas de valoración incluye 
una revisión de la información con el paciente, profesor o padres, un proceso que puede proporcionar la base para la discusión e indagación sobre el grado y nivel de los síntomas identificados (Quinlan, 2003).

\subsection{TESTS PSICOMÉTRICOS}

Los tests psicométricos se utilizan para obtener información sobre las funciones cognitivas. Su utilización con niños con posible TDAH debe tener en cuenta ciertas peculiaridades. En primer lugar, los efectos de los síntomas sobre las funciones cognitivas. En el TDAH los problemas de atención pueden interferir en las tareas de atención voluntaria, atención sostenida y atención alternante de modo muy variable. Es posible que el resultado de la valoración sea inferior al potencial real o, en ocasiones, superior. En casi todos los pacientes algunas funciones de la atención permanecen intactas y muchos clínicos han observado el fenómeno de "hiperenfoque", o capacidad para concentrarse en una tarea determinada y excluir cualquier distracción. En segundo lugar, los efectos de la situación. La situación de test puede ser vivida de modos muy diferentes por el niño. Si la interpreta como una continuación de otras situaciones de valoración negativa, en la escuela o durante la realización de tareas en el hogar, puede responder con desinterés o incluso negativismo. Si, en cambio, la ve como una situación novedosa e individual, y una oportunidad para demostrar su capacidad, la motivación y ausencia de estímulos distractores pueden provocar una concentración superior a la que demostraría en las situaciones cotidianas. En el primer caso los resultados del test podrían infravalorar las capacidades del niño, y en el segundo disimular los déficits subyacentes (Hallowell y Ratey, 1994). En tercer lugar, los efectos de las propias pruebas. Los tests varían en las exigencias que plantean al sujeto. Dada la variabilidad de los síntomas del TDAH, es posible que dos tests diferentes de la misma habilidad produzcan 
resultados diferentes. Esto puede suceder con tests de atención, memoria o lectura. Los resultados de un test de atención que utiliza estímulos visuales pueden ser diferentes de los de otro que utiliza estímulos auditivos. Una prueba de memoria que utiliza series de dígitos puede producir resultados diferentes a otra que utiliza palabras o un relato corto. La capacidad para leer puede variar en función de la extensión del texto utilizado. Estas diferencias, que pueden aparecer en la exploración de cualquier niño, pueden ser extremas en niños con TDAH y llevar a conclusiones erróneas (Quinlan, 2003). Una buena valoración psicométrica debe tener en cuenta la posible interferencia de los déficits en los resultados, tener en cuenta la actitud de los niños y combinar diferentes procedimientos de valoración.

\subsubsection{EVALUACION GENERAL DE APTITUDES COGNOSCITIVAS}

Los tests de inteligencia general, o CI, tienen una gran utilidad para comprender la situación del paciente. Los más utilizados, como las escalas de Wechsler, ofrecen información sobre varias funciones intelectuales y una o varias puntuaciones resumen. Esto permite trazar un perfil del funcionamiento cognitivo que refleja el nivel de las funciones afectadas por el trastorno, así como el de las funciones no afectadas. Esto permite estimar el potencial del sujeto a partir de sus mejores resultados y dar una idea orientativa del grado de interferencia que provoca la enfermedad (Quinlan, 2003).

Los tests de inteligencia general más utilizados en la práctica clínica son las escalas de Weschler, con formas diferentes para niños en edad preescolar, escolar y adultos, la Escala de inteligencia de Stanford-Binet y algunos tests breves de inteligencia, como el Test breve de inteligencia de Kaufman. 


\subsubsection{TESTS DE ATENCIÓN}

Los tests de valoración de la atención tienen diferentes orígenes. Uno de los formatos más utilizados, las Pruebas de Rendimiento Contínuo o Continuous Performance Test, conocidos por las siglas CPT, se desarrollaron inicialmente para estudiar la atención en Esquizofrenia y alteraciones neurológicas. Posteriormente se aplicaron al estudio del TDAH y se desarrollaron nuevas formas, con diferencias en presentación, modalidades sensoriales (visual frente a auditiva) y características de respuesta (respuesta a estímulos frente a evitación de la respuesta a estímulos). El más utilizado en nuestro medio es el Test de Rendimiento Continuo de Conners o CPT (Conners, 1985). Se trata de una prueba informatizada de 14 minutos de duración, útil para valorar la atención focal y sostenida, así como la impulsividad cognitiva. Otras pruebas de rendimiento contínuo son las Gordon $(1983,1986)$ y el el Test de Variables de Atención o TOVA, de Greenberg y Waldman (1993).

Hay un gran número de estudios que muestran la utilidad de los tests de rendimiento continuo en el estudio de la atención en niños con TDAH (Barkley, 1990; Corkum y Siegel, 1993; Power, 1992; Seidman y cols., 1997). Por otra parte, los CPT parecen sensibles a los efectos de los tratamientos, especialmente con medicación estimulante. Esto ha llevado frecuentemente a utilizar los CPT para medir la respuesta al tratamiento.

\subsubsection{PRUEBAS DE MEMORIA}

La forma de memoria más estudiada en pacientes con TDAH es la memoria de trabajo a corto plazo. Los tests utilizados para evaluarla varían en el tipo de prueba que debe realizar el sujeto. En unos casos se pide al sujeto que memorice y repita inmediatamente listas de dígitos (subtest de las escalas de Weschler) y en otros listas de palabras, frases y relatos 
(Escala de memoria lógica de Weschler). Otras pruebas, en cambio, se centran en la memorización diferida (Test de aprendizaje verbal de California, Evaluación de amplio espectro de memoria y aprendizaje, Escala de memoria de Weschler, Escala de memoria para niños). Cada prueba implica diferentes demandas sobre la memoria. Los test de memoria visual son los menos usados para evaluar el TDAH y parecen ser los menos vulnerables al trastorno (Quinlan, 2003).

La memoria de dígitos aparece en varias formas de las escalas de Weschler y en las escalas de Stanford-Binet. La prueba tiene dos componentes: repetición de dígitos en el orden de presentación y repetición en orden inverso a la presentación. Aunque ambos componentes son tratados como dos partes de una escala simple, cada vez hay más pruebas de que la memorización de dígitos en orden directo es diferente de la realizada en sentido inverso. Las puntuaciones de niños con TDAH en memoria de dígitos frecuentemente son inferiores a las obtenidas en otros subtest y suelen correlacionar con puntuaciones bajas en los otros tests del índice de concentración, como búsqueda de símbolos y aritmética. Sin embargo, existen personas con TDAH que no presentan déficit en memoria de dígitos, pero sí en otras áreas. Estos sujetos son capaces de prestar atención durante el breve periodo de tiempo requerido para la tarea, pero son incapaces de mantener el nivel de vigilancia durante periodos de tiempo más largos.

Otro modo de valorar la memoria es examinar la capacidad para aprender listas de palabras. El test típico de aprendizaje de listas requiere que el paciente aprenda 10-15 palabras sin ningún orden específico. Una variante del aprendizaje de listas es el aprendizaje de pares asociados, o sea, palabras aprendidas como parejas, con la letra inicial utilizada como clave para recordarlas. El aprendizaje de listas representa una longitud intermedia de material para memorizar, que utiliza la memoria de trabajo, pero con contenidos breves. 
El test de aprendizaje verbal de California (Delis y cols, 1987) es un test de aprendizaje de listas con una presentación múltiple, que utiliza un procedimiento de interferencia estándar antes de plantear un ensayo de memorización diferida. Los ítems pertenecen a una de cuatro categorías: frutas, hierbas y especias, prendas de vestir y herramientas. El instrumento se ha utilizado extensivamente con pacientes neurológicos y pacientes adultos con TDAH (Seidman y cols., 1997). También existe una versión para niños (Delis y cols., 1994).

La repetición de frases se utiliza en las exploraciones neuropsicológicas. Se ha demostrado que es una medida sensible a alteraciones de la atención (Lezak, 1991; Lezak y cols., 1990). La evaluación de la memoria de frases puede realizarse con tests específicos, como el Test de Repetición de Frases (Benton y Hamsher, 1989), o la prueba de Spreen y Strauss (1991) o con subescalas de tests más generales, como la Escala de Intigencia de Stanford-Binet (Thorndike y cols., 1986), o el Test de Lenguaje para adolescentes (Hammill y cols., 1994).

\subsection{OTRAS MEDIDAS NEUROPSICOLÓGICAS}

Los tests neuropsicológicos exploran el funcionamiento de las diferentes áreas y sistemas del cerebro de un paciente a través de la medición de sus capacidades cognitivas. Permiten identificar debilidades en áreas o funciones específicas, como, por ejemplo, problemas de memoria, atención o lenguaje y relacionarlas con el funcionamiento de las áreas cerebrales correspondientes. Por ejemplo, el test de Stroop y el Wisconsin Card Sorting Test (WCST) son útiles para valorar la función del lóbulo frontal, la capacidad de adaptación a los cambios, las habilidades de alternancia, la flexibilidad y el control de la actividad mental. Por este motivo, se utilizan con frecuencia en la valoración de los pacientes con TDAH. 
Estas pruebas, denominadas tests de función ejecutiva, evalúan la atención dividida y la resistencia a la interferencia (Stroop), y la flexibilidad mental (WCST) (Wisconsin card sorting test). El Stroop, en su versión baremada por Golden (1994), incluye test de palabra, colores y palabras-colores. Evalúa la flexibilidad cognitiva, la resistencia a la interferencia procedente de estímulos externos, la creatividad, la psicopatología y la complejidad cognitiva. La palabra coloreada suscita una respuesta verbal automática que requiere muchas de las funciones neuropsicológicas que son necesarias para nombrar los colores. La lámina de interferencia del Stroop mide básicamente la capacidad del sujeto para separar los estímulos de nombrar colores y palabras. Los estímulos del Stroop afectan, por tanto a niveles básicos de la capacidad del sujeto para clasificar información de su entorno y reaccionar selectivamente a esa información. Permite obtener una puntuación de interferencia que refleja la capacidad de concentración (Golden, 1994).

Los estudios han confirmado la utilidad de la prueba de Stroop en la valoración de niños con posible TDAH. Según Capdevilla y cols. (2005) en la prueba Stroop-color e interferencia, los niños con TDAH obtienen un rendimiento pobre. En investigaciones realizadas por Bará- Jiménez y cols (2003) comparando un grupo control e con niños TDA y TDAH, se objetivaron diferencias significativas en la velocidad de lectura (TDA) y en la velocidad de denominación (TDAH), así como en la interferencia o control inhibitorio en el grupo TDAH. Este resultado es coherente con las teorías propuestas por Barkley (1997) sobre la alteración de las funciones ejecutivas y la inhibición comportamental en el TDAH.

El test de clasificación de Winconsin (WSCT) consta de 4 cartas estímulo, que se colocan frente al sujeto y dos barajas de 64 cartas cada una. La tarea del niño es emparejar cada una de las cartas con una de las que sirven como estímulo, según un criterio cambiante no explicitado. También existe una versión para ordenador. En recientes investigaciones, Capdevilla y cols (2005) encuentran diferencias en el rendimiento de este tests en niños de 
TDAH combinado y el TDA. Las diferencias entre subtipos han sido cuantitativas y cualitativas. Encontraron que en los niños con TDAH combinado en comparación con el TDA o con el TDAH de predominio impulsivo, la ejecución en la prueba fue mala en todas las medidas, sugiriendo déficit en varios mecanismos ejecutivos. Ambos grupos sólo han compartido un alto porcentaje de errores perseverativos.

La perseveración puede indicar dificultades en el niño al no prever que hacer al recibir el feedback de corrección desde el monitor del ordenador. En ambos grupos, el TDA, el TDAH y el TDAH combinado, se obtienen malos resultados en los errores perseverativos y en la habilidad conceptual de este test. En la ejecución del WCST, se obtienen puntuaciones significativamente menor en la ejecución del test en estos niños.

En otra investigación realizada por Etchepareborda y cols (2004), se demostró que los niños con TDAH cometieron más errores perseverativos que el grupo control, el promedio de errores simples fueron de 28 con respecto al 13 en el grupo control, y el promedio de errores de perseveración de 10 frente a 1 . Se observó una serie de variables neuropsicológicas con alto grado de significación estadística cuando se las relacionó con el número de series logradas en el WCST.

\subsubsection{EL TEST DE LA FIGURA COMPLEJA DE REY-OSTERRIETH}

Con este test se puede evaluar la capacidad visoconstructiva y la memoria visual. Permite la valoración de diferentes procesos cognitivos que implican habilidades de planificación y de organización, estrategias de resolución de problemas y funciones motoras. Consiste en la reproducción de una figura sin significado de elevada complejidad geométrica por su riqueza de detalles. Consta de dos partes, la primera, de copia y la segunda de 
ejecución de memoria a los 3 y a los 30 minutos. El tiempo de aplicación es de 10 minutos aproximadamente, excluyendo el ensayo diferido.

En investigaciones realizadas por Bará-Jiménez y cols (2003) con población infantil colombiana, se aplicó este test a niños con TDA Y TDAH combinado. Obtuvieron que las puntuaciones de realización diferida de los sujetos del grupo inatento se situaban significativamente por debajo de los grupos control y TDAH combinado. Lo interpretaron como resultado de la dificultad en la memoria visual, memoria de trabajo y particularmente en el mantenimiento de la representación de los eventos por tiempos prolongados.

En el TDAH se pueden observar dificultades a la hora de percibir las figuras geométricas básicas, omisión de partes del dibujo o alteraciones de su representación. Esto sugiere alteración de las habilidades constructivas y de la memoria no verbal.

\subsection{RESUMEN}

La evaluación del TDAH se realiza fundamentalmente a través de la entrevista clínica y recogida de observaciones conductuales de padres y docentes (AACAP, 1997). Las valoraciones psicométricas generales y de funciones específicas sirven para complementar o precisar la información obtenida en la entrevista, así como para valorar los progresos en el tratamiento. No tienen, en cambio, valor diagnóstico. Las escalas de observación conductual cubiertas por padres y docentes, son altamente subjetivas. Las valoraciones de inteligencia, lectura y habilidades escolares sirven para obtener información útil, pero sin capacidad para discriminar niños con TDAH y niños sin TDAH. Las pruebas de atención o memoria se diseñaron para explorar otro tipo de problemas de salud. En resumen, no contamos con una prueba que permita diagnosticar objetivamente el TDAH. 
Esta es una laguna importante en el abordaje del problema. Una patología que supone la mayor parte de las consultas en los servicios de Salud Mental, en la que se han encontrado hallazgos neurofisiológicos, biológicos y genéticos, y cuyo principal tratamiento es farmacológico, debería poder ser diagnosticada con una prueba objetiva o combinación de pruebas objetivas.

Es posible que el problema tenga relación con la historia del trastorno. Como hemos visto, desde su identificación inicial ha experimentado sucesivos cambios de definición y conceptualización. La observación del trastorno se inició en niños hiperactivos y las primeras definiciones se centraron en los síntomas de hiperactividad e impulsividad, así como en el carácter infantil y su remisión a lo largo de la adolescencia. A medida que mejoraba el conocimiento del cuadro y se disponía de información sobre su evolución a lo largo de los años, el énfasis se desplazó a los síntomas de atención, concentración, esfuerzo y memoria, así como a su carácter potencialmente crónico. La definición pasó de "trastorno de hiperactividad" a "trastorno por déficit de atención". Como resultado de los cambios de conceptualización, y, correlativamente, de criterios diagnósticos, el enfoque de la evaluación fue transformándose. Esto podría explicar el escaso desarrollo actual de herramientas diagnósticas, especialmente acusado si lo comparamos con el desarrollo de tratamientos farmacológicos. La gran paradoja de la situación actual es que la respuesta clínica a la enfermedad es notablemente mejor conocida, más precisa y efectiva que los procedimientos para diagnosticarla. 
Utilidad de la cartografía cerebral en el diagnóstico del TDAH 
CAPITULO 8. INSTRUMENTOS COMPLEMENTARIOS DE EVALUACION NEUROFISIOLOGICA EN EL TDAH 
Utilidad de la cartografía cerebral en el diagnóstico del TDAH 


\section{INTRODUCCIÓN}

Para la evaluación global del TDAH, en clínica se utilizan como métodos complementarios de valoración la cartografía cerebral o EEG cuantificado, el EEG convencional o de vigilia, los potenciales evocados (PE), que engloban los potenciales cognitivos, y para el estudio de posibles alteraciones de sueño o la presencia de posibles trastornos paroxísticos de pronóstico favorable, el Polisomnograma nocturno (PSG). Con estos registros neurofisiológicos se consigue la captación de los cambios en los potenciales de membrana de las dentritas y somas celulares de las células nerviosas. Los potenciales sinápticos generan cambios positivos, que corresponden a la excitabilidad, y, por otro lado, cambios negativos, correspondientes a la inhibición en la concentración extracelular de iones (Periañez y Barceló, 2003). El EEG registra en el cuero cabelludo el volumen de la suma del flujo de potenciales de conducción (EEG) (Coles y Rugg, 1995).

En este capítulo presentaremos las principales técnicas neurofisiológicas de evaluación complementaria en el TDAH. 


\subsection{CARACTERISTICAS TÉCNICAS DE LOS ESTUDIOS NEUROFISIOLÓ- GICOS}

\subsubsection{EL ELECTROENCEFALOGRAMA (EEG)}

El EEG permite obtener y registrar la actividad bioeléctrica cerebral, espontánea o inducida por procedimientos de activación. Tejeiro (2005), en su manual sobre electroencefalografía clínica básica, define el EEG como un registro de la actividad eléctrica de la corteza cerebral, obtenido con electrodos colocados en el cuello cabelludo, siguiendo el sistema internacional 10-20 de Jasper para el montaje de los electrodos.

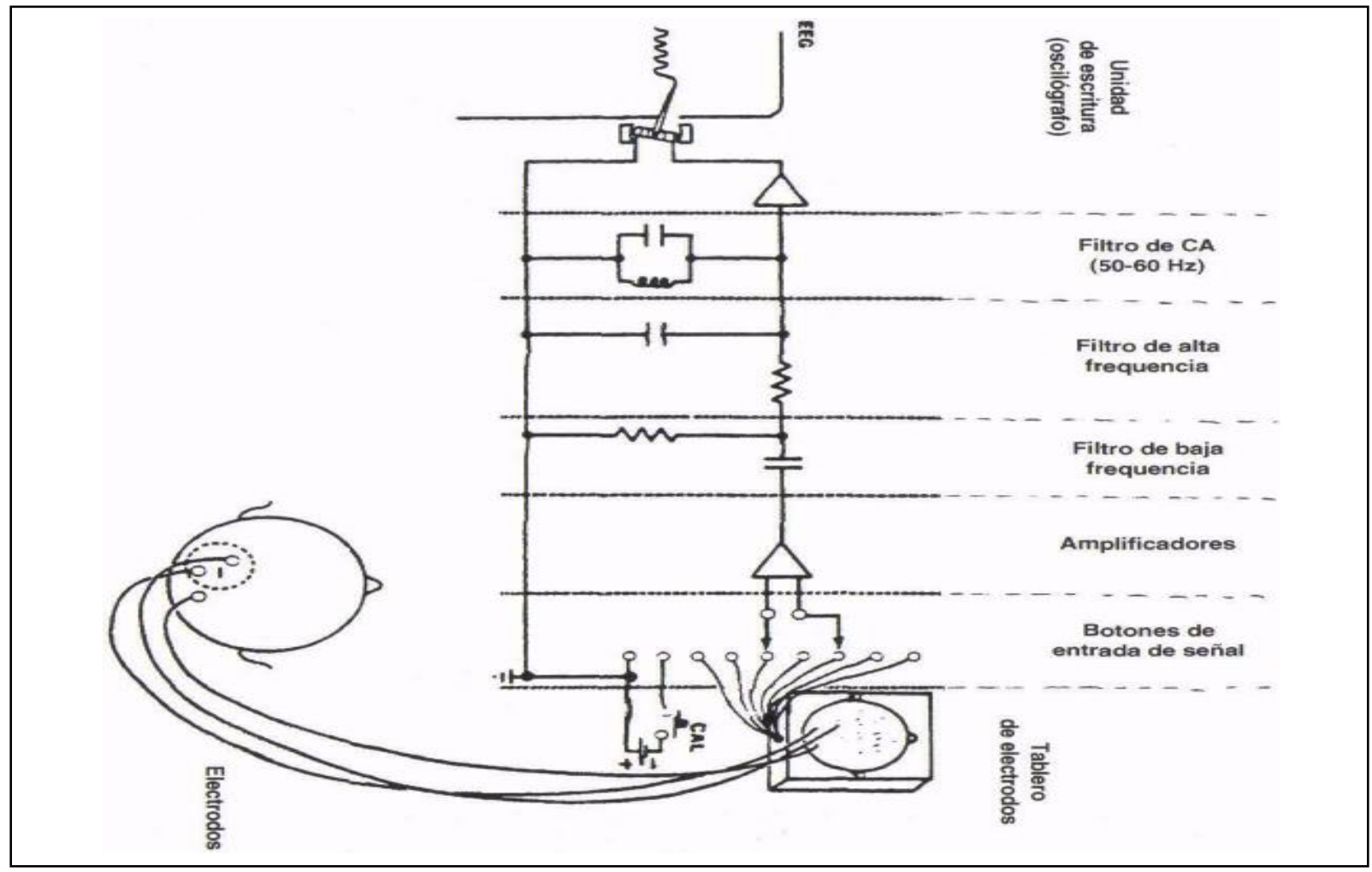

Figura 4 Electroencefalografía básica Tejeiro, 2005. 
A su vez, esta señal es trasmitida hacia las entradas de un sistema electrónico que la amplifica y filtra. Finalmente, se envían a un oscilógrafo que permite obterner un registro gráfico de las ondas cerebrales en tiras de papel en movimiento continuo.

Cabe destacar que en la actualidad se dispone de nuevos avances en el registro de la señal por medio del registro digital, no siendo necesario usar el formato papel. Esta tecnología aporta grandes ventajas prácticas, como la posibilidad de visualizar el EEG con montajes o escalas de tiempo y voltajes diferentes a las utilizadas durante su adquisición.

Según Tejeiro (2005), el EEG puede ser considerado como una extensión del examen neurológico en la evaluación de aspectos de la función cerebral, no siempre accesibles a las pruebas clínicas convencionales. Es un procedimiento no invasivo que es monitorizado e interpretado por neurofisiólogos. Además, sirve para evidenciar anormalidades eléctricas en la corteza cerebral y permite identificar otras patologías cerebrales con síntomas semejantes al TDAH, como pueden ser las ausencias (crisis parciales) (Van-Wielink, 2005). Por ello, la utilidad del EEG puede ser grande si el clínico conoce sus indicaciones y es consciente de sus limitaciones. En su estado de desarrollo actual debe ser utilizado como método auxiliar, y la información que proporciona debe analizarse en el estudio global del niño: anamnesis, exploración física, análisis complementarios y pruebas neuropsicológicas realizadas.

\subsubsection{LA CARTOGRAFIA CEREBRAL O EEG CUANTIFICADO (EEGq)}

La cartografía cerebral, o EEG cuantificado, permite descomponer en bandas de frecuencia la actividad bioeléctrica cerebral y obtener su registro digitalizado. Para Cabanyes y cols. (1999) la cuantificación de la actividad eléctrica y los mapas que recogen la topografía de la señal bioeléctrica cerebral permiten profundizar en la fisiopatología del SNC. 
Entre sus ventajas con respecto al EEG convencional, están su altísima resolución temporal y las características de la información que aporta, tanto por su naturaleza, que implica la actividad neuronal producto de la electrogenésis cerebral, cambiante según su situación funcional y externa, como por el formato digital del registro.

La señal bioeléctrica se diferencia en ritmos específicos, caracterizados por su frecuencia, amplitud, reactividad, estabilidad, morfología, topografía y sincronismo. La señal obtenida es modificada por medio del análisis de Fourier. Una vez digitalizada la señal, debe procesarse matemáticamente para evaluar los distintos parámetros de interés en la metodología de la EEGq. Cada uno de estos parámetros describe aspectos independientes de la actividad bioeléctrica cerebral y es sensible a los cambios psicofísicos del paciente y a la presencia de determinadas enfermedades.

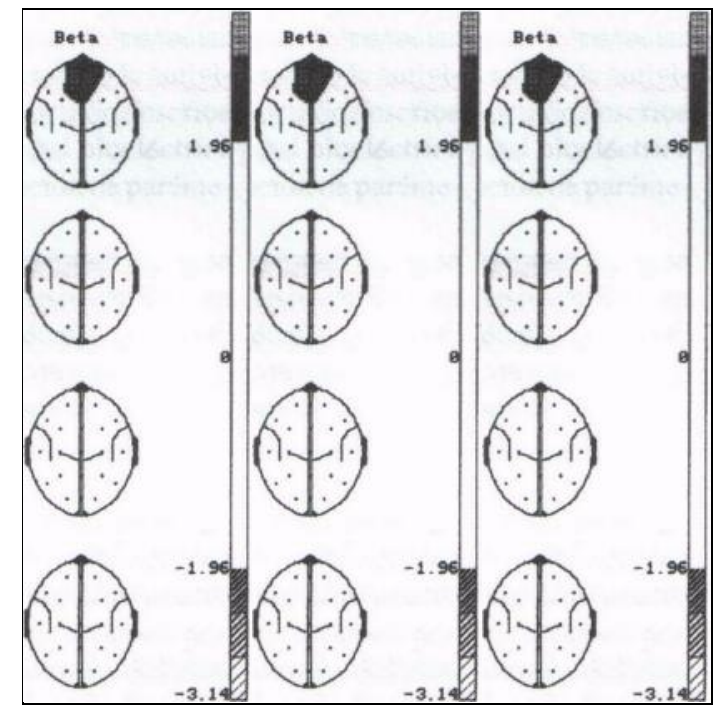

Figura 5. Mapas de significación estadísticas de un EEG cuantificado. (Cabanyes-Trufino, 1999)

Es necesario disponer de espectros de frecuencia de épocas de registro, aisladas y acumuladas. Esto permite obtener el análisis neurométrico que calcula las diferencias entre los valores teóricos adecuados a la edad, que se extraen por el desarrollo de ecuaciones específicas. Con el apoyo de diferentes instrumentos matemáticos se consigue un análisis más 
fino de las señales eléctricas (Cabanyes y cols, 1999). A partir de ahí se obtienen las puntuaciones $Z$, que definen la probabilidad de que un valor observado se encuentre dentro de los baremos de la normalidad, teniendo en cuenta la dispersión de la población normal y las diferencias que se pueden encontrar en función de la edad.

Una vez que los datos de la EEGq se registran, pueden compararse en sus resultados con un banco de datos obtenidos de diversos pacientes con trastornos del neurodesarrollo como puede ser el TDAH, demencia o depresión. Esto puede ser una ayuda importante para mejorar el proceso diagnóstico. Como expone Valdizán y cols. (1998) el EEGq ayuda a establecer una diagnosis de maduración cerebral, no accesible hasta ahora mediante la mera inspección visual del registro del EEG convencional.

Los progresos en las técnicas informáticas pueden traer importantes mejorías en las técnicas de cartografía cerebral en los próximos años.

\subsubsection{POTENCIALES EVOCADOS (PE)}

Con potenciales evocados nos referimos a respuestas provocadas a estímulos periféricos conocidos y normalizados, o sea, modificaciones del potencial eléctrico producido por el sistema nervioso en respuesta a una estimulación externa, especialmente sensorial (un sonido, una imagen, etc.), pero también a un evento interno como una actividad cognitiva, registrados con el EEG. Cuando un tren de estímulos sensoriales de cualquier tipo llega al cerebro, provoca secuencias características de ondas en el trazado electroencefalográfico (EEG), o potenciales evocados. Son diferentes para cada modalidad sensorial y su variabilidad también depende de la intensidad del estímulo. Característicamente presentan una relación estable en el tiempo respecto al estímulo. 
Los potenciales evocados exógenos cognitivos utilizados en el estudio del TDAH son la onda P300 y la N400. Valdizán y cols (2004) indican que a pesar de su dificultad técnica, estos potenciales tienen un alto interés científico y clínico por su relación con el funcionamiento cognitivo.

Según de Bortoli (2001), la P300 es una onda positiva con pico alrededor de los 300 milisegundos, que aparece cuando el sujeto en un estado de atención discrimina un estímulo relevante de otro. Se utiliza para esta monitorización, el paradigma odd-ball que implica la tarea de reconocimiento de un estímulo denominado target, que aparece de manera aleatoria entre otro estímulo más frecuente, denominado estimulo estándar.

Los principales parámetros de evaluación de esta onda son la amplitud y la latencia. La amplitud, tal como la definen Valdizán y cols (2004), es un índice de la actividad atencional de las regiones cerebrales, relacionada con la cantidad y complejidad de la información procesada. En cuanto a la latencia, es una medida de la velocidad de clasificación del estímulo, independiente del proceso de selección de la respuesta y del tiempo de realización. Una latencia menor indica una alta capacidad de procesamiento cognitivo y su incremento va unido a una disminución de las funciones cognitivas. La P300 depende de la edad, comenzando con una larga latencia que va decreciendo progresivamente en 1,25 por año hasta los 18 meses de vida.

La latencia de la P300 es una medida de la velocidad de clasificación cerebral de estímulos, generalmente no relacionada con el proceso de selección de respuesta (Pfefferbaum y cols, 1985; Verleger, 1997). Es independiente del tiempo de reacción conductual, porque indica el tiempo de procesamiento antes de la respuesta. Refleja el tiempo requerido para asignar recursos y realizar la puesta al día de la memoria en una tarea dada.

Según Polich (1986), la onda o componente P300 es la más característica de los componentes bioeléctricos relacionados con los procesos de nivel superior que corresponden 
a la discriminación y reconocimiento de un estímulo. Polich $(1990 ; 1998)$ encuentra una alta correlación entre la latencia de la P300 y el rendimiento, por lo que esta onda puede indicar los cambios relacionados con el envejecimiento evolutivo normal y las enfermedades cognitivas.

En cuanto al otro potencial cognitivo estudiado en el TDAH, es el potencial evocado auditivo N400. Esta onda aparece como respuesta negativa entre los 300 y 1000 ms y permite el estudio neurofisiológico del lenguaje (Valdizán, 2004). Se considera que evalúa la capacidad de contextualización semántica o la discriminación estimulo incongruente. Es un potencial que tiene un paradigma particular, sensible a la relación semántica entre la palabra y su contexto en la frase. Esta onda es independiente de la frecuencia de presentación del estímulo.

\subsubsection{EL POLISOMNOGRAMA: PSG}

Los estudios neurofisiológicos realizados en niños con TDAH, indican que un alto porcentaje de estos niños presentan alteraciones en el sueño. Según Corkum y cols (1998) y Greenhill y cols (1983) pueden presentar un sueño de mala calidad, con insomnio inicial y de mantenimiento, disminución de la latencia del sueño, múltiples despertares, enuresis, parasomnias como bruxismo y sonambulismo, y el síndrome de piernas inquietas. Además, presentan menor porcentaje de sueño REM, mayor porcentaje de sueño lento y menor eficiencia de sueño.

En su manual sobre electrofisiología clínica Tejeiro (2005) explica que con el Polisomnograma se obtiene la identificación de los estados de vigilia y sueño monitorizando a su vez otras variables fisiológicas, como las respiratorias y cardiovasculares. El registro y posterior análisis de los diferentes parámetros de estas variables, es útil para evaluar los 
trastornos del sueño. Con el PSG se registran el estado de vigilia, y las diferentes fases del sueño, los movimientos oculares, la actividad muscular y los parámetros respiratorios y cardiorrespiratorios

La PSG permite analizar los estadios del sueño y los siguientes parámetros:

1) Tiempo total de cama: tiempo que transcurre desde que los pacientes se meten en la cama, con los electrodos colocados y la luz apagada, hasta que finaliza el registro.

2) Periodo de sueño: Tiempo que transcurre tras apagar las luces hasta que el niño concilia el sueño, menos el tiempo que permanece acostado en la cama despierto por la mañana.

3) Tiempo total de sueño: Tiempo que el niño permanece dormido, descontando el tiempo de los despertares después de iniciarse el sueño.

4) Índice de eficacia del sueño: Resultado de dividir el tiempo total de sueño por el tiempo total de cama y multiplicar por 100 .

5) Porcentaje de cada estadio: Tiempo expresado en tanto por ciento que permanece en cada fase del sueño, referido al periodo de sueño, sin olvidar el porcentaje que el niño permanece despierto.

6) Latencia en el inicio de sueño: Es el tiempo que transcurre desde el inicio del estudio tras apagar las luces, en disposición a dormir, hasta que se manifiesta la primera fase del sueño,

7) Número de cambios de estadios y de despertares: cuando la duración es mayor de un minuto, ambas variables ofrecen una medida de la desestructuración del sueño.

8) Latencia de cada estadio: Es el tiempo que tarda en presentarse cada uno de los diferentes estadios, por primera vez en toda la noche. 
9) Número de episodios REM y duración media: Es la suma de los periodos REM que se evidencia durante todo el estudio, separados al menos 15 minutos de cualquier otra fase REM precedente o siguiente.

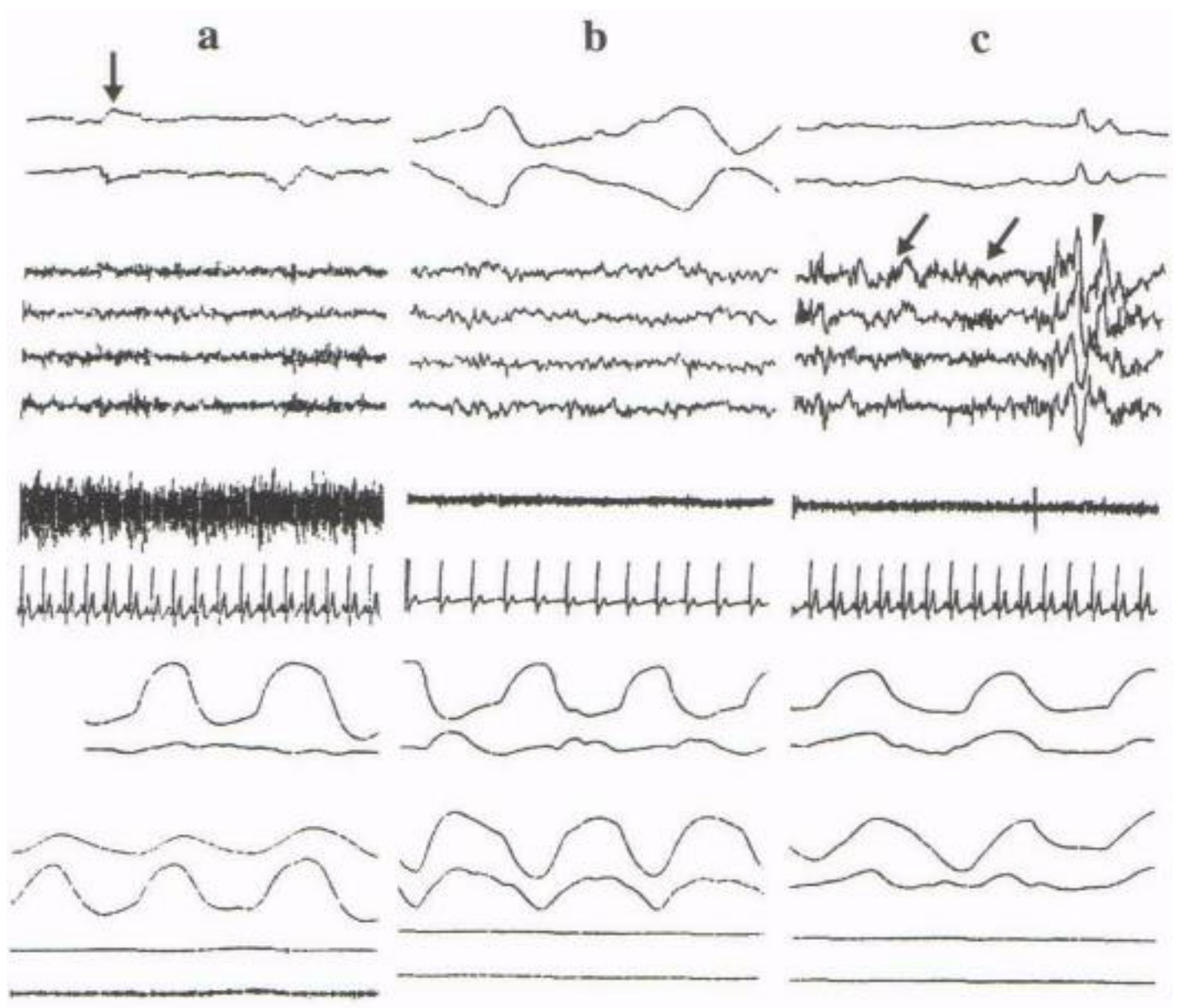

Figura 6 Registro PSG convencional. Algunas partes del registro (Tejeiro, 2005)

\subsection{RESUMEN}

En este capítulo, se han revisado las principales técnicas neurofisiológicas para la evaluación complementaria del TDAH. Estos registros neurofisiológicos permiten establecer los límites normales de actividad electroencefalográfica en función de la edad y desarrollo cortical de los niños con TDAH. 
Con el estudio neurofisiológico riguroso, mediante una técnica de análisis de las ondas alfa, beta, delta y theta se consigue conocer características del funcionamiento y nivel de maduración cerebral. Esto ha permitido observar que un porcentaje alto de niños con TDAH presentan alteraciones electroencefalográficas. El conocimiento de estas alteraciones y su correlación con los correlatos neuroquímicos y neuroanatómicos del TDAH, es sin duda, un reto pendiente.

Por otra parte, los avances recientes en informática ponen a disposición de los clínicos técnicas más precisas de registro, análisis y comparación de la señal eléctrica (Kropotov, 2009) Es un campo en constante renovación. Si en los próximos años se generaliza su uso, podrán proporcionar información más objetiva para el diagnóstico del TDAH. 
Capitulo 9. Tratamiento del TDAH

CAPITULO 9. TRATAMIENTO DEL TDAH 
Utilidad de la cartografía cerebral en el diagnóstico del TDAH 


\section{INTRODUCCIÓN}

El TDAH es un trastorno neuroevolutivo que afecta a la totalidad del desarrollo emocional, cognitivo, comportamental y social. Por este motivo, la intervención clínica debe articularse en un programa multidisciplinar que combine, en función de las necesidades de cada caso, tratamientos cognitivo-conductuales, tratamientos farmacológicos e intervención escolar. Según Orjales (1998) la intervención óptima es la que cumple las siguientes condiciones:

1) El programa debe ser elaborado de forma individualizada: Tras la obtención de todos los datos del niño, el programa debe establecer y exponer las características comportamentales y cognitivas del niño evaluado, incluyendo toda la información básica obtenida de una evaluación exhaustiva, que nos permita valorar de qué modo este trastorno se está reflejando en los aspectos más relevantes del desarrollo del niño.

2) El programa debe incluir los dominios en los que el niño con TDAH

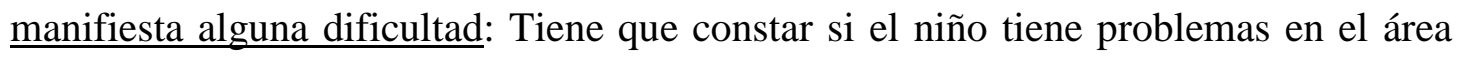
cognitiva, en la que se pueden encontrar dificultades en la calidad y el tipo de estrategias que utiliza en resolver tareas, problemas, el estilo de funcionamiento, si presenta un estilo impulsivo o reflexivo, y si su procesamiento de la información es dependiente o independiente de campo. También es importante conocer el grado de consciencia del problema y valorar el área emocional. En este área hay que tener en cuenta el nivel de tolerancia a la frustración, el tipo de reacciones emocionales que el niño presenta tras una experiencia frustrante, la existencia o no de actitudes 
depresivas y si existen síntomas de ansiedad. Por otro lado, hay que valorar el área comportamental, identificando el tipo de refuerzo que parece ser más eficaz, si existen problemas de conducta y de qué tipo, cómo son los hábitos de estudio y si el niño presenta hiperactividad motriz.

3) El programa debe establecer en qué medida estas dificultades afectan al ámbito escolar: Destacando el modo en que afecta la falta de base académica, el nivel de comprensión y fluidez lectora, la agilidad del cálculo mental y los hábitos de estudio. En cuanto al ámbito escolar, hay que examinar la relación del niño con sus iguales, si existen estrategias de solución de problemas con los compañeros, si existe agresividad en el niño o si presenta hiperadaptación a las normas.

Es necesario seguir unas pautas, a realizar por los diferentes especialistas, como pueden ser los psicólogos, neurólogos y psicopedagogos, para realizar de forma conjunta (Orjales, 1998). Estas pautas son las siguientes:

1) Realizar un diagnóstico diferencial, en el que conste la definición exacta del tipo de trastorno que presenta el niño.

2) Establecer el diagnóstico de posición, que describa la situación actual en la que se encuentra el niño, la gravedad del trastorno y todos los aspectos anteriormente mencionados del diagnóstico y que sirven de referencia, respecto al cual se va a diseñar el tratamiento.

3) Desarrollar el programa de intervención, que contemple el tratamiento especializado, un programa a realizar en casa y las orientaciones específicas a su caso y las orientaciones específicas para el profesor.

Desde el punto de vista de la intervención, dos son los tratamientos que han mostrado más efectividad en la hiperactividad infantil: el tratamiento farmacológico y el tratamiento cognitivo-conductual. La aplicación conjunta de ambos ha demostrado ser la intervención 
más eficaz para el tratamiento de este trastorno (Orjales, 1998). En este capítulo trataremos en primer lugar los tratamientos farmacológicos y a continuación las diferentes intervenciones psicosociales, en las que se incluyen tratamientos cognitivo-conductuales e intervenciones escolares.

\subsection{TRATAMIENTO FARMACOLÓGICO}

El tratamiento farmacológico del TDAH se remonta a 1937, cuando Bradley observó que la benzedrina producía una mejoría significativa en niños con comportamientos disruptivos. Observó una mejoría significativa del humor, la conducta y el aprendizaje en respuesta a la administración de benzedrina en 30 niños de 5 a 14 años de edad durante un periodo de 30 días de observación en régimen de ingreso (Staufer y Greydanus, 2005). Posteriormente se ha probado la eficacia y seguridad de otros agentes, aunque los psicoestimulantes siguen constituyendo el tratamiento de primera línea.

Los fármacos que se usan actualmente para el tratamiento de los síntomas del TDAH se pueden agrupar en dos grupos, según su efecto sobre el SNC. Los estimulantes del SNC aumentan la dopamina y la noradrenalina, mientras que los no estimulantes del SNC actúan únicamente sobre el sistema noradrenérgico (Castellanos y Acosta, 2011). Los grupos farmacológicos utilizados incluyen psicoestimulantes y antihipertensivos (Pozo de Castro y cols, 2005, Díaz Atienza, 2006). 


\subsubsection{FARMACOS ESTIMULANTES}

El metilfenidato es un estimulante del SNC. El mecanismo de acción por el que reduce la sintomatología del TDAH no se conoce con precisión, aunque se cree que incrementa las concentraciones de noradrenalina y dopamina en la corteza frontal y regiones subcorticales asociadas con la motivación y la recompensa. Los cambios en la neurotransmisión se producen fundamentalmente en la dopamina y en la noradrenalina, ambos en el espacio intersináptico. El metilfenidato actuaría activando el sistema dopaminérgico por inhibición de la recaptación de la dopamina (Díaz de Atienza, 2006).

En la instauración y ajuste del tratamiento farmacológico con metilfenidato, se deberán tener en cuenta los siguientes factores: severidad del TDAH, si se asocia o no con trastornos comórbidos y de qué tipo, efectos secundarios, facilidad o disponibilidad para aplicar el tratamiento según horario, preferencias de los padres o del niño y problemas escolares (Txakartegi y cols, 2006)

Las anfetaminas existen en dos formas estereoisoméricas: levo y dextro. La forma comercial más usada es una combinación de cuatro sales de anfetaminas, en una proporción de 3 a 1 de dextroanfetamina frente a la levoanfetamina (Castellanos y cols, 2011). A diferencia del metilfenidato, que bloquea los transportadores de noradrenalina y dopamina, las anfetaminas aumentan el nivel de noradrenalina y dopamina en la sinapsis, activando el sistema noradrenérgico por liberación de noradrenalina en el hipocampo (Díaz de Atienza, 2006). Tal como expone Castellanos y cols. (2011), el metilfenidato únicamente amplifica procesos endógenos, mientras que las anfetaminas tienen efectos fuertes sobre la noradrenalina y dopamina, sin importar el nivel de función endógena.

El metilfenidato y las anfetaminas son útiles en alrededor del $70 \%$ de los pacientes con TDAH (Staufer y Greydanus, 2005). Producen mejoras en los procesos cerebrales de alerta y por lo tanto mejoran el rendimiento de aquellas tareas que necesiten un cierto nivel de 
vigilancia (procesos atencionales). Además producen mejoras en la variabilidad de respuesta, impulsividad, rendimiento en tareas cognitivas como procesos de memoria, especialmente en memoria a corto plazo, memoria de trabajo y tiempo de reacción. Existe además, una mejora a la hora de elegir entre estímulos simultáneos (Díaz de Atienza, 2006). En el ámbito escolar se observa un incremento del tiempo de reposo en el aula, una mayor capacidad para la resolución de problemas en relación con su grupo de iguales, mejora de capacidad en el span atencional de tipo sostenido, una mejora que se traduce en una mejor realización de las tareas escolares y disminución de la impulsividad (Díaz de Atienza, 2006).

Tabla 10. Efectos terapéuticos de los psicoestimulantes. (Díaz de Atienza, 2006; Toro y cols, 1998)

1. Efectos conductuales:

- Disminución de la hiperactividad.

- Mejoría de las conductas agresivas, impulsivas y desobediencia en casa y escuela.

- Disminución de las conductas perturbadoras e inquietud entre tareas.

\section{Efectos cognitivos}

- Mejora en atención

- Aumento del nivel de autocontrol y autorregulación

- Mejoría en la resolución de problemas y procesamiento de la información

\section{Efectos académicos}

- Mejoría del rendimiento académico

- Sin efecto directo sobre el aprendizaje

\section{Efectos sobre las habilidades sociales}

- Mejoría en la interacción con los padres, hermanos y compañeros de clase y profesores

- Aumento de la obediencia y cumplimiento de tareas

- Modulación de la intensidad de las conductas, mejoría de la comunicación y aumento del nivel de respuesta disminuyendo el número de interacciones negativas

- No se observan efectos en la conducta prosocial. 


\subsubsection{FÁRMACOS NO ESTIMULANTES}

La Atomoxetina fue introducida en 2003 y ha sido aprobada por la FDA para el tratamiento del TDAH en niños, adolescentes y adultos. Es un fármaco no estimulante que aumenta los niveles del neurotransmisor noradrinalina inhibiendo su recaptación. No tiene efecto primario sobre el nivel de dopamina (Staufer y Greydanus, 2005). Puede provocar una amplia variedad de efectos secundarios, y puede interactuar con la paroxetina y fluoxetina. Los principales efectos secundarios, según Staufer y Greydanus (2005), son anorexia, sequedad de boca, nauseas persistentes, somnolencia o insomnio, disforia y cambios de humor, cansancio, letargia y astenia, aumento de la frecuencia del pulso y la tensión arterial, aparición de palpitaciones, estreñimiento y dificultad para la micción, alteración del interés o la función sexual y mareos.

El bupropión es un antidepresivo usado a veces para el tratamiento del TDAH. Ha sido aprobado por la FDA como antidepresivo para niños, adolescentes y adultos. No está clasificado como estimulante y ha sido empleado como terapia sustitutiva para la deshabituación tabáquica. Sus mecanismos de acción comprenden inhibición de la captación de los neurotransmisores serotonina, dopamina y noradrenalina. Los efectos pueden ser más débiles que los de los estimulantes (Staufer y Greydanus, 2005). Aunque no suele ser el fármaco de primera elección para el tratamiento del TDAH, el bupropion puede ser una herramienta terapéutica útil en algunos casos, solo o en combinación con algún estimulante. Su uso se puede considerar si existe depresión, tabaquismo importante o antecedentes de efectos secundarios indeseables de la cafeína. Algunos individuos que no toleran ninguno de los estimulantes, responden bien al bupropión (Staufer y Greydanus, 2005). 


\subsubsection{LA PREOCUPACION SOCIAL POR EL TRATAMIENTO FARMACOLÓGICO}

Tal como señala Díaz Atienza (2006), el uso de los psicoestimulantes ha provocado un debate social. Posiblemente su utilización con niños haya contribuido a incrementar la controversia. Los aspectos más controvertidos tienen que ver con los efectos secundarios, los efectos a largo plazo, el riesgo de desarrollar dependencia o favorecer la dependencia de otras sustancias y el uso indebido.

Aunque existen efectos secundarios, la mayoría son infrecuentes. A continuación se resumen los más frecuentes (Díaz Atienza, 2006).

1. Efectos secundarios cardiovasculares: pueden dar lugar a un incremento de la frecuencia cardiaca y de la tensión arterial diastolita; igualmente pueden aparecer extrasístoles. Recientemente la FDA advirtió sobre el peligro de los efectos secundarios cardiovasculares de los psicoestimulantes a raíz de varias muertes EE.UU.

2. Efectos gastrointestinales: los más frecuentes son las náuseas, y ocasionalmente los vómitos. También se han observado dolores abdominales y con menor frecuencia estreñimiento.

3. Efectos dermatológicos: Puede aparecer rash cutáneo. En ese caso es necesario suspender la medicación.

4. Efectos neurovegetativos: El insomnio puede aparecer en el 80-90 \% de los casos, aunque está muy relacionado con la hora en la que se produce la toma. La fatiga y el letargo pueden aparecer en el 19\% de los casos.

5. Efectos sobre el Sistema Nervioso Central: son muy numerosos y de distinta gravedad e intensidad. Las cefaleas se presentan en un 30-40\%. Otros efectos 
secundarios son los vértigos, estereotipias motoras, tics y movimientos coreiformes, hipersensibilidad auditiva (hiperestesia), hormigueo en los miembros superiores y/o inferiores, disforia o malestar psicológico, e incremento o aparición de irritabilidad. Con poca frecuencia, pueden aparecer síntomas psicóticos de tipo paranoide, que suelen desaparecer con la supresión de la medicación. También puede aparecer labilidad emocional caracterizada por llanto fácil e incontrolable y tristeza.

6. Efectos sobre el sistema endocrino: el efecto secundario más estudiado es el retraso en el crecimiento. Sobre este aspecto las investigaciones ofrecen resultados contradictorios, aunque parece cierto que el tratamiento continuado con psicoestimulantes puede reducir el crecimiento entre dos y cinco centímetros.

Diversas investigaciones plantearon que la exposición a los psicoestimulantes incrementaba el riesgo de consumo de tabaco y cocaína en la vida adulta (Lambert y cols, 1998). Posteriormente Barkley y cols (2003) llegaron a resultados opuestos, concluyendo que el uso de psicoestimulantes con niños con TDAH es un favor de prevención del consumo de sustancias adictivas en edades posteriores. Ese mismo año, Wiley y cols (2003) realizaron un metaanalisis sobre el tema y llegaron a la conclusión de que la variable de riesgo que mejor predice la asociación entre tratamiento con estimulantes y posterior consumo de drogas, especialmente la cocaína, son los trastornos de conducta. Para otros investigadores la variable fundamental no sería el consumo de psicoestimulantes, sino la gravedad del trastorno, factores psicosociales como la edad y patrones de ocio, variables personales como la autoestima, y los resultados escolares (Staufer y Greydanus, 2005).

Wilens y cols (2006) estudiaron los usos indebidos de los psicoestimulantes. Los principales son la transferencia de medicación de pacientes con TDAH a no pacientes como forma de confraternización social, el uso como alivio de problemas psicológicos, los 
incrementos de dosis sin indicación médica y la combinación de los psicoestimulantes con otras sustancias ilícitas. Estiman que puede darse en el $22 \%$ de los casos. De estos, el $80 \%$ presenta comórbidamente con el TDAH un trastorno de conducta y es más frecuente en hombres (Wiley y cols, 2006).

La controversia sigue abierta, con colectivos de profesionales y otros de no profesionales, que mantienen una lucha muy activa contra cualquier medicación psicotrópica. La evidencia científica, sin embargo, señala que son fármacos bastante seguros y que si se sopesan los riesgos y beneficios, claramente se obtienen más beneficios que riesgos (Díaz Atienza, 2006). Esta es la postura de las principales asociaciones médicas y de la Organización Mundial de la Salud.

\subsection{INTERVENCIONES PSICOSOCIALES}

Las intervenciones psicosociales abarcan una gran variedad de actividades conductuales y sociales (Brown, 2003; Orjales, 1998; Ramos-Quiroga y cols., 2006) . Es una categoría amplia que incluye las diferentes intervenciones no farmacológicas, como conversaciones entre un clínico y un paciente, sesiones para enseñar a padres estrategias de control conductual para aplicar en el hogar, terapia familiar para mejorar la comunicación entre los adolescentes y sus padres, y muchos otros tipos de interacción interpersonal. Sus propósitos generales, según Brown (2003), son los siguientes:

1. Informar a los pacientes y familias sobre la naturaleza, causas y evolución del trastorno, así como otros trastornos de conducta asociados, y sobre los riesgos y beneficios de las opciones terapéuticas disponibles. 
2. Establecer mecanismos de registro del funcionamiento de los pacientes y ajustar los tratamientos que están recibiendo.

3. Enseñar habilidades de manejo y protección a pacientes con el trastorno y a sus familias.

4. Proporcionar terapia de apoyo a pacientes con el trastorno y a sus familias.

Pueden ser muy útiles para sujetos con el trastorno y sus familiares. En primer lugar, proporcionan una base para comprender la naturaleza del problema, pudiendo actuar como antídoto del sentido de aislamiento e indefensión que desmoraliza a tantos sujetos y familias afectadas por un TDAH. En segundo lugar, mejoran los beneficios de los tratamientos farmacológicos. En tercer lugar, pueden desempeñar un papel crítico al ayudar a pacientes con el trastorno y a sus familias a controlar los aspectos de sus alteraciones asociadas con tales trastornos que no han cambiado suficientemente mediante la medicación sola. Finalmente, permiten implicar en el tratamiento a los niños y adolescentes, padres, hermanos u otros familiares que a menudo interactúan con la persona que padece el trastorno, y profesores, tutores escolares, entrenadores deportivos $\mathrm{u}$ otras personas que pueden desempeñar un papel importante en su vida cotidiana (Brown, 2003).

Las intervenciones psicosociales se desarrollan de formas muy diversas: conversaciones frente a frente, individuales o de grupo, conversaciones telefónicas, correos electrónicos, comunicaciones por Internet, radio o programas de televisión, libros, folletos, periódicos o artículos de revistas. Unas veces son sistemáticas, en forma de programas estructurados de sesiones terapéuticas o talleres de formación desarrollados de modo programado y cuidadosamente planificado durante un periodo largo de tiempo. Otras veces son encuentros casuales, como breves conversaciones en un momento dado de una manera espontánea. A continuación se revisarán los diferentes tipos de intervención psicosocial. 


\subsubsection{INTERVENCIONES PARA INFORMAR SOBRE EL TDAH Y LOS TRASTOR- NOS CÓMORBIDOS}

Para Brown (2003) las intervenciones psicosociales más importantes son las que ayudan a informar sobre el trastorno y los trastornos de conducta. La información sobre la naturaleza, causa y curso del trastorno es el punto de partida de una relación terapéutica adecuada. Proporciona un punto de vista alternativo a las personas con TDAH, no culpabilizador y clarificador, útil para que el paciente y su familia se formen una idea adecuada del problema y sus repercusiones. Si el profesional muestra una actitud de respeto y de empatía, dará al paciente y su familia oportunidad para expresar sus ideas, expectativas y temores y permitirá que el clínico conozca la información de que disponen. No es infrecuente que las personas con este trastorno y sus familiares manejen información insuficiente o sesgada sobre los problemas a los que se enfrentan, incluyendo la asociación con trastornos de comportamiento y otros trastornos comórbidos.

\subsubsection{INTERVENCIONES PARA INFORMAR SOBRE EL TRATAMIENTO}

Después de que un paciente y su familia han recibido información básica sobre la naturaleza del trastorno y se ha establecido el diagnostico, hay que informar acerca de las opciones y recomendaciones terapéuticas. Los pacientes y sus familiares deben comprender la naturaleza de las alteraciones y la contribución de factores neuroquímicos a los síntomas para poder colaborar plena y eficazmente en el proceso terapéutico. Las ideas sobre el uso de medicación pueden ser confusas. Pueden esperar una curación rápida con pequeñas dosis o temer que la medicación sea peligrosa y deba evitarse a toda costa. Otras familias pueden haber recibido información sobre la utilidad terapéutica de restricciones alimentarías, 
suplementos dietéticos y otras estrategias terapéuticas que, por el momento, no están apoyadas adecuadamente por la investigación científica. En todos estos casos es necesaria una actitud abierta que permita al clínico conocer las preocupaciones e ideas de la familia. Tanto si se espera que la medicación sea una panacea mágica como una amenaza peligrosa, debe informar objetivamente sobre los usos y limitaciones, y riesgos y beneficios de los tratamientos farmacológicos. Deben aclararse los beneficios esperables, los posibles efectos secundarios, la variabilidad de respuesta al tratamiento y el proceso de ajuste de dosis (Brown, 2003).

En casos de TDAH complicado con trastorno de conducta u otros trastornos comórbidos, la utilidad de una información adecuada aún es mayor. Hay que aclarar los múltiples aspectos de las dificultades del paciente, la necesidad de combinar varias intervenciones, identificar los síntomas diana de cada tratamiento, y establecer unas expectativas razonables.

\subsubsection{INTERVENCIONES PARA REGISTRAR Y MODIFICAR EL CURSO DEL TRATAMIENTO}

La evaluación inicial es la base del diagnóstico y el plan terapéutico inicial. A partir de este punto de partida, hay que sentar las bases de un proceso de registro y evaluación continua que implique productivamente al paciente, su familia, profesores y otras personas que puedan desempeñar un papel importante en la vida del paciente. Esta información es fundamental para minimizar los efectos adversos y maximizar los beneficios terapéuticos, dar continuidad a las intervenciones, prevenir el incumplimiento de prescripciones y abandono terapéutico, mejorar la colaboración de los familiares y docentes directa o indirectamente implicados, conseguir un ajuste óptimo de la dosis de medicación, conocer los efectos 
secundarios que puedan aparecer, e identificar las mejorías en los síntomas diana. Stine (1994) describió varios factores psicosociales y psicodinámicos que pueden afectar el cumplimiento de un tratamiento con psicoestimulantes, como la pasividad o negativismo del paciente o familiares con respecto a la enfermedad, desinformación, el estigma percibido o real del tratamiento farmacológico o ideas preconcebidas sobre la medicación. A estos hay que añadir posibles conflictos entre los miembros de la familia, provocados por desacuerdos sobre la validez e idoneidad del diagnóstico y tratamiento. Otras veces, el desacuerdo tiene un origen diferente, como los problemas conyugales no resueltos.

Según Strupp y cols. (1995) la evaluación de los efectos del tratamiento debe combinar el punto de vista del paciente, la de otras personas del entorno del paciente y la del clínico que lleva a cabo el tratamiento. Con niños y adolescentes es importante conocer las impresiones de los profesores, recogidas en escalas de valoración e informes psicopedagógicos. Integrando las diferentes informaciones es posible conocer mejor los diversos aspectos de la respuesta al tratamiento, favorables o no, en distintos momentos y ámbitos.

La evaluación de la eficacia de los tratamientos, según Brown (2003) consta de tres fases:

1. Recogida de información de diferentes fuentes (familia, escuela, relaciones sociales), sobre todas las áreas relevantes del funcionamiento del paciente (comida, sueño, salud general, sentimientos subjetivos, escuela, relaciones interpersonales).

2. Integración de los datos para formar una idea clara sobre el proceso del tratamiento e identificación de los factores que facilitan o impiden su efectividad.

3. Formulación de un plan para mantener los beneficios y minimizar los problemas, de forma que el paciente obtenga el máximo beneficio durante un periodo largo de tiempo. 
De este modo, las intervenciones para registrar y ajustar los tratamientos son elementos fundamentales de un trabajo clínico eficaz.

\subsubsection{INTEVENCIONES PARA ENSENAR HABILIDADES DE MANEJO A PACIENTES CON TDAH SUS FAMILIAS Y PROFESORES}

Otro aspecto importante que debe cubrirse con las intervenciones psicosociales tiene que ver con las habilidades de manejo de la situación. Con frecuencia, cuando los padres llegan a consulta, su capacidad para ayudar y controlar el comportamiento de los niños con TDAH ya se ha visto desbordada. En esos casos hay que evaluar las dificultades e identificar los factores del niño, el funcionamiento del hogar y el ambiente natural que contribuyen a provocar y mantener los problemas. Puede ser muy útil enseñar a los padres los principios básicos de la modificación de conducta, que les ayudarán a no reforzar involuntariamente las conductas difíciles de su hijo que están intentando cambiar y a desarrollar interacciones más coherentes y eficaces, reduciendo conflictos innecesarios y potenciando conductas adecuadas.

El modelo más utilizado en nuestro medio es el de Barkley (1998), que desarrolló un enfoque sistemático para enseñar habilidades de intervención a padres de menores con TDAH y problemas de conducta agresiva y negativista.

La eficacia de la enseñanza de habilidades a los padres ha sido contrastada por diversas investigaciones. Kazdin (1997) evaluó pruebas, evolución y resultados de diversos procedimientos de formación para padres. Encontró que las técnicas de intervención conductual pueden ser muy útiles para tratar eficazmente las conductas problemáticas de los niños con TDAH, aunque con diferencias de eficacia según la edad de los niños. Otros autores han corroborado este resultado: la eficacia de la enseñanza a padres de habilidades de modificación de conducta es mayor en niños de corta edad y disminuye significativamente 
con adolescentes. Para este grupo de edad parece ser más eficaz formar en los padres habilidades de negociación (Dishion y Patterson, 1991; Robin, 1998; Ruma y cols., 1996).

La formación de los padres debe evitar modelos simplistas. Es necesario recurrir a modelos sistematizados en programas de eficacia demostrada. Tal como señalan Patterson y Chamberlain (1994) existen bastantes formas de resistencia al cambio que pueden impedir a los padres utilizar las nuevas habilidades educativas que han aprendido. La ignorancia de las técnicas eficaces no es el único factor que provoca que los padres dejen de ser eficaces al tratar la conducta de su hijo. Según Kazdin y Kagan (1994) la disfunción en el funcionamiento de los padres, individual y familiar, a menudo forma parte de un grupo más amplio de factores psicológicos y sociales que favorecen globalmente la resistencia al cambio. Si no se tiene en cuenta esta dificultad, y se aborda específicamente en la estructura del programa, es posible que las intervenciones sólo obtengan beneficios transitorios. Pelham y Washbrush (2000) describieron un enfoque exhaustivo que integra múltiples intervenciones conductuales para el trastorno, incluyendo educación de los padres e intervenciones directas con el niño a lo largo de dos o más años, así como procedimientos para la prevención de recaídas y sesiones de mantenimiento.

En un programa terapéutico completo, la formación de los padres puede incluir sesiones de grupo semanales dirigidas por el terapeuta, destinadas a tratar conductas problemáticas de los niños y problemas conductuales y emocionales de los padres u otros familiares. Las intervenciones escolares pueden incluir consultas regulares entre el profesor de clase y un clínico experimentado en técnicas terapéuticas conductuales, centradas en las dificultades académicas y de interacción con los compañeros. En estas intervenciones se utilizan registros diarios, contratos conductuales y tutorías extraescolares. 
Los programas de entrenamiento de habilidades de niños, padres y docentes pueden ser un componente importante de los tratamientos del TDAH. Su eficacia, sin embargo, se ve limitada por la necesidad de personal cualificado y otros recursos que no siempre están disponibles. Por otra parte, los estudios sobre la eficacia de las distintas modalidades terapéuticas en TDAH sugieren que los tratamientos conductuales son más eficaces cuando se combinan con un tratamiento farmacológico (MTA, 1999)

\subsubsection{INTERVENCIONES PSICOTERAPÉUTICAS}

La psicoterapia tradicional no es útil para tratar los síntomas del TDAH, pero puede ser necesaria para abordar problemas comórbidos, como trastornos de estado de ánimo, dificultades puntuales de estrés individual o familiar, o aspectos más generales, como la mejora de la autonomía, la capacidad para autoevaluarse correctamente y la autoestima. En la actualidad, las técnicas psicoterapéuticas más utilizadas son las cognitivo-conductuales.

Los tratamientos cognitivo-conductuales dirigidos a mejorar la autonomía se centran en la regulación del comportamiento, el autocontrol, la adaptación a las normas, los hábitos de vida, la autoevaluación y autocorrección (Orjales, 1998). Combinan técnicas de modificación de conducta, como el refuerzo, los programas de economía de fichas, la extinción, el costo de respuesta y el tiempo fuera, apoyo y reestructuración cognitiva (Douglas y Parry, 1983; Douglas y cols. 2001; Orjales, 1998).

Uno de los objetivos centrales de las intervenciones cognitivo conductuales es enseñar al niño a autoevaluar su propia conducta, tanto si es negativa como si es positiva. Orjales (1998) propone dos líneas de trabajo, centradas respectivamente en la autoevaluación general del comportamiento y la autoevaluación específica de las tareas realizadas en cada sesión. Con la autoevaluación general del comportamiento se busca que el niño tome conciencia de 
los puntos fuertes y débiles de su comportamiento y desarrolle progresivamente soluciones. Se realiza a lo largo de las sucesivas consultas, analizando los progresos de listas de conductas propuestas por el niño y el terapeuta y las soluciones a las dificultades observadas.

La autoevaluación específica y objetiva de las tareas realizadas durante la sesión tiene como objetivo que el niño ajuste sus expectativas a su rendimiento real. Para ello, al final de cada sesión el niño y el terapeuta valoran conjuntamente su ejecución en las diferentes actividades realizadas. Esto proporciona al niño un modelo reflexivo de análisis. Este tratamiento está indicado para niños mayores con buena capacidad cognitiva y una autoestima no deteriorada. En niños con baja autoestima dañada o en edades más pequeñas esta autoevaluación puede resultar conflictiva (Orjales, 1998).

\subsubsection{INTERVENCIONES EN EL MEDIO ESCOLAR}

Un gran número de casos de TDAH se detectan en el mundo escolar. El contexto de la clase se asemeja en cierto sentido a una prueba neuropsicológica, ya que los alumnos deben mantener la atención de forma sostenida, se requiere constancia y organización, autocontrol de los impulsos y permanecer un tiempo determinado quieto. Por este motivo el profesor está en una posición privilegiada para observar los síntomas del trastorno e informar a los padres de la necesidad de una evaluación especializada. El conocimiento del trastorno por el profesor puede ayudar de modo decisivo a la detección e intervención precoz del trastorno y, de este modo prevenir la aparición de complicaciones (Ramos-Quiroga y cols., 2006).

Además de su importancia como ámbito de detección, la actividad y situación escolar pueden jugar un papel decisivo en la evolución de los niños con TDAH. Por una parte, la actividad escolar, con su estructura planificada y recurrente, ayuda a la maduración y 
desarrollo de las funciones cognitivas. Es importante que el profesor ayude al niño con TDAH a organizar y ordenar su trabajo, debe creer en sus posibilidades y organizar un ambiente estructurado y con rutinas que le ayuden a conseguir los objetivos académicos. Si el ritmo, contenidos, nivel de exigencia y procedimientos de evaluación se adaptan a las posibilidades del niño con TDAH, pueden contribuir eficazmente a su desarrollo.

Por otra parte, el mundo escolar es el escenario inicial de la socialización, un factor esencial en la adquisición por el niño de modelos de comportamiento y resolución de problemas, así como desarrollo emocional. Si la relación del niño con TDAH con sus compañeros avanza positivamente pueden prevenirse gran número de dificultades. Por estos motivos, la observación del niño y sus dificultades, las adaptaciones e intervenciones de apoyo en el mundo escolar deben formar parte de los programas de rehabilitación de niños con TDAH.

\subsection{RESUMEN}

Resumiendo esta sección, el desarrollo de un programa terapéutico exige un proceso de control contínuo de la situación y revisiones periódicas de las necesidades. Jensen y Abikoff (2003) exponen los múltiples factores que deben considerarse al adaptar los planes terapéuticos a sujetos concretos y sus familias. El principal problema es determinar en cada momento qué intervención psicosocial será necesaria para desarrollar un tratamiento eficaz para sujetos con el trastorno y sus familias. Cuando se utilizan las intervenciones psicosociales apropiadas, se fomentan expectativas realistas en el paciente y sus familiares, decisivas para mantener el trabajo difícil y a menudo frustrante necesario para modificar los efectos destructivos del trastorno y sus complicaciones. 
CAPÍTULO 10. DISEÑO DE LA INVESTIGACIÓN 
Utilidad de la cartografía cerebral en el diagnóstico del TDAH 


\section{INTRODUCCIÓN}

Como hemos ido viendo a lo largo de la parte teórica, El TDAH es un trastorno de inicio en la infancia, caracterizado por un patrón persistente de conductas de desatención, hiperactividad e impulsividad, más frecuentes e intensas de lo que sería esperable para la edad y el nivel de desarrollo de la persona. Estas conductas interfieren de forma significativa en el rendimiento escolar o laboral y actividades cotidianas. Se diferencian subtipos, definidos por la sintomatología predominante: con predominio de déficit de atención, con predominio de hiperactividad e impulsividad y el combinado. Su prevalencia se estima entre el 3 y el $7 \%$ de la edad escolar.

A medio y largo plazo, se asocia en el DSM-IV-TR a fracaso escolar, problemas de comportamiento y dificultades en las relaciones sociales y familiares. (APA, 2001) y, es importante señalar que el Ministerio de Sanidad y Política Social (2009) considera que las conductas que caracterizan el TDAH son la expresión de disfunciones de estructuras cerebrales.

Por sus consecuencias potenciales y elevada prevalencia, el TDAH se ha convertido en un problema de salud pública de primera magnitud. Por una parte, la preocupación social de las familias se traduce en una elevada presión asistencial, siendo el primer motivo de consulta en los servicios de Salud Mental Infanto-Juvenil (Ministerio de Sanidad y Política Social, 2009). Los datos de esta Unidad en Burgos indican que las solicitudes de valoraciones de posibles TDAH, durante el año 2011, superaron el 65\% del total de solicitudes de consulta (Laez y cols., 2011), motivo por el cual las administraciones sanitarias se han visto obligadas 
a situar el TDAH entre sus prioridades de actuación en el campo de la salud mental infantojuvenil. Esta situación se concretó en nuestra comunidad con la puesta en marcha, a lo largo de 2011, del Protocolo de coordinación del trastorno por déficit de atención e hiperactividad de la Gerencia Regional de Salud (Láez y cols. 2011).

Hemos intentado describir el marco conceptual que sustenta lo que actualmente el mundo científico conoce en el corpus que nos ocupa. Toda la información presentada justifica la necesidad de estudiar e investigar más ampliamente, algunas de las características que están presentes en las personas afectadas por el trastorno TDAH.

Siendo éste un trastorno que cada vez está cobrando más importancia psicológica y social, por su amplia afectación y por los datos epidemiológicos que aumentan continuamente debido, entre otros factores, a la dimensionalidad de los criterios de los sistemas de clasificación y diagnóstico, estudios al respecto, se consideran muy necesarios.

Independientemente de los resultados que obtengamos, los estudios que como este, tengan la intención de clarificar y especificar o determinar características los consideramos de vital importancia para comprender mejor la problemática que estos afectados presentan. También somos conscientes que en este ámbito se están llevando a cabo numerosos estudios, pero no hemos encontrado estudios similares a este en los trabajos revisados hasta el momento, y su importancia como decimos es grande, al centrarse en la posibilidades de una mejor evaluación y de un diagnóstico más preciso, pues como es bien sabido un buen diagnóstico es previo y facilita las intervenciones el tratamiento y los apoyos que se han de prestar a los afectados.

En el ámbito clínico en el que nos desenvolvemos, nos parece relevante comprobar si existe alguna asociación entre los resultados que puede aportar la cartografía cerebral en la evaluación y diagnóstico de las personas afectadas con TDAH. 


\subsection{PLANTEAMIENTO DEL PROBLEMA}

Un problema no resuelto en la atención al TDAH es el procedimiento diagnóstico. No hay un marcador biológico específico que permita su diagnóstico mediante pruebas médicas (Ministerio de Sanidad y Política Social, 2009). El diagnóstico se realiza a partir de la información obtenida de los familiares durante la realización de la historia clínica, informes del personal educativo $\mathrm{y}$, como valoraciones complementarias, diversas pruebas psicométricas (SACyL, 2011). La gran subjetividad de esta forma de proceder queda patente en la desproporcionada disparidad de resultados de los estudios sobre cifras de prevalencia. Limitándonos a trabajos realizados en nuestro medio, los datos disponibles oscilan entre el 1\% (Farré y Narbona, 1989) y el 14,4\% de la población (Gómez-Beneyto et al., 1994). Un problema adicional es que no se exploran las disfunciones cerebrales que se postulan como etiología del trastorno. Incorporar estudios de la actividad cerebral en los procedimientos de valoración, podría suponer un avance importante.

La cartografía cerebral, (EEGq), es una técnica de representación y análisis de registros de la actividad eléctrica generada por las estructuras cerebrales. Esta señal es transformada en un valor numérico mediante el análisis espectral, de modo que la actividad neuronal queda representada mediante mapas topográficos cerebrales (Brain mapping), que representan la cantidad de actividad de un determinado rango de frecuencia o de amplitud. A pesar de ser una extensión del EEG utilizado rutinariamente en la práctica clínica, la EEGq ha permanecido confinada al ámbito de la investigación Tejeiro (2005). Quizás esta situación explique que en la actualidad aún no se haya desarrollado todo su potencial como herramienta diagnóstica. De hecho, la cartografía puede poner de manifiesto cambios funcionales sobre el patrón normal y es útil para valorar la evolución a lo largo del tiempo (Cabanyes, 1999).

Aplicada sistemáticamente y, si se constata su idoneidad, podría ser una importante contribución diagnóstica, ayudaría a desarrollar una imagen de la enfermedad relacionada con 
las disfunciones cerebrales subyacentes al trastorno, y serviría para diseñar programas de seguimiento y evaluación objetivos de la eficacia de los tratamientos.

La utilidad de la EEGq en la exploración del TDAH se ve avalada por la recomendación de la Academia Americana de Neurología y la Sociedad Americana de Neurofisiología clínica (Nuwer, 1997). La Academia en su revisión, considera que su ratio de calidad de evidencia es de clase II (evidencia proporcionada por uno o más estudios clínicos bien diseñados, como son los estudios de casos y controles o cohortes) y su ratio de recomendación es de tipo B, el segundo nivel de fuerza de recomendación (Nuwer, 1997).

A las consideraciones de orden teórico se añaden otras prácticas. En primer lugar, el estudio de la EEGq rentabiliza un recurso ya existente. Los hospitales de la red sanitaria pública disponen de servicios de neurofisiología que realizan rutinariamente estudios EEG y EEGq.

1. Se trata de una técnica de bajo coste.

1. Es una técnica no invasiva.

2. Proporciona información útil para las historias clínicas.

En la actualidad, se dispone de una considerable bibliografía sobre valoración neurofisiológica del TDAH. Las investigaciones han sacado a la luz varios patrones bioeléctricos característicos o perfiles de anomalías corticales que podrían servir para caracterizar diferentes subtipos del trastorno (Barry y cols., 2003; Chabot y Serfontein, 1996; Clarke, Barry y cols., 1998, 2001, 2002; Mann, 1992 o Monastra 1999, 2001). En este aspecto, nuestro trabajo mantiene y continúa una línea de investigación sólidamente establecida.

Nuestra principal aportación, además, tiene una característica que en nuestro entorno es demandada por muchos de los profesionales, está es la utilización de datos procedentes de nuestro medio sanitario. Los trabajos realizados citados a lo largo de esta tesis, fueron 
realizados también en medios sanitarios pero en otros países. Con frecuencia, sus resultados son poco aplicables en nuestro medio por diferencias de organización de la atención a estas psicopatologías y por medios disponibles.

\subsection{OBJETIVOS}

En la presente investigación nos proponemos investigar la utilidad de la técnica EEGq para el estudio y diagnóstico del TDAH.

Se proponen por tanto, dos objetivos:

Objetivo general: nos proponemos investigar la utilidad del EEGq para el estudio y diagnóstico del TDAH. Conocer si la EEGq tiene valor y sirve de ayuda como técnica en el diagnóstico de las personas afectadas por TDAH.

Objetivos secundarios: en particular, estamos interesados en valorar la capacidad del EEGq para diferenciar o discriminar personas afectadas con TDAH de sujetos controles sin diagnóstico,

En valorar la capacidad del EEGq para diferenciar o discriminar personas afectadas con TDAH con personas con otro tipo de diagnósticos psicopatológico y,

En comprobar si es útil el EEGq para diferenciar entre los diferentes tipos de TDAH.

\subsection{HIPÓTESIS}

Puesto que nuestro objetivo de investigación pretende demostrar la relevancia de diagnóstico descriptivo que tiene la EEGq con respecto al TDAH, nuestras hipótesis de trabajo, son las siguientes: 
1) La cartografía cerebral discriminará entre el grupo control (sin diagnóstico) versus el grupo con diagnóstico psicopatológico. Estos últimos presentarán un mayor riesgo de alteraciones.

2) La cartografía cerebral discriminará entre el grupo diagnosticado con TDAHT vs el de grupo sin diagnóstico Estos últimos presentarán un menor riesgo de alteraciones.

3) La cartografía cerebral discriminará entre el grupo diagnosticado con TDAHT vs el grupo otros diagnósticos psicopatológicos. Estos últimos presentarán un menor riesgo de alteraciones.

3) La cartografía cerebral discriminará entre los diferentes subtipos de TDAH.

\subsection{METODOLOGÍA}

Este trabajo de investigación responde a un diseño prospectivo, recogiéndose los datos primarios obtenidos de la planificación y del propósito de la investigación a medida que ocurren.

\subsubsection{PROCEDIMIENTO}

Cada participante se valora de modo individual e independiente en dos servicios, el de Neurofisiología y el Servicio de Psiquiatría Infanto-Juvenil, ambos del Complejo Hospitalario de Burgos. Los profesionales que valoran a los niños son psicólogos clínicos y psiquiatras especializados en atención a la población infanto-juvenil. Se incluyeron en la muestra los niños valorados durante 9 meses consecutivos. Las valoraciones neurofisiológicas fueron realizadas en el Servicio correspondiente sin conocimiento del 
diagnóstico establecido en la Unidad de Salud Mental y antes del inicio de cualquier tipo de tratamiento conductual o farmacológico.

\subsubsection{MUESTRA}

Para llegar a este contraste de hipótesis, se trabaja con una muestra incidental de 170 niños, todos ellos remitidos al Servicio de Psiquiatría Infanto-Juvenil desde los servicios de Atención Primaria de la red asistencial del SACyL en Burgos.

57 de ellos son diagnosticados de TDAH en sus variables tipológicas: TDAH (predominio inatento), TDAH (predominio hiperactivo) y TDAH (combinado).

31 sujetos tras su paso por el Servicio Infanto Juvenil fueron dados de alta sin siganóstico y,

82 recibieron un diagnóstico diferente al TDAH, lo que denominamos otras patologías,

Para estableer el diagnóstico se siguieron las directrices de los sistemas de clasificación DSM-IV-TR y CIE-10. Todos los participantes de la muestra tienen también recogidos los resultados de su EEGq realizadas por el servicio de Neurofisiología clínica del Complejo Hospitalario de Burgos.

La muestra está conformada por 129 niños y 41 niñas, con un rango de 4 a 17 años (edad media: 9,27 años), remitidos entre Junio de 2012 y Marzo de 2013 a la Unidad de Salud Mental-Infanto Juvenil de Burgos desde los servicios de atención primaria para su estudio psicopatológico.

Con los niños y jóvenes que participan se forman tres grupos que conforman las muestras: 
Tabla 11. Muestras del estudio.

\begin{tabular}{lll}
\hline Muestra 1 & Grupo TDAHT & $\mathbf{N}=\mathbf{5 7}$ \\
& TDAH-Combinado & $\mathrm{N}=34$ \\
& TDAH-Déficit de Atención & $\mathrm{N}=15$ \\
& TDAH- Impulsivo-Hiperactivo & $\mathrm{N}=3$ \\
& TDAH-Sin especificar & $\mathrm{N}=5$ \\
\hline Muestra 2 & Grupo OTRAS PATOLOGÍAS & $\mathbf{N}=\mathbf{8 2}$ \\
\hline Muestra 3 & Grupo SIN DIAGNÓSTICO (CONTROL) & $\mathbf{N}=\mathbf{3 1}$ \\
\hline TOTAL & & $\mathbf{N}=\mathbf{1 7 0}$
\end{tabular}

\subsubsection{SELECCIÓN Y CONTROL DE VARIABLES}

El Trastorno TDAH, se categoriza conforme al Sistema de Clasificación DSM-IV-TR (APA, 2001) o CIE-10 (OMS, 2002) y presenta las siguiente tipologías:

1 TDAH-Combinado

2 TDAH-Déficit Atención

3 TDAH-Impulsivo-Hiperactivo

4 TDAH-sin específicar

De igual manera y acorde con los anteriores sistemas de clasificación, el grupo de participantes incluido en Otras Patologías presenta alguno de los siguientes trastornos:

5 - Inteligencia Límite

6 - Trastorno de Conducta

7 - Trastorno de Ansiedad

8 - Depresión

9 - Trastorno de Lecto-escritura ó lectura

10-Enuresis

11-Trastorno del Desarrollo Coordinación

12-Trastorno Reactivo de la Vinculación 
13-Trastorno de la Conducta Alimentaria

14-Trastornos de Estrés/T. Adaptativo

15-Discapacidad Intelectual

16- Trastorno Expresivo del Lenguaje Expresivo, Lectura y Disfemia

17-Tics

18-Epilepsia

19- Trastorno de Personalidad

20-Diagnóstico Aplazado

21-Negligencia/Trastorno.Reactivo de la Vinculación

22- Trastorno Generalizado del Desarrollo

23-Terrores Nocturnos y,

24-Síndrome de Coffin-Noonan

En lo relativo a la Cartografía Cerebral las categorías estudiadas y sus códigos son los siguientes:

$0 \quad$ Normal

$1 \quad$ Enlentecimiento (sin especificar)

2 Enlentecimiento Frontal Derecho

3 Enlentecimiento Frontal Izquierdo

$4 \quad$ Enlentecimiento Bi Frontal

$5 \quad$ Enlentecimiento Prefrontal

6 Enlentecimiento-Otro

La variable género se concreta, como es obvio, en masculino y femenino. 
En cuanto a las variables contaminantes de este estudio, hemos considerado la posibilidad de que la muestra que es diagnosticada con "otras patologías psicopatológicas" al ser un conglomerado de diagnósticos particulares, alguno/s de ellos, por sus propias sintomatologías y características, tengan una posibilidad mayor de presentar EEGq con alteración y, en este caso, las diferencias que podamos encontrar con los TDAH al respecto se vean minimizadas. Puesto que esta variable nos ha sido imposible de controlar, al ser la muestra incidental, tendremos en cuenta esta posibilidad a la hora de interpretar los resultados que obtengamos.

\subsubsection{DESCRIPCIÓN DE LOS INSTRUMENTOS NEUROFISIO-LÓGICOS}

El trabajo de investigación realizado requiere el uso de determinados registros neurofisiológicos para obtener las EEGqs. Las características y especificidad de los que se utilizan se detallan a continuación:

El electroencefalograma (EEG) en reposo y ojos cerrados se ha realizado con un aparato de 18 canales (17 para EEG según el sistema 10/20; y 1 para EKO), acoplado a un programa de análisis digital de la señal analógica del EEG. Cada segmento elegido para el análisis comprende una longitud de al menos 4 segundos libres de artefactos. El espectro de frecuencias se clasificó según las bandas delta, theta, alía y beta.

La cartografía cerebral (EEGq) es una representación gráfica del EEG y da imágenes de las cuatro bandas de frecuencia. Se ha realizado en un aparato Track Walker. 5.0 obteniendo el análisis cuantitativo de la actividad eléctrica. Los métodos usados están basados en el análisis espectral del EEG usando la transformada rápida de Fourier (FFT). Produce varios parámetros numéricos de salida. Estos resultados son almacenados en diferentes modelos que pueden mostrarse e interpretarse con este programa informático. 
Los modelos calculados para el análisis EEG cuantitativo son:

1. CROSS: Este modelo localiza frecuencias donde aparece actividad eléctrica anormal así como su distribución espacial.

2. Broad band model: permite analizar el espectro del EEG y sus frecuencias. Permite seleccionar el número y los límites de rango de frecuencia por cada banda.

3. BBSP: Incluye poder absoluto, poder relativo y medidas de frecuencia media.

Se han hallado puntuaciones Z de los datos obtenidos en la EEGq comparándolos con la base de datos disponible en el programa y con un rango de edades desde los 5- 90 años.

Los EEG y Las EEGq se han clasificado según el ritmo dominante en:

1.- Normal: Cuando se registra en situación de reposo, aunque alerta, y es posible observar una variedad de ondas y ritmos que tienen unas características peculiares e identificatorias dentro de criterios de normalidad. Las ondas EEG se clasifican de acuerdo a su: 1) frecuencia (número de veces que una onda se repite en un segundo) en cuatro bandas: alfa, beta, theta y delta; 2) amplitud: determinada por la mediación y comparación de la distancia entre la línea base y el pico de onda expresada en $\mathrm{mV}$.

2.- Lentificación frontal derecha: Se define como la presencia de actividad de onda lenta (actividad theta 7-4 Hz) en zona anterior (frontal) derecha

3,- Lentificación frontal izquierda: Se define como la presencia de actividad de onda lenta (actividad theta 7-4 Hz) en zona anterior (frontal) izquierda

4.- Lentificación bifrontal: presencia de actividad de onda lenta (actividad Theta 4-7 $\mathrm{Hz}$ ) en zona frontal en los dos hemisferios cerebrales.

5.- Actividad irritativa focal o generalizada: presencia de actividad epileptiforme localizada o generalizada. 
6.- Otras alteraciones: Registro de actividad de ondas en el EEG que se desvían de lo normal y no se engloban en ninguna de las alteraciones propuestas.

\subsubsection{RECOGIDA Y ANÁLISIS DE DATOS}

Los datos que se necesitan de los participantes se incluyen en la base de datos del procesador estadístico IBM Stadistics SPSS, 20, directamente de los protocolos de recogida de resultados preparados para esta investigación y, además, se incluyen en los expedientes individuales de los participantes.

Necesitamos saber las características de nuestras muestras, por lo que es necesario estudiar, primeramente, un estudio de las particularidades de los participantes. Para ello usamos estadísticos descriptivos de frecuencias y porcentajes. A su vez, para intentar comprobar la relación entre variables, se puede utilizar el análisis de correlación de Pearson, el Chi Cuadrado o similares, la estimación de riesgo y la técnica de regresión logística, Estas últimas tienen por objeto cuantificar cómo influye en la probabilidad de aparición de un suceso la presencia o no de diversas variables así, como el valor o nivel de las mismas. 
Capítulo 11. Resultados

CAPÍTULO 11. RESULTADOS 
Utilidad de la cartografía cerebral en el diagnóstico del TDAH 


\subsection{CARACTERÍSTICAS DE LAS MUESTRAS}

La muestra está formada por 170 participantes que de forma incidental acudieron a consulta, derivados del Servicio de Atención Primaria, al Servicio Infanto-Juvenil del Complejo Hospitalario del SACyL de Burgos, durante los 9 meses que duró el estudio en el año 2012. Un porcentaje alto, el 75,9\% son de género masculino.

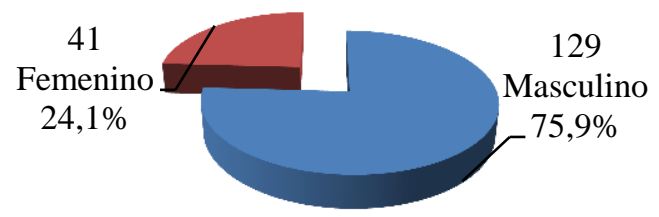

Figura 7. Características de la variable "género" de las muestras

La edad mínima es de 4 años y la máxima de 17. Obteniéndose una media de 9,22 años. Los porcentajes por edades se muestran a continuación.

Tabla 12. Frecuencias y porcentajes de la variable "edad"

\begin{tabular}{lrr} 
& \multicolumn{1}{c}{$\mathbf{N}$} & \multicolumn{1}{c}{$\%$} \\
\hline 4 & 4 & 2,4 \\
5 & 10 & 5,9 \\
6 & 16 & 9,4 \\
7 & 19 & 11,2 \\
8 & 22 & 12,9 \\
9 & 32 & 18,8 \\
10 & 18 & 10,6 \\
11 & 17 & 10,0 \\
12 & 7 & 4,1 \\
13 & 7 & 4,1 \\
14 & 8 & 4,7 \\
15 & 6 & 3,5 \\
16 & 3 & 1,8 \\
17 & 1 &, 6 \\
Total & 170 & 100,0
\end{tabular}


Al objeto de exponer más detalladamente la muestra general, hemos creado latabla 13, que nos proporciona una doble clasificación por género y por edad.

Tabla 13. Contingencia. "Edad"-"Sexo" de los participantes

\begin{tabular}{cccc} 
EDAD & \multicolumn{2}{c}{ Género } & Total \\
\hline & Masculino & Femenino & \\
\hline 4 & 4 & 0 & 4 \\
5 & 0 & 1 & 1 \\
5 & 7 & 2 & 9 \\
6 & 13 & 3 & 16 \\
7 & 11 & 8 & 19 \\
8 & 0 & 1 & 1 \\
8 & 0 & 1 & 1 \\
8 & 17 & 3 & 20 \\
9 & 26 & 6 & 32 \\
10 & 13 & 5 & 18 \\
11 & 1 & 0 & 1 \\
11 & 1 & 0 & 1 \\
11 & 12 & 3 & 15 \\
12 & 5 & 2 & 7 \\
13 & 5 & 2 & 7 \\
14 & 6 & 2 & 8 \\
15 & 5 & 1 & 6 \\
16 & 2 & 1 & 3 \\
17 & 1 & 0 & 1 \\
Total & 129 & 41 & 170
\end{tabular}

A continuación, se presentan las características de los participantes en relación a su diagnóstico. Observamos que 31, tras haber sido evaluados por el Servicio Infanto Juvenil, no han sido diagnosticados de ningún trastorno psicopatológico, 57 presentan TDAH en alguna de sus cuatro tipologías y 82 participantes han sido diagnosticados de otros trastornos mentales. La poca muestra que se dispone de los niños y jóvenes con trastorno de TDAH de tipo impulsivo-hiperactivo y sin especificar demuestra que son mucho menores los diagnósticos de este tipo que realizan los psicólogos y psiquiatras responsables de la evaluación y al estar planificado la duración de este estudio en nueve meses, el número no se ha podido ampliar. 
Tabla 14. Frecuencias y porcentajes de los "Diagnósticos 1"

\begin{tabular}{lcc} 
Diag $\mathbf{1}^{\mathbf{0}}$ & $\mathrm{N}$ & $\%$ \\
SIN TRASTORNO PSICOPATOLÓGICO & $\mathbf{3 1}$ & $\mathbf{1 8 , 2}$ \\
\hline TDAH-Combinado & 34 & 20,0 \\
TDAH-Déficit de atención & 15 & 8,8 \\
TDAH-Impulsivo-hiperactivo & 3 & 1,8 \\
TDAH-sin especificar & 5 & 2,9 \\
TOTAL TDH & $\mathbf{5 7}$ & $\mathbf{3 3 , 5}$ \\
& & \\
\hline Inteligencia límite & 12 & 7,1 \\
Trastorno de conducta & 11 & 6,5 \\
Trastorno de ansiedad & 5 & 2,9 \\
Depresión & 10 & 5,9 \\
Trastorno de lecto-escritura / lectura & 13 & 7,6 \\
Enuresis & 3 & 1,8 \\
trastorno del desarrollo de la coordinación & 1 &, 6 \\
Trastorno reactivo de la vinculación & 1 &, 6 \\
Trastorno de conducta alimentaria & 1 &, 6 \\
Trastorno de estrés / Adaptativo & 4 & 2,4 \\
Discapacidad intelectual & 1 &, 6 \\
Trastorno expresivo del lenguaje, lectura y disfemia & 4 & 2,4 \\
Tics & 2 & 1,2 \\
Epilepsia & 3 & 1,8 \\
Trastorno de la personalidad & 2 & 1,2 \\
Diagnóstico aplazado & 1 &, 6 \\
Negligencia /Trastorno reactivo de la vinculación & 3 & 1,8 \\
Trastorno del desarrollo & 1 &, 6 \\
Terrores nocturnos & 2 & 1,2 \\
Síndrome de Coffin-Noonan & 2 & 1,2 \\
TOTAL OTRO DIAGNÓSTICO & $\mathbf{8 2}$ & $\mathbf{4 8 , 2}$ \\
& & \\
\hline N TOTAL & $\mathbf{1 7 0}$ & $\mathbf{1 0 0}$
\end{tabular}

Aunque menos frecuente, hay niños y adolescentes a los que se les diagnostica un segundo diagnóstico psicopatológico, así, disponemos de 12 sujetos que tienen más de 1 diagnóstico psicopatológico, cuyas categorías aparecen a continuación: 
Tabla 15. Frecuencias y porcentajes de los "diagnósticos 2"

\begin{tabular}{lrr} 
Diag $\mathbf{2}^{\mathbf{0}}$ & $\mathbf{N}$ & \multicolumn{1}{c}{$\%$} \\
\hline Sin 2 & \multicolumn{1}{c}{ diagnóstico } & 92,9 \\
Trastorno específico de la lectura. & 1 &, 6 \\
Otros trastornos del desarrollo del aprendizaje escolar & 2 & 1,2 \\
Trastorno disocial desafiante y oposicionista. & 1 &, 6 \\
Otros trastornos de las emociones y del comportamiento & 1 &, 6 \\
en la infancia y adolescencia especificados. & 2 & 1,2 \\
Inteligencia Limite & 1 &, 6 \\
Mioclonías & 2 & 1,2 \\
Trastorno del Comportamiento & 1 &, 6 \\
Trastorno compulsivo & 1 &, 6 \\
TED-LE & &
\end{tabular}

Puesto que es aun menos usual que un mismo sujeto esté diagnosticado de un tercer trastorno psicopatológico, en nuestra muestra tan sólo hay 3 participantes que cumplen con este criterio.

Tabla 16 Frecuencias y porcentajes de los "diagnósticos 3"

\begin{tabular}{lrr} 
Diag $3^{\mathbf{0}}$ & N & \% \\
\hline Sin 3 diagnóstico & 167 & 98,2 \\
F81.8 Otros trastornos del desarrollo del aprendizaje escolar & 2 & 1,2 \\
& 1 &, 6
\end{tabular}

En cuanto a los descriptivos relacionados con los resultados de la cartografía, éstos nos indican que el 50\% de de los participantes (85), presentan normalidad en los resultados, los datos reflejan que ningún participante ha presentado enlentecimiento prefrontal, sin embargo sí hemos encontrado 21 sujetos con enlentecimiento no específico; 16 con enlentecimiento frontal derecho; 15 con enlentecimiento frontal izquierdo; 11 con enlentecimiento Bi Frontal y en 22 participantes se observó otro tipo de enlentecimiento. 
Tabla 17 Porcentajes de los resultados en la categorización de la “cartografía”, EEGq

\begin{tabular}{lrr} 
EEGq & N & \multicolumn{1}{c}{$\%$} \\
\hline Normalidad & 85 & 50,0 \\
Enlentecimiento sin especificar & 21 & 12,4 \\
Enlentecimiento frontal derecho & 16 & 9,4 \\
Enlentecimiento frontal izquierdo & 15 & 8,8 \\
Enlentecimiento Bi frontal & 11 & 6,5 \\
Enlentecimiento otro & 22 & 12,9 \\
Total & 170 & 100,0
\end{tabular}

En la tabla 18, recogemos las frecuencias encontradas según los resultados de la cartografía y en relación con las tres muestras de nuestro estudio. Como hemos comentado, ninguno de los participantes ha presentado enlentecimiento prefrontal y los TDAH están presentes en todo el resto de las posibilidades de la cartografía. Sólo 9 de los 57 afectados tienen una cartografía normalizada, el 16\%. Las más frecuentes son el enlentecimiento frontal derecho y el enlentecimiento sin especificar. También podemos observar que de tres muestras de nuestro estudio, los TDAH son los que con mayor frecuencia puntúan en las cartografías con anormalidad.

Tabla 18 Frecuencias de las tres muestras según los resultados en la "cartografía"

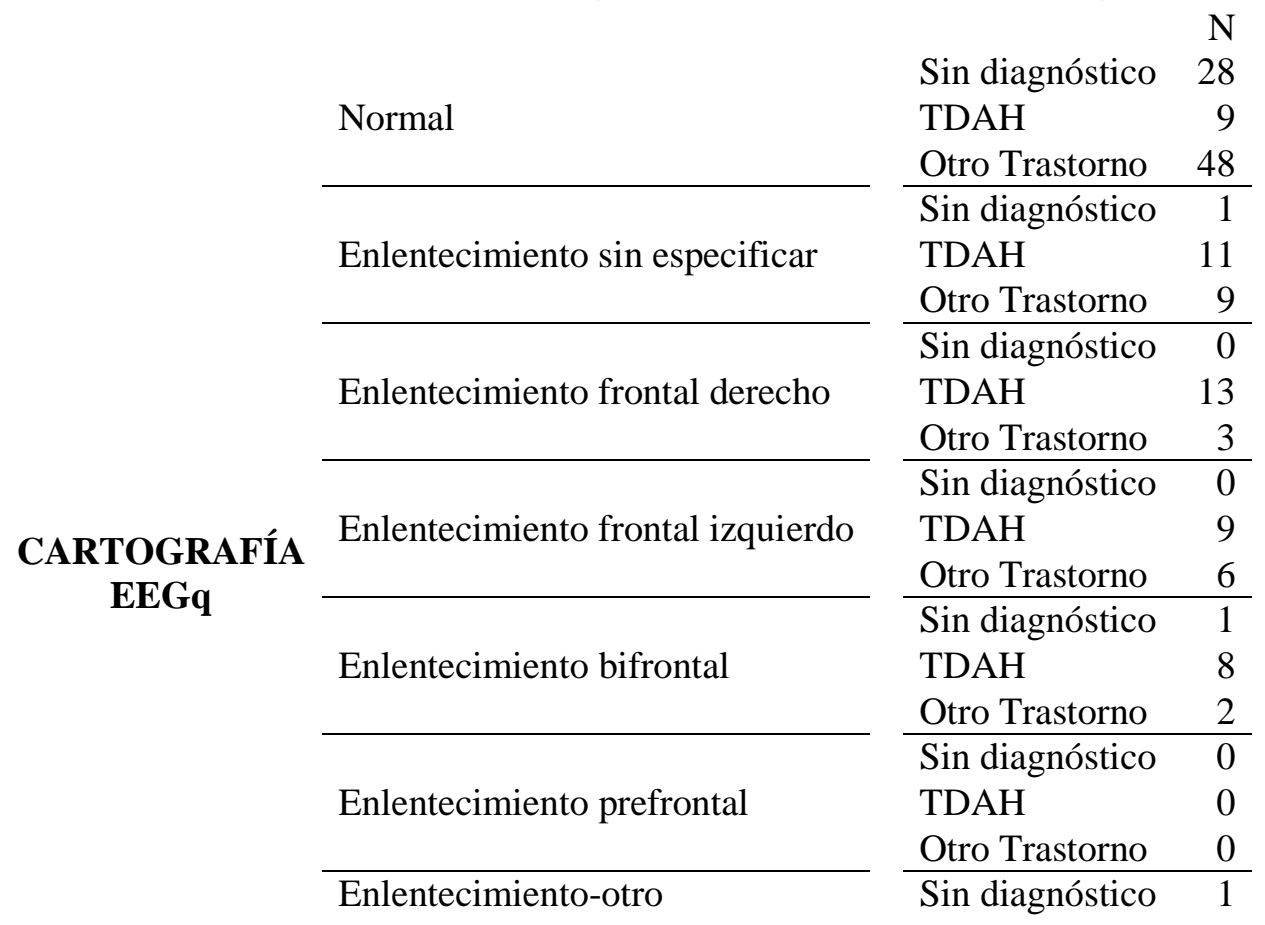


Otro Trastorno 14

Al centramos en observar por tipologías la muestra de TDAH con cartografía alterada, vemos que las personas afectadas se encuentran repartidas por el abanico de posibilidades, sin embargo se hace notar que el enlentecimiento sin especificar y el enlentecimiento frontal derecho son los más frecuentes en la muestra de niños y jóvenes diagnosticados con TDAHtipo combinado.

Tabla 19, Contingencia. "Cartografía"*”tipos de TDAH"

\section{TDAH}

\begin{tabular}{|c|c|c|c|c|c|c|}
\hline & Cartografía & $\begin{array}{c}\text { TDAH- } \\
\text { Combinado }\end{array}$ & $\begin{array}{l}\text { TDAH- } \\
\text { Déficit } \\
\text { Atención }\end{array}$ & $\begin{array}{c}\text { TDAH- } \\
\text { Impulsivo } \\
\text { Hiperactivo }\end{array}$ & $\begin{array}{c}\text { TDAH- } \\
\text { Sin } \\
\text { Especificar }\end{array}$ & $\mathbf{N}$ \\
\hline \multirow[t]{6}{*}{$\bar{a}$} & 0 Sin alteración & 4 & 3 & 1 & 1 & 9 \\
\hline & $\begin{array}{l}1 \text { Enlentecimiento } \\
\text { (sin especificar) }\end{array}$ & 8 & 1 & 1 & 1 & 11 \\
\hline & $\begin{array}{l}2 \text { Enlentecimiento } \\
\text { Frontal Derecho }\end{array}$ & 10 & 3 & 0 & 0 & 13 \\
\hline & $\begin{array}{l}3 \text { Enlentecimiento } \\
\text { Frontal Izquierdo }\end{array}$ & 4 & 4 & 0 & 1 & 9 \\
\hline & $\begin{array}{l}4 \text { Enlentecimiento } \\
\text { Bifrontal }\end{array}$ & 3 & 3 & 1 & 1 & 8 \\
\hline & $\begin{array}{l}6 \text { Enlentecimiento- } \\
\text { Otro }\end{array}$ & 5 & 1 & 0 & 1 & 7 \\
\hline \multicolumn{2}{|c|}{ Total } & 34 & 15 & 3 & 5 & 57 \\
\hline
\end{tabular}

A continuación presentamos una tabla de contingencias que describe la relación de los dos valores de la variable resultados de la cartografía (con y sin alteración) y los valores de la variable diagnóstico. Puesto que nos interesa centrarnos en los trastornos TDAH, hemos desglosado los tres tipos diferentes de clasificación del trastorno y englobado la muestra que no recibe ningún diagnostico por los evaluadores así como la que contiene otros trastornos psicopatológicos, en una sola categoría que denominamos “otras psicopatologías”. 
Tabla 20 Contingencia. “cartografía"*”subtipos de TDAH”, “otras psicopatologías" y "sin diagnóstico".

\begin{tabular}{|c|c|c|c|}
\hline & \multicolumn{2}{|c|}{ Alteración EEGq } & \multirow[b]{2}{*}{ Total } \\
\hline & Con Alteración & Sin Alteración & \\
\hline Sin Diagnóstico & 3 & 28 & 31 \\
\hline TDAH-Combinado & 30 & 4 & 34 \\
\hline TDAH-Déficit Atención & 12 & 3 & 15 \\
\hline TDAH-Impulsivo Hiperactivo & 2 & 1 & 3 \\
\hline TDAH- Sin Especificar & 4 & 1 & 5 \\
\hline Otras Psicopatologías & 34 & 48 & 82 \\
\hline Total & 85 & 85 & 170 \\
\hline
\end{tabular}

Para valorar la posible asociación de estas variables y, si es así, ver si son significativos los valores encontrados entre los diferentes subtipos de la variable diagnóstico y la cartografía llevamos a cabo la prueba del Chi Cuadrado, que permite contrastar si las dos variables utilizadas en el estudio son o no independientes, como vemos más abajo por el valor 49,96 y por la significatividad $\leq$ a 0,05 nos podemos asumir la relación de independencia, estas dos variables, están bastante relacionadas y las pruebas nos dicen que la asociación es alta y significativa

Tabla 21 Contraste de variables. "Cartografía"*”subtipos de TDAH", "otras psicopatologías" y "sin diagnóstico".

\begin{tabular}{lrrr} 
& Valor & gl & Sig. asintótica (bilateral) \\
\hline Chi-cuadrado de Pearson & $49,967($ a) & 5 &, 000 \\
Razón de verosimilitudes & 56,218 & 5 &, 000 \\
Asociación lineal por lineal & 44,852 & 1 &, 000 \\
N de casos válidos & 170 & &
\end{tabular}

La tabla siguiente se ha realizado sólo con las diferentes tipologías de TDAH al objeto de ver si cumplían relaciones entre sí. Observamos que más del $80 \%$ de los niños y jóvenes 
diagnosticados con este trastorno de los tipos combinado y de atención presentan una cartografía alterada.

En cuanto a los tipos impulsivo-hiperactivo y sin especificar, somos conscientes que al ser tan pocos casos no podemos sacar conclusiones fácilmente, pero con los que se poseen, y siendo esto una limitación, podemos decir que se sigue manteniendo dicho porcentaje en los de tipo sin especificar $y$, del $66 \%$ en los impulsivos-hiperactivos. Para facilitar su visualización, presentamos su representación gráfica

Tabla 22. Contingencia. "Tipos de TDAH”*”cartografía"

\begin{tabular}{lccrr} 
& \multicolumn{4}{c}{ Alteración si/ no } \\
\hline \multicolumn{1}{c}{ TIPOS DE TDAH } & $\begin{array}{c}\text { Con } \\
\text { alteración }\end{array}$ & $\begin{array}{c}\text { Sin } \\
\text { alteración }\end{array}$ & Total \\
\hline TDAH-Combinado & 30 & 4 & 34 \\
TDAH-Déficit Atención & 12 & 3 & 15 \\
TDAH-Impulsivo Hiperactivo & 2 & 1 & 3 \\
TDAH- Sin Especificar & 4 & 1 & 5 \\
Total & & 48 & & 9
\end{tabular}

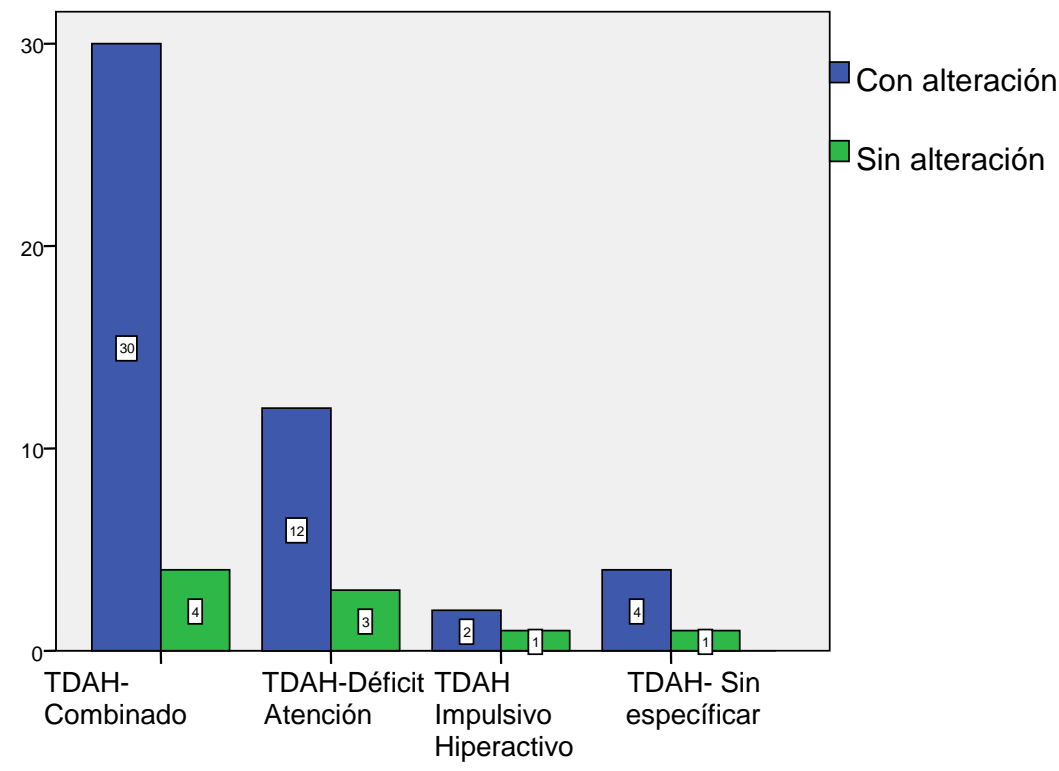

Figura 8. Grafico de barras. "Cartografía"*”tipos de TDAH" 


\subsection{COMPROBACIÓN DE LA ASOCIACIÓN Y EL RIESGO DE LAS ALTERACIONES EN LA CARTOGRAFIA EN LAS DIFERENTES MUESTRAS}

Con el fin de comprobar si las alteraciones en la EEGq están relacionadas con las diferentes muestras que hemos establecido, realizamos las pruebas de asociación, significación y estimación del riesgo.

\subsubsection{ESTUDIO DE ASOCIACIÓN DE LA ALTERACIÓN EN LA CARTOGRAFIA CON LA EXISTENCIA O NO DE DIAGNÓSTICO}

En la tabla 23 se observa que los niños y jóvenes que ha recibido algún tipo de diagnóstico presentan una frecuencia mayor de alteraciones en la cartografía que los que no han recibido diagnóstico (grupo control). Podemos observar que más de la mitad, el 58\% de los participantes afectados de trastornos mentales o psicopatológicos presentan alteración en la técnica cartográfica, mientras que tan sólo un 9,6\% de los que no han presentado ningún diagnóstico han manifestado alteración.

Tabla 23. Contingencia. "Cartografía"*”diagnóstico"

\section{Diagnóstico Psicopatológico}

\begin{tabular}{llccr} 
& & SI & NO & N \\
\hline \multirow{2}{*}{ Cartografía } & Con alteración & 82 & 3 & 85 \\
\multirow{2}{*}{ Total } & Sin alteración & 57 & 28 & 85 \\
& & 139 & 31 & 170
\end{tabular}




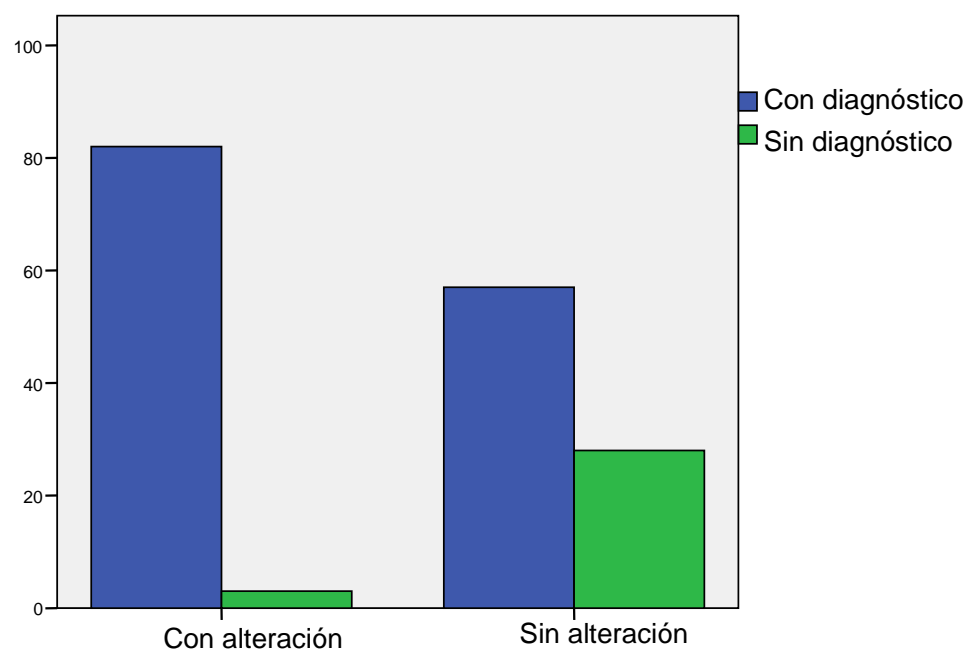

Figura 9. Gráfico de barras." cartografía"*”diagnóstico"

Para ver si dos variables se encuentran relacionadas debemos utilizar una medida de asociación, Para ello realizamos pruebas no paramétricas que nos ofrecen índices de significación. El Chi-Cuadrado, como el Estadístico Exacto de Fisher y el resto de pruebas que aparecen en la tabla 24, se pueden usar para valorar la asociación entre estas dos variables categóricas. El Chi-Cuadrado de Pearson ha resultado con un valor de asociación de 24,66 y el índice de significación $=.00$, este índice $\leq 0,05$ indica que el valor de la probabilidad de independencia es muy pequeña, mínima, por lo que podemos concluir que estas dos variables están relacionadas.

Tabla 24. Contraste de variables. "cartografía" *”diagnóstico"

Sig. Asintótica Sig. exacta Sig. Exacta

\begin{tabular}{lccccc} 
& Valor & gl & (bilateral) & (bilateral) (unilateral) \\
\hline Chi-cuadrado de Pearson & $\mathbf{2 4 , 6 5 8}$ & $\mathbf{1}$ & $\mathbf{, 0 0 0}$ & & \\
\hline Corrección por continuidad $^{\text {b }}$ & 22,725 & 1 &, 000 & & \\
\hline Razón de verosimilitudes & 27,784 & 1 &, 000 & & \\
\hline Estadístico exacto de Fisher & & & &, 000 &, 000 \\
\hline Asociación lineal por lineal & 24,513 & 1 &, 000 & & \\
\hline N de casos válidos & 170 & & & & \\
\hline
\end{tabular}


Cuando obtenemos tablas de contingencia como esta de $2 \times 2$, el procedimiento incluye la posibilidad de valorar el índice de riesgo. El riesgo es una medida del grado de asociación entre la presencia de una variable y la ocurrencia de un evento. La interpretación es sencilla, informa de ello el valor, pero, se ha de revisar que entre los límites del intervalo de confianza (IC), no se encuentren valores menores a 1. Pues en estos casos no se podría asumir esta asociación.

La primera fila indica que el riesgo estimado se refiere a la cartografía con alteración frente a la cartografía normal. Su valor (OR) es 13,427 y los IC son valores mayores de 1. Además, como vimos en la tabla 24 son significativos, están relacionados. El valor en la estimación de riesgo es de 13,42 e indica que entre los sujetos con diagnóstico psicopatológico la probabilidad (el riesgo) de encontrar alteraciones en la cartografía es 13,42 veces mayor que la de encontrar no alteración en la cartografía.

Las dos filas siguientes ofrecen dos índices de riesgo para un diseño de cohortes. Los resultados indican que por cada sujeto con diagnóstico psicopatológico, la probabilidad de encontrar una cartografía anómala es 1,44 veces mayor, que en los no diagnosticados, pues el riesgo que tienen estos es muy bajo $0,1 / 1$.

Tabla 25. Estimación de riesgo. "cartografía"*”diagnóstico".

IC Intervalo de confianza

al $95 \%$

\begin{tabular}{lrrr} 
& \multicolumn{2}{c}{ al 95\% } \\
\cline { 3 - 4 } & Valor & Superior & Inferior \\
\hline OR Razón de las ventajas para Alteración si/ no (Con & 13,427 & 3,894 & 46,292 \\
$\begin{array}{l}\text { alteración / Sin alteración ) } \\
\text { Para la cohorte sin diagnóstico y con diagnóstico }\end{array}$ & 1,439 & 1,233 & 1,679 \\
$\begin{array}{l}\text { Con diagnóstico psicopatológico } \\
\text { Para la cohorte sin diagnóstico y con diagnóstico }\end{array}$ & & & \\
$\begin{array}{l}\text { Sin diagnóstico } \\
\text { N de casos válidos }\end{array}$ & 107 &, 034 &, 339 \\
& 170 & &
\end{tabular}


Sintetizando, los dos análisis anteriores y el relativo a la estimación de riesgo nos expresan que hay asociación entre las dos variables. La probabilidad de niños y adolescentes diagnosticados de cualquier psicopatología que presentan alteración en la cartografía es mayor que en los que no han sido diagnosticados de trastornos psicopatológicos. Con una Chi-Cuadrado de valor 24,658, (p asociado $\leq 0,05$ ). La fuerza de dicha asociación, (OR), es 13,427, con un índice de confianza (IC) al 95\% adecuado, mayor de 1.

Los datos confirman la importancia del EEGq y su apacidad de discriminar entre niños y adolescentes diagnosticados de algún trastorno mental y aquellos que resultaron sin ningún diagnóstico. Queda confirmada la primera hipótesis.

Tras estos resultados, ahora interesa valorar si la cartografía cerebral discriminará entre el grupo completo diagnosticado con TDAH vs grupo control, sin diagnóstico, para ello llevamos a cabo los mismos procedimientos estadísticos y obtenemos los datos que se exponen a continuación.

\subsubsection{ESTUDIO DE ASOCIACIÓN DE LA ALTERACIÓN DE LA CARTOGRAFÍA CON LA MUESTRA COMPLETA DE TDAH}

En la tabla 26, de contingencia, observamos que sólo $9(6,9 \%)$ de los 57 niños y adolescentes con TDAHT (que engloba todos los subtipos) no presentan alteración en la cartografía cerebral computarizada. Frente a ello, encontramos una alta cifra, $28(90,3 \%)$.de los 31 que no recibieron diagnóstico (grupo control), que tampoco presentaron alteración cartográfica. Las diferencias entre ambas muestras parecen evidentes. 
Tabla 26 Contingencia. "cartografía"*TDAHT y" Sin diagnóstico"

\begin{tabular}{llrrr} 
& TDAHT & Sin diagnóstico & Total \\
\hline Alteración si/ no & Con alteración & 48 & 3 & 51 \\
& Sin alteración & 9 & 28 & 37 \\
Total & 57 & 31 & 88
\end{tabular}

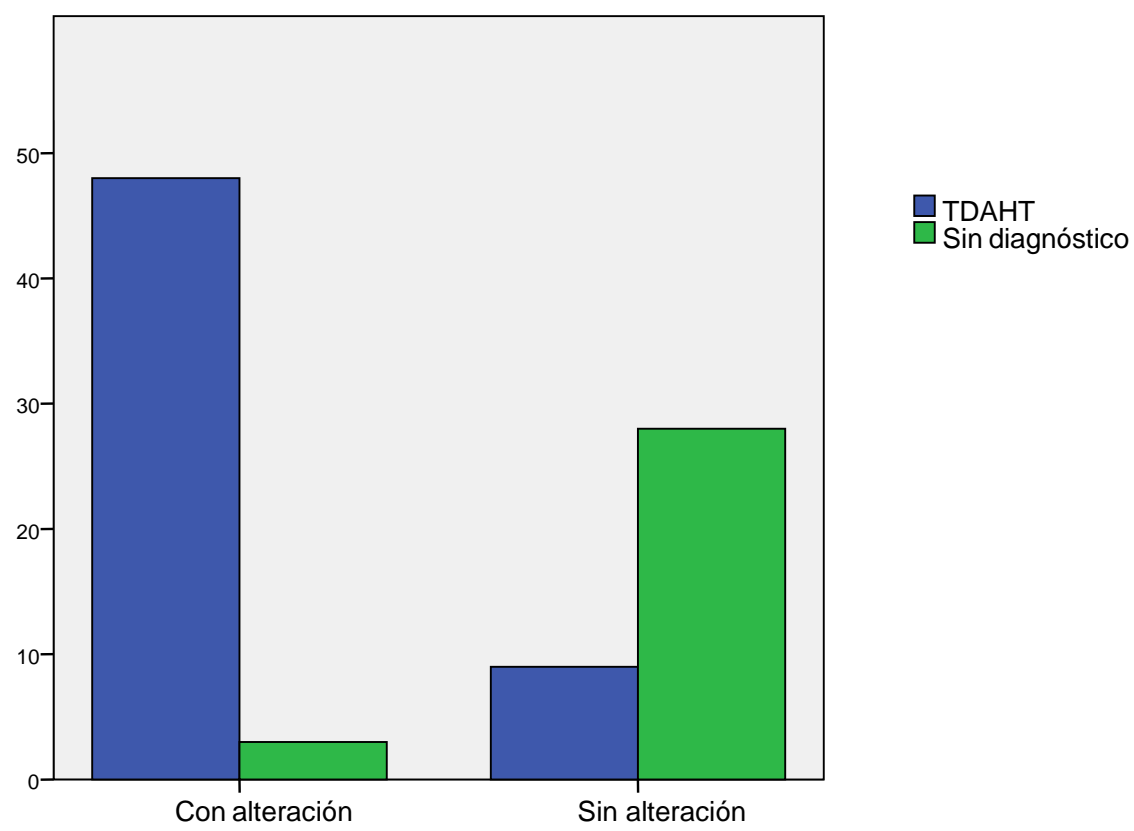

Figura 10 "cartografía” si/ no * TDAHT y" Sin diagnóstico".

Interesa saber, de nuevo si hay relación entre las variables TDAH y cartografía, por ello llevamos a cabo las pruebas de Chi-Cuadrado y la estimación de riesgo. Los datos que aparecen en la tabla 27 indican una alto valor asociativo 45,77 y significativo. 
Tabla 27 Contraste de variables. "cartografía”*TDAHT y" Sin diagnóstico"

\begin{tabular}{|c|c|c|c|c|c|}
\hline & Valor & gl & $\begin{array}{c}\text { Sig. asintótica } \\
\text { (bilateral) }\end{array}$ & $\begin{array}{c}\text { Sig. exacta } \\
\text { (bilateral) }\end{array}$ & $\begin{array}{c}\text { Sig. exacta } \\
\text { (unilateral) }\end{array}$ \\
\hline $\begin{array}{l}\text { Chi-cuadrado de } \\
\text { Pearson }\end{array}$ & $45,777(b)$ & 1 & ,000 & & \\
\hline $\begin{array}{l}\text { Corrección por } \\
\text { continuidad(a) }\end{array}$ & 42,769 & 1 & ,000 & & \\
\hline $\begin{array}{l}\text { Razón de } \\
\text { verosimilitudes }\end{array}$ & 50,323 & 1 & ,000 & & \\
\hline $\begin{array}{l}\text { Estadístico exacto de } \\
\text { Fisher }\end{array}$ & & & &, 000 &, 000 \\
\hline $\begin{array}{l}\text { Asociación lineal por } \\
\text { lineal }\end{array}$ & 45,257 & 1 & ,000 & & \\
\hline $\mathrm{N}$ de casos válidos & 88 & & & & \\
\hline
\end{tabular}

El riesgo estimado lo podemos ver en la tabla 28. De nuevo, los datos se refieren a la cartografía con alteración frente a la cartografía normal. Su valor (OR) es 49,77 y entre los valores IC no está incluido el valor 1. Indica que entre los sujetos con TDAHT estudiados la probabilidad (el riesgo) de encontrar una cartografía cerebral alterada es casi 50 veces mayor que la de encontrar no alteración en la cartografía.

Los índices de riesgo para un diseño de cohortes indican que se podría esperar que por cada sujeto con TDAHT la probabilidad de encontrar una cartografía anómala es 3,87 veces mayor, mientras que los no diagnosticados el riesgo que tienen es muy bajo 0,08/1.

Tabla 28 Estimación de riesgo. "cartografía”*TDAHT y” Sin diagnóstico"

\begin{tabular}{lccr} 
& & \multicolumn{2}{c}{ IC Intervalo de confianza al } \\
\cline { 3 - 4 } & Va) & \\
\cline { 3 - 4 } & Valor & Superior & Inferior \\
\hline $\begin{array}{l}\text { OR Razón de las ventajas para Alteración si/ } \\
\text { no }\end{array}$ & 49,778 & 12,432 & 199,307 \\
$\begin{array}{l}\text { Para la cohorte TDAH } \\
\text { y sin diagnóstico = TDAHT }\end{array}$ & 3,869 & 2,183 & \multirow{2}{*}{6,859} \\
$\begin{array}{l}\text { Para la cohorte TDAH } \\
\text { y sin diagnóstico = sin diagnóstico }\end{array}$ &, 078 &, 026 &, 237 \\
N de casos válidos & 88 & &
\end{tabular}


Los dos análisis anteriores y el relativo a la estimación expresan que hay una clara asociación entre las variables. La probabilidad de niños y adolescentes afectados de TDAHT que presentan alteración en la cartografía es bastante mayor que en los que no han recibido diagnóstico. Con una Chi-Cuadrado de valor 45,77, ( $\mathrm{p}$ asociado $\leq 0,05$ ). La fuerza de dicha asociación, (OR), es 49,77, con un índice de confianza (IC) al 95\% adecuado, que representa el riesgo que tienen los niños y jóvenes con TDAHT de presentar una cartografía con alteración.

Los datos confirman la importancia del EEGq en los niños y adolescentes diagnosticados de TDAHT pues el riesgo de tener una alteración que recoge la cartografía es muy alto.

Tras estos resultados, queremos profundizar y conocer el riesgo de las diferentes tipologías del TDAH. Comenzamos por el TDAH-Combinado, que como sabemos engloba los criterios sintomatológicos del déficit de atención y los de la impulsividad e hiperactividad.

\subsubsection{ESTUDIO DE ASOCIACIÓN DE LA ALTERACIÓN EN LA CARTOGRAFÍA CON LOS DIAGNÓSTICOS DE TDAH TIPO COMBINADO}

Observamos en el siguiente resultado la gran frecuencia que existe de niños y jóvenes afectados de este tipo de trastorno que manifiestan cartografía con alteración frente a los que no recibieron diagnóstico.

Tabla 29 Contingencia. Alteración en la "cartografía"* "TDAH-Combinado"

Diagnóstico

\begin{tabular}{ccc} 
TDAH-Combinado & Sin diagnóstico & $\mathbf{N}$ \\
\hline 30 & 33
\end{tabular}

\begin{tabular}{llccc}
\hline Alteración si/ no & Con alteración & 30 & 3 & 33 \\
& Sin alteración & 4 & 28 & 32 \\
Total & & 34 & 31 & 65
\end{tabular}




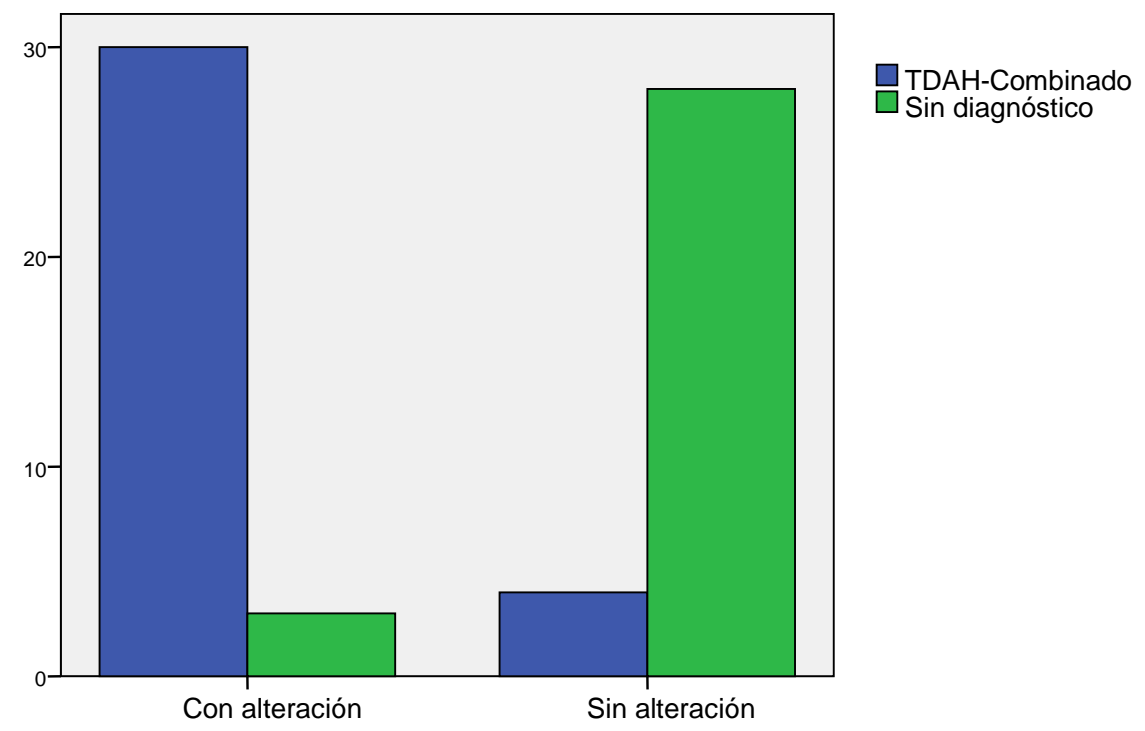

Figura 11. Chi cuadrado. Alteración en la "cartografía”* “TDAH Combinado”.

Tabla 30. Contraste de variables. Alteración en la "cartografía"* "TDAH-Combinado". ",

\begin{tabular}{|c|c|c|c|c|c|}
\hline & Valor & gl & $\begin{array}{l}\text { Sig. asintótica } \\
\text { (bilateral) }\end{array}$ & $\begin{array}{c}\text { Sig. exacta } \\
\text { (bilateral) }\end{array}$ & $\begin{array}{l}\text { Sig. exacta } \\
\text { (unilateral) }\end{array}$ \\
\hline $\begin{array}{l}\text { Chi-cuadrado de } \\
\text { Pearson }\end{array}$ & $40,038(b)$ & 1 & ,000 & & \\
\hline $\begin{array}{l}\text { Corrección por } \\
\text { continuidad(a) }\end{array}$ & 36,956 & 1 & ,000 & & \\
\hline $\begin{array}{l}\text { Razón de } \\
\text { verosimilitudes }\end{array}$ & 45,751 & 1 & ,000 & & \\
\hline $\begin{array}{l}\text { Estadístico exacto de } \\
\text { Fisher }\end{array}$ & & & & ,000 & ,000 \\
\hline $\begin{array}{l}\text { Asociación lineal } \\
\text { por lineal }\end{array}$ & 39,422 & 1 & ,000 & & \\
\hline N de casos válidos & 65 & & & & \\
\hline
\end{tabular}


Tabla 31 Estimación de riesgo. Alteración en la "cartografía"* TDAH-Combinado.

\begin{tabular}{lrrr} 
& & \multicolumn{2}{c}{ Intervalo de confianza al } \\
& 95\% & \\
& Valor & Superior & Inferior \\
\hline $\begin{array}{l}\text { Razón de las ventajas para Alteración si/ no } \\
\text { (Con alteración / Sin alteración ) }\end{array}$ & 70,000 & 14,374 & 340,890 \\
$\begin{array}{l}\text { Para la cohorte TDAH combinado = TDAH- } \\
\text { Combinado }\end{array}$ & 7,273 & 2,890 & 18,305 \\
$\begin{array}{l}\text { Para la cohorte TDAH combinado = sin } \\
\text { diagnóstico }\end{array}$ &, 104 &, 035 &, 308 \\
N de casos válidos & 65 & &
\end{tabular}

Lo que nos expresan las tres anteriores tablas (29,30 y 31), es que hay asociación entre las dos variables. El porcentaje de participantes con TDAH-Combinado es mayor en cartografía con alteración que en cartografía normalizada. Se ha encontrado un Chi-cuadrado de valor 40,03 con una significatividad $\leq 0,05$. La fuerza de dicha asociación es 70 (con un índice de confianza (IC) al 95\% adecuado, no estando incluido entre los límites el valor 1), que representa el alto riesgo que tienen los pacientes con este trastorno de presentar una cartografía con alteración. La probabilidad (el riesgo) de encontrar alteraciones en la cartografía es 70 veces mayor que la de encontrar no alteración en la cartografía.

En cuanto al estudio de diseño de cohortes, los valores indican que se podría esperar que por cada sujeto con TDAH-Combinado la probabilidad de encontrar una cartografía anómala es de 7,3. En el grupo control o no diagnosticados, la posibilidad de presentar alteración es 0,1/1.

Continuamos realizando este tipo de pruebas, para comprobar ahora si existe asociación y obtener los valores de riesgo con la muestra de TDAH de tipo Déficit de Atención. Tras la presentación de los datos sintetizamos los resultados 


\subsubsection{ESTUDIO DE ASOCIACIÓN DE LA ALTERACIÓN DE LA CARTOGRAFÍA CON LOS DIAGNÓSTICOS DE TDAH TIPO DEFICIT DE ATENCIÓN}

De nuevo observamos en los datos que siguen que el $80 \%$ de los niños y jóvenes afectados presenta una cartografía alterada, frente al 9,7 de los que no recibieron diagnóstico.

Tabla 32 Contingencia. "cartografía"* "TDAH-Déficit Atención”

\begin{tabular}{llccc} 
& \multicolumn{3}{c}{ Diagnóstico } & \\
\cline { 3 - 4 } & & TDAH-Déficit Atención & Sin diagnóstico & N \\
\hline Alteración si/no & Con alteración & 12 & 3 & 15 \\
& Sin alteración & 3 & 28 & 31 \\
Total & 15 & 31 & 46
\end{tabular}

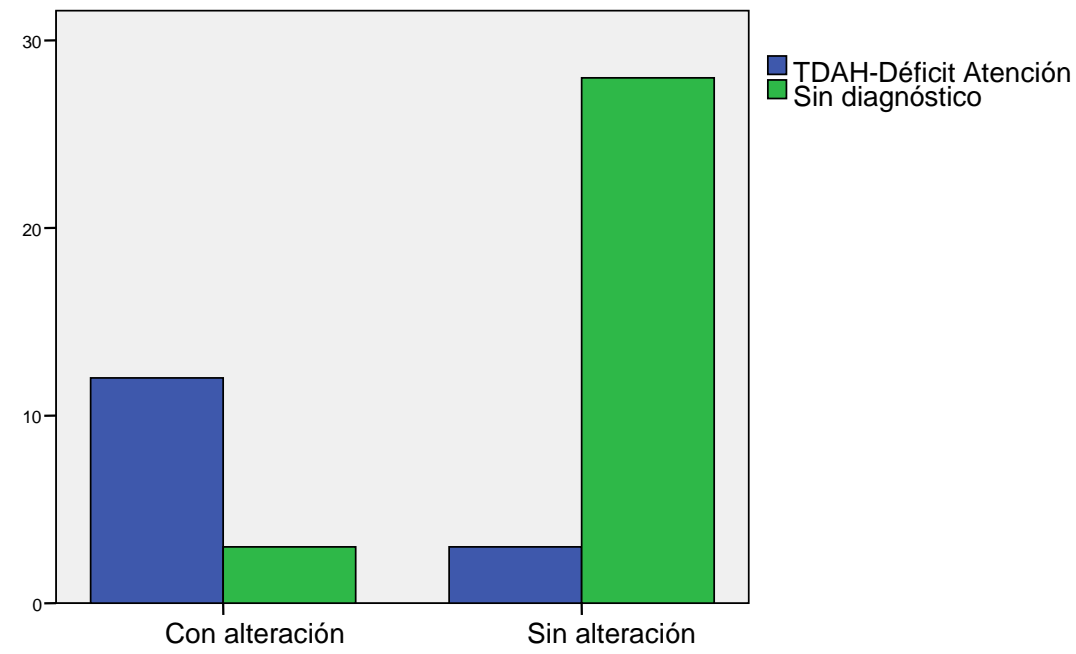

Figura 12, “cartografía” * “TDAH Déficit Atención”

El Chi-Cuadrado de Pearson ha resultado con un valor de asociación de 22,7 y el índice de significación $=.00$, este índice $\leq 0,05$ indica que el valor de la probabilidad de independencia es muy pequeña, mínima, por lo que podemos concluir que estas dos variables están relacionadas. 
Tabla 33. Contraste de variables. "cartografía" *” TDAH-Déficit Atención”.

\begin{tabular}{|c|c|c|c|c|c|}
\hline & Valor & gl & $\begin{array}{c}\text { Sig. asintótica } \\
\text { (bilateral) }\end{array}$ & $\begin{array}{c}\text { Sig. exacta } \\
\text { (bilateral) }\end{array}$ & $\begin{array}{c}\text { Sig. exacta } \\
\text { (unilateral) }\end{array}$ \\
\hline $\begin{array}{l}\text { Chi-cuadrado de } \\
\text { Pearson }\end{array}$ & $22,748(b)$ & 1 & ,000 & & \\
\hline $\begin{array}{l}\text { Corrección por } \\
\text { continuidad(a) }\end{array}$ & 19,661 & 1 & ,000 & & \\
\hline $\begin{array}{l}\text { Razón de } \\
\text { verosimilitudes }\end{array}$ & 23,362 & 1 & ,000 & & \\
\hline $\begin{array}{l}\text { Estadístico exacto de } \\
\text { Fisher }\end{array}$ & & & & ,000 & ,000 \\
\hline $\begin{array}{l}\text { Asociación lineal por } \\
\text { lineal }\end{array}$ & 22,254 & 1 & ,000 & & \\
\hline N de casos válidos & 46 & & & & \\
\hline
\end{tabular}

La prueba de asociación de Chi-Cuadrado indica un valor de 22,7 y significativa, lo que implica una relación entre las variables TDAH-Déficit de Atención y Cartografía. En esta ocasión, el procesador de datos nos indica que hay una casilla con una frecuencia esperada inferior a 5, la frecuencia anómala que detecta el SPSS es 4,89, no muy lejana del 5. Aun sabiendo que esto podría considerarse una pequeña limitación de la validez en nuestros resultados, damos por válidos los resultados y continuamos con la exposición.

El valor en la estimación de riesgo es de 22,7 e indica que entre los sujetos con TDAH-Déficit de Atención la probabilidad (el riesgo) de encontrar alteraciones en la cartografía es 37,33 veces mayor que la de encontrar no alteración en la cartografía.

Los índices de riesgo para un diseño de cohortes indican que por cada sujeto con TDAH-Déficit de Atención, la probabilidad de encontrar una cartografía anómala es 8,27 veces mayor, mientras que los no diagnosticados, pues el riesgo que tienen es muy bajo $0,22 / 1$. 
Tabla 34. Estimación de riesgo. "cartografía"*”TDAH-Déficit Atención".

\begin{tabular}{lrrr} 
& & \multicolumn{2}{c}{$\begin{array}{c}\text { Intervalo de confianza al } \\
\mathbf{9 5 \%}\end{array}$} \\
\cline { 3 - 4 } & Valor & Superior & Inferior \\
\hline Razón de las ventajas para Alteración si/ no & 37,333 & 6,570 & 212,132 \\
$\begin{array}{l}\text { Con alteración / Sin alteración ) } \\
\text { Para la cohorte TDAH Déficit Atención = TDAH- }\end{array}$ & 8,267 & 2,739 & 24,954 \\
$\begin{array}{l}\text { Déficit Atención } \\
\text { Para la cohorte TDAH Déficit Atención = Sin } \\
\text { diagnóstico }\end{array}$ &, 221 &, 080 &, 613 \\
N de casos válidos & 46 & &
\end{tabular}

Tras estos resultados que consideramos también relevantes, continuamos ahora con el estudio de la muestra de TDAH de tipo Impulsivo Hiperactivo.

\subsubsection{ESTUDIO DE ASOCIACIÓN DE LA ALTERACIÓN DE LA CARTOGRAFÍA CON LOS DIAGNÓSTICOS DE TDAH TIPO IMPULSIVO HIPERACTIVO}

Los resultados que a continuación se presentan se caracterizan por tener un bajo número de niños y jóvenes afectados con este trastorno, recordamos que la baja frecuencia se debe a la programación del estudio, a lo largo de los 9 meses que duró la recogida de información no se llevaron a cabo más que 3 diagnósticos con esta tipología, Puesto que la muestra recogida es incidental no podemos añadir más casos a esta variable tipológica. Los resultados que obtenemos puede que no sean del todo válidos, sabemos que las pruebas de asociación controlan y corrigen en lo que pueden este tipo de diferencias, por lo que nos atrevemos a exponerlas.

Vemos, en la siguiente tabla 35, que un $10 \%$ de los niños y jóvenes que no recibieron diagnóstico presentan alteración en la cartografía frente a un 66,6\% de los afectados de TDAH-Impulsivo hiperactivo. Aunque las frecuencias sean muy diferentes en cuanto al número de casos los porcentajes son al menos algo reveladores. 
Tabla 35. Contingencia. "cartografía”*TDAH-Impulsivo-Hiperactivo.

TDAH Impulsivo-Hiperactivo

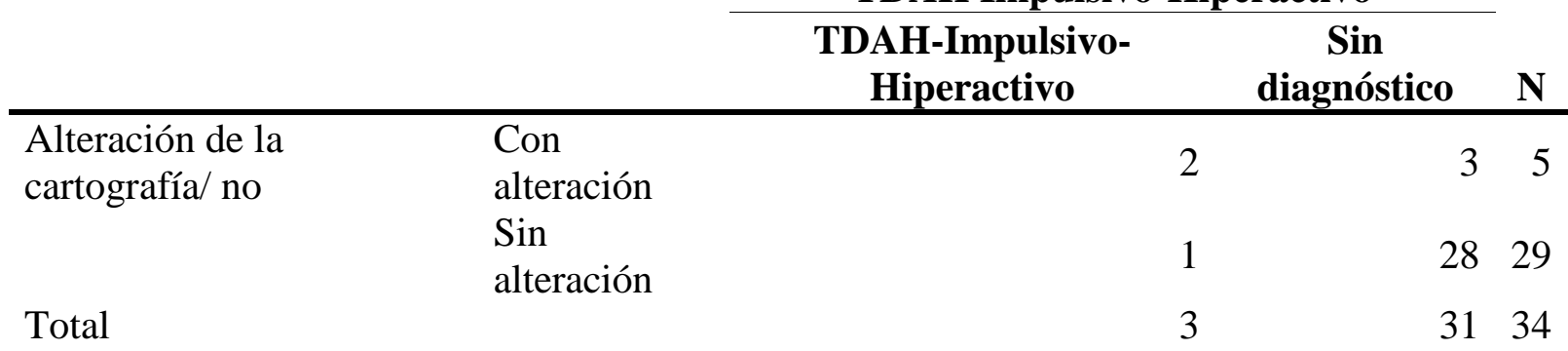

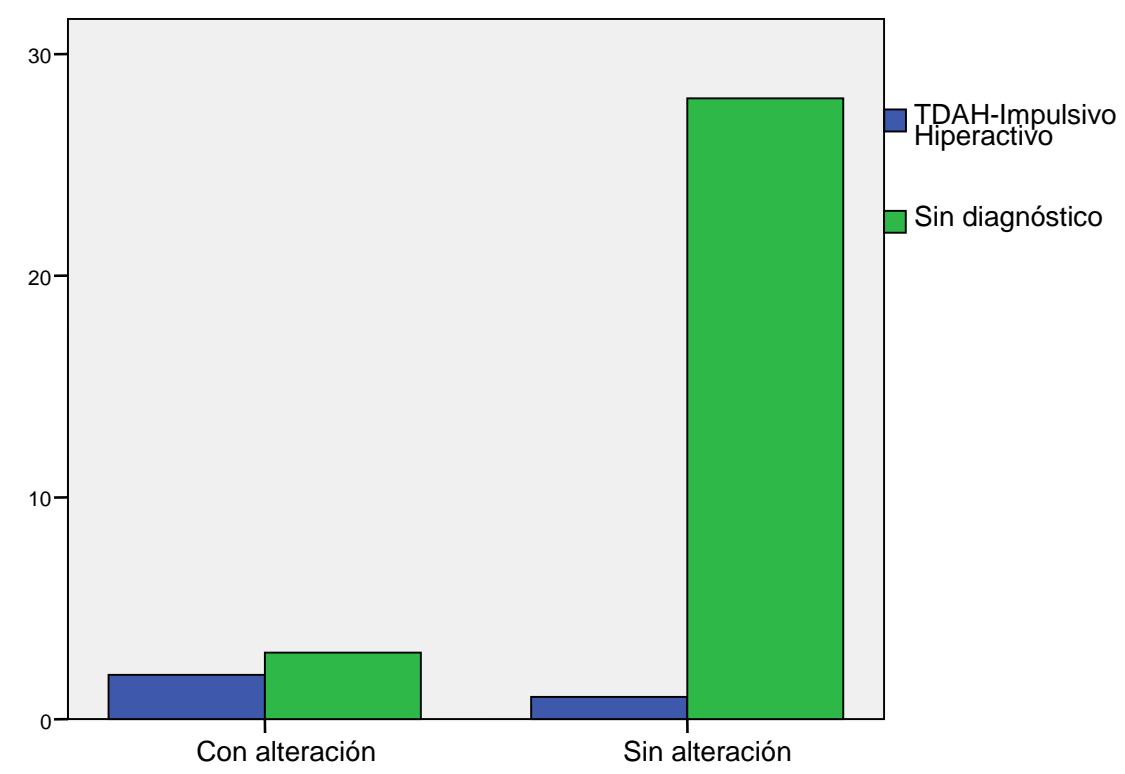

Figura 13. "cartografia"*”TDAH-Impulsivo Hiperactivo."

El Chi-Cuadrado de Pearson ha resultado con un valor de asociación de 7,08 y el índice de significación $=.008$, este índice $\leq 0,05$ indica que estas dos variables están relacionadas. Sin embargo obtenemos en el $75 \%$ de las casillas unos valores bajos no esperados, posiblemente esto sea debido a la gran diferencia de la $\mathrm{N}$ entre ambas variables, por lo que, procurando ser sensatos, consideramos que los resultados no son del todo válidos. 
Tabla 36. Contraste de variables. "cartografía”*”TDAH-Impulsivo-Hiperactivo".

\begin{tabular}{|c|c|c|c|c|c|}
\hline & Valor & gl & $\begin{array}{c}\text { Sig. asintótica } \\
\text { (bilateral) }\end{array}$ & $\begin{array}{c}\text { Sig. exacta } \\
\text { (bilateral) }\end{array}$ & $\begin{array}{c}\text { Sig. exacta } \\
\text { (unilateral) }\end{array}$ \\
\hline $\begin{array}{l}\text { Chi-cuadrado de } \\
\text { Pearson }\end{array}$ & $7,082(b)$ & 1 & ,008 & & \\
\hline $\begin{array}{l}\text { Corrección por } \\
\text { continuidad(a) }\end{array}$ & 3,268 & 1 & ,071 & & \\
\hline $\begin{array}{l}\text { Razón de } \\
\text { verosimilitudes }\end{array}$ & 4,864 & 1 & ,027 & & \\
\hline $\begin{array}{l}\text { Estadístico exacto de } \\
\text { Fisher }\end{array}$ & & & &, 050 &, 050 \\
\hline $\begin{array}{l}\text { Asociación lineal por } \\
\text { lineal }\end{array}$ & 6,874 & 1 & ,009 & & \\
\hline $\mathrm{N}$ de casos válidos & 34 & & & & \\
\hline
\end{tabular}

Aun reconociendo que podríamos no estar dentro de la verdad de los datos, el valor en la estimación de riesgo es de 7,08 e indica que entre los sujetos con TDAH-Impulsivohiperactivo la probabilidad (el riesgo) de encontrar alteraciones en la cartografía es 7,08 veces mayor que la de encontrar no alteración en la cartografía.

Los índices de riesgo para un diseño de cohortes, indican que por cada sujeto con TDAH-Impulsivo-hiperactivo, la probabilidad de encontrar una cartografía anómala es 11,6 veces mayor, mientras que el riesgo que tienen los no diagnosticados es $0,6 / 1$.

Tabla 37. Estimación de riesgo. "cartografía"*”TDAH-impulsivo Hiperactivo".

\begin{tabular}{lrrr} 
& & \multicolumn{2}{c}{$\begin{array}{c}\text { Intervalo de confianza al } \\
\mathbf{9 5 \%}\end{array}$} \\
\cline { 3 - 4 } & Valor & Superior & Inferior \\
\hline $\begin{array}{l}\text { Razón de las ventajas para Alteración si/ no } \\
\text { (Con alteración / Sin alteración ) }\end{array}$ & 18,667 & 1,280 & 272,127 \\
$\begin{array}{l}\text { Para la cohorte TDAH impulsivo hiperactivo } \\
\text { TDAH-Impulsivo Hiperactivo }\end{array}$ & 11,600 & 1,279 & 105,201 \\
$\begin{array}{l}\text { Para la cohorte TDAH impulsivo hiperactivo = Sin } \\
\text { diagnóstico }\end{array}$ &, 621 &, 303 & 1,275 \\
N de casos válidos & 34 & &
\end{tabular}

Como hemos podido ver en esta muestra disponemos de muy pocos participantes. El procesador estadístico no ha presentado problemas, en la resolución de las tablas, y siguen 
siendo significativas, los valores de riesgo indican una probabilidad en los TDAH de tipo Impulsivo Hiperactivo de presentar cartografía anómala de 18,66 veces mayor que las personas sin diagnóstico.

El último estudio que presentamos de este epígrafe, recoge los estadísticos que indican la relación existente entre la cartografía y el TDAH-de tipo sin especificar.

\subsubsection{ESTUDIO DE ASOCIACIÓN DE LA ALTERACIÓN DE LA CARTOGRAFÍA CON LOS DIAGNÓSTICOS DE TDAH SIN ESPECIFICAR}

Observamos de nuevo, al igual que vimos con los participantes diagnosticados de trastorno Impulsivo Hiperactivo que la muestra es muy pequeña. Aun así, el procesador estadístico ha resuelto las tablas. El porcentaje de niños y jóvenes con este trastorno que presentan una alteración en la cartografía es del $80 \%$ frente a los 9,67\% de los que no recibieron diagnóstico.

Tabla 38. Contingencia. "cartografía"*TDAH-“Sin Especificar".

TDAH sin Especificar

\section{TDAH-Sin Especificar Sin diagnóstico $\mathbf{N}$}

\begin{tabular}{llrrr}
\hline Alteración si/no & Con alteración & 4 & 3 & 7 \\
& Sin alteración & 1 & 28 & 29 \\
Total & & 5 & 31 & 36
\end{tabular}




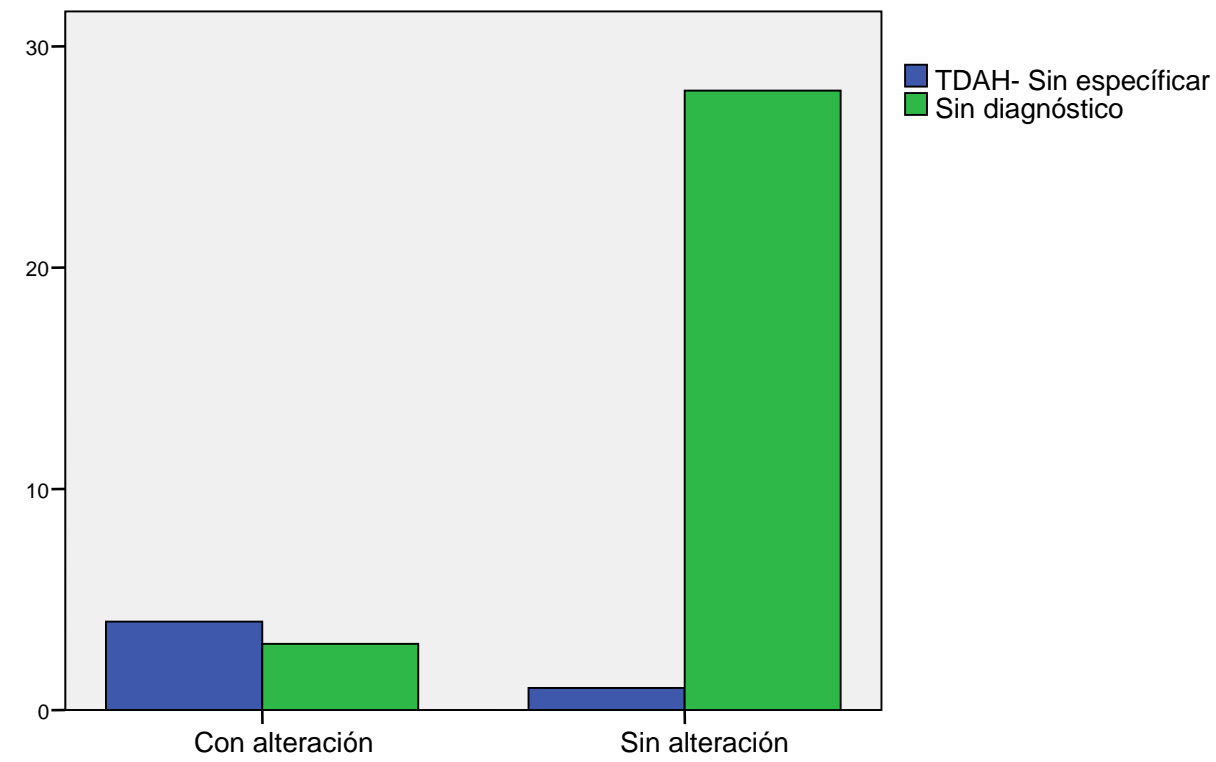

Figura 14. "cartografía"*”TDAH-Sin Especificar".

La asociación de nuevo resulta $\leq 0,05$, por lo que ambas variables manifiestan están relacionadas de forma significativa. Al realizar la prueba de Chi-Cuadrado de Pearson, el procesador nos indica un valor de asociación de 13,6 pero que la frecuencia encontrada en más del $20 \%$ de las casillas es inferior a la esperada. No podemos tomar los resultados con la validez que deseáramos, el problema se deriva, como sabemos, de ser la muestra incidental.

Tabla 39. Contraste de variables. "cartografía"*”TDAH-Sin Especificar"

\begin{tabular}{|c|c|c|c|c|c|}
\hline & Valor & gl & $\begin{array}{c}\text { Sig. asintótica } \\
\text { (bilateral) }\end{array}$ & $\begin{array}{c}\text { Sig. exacta } \\
\text { (bilateral) }\end{array}$ & $\begin{array}{l}\text { Sig. exacta } \\
\text { (unilateral) }\end{array}$ \\
\hline $\begin{array}{l}\text { Chi-cuadrado de } \\
\text { Pearson }\end{array}$ & $13,593(b)$ & 1 & ,000 & & \\
\hline $\begin{array}{l}\text { Corrección por } \\
\text { continuidad(a) }\end{array}$ & 9,475 & 1 & ,002 & & \\
\hline $\begin{array}{l}\text { Razón de } \\
\text { verosimilitudes }\end{array}$ & 10,751 & 1 & ,001 & & \\
\hline $\begin{array}{l}\text { Estadístico exacto de } \\
\text { Fisher }\end{array}$ & & & & ,003 & ,003 \\
\hline $\begin{array}{l}\text { Asociación lineal por } \\
\text { lineal }\end{array}$ & 13,216 & 1 & ,000 & & \\
\hline $\mathrm{N}$ de casos válidos & 36 & & & & \\
\hline
\end{tabular}


El valor en la estimación de riesgo es de 37,33 e indica que entre los sujetos con TDAH-Sin Especificar la probabilidad (el riesgo) de encontrar alteraciones en la cartografía es 37,33 veces mayor que la de encontrar no alteración en la cartografía.

Los índices de riesgo para un diseño de cohortes indican que por cada sujeto con TDAH-Sin Especificar, la probabilidad de encontrar una cartografía anómala es 16,57 veces mayor, frente a los no diagnosticados, pues el riesgo que tienen es muy bajo 0,4/1.

Tabla 40. Estimación de riesgo. "cartografía" *”TDAHS-Sin Especificar".

\begin{tabular}{|c|c|c|c|}
\hline & \multirow[b]{2}{*}{ Valor } & \multicolumn{2}{|c|}{$\begin{array}{l}\text { Intervalo de confianza al } \\
\qquad 95 \%\end{array}$} \\
\hline & & Superior & Inferior \\
\hline $\begin{array}{l}\text { Razón de las ventajas para Alteración si/ no } \\
\text { (Con alteración / Sin alteración ) }\end{array}$ & 37,333 & 3,083 & 452,044 \\
\hline $\begin{array}{l}\text { Para la cohorte TDAH sin especificar }=\text { TDAH- Sin } \\
\text { Especificar }\end{array}$ & 16,571 & 2,177 & 126,166 \\
\hline $\begin{array}{l}\text { Para la cohorte TDAH sin especificar }=\text { Sin } \\
\text { diagnóstico }\end{array}$ & ,444 & , 188 & 1,047 \\
\hline $\mathrm{N}$ de casos válidos & 36 & & \\
\hline
\end{tabular}

Una vez realizadas todas las pruebas y vistos los resultados que nos interesaba conocer para valorar la relevancia que tiene la cartografía cerebral anómala en las muestras de TDAH y sus tipologías (epígrafes 11.2.2-11.2.6), comprobando que estas están muy asociadas y observando las grandes diferencias estimadas del riesgo frente a los niños y jóvenes que no obtuvieron diagnóstico, podemos confirmar la hipótesis segunda.

Ahora nos interesa explorar si sucede lo mismo al comparar la muestra de TDAH (en global y por tipología) con la muestra compuesta por las personas diagnosticadas por otro tipo de trastornos psicopatológicos.

A continuación exponemos un nuevo bloque de tablas, cuya pretensión es valorar si la cartografía cerebral discrimina a la muestra de las personas con TDAH, en sus 4 diversos tipos, versus la muestra que presenta otro tipo de trastornos psicopatológicos. 


\subsection{COMPROBACIÓN DEL RIESGO QUE RELACIONA LAS ALTERACIONES EN LA CARTOGRAFIA EN EL TDAH COMPARANDOLO CON OTROS DIAGNÓSTICOS PSICOPATOLÓGICOS}

\subsubsection{ESTUDIO DE ASOCIACIÓN DE LA ALTERACIÓN DE LA CARTOGRAFÍA}

\section{CON TODOS LOS TIPOS DE DIAGNÓSTICOS DE TDAH}

En primer lugar aparece la tabla 41 de contingencia, de los diagnosticados de TDAH (englobando todos las tipologías) y los diagnosticados de otras psicopatologías.

Observamos que el $84 \%$ de los afectados por TDAHT presentan cartografía alterada frente al $41,4 \%$ de los afectados por otro diferente diagnóstico psicopatológico.

Tabla 41. Contingencia “cartografía”"’TDAHT y otro diagnóstico".

\section{Diagnóstico}

\begin{tabular}{llrrr} 
& & TDAHT & Otro diagnóstico & N \\
\hline Alteración si/ no & Con alteración & 48 & 34 & 82 \\
& Sin alteración & 9 & 48 & 57 \\
Total & 57 & 82 & 139
\end{tabular}

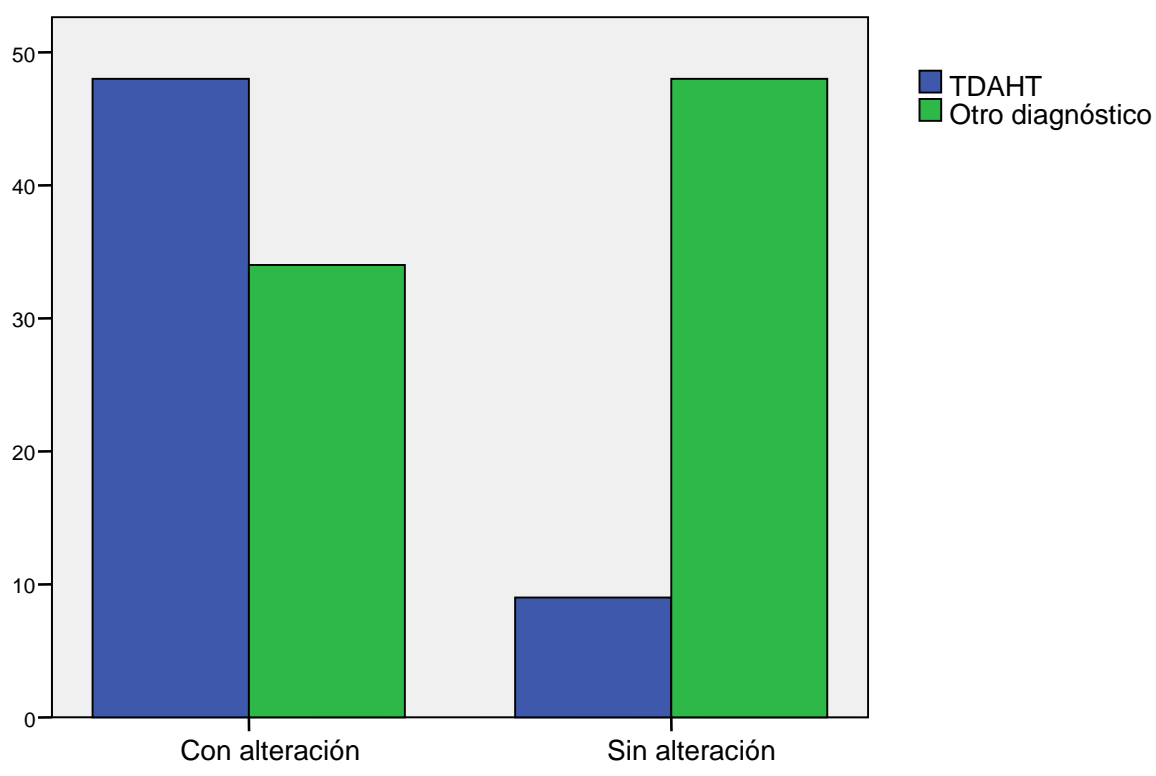

Figura 15. Gráfico de barras "cartografía"*”TDAHT y otro diagnóstico". 
La prueba de Chi Cuadrado expresa un valor de 25,4 y significatividad en la asociación de ambas variables (diagnóstico y cartografía), $\mathrm{p} \leq 0,05$, lo que indica que ambas están relacionadas.

Tabla 42. Contraste de variables. "cartografía"*”TDAHT y otro diagnóstico".

\begin{tabular}{lrrrrr} 
& Valor & gl & $\begin{array}{c}\text { Sig. asintótica } \\
\text { (bilateral) }\end{array}$ & $\begin{array}{c}\text { Sig. exacta } \\
\text { (bilateral) }\end{array}$ & $\begin{array}{c}\text { Sig. exacta } \\
\text { (unilateral) }\end{array}$ \\
\hline $\begin{array}{l}\text { Chi-cuadrado de } \\
\begin{array}{l}\text { Pearson } \\
\text { Corrección por }\end{array}\end{array}$ & $25,400(\mathrm{~b})$ & 1 &, 000 & & \\
$\begin{array}{l}\text { continuidad(a) } \\
\begin{array}{l}\text { Razón de } \\
\text { verosimilitudes }\end{array}\end{array}$ & 23,663 & 1 &, 000 & & \\
$\begin{array}{l}\text { Estadístico exacto de } \\
\text { Fisher }\end{array}$ & 27,177 & 1 &, 000 &, 000 & \\
$\begin{array}{l}\text { Asociación lineal por } \\
\text { lineal }\end{array}$ & 25,217 & 1 & & & \\
N de casos válidos & 139 & &, 000 & & \\
& & & & &
\end{tabular}

En cuanto a la estimación de riesgo, el valor obtenido es de 7,5 e indica que entre los sujetos con TDAHT (incluyendo todas su posibles tipologías), la probabilidad (el riesgo) de encontrar alteraciones en la cartografía es 7,5 veces mayor que la de encontrar no alteración en la cartografía.

Los valores de riesgo para un diseño de cohortes indican que por cada sujeto con diagnóstico psicopatológico, la probabilidad de encontrar una cartografía anómala es 3,7 veces mayor, que los que presentan otro tipo de trastornos psicopatológicos, pues el riesgo que tienen es muy bajo 0,49/1.

Estos resultados, al ser significativos y tener unos índices de confianza (IC) adecuados, nos manifiestan la importancia que tiene la cartografía para el diagnóstico del trastorno que estudiamos frente a otros trastornos mentales o psicopatológicos. 
Tabla 43. Estimación de riesgo. "cartografía”*”TDAHT” y “otro diagnóstico".

Intervalo de confianza al $95 \%$

\begin{tabular}{lrrr} 
& Valor & Superior & Inferior \\
\hline Razón de las ventajas para Alteración si/ no & 7,529 & 3,262 & 17,381 \\
Con alteración / Sin alteración ) & 3,707 & 1,981 & 6,937 \\
Para la cohorte Diagnóstico = TDAHT &, 492 &, 372 &, 652 \\
Para la cohorte Diagnóstico = Otro diagnóstico & 139 & & \\
N de casos válidos & &
\end{tabular}

En los siguientes epígrafes queremos comprobar cómo se comporta la técnica cartográfica antes los diferentes tipos, Comenzamos por estudiar el TDAH-Combinado.

\subsubsection{ESTUDIO DE ASOCIACIÓN DE LA ALTERACIÓN DE LA CARTOGRAFÍA CON LOS DIAGNÓSTICOS DE TDAH TIPO COMBINADO}

Vemos en los resultados que aparecen a continuación que el 88,2\% de los niños y jóvenes que han presentado TDAHT presentan una cartografía con alteración frente al 41,6\% de los diagnosticados de otras psicopatologías.

Tabla 44. Contingencia. "cartografía”*”TDAH-combinado" y "otro diagnóstico".

\section{Diagnóstico}

\begin{tabular}{llrrr} 
& & TDAH-Combinado & Otro diagnóstico & N \\
\hline Alteración si/ no & Con alteración & 30 & 34 & 64 \\
& Sin alteración & 4 & 48 & 52 \\
Total & 34 & 82 & 116
\end{tabular}




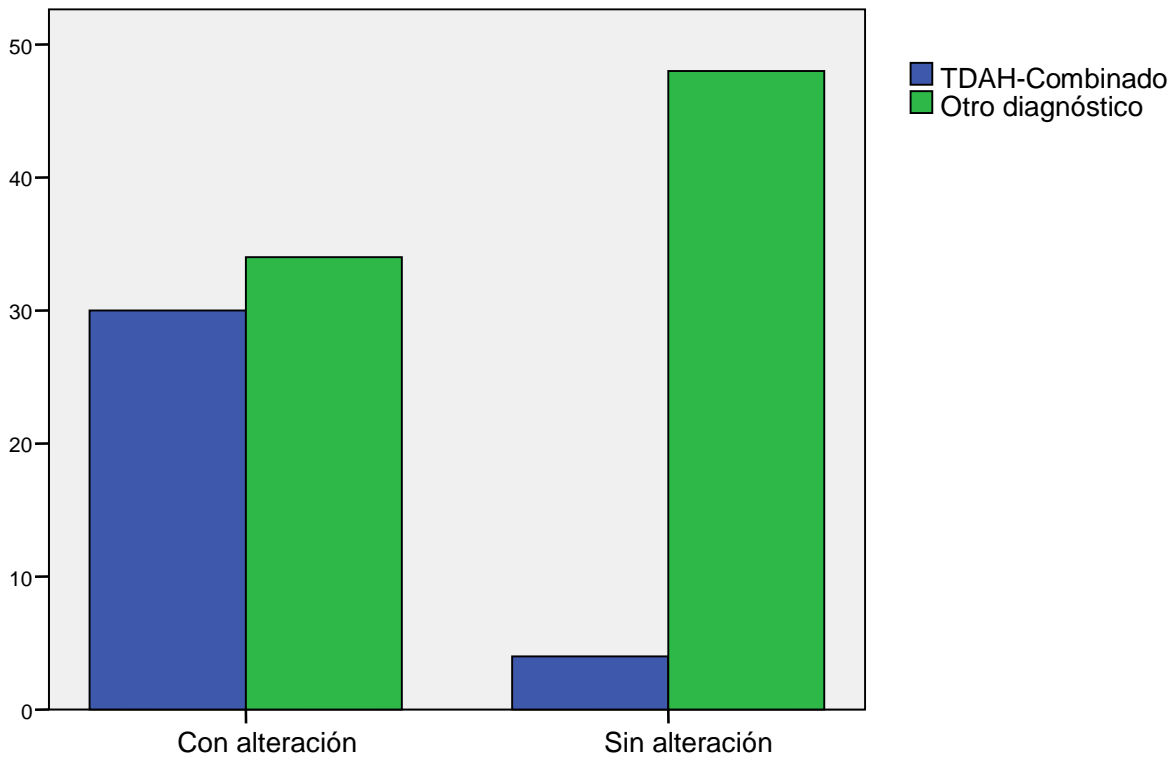

Figura 16. Grafico de barras. "cartografía"*”TDAH-combinado" y "otro diagnóstico"-

El Chi-Cuadrado de Pearson ha resultado con un valor de asociación de 21,2 y el índice de significación $=.00$, este índice $\leq 0,05$ indica que el valor de la probabilidad de independencia es muy pequeña, mínima, por lo que podemos concluir que estas dos variables están relacionadas.

Tabla 45. Contraste de variables. "cartografía"*”TDAH-Combinado" y "otro diagnóstico".

\begin{tabular}{|c|c|c|c|c|c|}
\hline & Valor & gl & $\begin{array}{l}\text { Sig. asintótica } \\
\text { (bilateral) }\end{array}$ & $\begin{array}{c}\text { Sig. exacta } \\
\text { (bilateral) }\end{array}$ & $\begin{array}{l}\text { Sig. exacta } \\
\text { (unilateral) }\end{array}$ \\
\hline $\begin{array}{l}\text { Chi-cuadrado de } \\
\text { Pearson }\end{array}$ & $21,259(b)$ & 1 &, 000 & & \\
\hline $\begin{array}{l}\text { Corrección por } \\
\text { continuidad(a) }\end{array}$ & 19,410 & 1 & ,000 & & \\
\hline $\begin{array}{l}\text { Razón de } \\
\text { verosimilitudes }\end{array}$ & 23,662 & 1 & ,000 & & \\
\hline $\begin{array}{l}\text { Estadístico exacto de } \\
\text { Fisher }\end{array}$ & & & & ,000 & ,000 \\
\hline $\begin{array}{l}\text { Asociación lineal por } \\
\text { lineal }\end{array}$ & 21,075 & 1 &, 000 & & \\
\hline $\mathrm{N}$ de casos válidos & 116 & & & & \\
\hline
\end{tabular}


Como sabemos, la primera fila de la tabla 45 indica que el riesgo estimado se refiere a la cartografía con alteración frente a la cartografía normal. En cuanto al índice obtenido, la estimación de riesgo, el valor es de 21,25 e indica que entre los sujetos con TDAHCombinado, la probabilidad (el riesgo) de encontrar alteraciones en la cartografía es 21,25 veces mayor que la de encontrar no alteración en la cartografía.

Los valores de riesgo para un diseño de cohortes indican que por cada sujeto con diagnóstico psicopatológico, la probabilidad de encontrar una cartografía anómala es 6,09 veces mayor, que los que presentan otro tipo de trastornos psicopatológicos, pues el riesgo que tienen es muy bajo $0,57 / 1$.

Tabla 46. Estimación de riesgo. "cartografía"*”TDAH-Combinado" y "otro diagnóstico".

\begin{tabular}{lrrr} 
& \multicolumn{3}{c}{$\begin{array}{c}\text { Intervalo de confianza al } \\
\text { 95\% }\end{array}$} \\
\cline { 3 - 4 } & Valor & Superior & Inferior \\
\hline Razón de las ventajas para Alteración si/ no (Con & 10,588 & 3,414 & 32,843 \\
alteración / Sin alteración ) & 6,094 & 2,294 & 16,188 \\
Para la cohorte Diagnóstico = TDAH-Combinado &, 576 &, 451 &, 734 \\
Para la cohorte Diagnóstico = Otro diagnóstico & 116 & & \\
N de casos válidos & &
\end{tabular}

De nuevo las diferencias en cuanto al riesgo existen. La estimación del riesgo nos dice que la probabilidad de obtener un resultado anómalo en la cartografía es muy grande en los niños y jóvenes diagnosticados de TDAH tipo Combinado.

\subsubsection{ESTUDIO DE ASOCIACIÓN DE LA ALTERACIÓN DE LA CARTOGRAFÍA CON LOS DIAGNÓSTICOS DE TDAH-DEFICIT DE ATENCIÓN}

En cuanto al tipo Déficit de Atención, los resultados que se reflejan en la tabla 47 indican que el $80 \%$ de los afectados por este tipo de trastorno presentan una cartografía con 
alteraciones frente al $41,4 \%$ de los que presentan otro tipo distinto de trastorno psicopatológico.

Tabla 47. Contingencia. “cartografía”*”TDAH-Déficit de atención” y “otro diagnóstico".

\section{Diagnóstico}

TDAH-Déficit Atención Otras patologías N

\begin{tabular}{ll}
\hline Alteración si/ no & Con alteración \\
& Sin alteración
\end{tabular}

Total

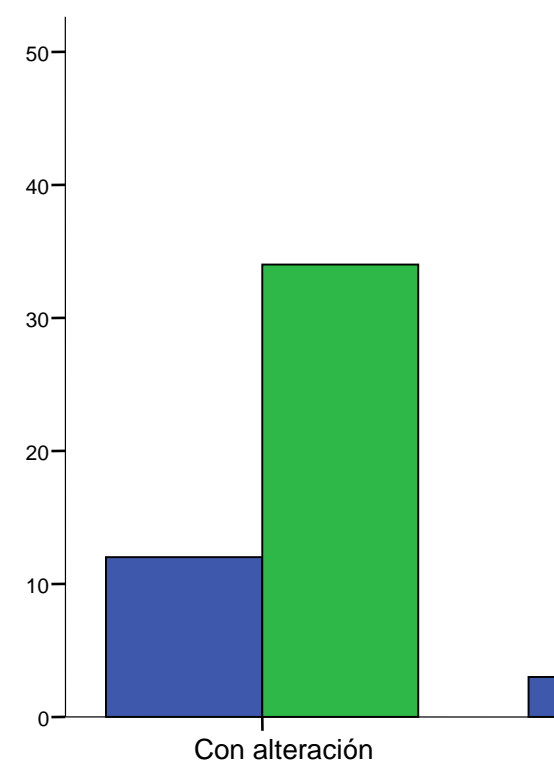

12

3

15

$34 \quad 46$

$48 \quad 51$

8297

Figura 17 Gráfico de barras. “cartografía”*”TDAH-Déficit de atención” y “otro diagnóstico"

Podemos observar que la muestra de diagnosticados de déficit de atención es más pequeña que la de diagnosticados con otras patologías. Sabiendo que los estadísticos de las medidas de asociación que utilizamos tienen en cuenta esto y lo controlan y no habiendo ningún error de frecuencias esperadas, o los resultados en las pruebas de contraste de variables manifiestan una relación entre variables de 7,55, significativa al ser $\leq 0,5$. 
Tabla 48. Contraste de variables. "cartografía"*”TDAH-Déficit de atención" y "otro diagnóstico"

\begin{tabular}{|c|c|c|c|c|c|}
\hline & Valor & gl & $\begin{array}{c}\text { Sig. asintótica } \\
\text { (bilateral) }\end{array}$ & $\begin{array}{c}\text { Sig. exacta } \\
\text { (bilateral) }\end{array}$ & $\begin{array}{c}\text { Sig. exacta } \\
\text { (unilateral) }\end{array}$ \\
\hline $\begin{array}{l}\text { Chi-cuadrado de } \\
\text { Pearson }\end{array}$ & $7,553(b)$ & 1 & ,006 & & \\
\hline $\begin{array}{l}\text { Corrección por } \\
\text { continuidad(a) }\end{array}$ & 6,086 & 1 &, 014 & & \\
\hline $\begin{array}{l}\text { Razón de } \\
\text { verosimilitudes }\end{array}$ & 7,926 & 1 & ,005 & & \\
\hline $\begin{array}{l}\text { Estadístico exacto de } \\
\text { Fisher }\end{array}$ & & & & ,010 & ,006 \\
\hline $\begin{array}{l}\text { Asociación lineal por } \\
\text { lineal }\end{array}$ & 7,475 & 1 & ,006 & & \\
\hline $\mathrm{N}$ de casos válidos & 97 & & & & \\
\hline
\end{tabular}

La primera fila de la tabla 49 indica que el riesgo estimado se refiere a la cartografía con alteración frente a la cartografía normal. En cuanto a la estimación de riesgo, el valor obtenido es de 5,64 e indica que entre los sujetos con TDAH-Déficit de Atención, la probabilidad (el riesgo) de encontrar alteraciones en la cartografía es 5,64 veces mayor que la de encontrar no alteración en la cartografía.

Los valores de riesgo para un diseño de cohortes indican que por cada sujeto con diagnóstico psicopatológico, la probabilidad de encontrar una cartografía anómala es 4,43 veces mayor, que los que presentan otro tipo de trastornos psicopatológicos, pues el riesgo que tienen es muy bajo $0,78 / 1$.

Tabla 49. Estimación de riesgo. "cartografía"*”TDAH-Déficit de atención" y "otro diagnóstico".

Intervalo de confianza al $95 \%$

\begin{tabular}{lrrr} 
& Valor & Superior & Inferior \\
\hline Razón de las ventajas para Alteración si/ no (Con & 5,647 & 1,480 & 21,550 \\
alteración / Sin alteración ) & & & 1,335 \\
Para la cohorte Diagnóstico = TDAH-Déficit Atención & 4,435 &, 653 &, 945 \\
Para la cohorte Diagnóstico = 4 &, 785 & & \\
N de casos válidos & 97 & &
\end{tabular}


Todos los valores obtenidos expresan que el riesgo de obtener una cartografía con alguna alteración en los niños y jóvenes con TDAH-Déficit de Atención es importante y digno de tener en cuenta.

\subsubsection{ESTUDIO DE ASOCIACIÓN DE LA ALTERACIÓN DE LA CARTOGRAFÍA CON LOS DIAGNÓSTICOS DE TDAH TIPO IMPULSIVO HIPERACTIVO}

Observamos ahora los resultados correspondientes al TDAH de tipo Impulsivo Hiperactivo, sabemos que el número de participantes de esta submuestra es muy pequeño, habiendo grandes diferencias entre las frecuencias de las variables que nos interesa estudiar, por lo que presentamos los resultados en este estudio, sabiendo que los debemos tratar con cautela. Vemos que el porcentaje encontrado en la muestra de TDAH-Impulsivo Hiperactivo que manifiesta cartografía alterada es del $66,6 \%$ frente a la muestra de afectados por otro tipo de trastorno psicopatológico que es del $43,6 \%$.

Tabla 50. Contingencia. “cartografía"*”TDAH-Impulsivo-hiperactivo y otro diagnóstico".

Diagnóstico

TDAH-Impulsivo Hiperactivo Otro trastorno $\mathbf{N}$

\begin{tabular}{lllll}
\hline Alteración si/ no & Con alteración & 2 & 38 & 40 \\
& Sin alteración & 1 & 49 & 50 \\
Total & & 3 & 87 & 90
\end{tabular}




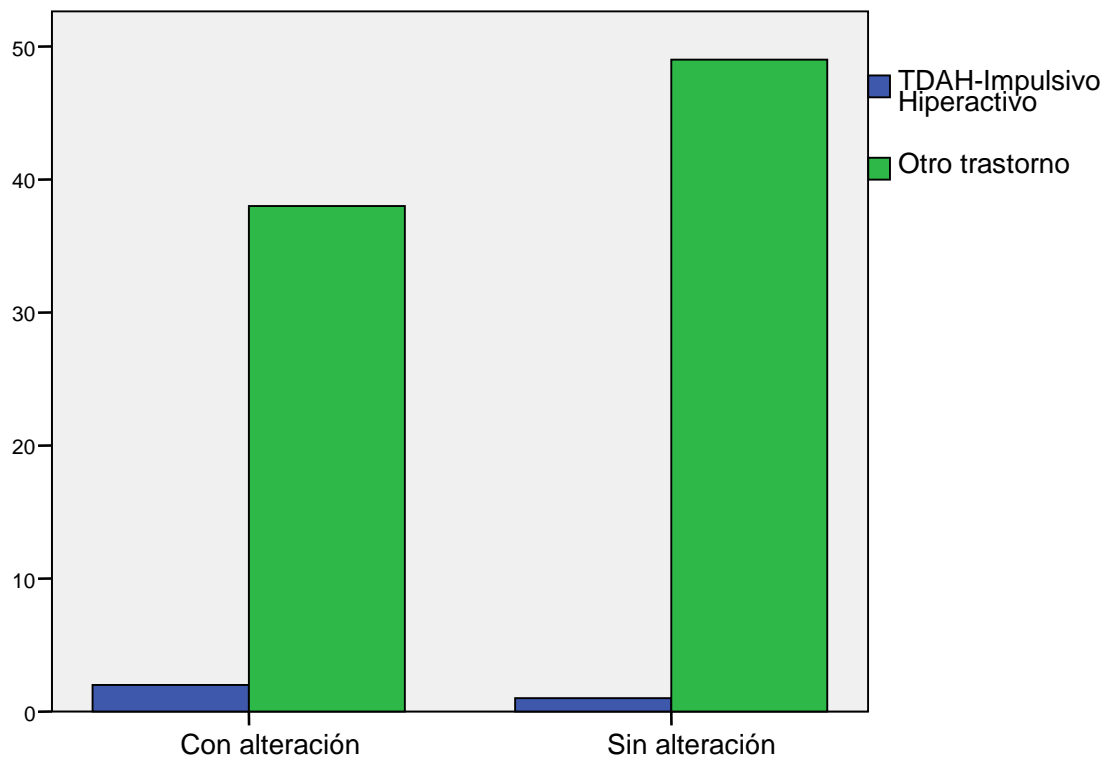

Figura 18. Gráfico de barras. "cartografía"*"TDAH-Impulsivo-hiperactivo y otro diagnóstico".

Con un valor de Chi Cuadrado de 0,6 y una $\mathrm{p} \geq 0,05$, la relación entre las dos variables estudiadas en este caso no se observan. Ambas se muestran en el procesador de datos como independientes. Además ha encontrado que el $50 \%$ de las casillas tienen una frecuencia esperada inferior a 5, y eso de nuevo indica que los resultados no son del todo válidos.

Tabla 51. Contraste de variables. "cartografía"*”TDAH-Impulsivo-hiperactivo" y "otro diagnóstico"

\begin{tabular}{|c|c|c|c|c|c|}
\hline & Valor & gl & $\begin{array}{c}\text { Sig. asintótica } \\
\text { (bilateral) }\end{array}$ & $\begin{array}{c}\text { Sig. exacta } \\
\text { (bilateral) }\end{array}$ & $\begin{array}{r}\text { Sig. exacta } \\
\text { (unilateral) }\end{array}$ \\
\hline $\begin{array}{l}\text { Chi-cuadrado de } \\
\text { Pearson }\end{array}$ & ,621(b) & 1 & ,431 & & \\
\hline $\begin{array}{l}\text { Corrección por } \\
\text { continuidad(a) }\end{array}$ & ,039 & 1 &, 844 & & \\
\hline $\begin{array}{l}\text { Razón de } \\
\text { verosimilitudes }\end{array}$ & ,621 & 1 & ,431 & & \\
\hline $\begin{array}{l}\text { Estadístico exacto de } \\
\text { Fisher }\end{array}$ & & & &, 583 & ,416 \\
\hline $\begin{array}{l}\text { Asociación lineal por } \\
\text { lineal }\end{array}$ & ,614 & 1 & ,433 & & \\
\hline N de casos válidos & 90 & & & & \\
\hline
\end{tabular}


En cuanto a la estimación de riesgo, el valor obtenido es de 2,58 e indicaría que entre los sujetos con TDAH de tipo Hiperactivo Impulsivo, la probabilidad (el riesgo) de encontrar alteraciones en la cartografía es 2,58 veces mayor que la de encontrar no alteración en la cartografía.

Los valores de riesgo para un diseño de cohortes indican que por cada sujeto con diagnóstico psicopatológico, la probabilidad de encontrar una cartografía anómala es 2,5 veces mayor, que los que presentan otro tipo de trastornos psicopatológicos, pues el riesgo que tienen es muy bajo $0,97 / 1$.

Tabla 52. Estimación de riesgo. "cartografía"*TDAH-Impulsivo-hiperactivo y otro diagnóstico.

\begin{tabular}{lrrr} 
& & \multicolumn{2}{c}{$\begin{array}{c}\text { Intervalo de confianza al } \\
\text { 95\% }\end{array}$} \\
\cline { 3 - 5 } & Valor & Superior & Inferior \\
\hline $\begin{array}{l}\text { Razón de las ventajas para Alteración si/ no (Con } \\
\text { alteración / Sin alteración ) }\end{array}$ & 2,579 &, 225 & 29,516 \\
$\begin{array}{l}\text { Para la cohorte Diagnóstico = TDAH-Impulsivo } \\
\text { Hiperactivo }\end{array}$ & 2,500 &, 235 & 26,588 \\
Para la cohorte Diagnóstico = Otro trastorno &, 969 &, 894 & 1,052 \\
N de casos válidos & 90 & &
\end{tabular}

Puesto que la asociación no es significativa probablemente la estimación de riesgo no sea del todo válida. Comprobamos también esta consideración al observar valores de los intervalos de confianza que contienen la cifra 1 y esto indica que dificultades para la validez de los datos. Queda este aspecto por tanto, sin comprobar, pero consideramos muy necesario que se lleve a cabo en próximos estudios con una muestra más amplia.

Exploramos ahora la asociación de la cartografía con el TDAH-Sin especificar. 


\subsubsection{ESTUDIO DE ASOCIACIÓN DE LA ALTERACIÓN DE LA CARTOGRAFÍA CON LOS DIAGNÓSTICOS DE TDAH TIPO SIN ESPECIFICAR}

El porcentaje encontrado de niños y jóvenes que presentan una cartografía alterada es en el caso de los TDAH-Sin especificar del $80 \%$ frente a $141,5 \%$ de la muestra de diagnosticados con otros diagnósticos psicopatológicos.

Tabla 53. Contingencia. "cartografía”*TDAH-Sin especificar y otro diagnóstico.

\begin{tabular}{llrrr} 
& \multicolumn{3}{c}{ Diagnóstico } & \\
\cline { 3 - 4 } & & TDAH-Sin especificar & Otro Trastorno & N \\
\hline Alteración si/no no & Con alteración & 4 & 34 & 38 \\
& Sin alteración & 1 & 48 & 49 \\
Total & & 5 & 82 & 87
\end{tabular}

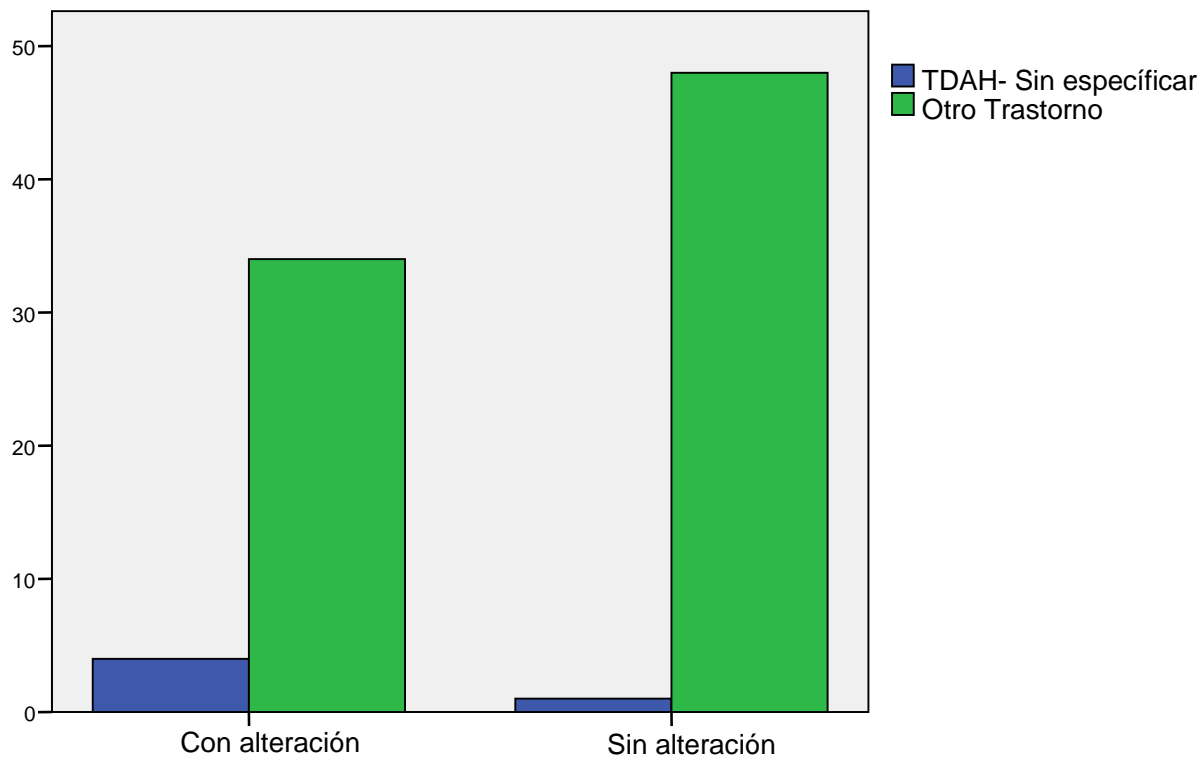

Figura 19. Gráfico de barras. “cartografía”*TDAH-Sin especificar y otro diagnóstico.

Los resultados de contraste de estas dos variables no son significativos, indican, al igual que hemos visto al estudiar la variable de TDAH-Impulsivo Hiperactivo que entre ellas hay una relación de independencia. Por ende, el 50\% de las casillas tiene un valor menor del 
esperado. Con todas estas consideraciones la cautela en la interpretación de estos datos ha de ser tomada con mucha cautela.

Tabla 54. Contraste de variables. "cartografía"*TDAH-Sin especificar y otro diagnóstico.

\begin{tabular}{|c|c|c|c|c|c|}
\hline & Valor & gl & $\begin{array}{l}\text { Sig. asintótica } \\
\text { (bilateral) }\end{array}$ & $\begin{array}{l}\text { Sig. exacta } \\
\text { (bilateral) }\end{array}$ & $\begin{array}{l}\text { Sig. exacta } \\
\text { (unilateral) }\end{array}$ \\
\hline $\begin{array}{l}\text { Chi-cuadrado de } \\
\text { Pearson }\end{array}$ & $2,845(b)$ & 1 & ,092 & & \\
\hline $\begin{array}{l}\text { Corrección por } \\
\text { continuidad(a) }\end{array}$ & 1,494 & 1 & ,222 & & \\
\hline $\begin{array}{l}\text { Razón de } \\
\text { verosimilitudes }\end{array}$ & 2,935 & 1 & ,087 & & \\
\hline $\begin{array}{l}\text { Estadístico exacto de } \\
\text { Fisher }\end{array}$ & & & & ,163 &, 111 \\
\hline $\begin{array}{l}\text { Asociación lineal por } \\
\text { lineal }\end{array}$ & 2,812 & 1 & ,094 & & \\
\hline $\mathrm{N}$ de casos válidos & 87 & & & & \\
\hline
\end{tabular}

En cuanto a la estimación de riesgo, el valor obtenido es de 5,6 e indica que entre los sujetos con TDAHT-Sin Especificar la probabilidad (el riesgo) de encontrar alteraciones en la cartografía es 5,6 veces mayor que la de encontrar no alteración en la cartografía.

Los valores de riesgo para un diseño de cohortes indican que por cada sujeto con diagnóstico psicopatológico, la probabilidad de encontrar una cartografía anómala es 5,1 veces mayor, que los que presentan otro tipo de trastornos psicopatológicos, pues el riesgo que tienen es muy bajo 0,91/1.

Tabla 55. Estimación de riesgo. "cartografía”*TDAH-Sin especificar y otro diagnóstico.

\begin{tabular}{lrrr} 
& & \multicolumn{2}{c}{ Intervalo de confianza al } \\
\cline { 3 - 4 } & V5\% & \\
\cline { 3 - 4 } & Superior & Inferior \\
\hline Razón de las ventajas para Alteración si/ no (Con & 5,647 &, 604 & 52,776 \\
alteración / Sin alteración ) & 5,158 &, 601 & 44,278 \\
Para la cohorte Diagnóstico = TDAH- Sin especificar &, 913 &, 813 & 1,026 \\
Para la cohorte Diagnóstico = Otro Trastorno & 87 & & \\
N de casos válidos & &
\end{tabular}


Debido, posiblemente, al bajo número de casos de esta submuestra las limitaciones del procesador a la hora de interpretar los datos han quedado expresadas. No podemos adelantar nada más de esta variable en este estudio. Tan sólo que es una vía abierta a nuevos estudios con un mayor número de participantes afectados de esta tipología de TDAH.

Como síntesis del conjunto de tablas expuestas en el epígrafe 11.3., consideramos que la cartografía cerebral anómala es bastante más frecuente en las personas con TDAH y en todas sus tipologías que en las personas diagnosticadas de otros trastornos psicopatológicos. El riesgo es bastante mayor y confirma la tercera hipótesis.

\subsection{PRUEBA DE REGRESIÓN LÓGISTICA}

Queremos observar a través de otro tipo de estadístico las relaciones y probabilidades de aparición de la cartografía anómala ente las variables que suscitan especial interés en este estudio, los tipos de TDAH, por lo que podría resultar adecuado y pertinente llevar a cabo un estudio de regresión. Puesto que las variables que queremos estudiar no son continuas sino categóricas, llevamos a cabo la regresión logística con los 4 tipos de TDAH.

La regresión logística tiene como objetivo primordial el de cuantificar cómo influye en la probabilidad de aparición de un suceso, habitualmente dicotómico, la presencia o no de diversos factores y el valor o nivel de los mismos. También puede ser usada para estimar la probabilidad de aparición de cada una de las posibilidades de un suceso con más de dos categorías.

Desde la teoría que sustenta este análisis al aplicar un modelo de regresión logística, no se construye un modelo de regresión para estimar los valores reales de la variable de interés, se construye una función basada en el cálculo de la probabilidad de que la variable de interés adopte el valor del evento previamente definido. De forma que el procesador de datos 
crea o construye una variable dependiente que estima sí puede tomar cualquier valor (no está restringida a un rango de valores) y así podemos recurrir a los métodos de estimación de los modelos de regresión tradicionales para construir el modelo de regresión logística.

La identificación del mejor modelo de regresión logística se realiza mediante la comparación de modelos utilizando el cociente de verosimilitud, que indica a partir de los datos de la muestra cuanto más probable es un modelo frente al otro. La diferencia de los cocientes de verosimilitud entre dos modelos se distribuye según la ley de la Ji-cuadrado con los grados de libertad correspondientes a la diferencia en el número de variables entre ambos modelos.

En nuestro caso, la variable EEGq, la consideramos predictora y por tanto dependiente y es la que se desea modelizar, como es habitual en esta técnica, la variable es categórica y dicotómica (normalidad/alteración). El objetivo es obtener un índice de la probabilidad de que ocurra esta alteración cerebral o no en función de las diferentes tipologías de TDAH. Tras el procedimiento de introducción de datos, obtenemos la primera tabla (tabla 56).

Tabla 56. Regresión. Resumen del procesamiento de datos.

Casos no ponderados $^{\mathrm{a}} \quad \mathrm{N} \%$

Casos seleccionados Incluidos en el análisis 170 100,0

Casos perdidos $\quad 0 \quad, 0$

En la tabla 57, el procesador especifica la codificación de la variable dependiente (que debe ser dicotómica). Internamente el programa asigna el valor 0 al menor de los dos códigos, y el valor 1 al mayor. Es importante que el valor 1 identifique a la categoría de la variable dependiente que resulte ser el resultado evaluado (en nuestro caso "alteración"), ya 
que ello permite comprender mejor el coeficiente bi de las variables independientes y de control: un coeficiente de regresión positivo indicará que la probabilidad de alteración en la cartografía (valor interno 1) se incrementa con alguno de los tipos de TDAH.

Tabla 57 Regresión. Codificación de la variable dependiente

\begin{tabular}{lc}
\hline \multicolumn{2}{l}{ Valor original } \\
\hline Vormal & $\mathbf{0}$ \\
Alteración & $\mathbf{1}$
\end{tabular}

La tabla 58, muestra la codificación empleada en las variables independientes y de control (covariables). Sólo ha considerado oportunas tres variables y nos indica que la categoría codificada como 1 es Sin TDAH y la codificada como 0 es TDAH-Combinado y TDAH-Déficit de atención. Indicándonos además la frecuencia absoluta de los casos.

En el cuadro de definir variables categóricas hemos seleccionado en la casilla de contraste indicador y en categoría de referencia última (opciones que da el programa por defecto), la categoría codificada con el valor interno más bajo (0), por tanto será la de referencia, la "última" para el SPSS. Por tanto, vamos a obtener la probabilidad de estar afectado de alteración de la cartografía de las personas sin TDAH frente a las de tipo combinado y déficit de atención y de la alteración de la cartografía frente a las personas con TDAH combinado y las que no padecen TDAH. 
Tabla 58. Regresion. Codificación de las variables categóricas.

\begin{tabular}{crrr}
\hline & \multicolumn{3}{c}{ Codificación de parámetros } \\
\cline { 2 - 4 } & $\mathbf{N}$ & $\mathbf{( 1 )}$ & $\mathbf{( 2 )}$ \\
\hline Tipo de TDAHT $\sin$ TDAHT & 31 & $\mathbf{1 , 0 0 0}$ &, 000 \\
TDAH Combinado & 57 &, 000 & $\mathbf{1 , 0 0 0}$ \\
TDAH Déficit atención 82 & $\mathbf{, 0 0 0}$ & $\mathbf{, 0 0 0}$
\end{tabular}

Finalmente, se presenta el parámetro estimado (B), su error estándar (E.T.) y su significación estadística con la prueba de Wald, que es un estadístico que sigue una ley Chi cuadrado con 1 grado de libertad. Y la estimación de la OR (Exp (B) (fuerza de la asociación). En la ecuación de regresión sólo aparece, en este primer bloque, la constante. Sin embargo, como vemos en la subtabla inferior, como tiene una significación estadística asociada al índice de Wald de 0,029, el proceso automático por pasos continuará, incorporándola a la ecuación.15.

Tabla 59. Regresión. Variables de la ecuación.

\begin{tabular}{crrrrr}
\hline & B & E.T. Wald & gl Sig. & $\operatorname{Exp}(\mathrm{B})$ \\
\hline Paso $1^{\text {a }}$ TDAHT & \multicolumn{4}{r}{37,121} & 2,000 \\
TDAHT(1) & $-1,889,648$ & 8,508 & $1, \mathbf{0 0 4}$ & $\mathbf{, 1 5 1}$ \\
TDAHT(2) & $2,019,427$ & 22,370 & $1, \mathbf{0 0 0}$ & $\mathbf{7 , 5 2 9}$ \\
Constante & $-, 345,224$ & 2,367 & 1,124 &, 708 \\
\hline
\end{tabular}

a. Variable(s) introducida(s) en el paso 1: TDAHT.

Las primeras tablas (57 y58) nos indican que recodificación ha tomado el SPSS. Vemos que para la variable cartografía total la ha tomado al igual que en nuestro archivo y para la variable de TDAHT ha creado dos variables dicotómicas para realizar mejor la 
regresión binaria. Como en ambas variables nuevas el valor de déficit de atención es 0 , quiere decir que el SPSS toma como referencia dicha variable.

La tabla 59 nos muestra la significación y los odds ratios: Observamos que comparando con tener déficit de atención, tener TDAHT combinado multiplica por 7,529 y no tener TDAHT multiplica con 0,151 las probabilidades de tener cartografía total con alteración (en ambos casos se alcanza la significación estadística $(\mathrm{p} 1=0,004, \mathrm{p} 2=0,000)$ ).

Estos resultados manifiestan que existen algunas diferencias entre dos de los tipos de TDAH, presentando una mayor probabilidad de tener una cartografía alterada los niños y jóvenes que son diagnosticados con el tipo combinado. No hemos podido establecer discrepacias en este sentido con el resto de tipologías del trastorno, por lo que consideramos que la cuarta hipótesis del estudio se confirma sólo en parte. 
CAPÍTULO 12. CONCLUSIONES, DISCUSION Y LÍNEAS FUTURAS 
Utilidad de la cartografía cerebral en el diagnóstico del TDAH 


\subsection{CONCLUSIONES DEL ESTUDIO}

Tras la obtención e interpretación de los resultados obtenidos en este estudio exponemos a continuación, de modo sintético, las conclusiones más relevantes:

1. La cartografía cerebral es una técnica muy digna de tener en cuenta en el diagnóstico pues proporciona una valiosa ayuda a la hora de comprender y completar información importante de las personas afectadas de TDAH.

2. Por sí sóla no permite discriminar a los niños y jóvenes afectados de TDAH pero ayuda y facilita el diagnóstico, proporcionando además, mayor comprensión de esta patología.

3. La muestra de participantes con TDAH ha manifestado ser la que con mayor frecuencia ha presentado una cartografía cerebral alterada.

4. Alrededor del $80 \%$ de los que fueron diagnosticados de TDAH de los tiposcombinado, con déficit de atención y sin especificar presentan alteración cartográfica, y el $66 \%$ en la tipología impulsivo-hiperactivo.

5. Las alteraciones más frecuentes en la cartografía de los niños y jóvenes afectados con TDAH son el enlentecimiento frontal derecho y el enlentecimiento si especificar, seguido del enlentecimiento frontal izquierdo y el bi frontal. 
6. La estimación de riesgo de presentar alteración cerebral en la muestra con diagnóstico psicopatológico (TDAH y otras psicopatologías) es 13,42 veces mayor que en los participantes de la muestra que no obtuvo diagnostico alguno.

7. El riesgo para los TDAH ha resultado ser 49,7 veces mayor que para los no diagnosticados. *En la muestra de TDAH-combinado, es riesgo se eleva a 70 veces más. *Si el TDAH es de tipo déficit de atención, la probabilidad es 37,3 veces mayor.* Si el tipo de TDAH es impulsivo o hiperactivo se ha obtenido un riesgo de 18,1 y de 37,3 veces mayor, respectivamente, que en los que no recibieron diagnóstico.

8. Comparando la muestra de TDAH con la del conjunto de diagnosticados con otros trastornos psicopatológicos el riesgo de presentar alteración cartográfica de los TDAH es 24,4 veces mayor.

9. Por tipologías:

* el de tipo combinado ha resultado ser 10,8 veces mayor.

*el déficit de atención, 5,64 veces.

*el hiperactivo-impulsivo 2,57 y *el TDAH sin especificar 5,6 veces mayor.

10. El estudio de la regresión logística indica que la probabilidad de presentar alteración cartográfica al tener un TDAH-combinado comparado con tener un diagnóstico de TDAH-déficit de atención, se multiplica por 7,5, frente al no estar diagnósticado de TDAH pues, el de estos últimos, el riesgo es muy pequeño, el 0,15. 


\subsection{DISCUSIÓN Y LINEAS FUTURAS DE INVESTIGACION}

Desde las primeras descripciones del trastorno hasta lo que se conoce actualmente sobre el mismo, se han ido realizando cambios en estas descripciones. En el inicio se consideró con determinación la idea de un origen orgánico del cuadro y la aparición de los síntomas en niños que habían padecido encefalitis reforzó la idea de que los problemas tenían su origen en lesiones cerebrales. Las dificultades para constatar tales lesiones llevaron a postular el concepto de daño cerebral mínimo y, posteriormente, disfunción cerebral mínima. Por otra parte, el descubrimiento de los efectos de los psicoestimulantes impulsó una reflexión sobre otro tipo de anomalía cerebral, no estructural, sino neuroquímico.

El proceso de definición del trastorno sugiere actualmente la existencia de un cuadro complejo, con tres grupos de síntomas (atención, impulsividad, hiperactividad) y de origen orgánico, sea por lesión estructural o por fallos neuroquímicos. A medida que se ha ido avanzando en el conocimiento de este trastorno, el TDAH aparece como una entidad patológica compleja, que afecta sutilmente al funcionamiento cognitivo y conductual. Para explicarlo, se han propuesto diversas hipótesis sobre la estructura anatómica, neurofisiológica y neuroquímica que estaría afectada en este trastorno. Todo ello sugiere que en el TDAH se combinan alteraciones morfológicas, funcionales y de la conectividad de varios circuitos que intervienen en las funciones ejecutivas (Rubia y cols, 2014). Sin embargo, hasta la fecha no se han identificado biomarcadores objetivos del trastorno. Una parte de la dificultad tiene que ver con las limitaciones de las investigaciones, con muestras pequeñas o problemas de diseño. Otra, tiene que ver con la naturaleza del propio trastorno. Al igual que otras condiciones médicas, el TDAH posiblemente sea una condición compleja que no tiene causa única (Van-Wielink, 2005). Todas estas alteraciones darían como resultado, afectación de las funciones ejecutivas $\mathrm{y}$, como consecuencia, de dicha alteración, la incapacidad que tienen 
estos niños para ser capaces de automonitorar su desempeño y responder con éxito a las demandas del medio.

Los niños con TDAH, en líneas generales, tienen un nivel intelectual y de procesamiento de la información dentro de los parámetros de la normalidad. Su aprendizaje, tanto académico, social o comportamental se va desarrollando, aunque mucho más lento que los niños sin este trastorno del neurodesarrollo. Necesitan la tutela de alguien que les guíe para que puedan poner en marcha estas habilidades adquiridas. Sin esta monitorización constante, estos niños no las utilizan o lo hacen de un modo muy desorganizado.

Todo este conocimiento, nos lleva a realizar evaluaciones mucho más concretas en torno al trastorno. La evaluación del TDAH se realiza fundamentalmente a través de la entrevista clínica y recogida de observaciones conductuales de padres y docentes (AACAP, 1997). Las valoraciones psicométricas generales y de funciones específicas sirven para complementar o precisar la información obtenida en la entrevista, así como para valorar los progresos en el tratamiento. No tienen, en cambio, valor diagnóstico. Las escalas de observación conductual cubiertas por padres y docentes, son altamente subjetivas. Las valoraciones de inteligencia, lectura y habilidades escolares sirven para obtener información útil, pero sin capacidad para discriminar niños con TDAH y niños sin TDAH. Las pruebas de atención o memoria se diseñaron para explorar otro tipo de problemas de salud. En resumen, no contamos con una prueba que permita diagnosticar objetivamente el TDAH.

Esta es una laguna importante en el abordaje del problema. Una patología que supone la mayor parte de las consultas en los servicios de Salud Mental, en la que se han encontrado hallazgos neurofisiológicos, biológicos y genéticos, y cuyo principal tratamiento es farmacológico, debería poder ser diagnosticada con una prueba objetiva o combinación de pruebas objetivas. 
Es posible que el problema tenga relación con la historia del trastorno. Como hemos visto, desde su identificación inicial ha experimentado sucesivos cambios de definición y conceptualización. La observación del trastorno se inició en niños hiperactivos y las primeras definiciones se centraron en los síntomas de hiperactividad e impulsividad, así como en el carácter infantil y su remisión a lo largo de la adolescencia. A medida que mejoraba el conocimiento del cuadro y se disponía de información sobre su evolución a lo largo de los años, el énfasis se desplazó a los síntomas de atención, concentración, esfuerzo y memoria, así como a su carácter potencialmente crónico. La definición pasó de "trastorno de hiperactividad" a "trastorno por déficit de atención". Como resultado de los cambios de conceptualización, y, correlativamente, de criterios diagnósticos, el enfoque de la evaluación fue transformándose. Esto podría explicar el escaso desarrollo actual de herramientas diagnósticas, especialmente acusado si lo comparamos con el desarrollo de tratamientos farmacológicos. La gran paradoja de la situación actual es que la respuesta clínica a la enfermedad es notablemente mejor conocida, más precisa y efectiva que los procedimientos para diagnosticarla. Otra cuestión importante a tener en cuenta es lo referente a la evaluacion complementaria que se realiza para llegar al diagnóstico del TDAH, hablamos de la evaluación neurofisiológica, que gracias a los avances recientes en informática ponen a disposición de los clínicos técnicas más precisas de registro, análisis y comparación de la señal eléctrica (Kropotov, 2009) Es un campo en constante renovación. Si en los próximos años se generaliza su uso, podrán proporcionar información más objetiva para el diagnóstico del TDAH.

Una vez que se ha realizado la evaluación, y se han tenido cuenta criterios diagnósticos del trastorno, más todas aquellas pruebas necesarias que apoyen al diagnostico y definan el trastorno, se hace necesario el desarrollo de un programa terapéutico que conlleve un proceso de control contínuo de la situación y revisiones periódicas de las necesidades. 
Jensen y Abikoff (2003) exponen los múltiples factores que deben considerarse al adaptar los planes terapéuticos a sujetos concretos y sus familias. El principal problema es determinar en cada momento qué intervención psicosocial será necesaria para desarrollar un tratamiento eficaz para sujetos con el trastorno y sus familias. Cuando se utilizan las intervenciones psicosociales apropiadas, se fomentan expectativas realistas en el paciente y sus familiares, decisivas para mantener el trabajo difícil y a menudo frustrante necesario para modificar los efectos destructivos del trastorno y sus complicaciones.

El TDAH es una alteración de naturaleza crónica, pero este hecho no significa que no pueda o no deba tratarse, sino que pone de manifiesto la necesidad de descubrir nuevas alternativas terapéuticas, farmacológicas y educativas, que garanticen la eficacia a largo plazo de dichos tratamientos y una adecuada mejoría clínica, (Mediavilla-Garcia, 2003).

La valoración neurofisiológica como evaluación complementaria en el diagnóstico del TDAH abre un nuevo campo de posibilidades aunque también presenta algunas limitaciones. Hasta hace poco, la bibliografía científica en torno al TDAH planteaba la inexistencia de pruebas neurobiológicas y neurofisiológicas específicas para establecer el diagnóstico preciso de este trastorno del neurodesarrollo. Las investigaciones llevadas a cabo no encontraban resultados consistentes y comunes que avalaran un patrón neurofisiológico y neurobioquímico del TDAH, (Catelan-Mainardes y cols, 2010).

Los datos procedentes de estos estudios no son, en general, muy concluyentes, posiblemente, y una vez más, debido a las muestras usadas, tan diferentes y heterogéneas de sujetos y a los criterios de los diferentes subtipos de TDAH que han ido cambiando con el cuadro nosológico a lo largo del tiempo (Smeyer, 1999; Snyder y Hall, 2006).

A medida que vamos avanzado en el conocimiento de este trastorno, la tecnología aplicada a las neurociencias ha permitido una mayor precisión tanto en la exploración funcional del cerebro como en la confirmación y elaboración de diagnósticos diferenciales 
para trastornos como el TDAH. Prueba de ello son los avances que se han dado hasta el momento con técnicas de exploración funcional del cerebro, tales como el electroencefalograma cuantificado $(\mathrm{EEGq})$, la resonancia magnética funcional o la magnetoencefalografía, entre otros. Estas técnicas, si bien no brindan por sí solas el diagnóstico, son herramientas de gran importancia y complementan la evaluación neuropsicológica y la perspectiva semiológica de los profesionales que trabajan en salud mental, (Delgado-Mejia y cols, 2014).

Los estudios neurofisiológicos mencionados nos están proporcionando un conocimiento cada vez más detallado de la implicación de distintas áreas cerebrales en el procesamiento de la información.

Algunos estudios similares (Barry y cols, 2003) encuentran alteración en coherencia interhemisférica en bandas delta y theta, que consistió en una elevación de dicha coherencia y a su vez un aumento de la coherencia en banda alfa.

Clarke, (2000, 2002), Janzen y cols (1995) y Valdizán, (1998), encontraron que las ratios entre diferentes ondas, como puede ser la ratio Theta/ alfa o la ratio Theta/ beta, obtienen tambien índices significativos patológicos en esta población.

Los registros previos EEG no han sido del todo concluyentes en documentar la prevalencia y naturaleza de las disfunciones neurofisiológicas en TDA o TDAH. Pero al igual que en nuestro estudio llevado a cabo con EEGq las investigaciones que han usado registros convencionales EEG, muestran hallazgos anormales entre un 30 y un $60 \%$ de los niños con TDAH, (Swartwood y cols 2003).

Si tenemos en cuenta los principales parámetros neurofisiológicos empleados en el estudio cuantitativo del EEG (EEGq), siendo la Potencia Absoluta, Potencia Relativa, Amplitud de onda, Frecuencia media y Coherencia EEG de la onda, basándonos en estos métodos de análisis empleados, encontraron alteraciones que consisten en un incremento en 
la potencia absoluta y potencia relativa para la onda Theta, predominantemente en zonas frontales y prefrontales. (Clarke y cols, 1998; Chabot y Serfontein, 1996; Lazzaro y cols, 1998; Lubar, 1991). Nuestro estudio ha obtenido resultados similares aunque hemos delimitado más la localización, obteniendo alteración en zona frontal derecha y sin especificar.

Todos estos estudios neurofisiológicos mencionados, incluido el nuestro, están proporcionando un conocimiento cada vez más detallado de la implicación de distintas áreas cerebrales en el procesamiento de la información y tal repercusión tiene esto, que en Julio del 2013, la FDA (Food and Drug Administration) estadounidense aprobó el primer Cociente theta/beta (NEBA) en el diagnóstico del trastorno por déficit de atención/hiperactividad.

Recientemente, el sistema NEBA ha ido surgiendo como alternativa en el proceso diagnóstico ante la necesidad de determinar con mayor precisión si los síntomas de hiperactividad, impulsividad y desatención son manifestaciones de un TDAH primario, secundario o responden a una sintomatología comórbida de otros trastornos asociados. Se trata de un método no invasivo que permite reconocer un biomarcador electroencefalográfico para el TDAH, identificado en la relación theta/ beta estandarizada, que arroja información no sólo sobre el registro de los diferentes tipos de impulsos eléctricos que emiten las neuronas en el cerebro sino también sobre la frecuencia de emisión de dichos impulsos (FDA, 2013). De este modo, este sistema permite calcular e identificar el cociente theta/beta característico en el TDAH, (Delgado-Mejia y cols, 2014).

Según lo descrito por diferentes autores, (FDA, 2013; Loo y cols, 2012., NEBA, 2013) el cociente theta/beta, obtenido a través de la colocación de un electrodo de contacto en el cuero cabelludo en la región conocida como vértex o su equivalente neurofisiológico $(\mathrm{Cz})$, es superior en niños y adolescentes con TDAH en comparación con grupos controles lo que permite postularlo como indicador de gran relevancia en el diagnóstico de este trastorno 
(Amer y cols, 2010; Bresnahan y cols, 1999; Nazari y cols, 2011; Reyes- Zamorano y cols, 2010).

En resumen, estos avances y sus hallazgos proporcionarán una guía inicial abierta a futuras investigaciones que permitirán examinar cada vez con mayor precisión, la técnica de la EEGq como indicador para el diagnóstico del TDAH. 
Utilidad de la cartografía cerebral en el diagnóstico del TDAH 
REFERENCIAS BIBLIOGRÁFICAS 
Utilidad de la cartografía cerebral en el diagnóstico del TDAH 


\section{REFERENCIAS BIBLIOGRÁFICAS}

Abad-Mas, L., Ruiz-Andrés, R, Moreno- Madrid, F., Herrero, R., Suay, E. (2013). Intervención psicopedagógica en el trastorno por déficit de atención/ hiperactividad. Rev Neurol, 57 (Supl 1): S193-20.

Achenbach, T.M. (1991). Integrative Guide for the 1991 CBCL14- 18, YSR, and, TRF Profiles. Burlington: University of Vermont, Department of Psychiatry.

Alcaina-Prósper T, Miota-Ibarra I, Pélaz S. y De La Fuente J.E. (2000) Trastornos hipercinéticos. En J.R. Gutiérrez y F. Rey. Planificación terapéutica de los trastornos psiquiátricos del niño y del adolescente. Madrid: SmithKline Beecham, 335-445.

Allen, G., Buxton, R.B., Wong, E.C. y Courchesne, E. (1997). Attentional activation of the cerebellum independent of motor movement. Science, 275, 1940- 1943.

Almeida, L.G. (2005). Alteraciones anatómico-funcionales en el trastorno por déficit de atención con hiperactividad. Salud Mental, 28(3), 1-12.

Amer D.A., Rakhawy, M.Y., El Kholy, S.H.(2010). Quantitative EEG in children with attention deficit hyperactivity disorder. Egypt J Neurol Psychiatr Neurosurg, 47: 399-406. 
American Academy of Children and Adolescent Psychiatriy: Practice parameters for the treatment of children, adolescents, and adults with atenttion-deficit/hyperactivity Disorder. American Academy of Child and Adolescent Psychiatry. J Am Acad Chil Adolesc Psychiatry. 36 (10 suppl.), 85S-121S, 1997.

APA. American Psychiatric Association. (1984). DSM-III Manual diagnóstico y estadístico de los trastornos mentales. Barcelona: Masson.

APA. American Psychiatric Association. (1995). DSM-IV Manual diagnóstico y estadístico de los trastornos mentales. Barcelona: Masson.

APA. American Psychiatric Association (2002). Manual diagnóstico y estadístico de los trastornos mentales (DSM-IV-TR). Barcelona: Masson.

Anastasi, A. (1988). Psychological Testing, 6 th Edition. New York: Mcmillan.

Anderson, W. (1963). The hyperkinetic child: A neurological appraisal. Neurology, 13, 968973.

Anderson, C.M., Polcari, A.M., Lowen, S.B., Renshaw, P.F. y Teicher, M.H. (2002). Effects of methylphenidate on functional magnetic resonance relaxometry of the cerebellar vermis in children with ADHD. Am J Psychiatry. 159, 1322- 1328.

Arán, V., Mias, C.D. (2009). Neuropsicología del Trastorno por Déficit de Atención/Hiperactividad: subtipos predominio Déficit de Atención y predominio Hiperactivo-Impulsivo. Revista Argentina de Neuropsicología, 13, 14-28

Ardila, A., Roselli, M. (2007). Neuropsicología clínica. México: Manual Moderno. 
Arns, M., Gunkelman, J., Olbrich, S., Sander, C. y Hegerl, U (2011). EEG Vigilance and Phenotypes in Neuropsychiatry: Implications for Intervention. Neurofeedback and Neuromodulation Techniques and Applications. London: Elsevier Inc.

Arolt, V. (2008) Aufmerksamkeitsdefizit-/Hyperaktivita“tssto“rung.Wachsendes Wissen erfordert neue therapeutische Mo“glichkeiten. Nervenarzt, 79, 769-770.

Aylward, E.H., Reiss, A. L., Reader, M.J., Singer, H.S., Brown, J.E. y Denckla, M.B. (1996). Basal ganglia volumes in children with attention- deficit hyperactivity disorder. $J$ Child Neurol. 11, 112- 115.

Ball, D.M., Tiernan, J., Janusz. y Furr, A. (1997). Sleep patterns among children with attention deficit hyperactivity disorder: a reexamination of parent perceptions. $J$. Pediatric. Psychol. 22, 389-398.

Bente, D. (1964). Die insuffizienz des vigilitatstonus. Thesis, Habilitationsschrift, Erlangen.

Barry, R.J., Clarke, A.R., McCarthy, R. y Selikowitz, M. (2002). EEG coherence in attentiondeficit/hyperactivity disorder: a comparative study of two DSM-IV types. Clin Neurophysiol. 113, 579-585.

Barry, R.J., Johnstone, S. J. y Clarke, A.R. (2003). A review of electrophysiology in attention-deficit/ hyperactive disorder: II Event-related potentials. Clinical Neurophysiology, 114, 184-198.

Barry, R.J, Clarke, A.R. y Stuart, J.J. (2003). A review of electrophysiology in attentiondeficit/ hyperactive disorder: I Qualitative and quantitative electroencephalography. Clinical Neurophysiology 114, 171-183. 
Barkley R.A. (1987). Behavioral inhibition, sustained attention, and executive functions: Constructing a unifying theory of ADHD. Psychol Bull, 121: 65-94

Barkley, R.A. (1991). Attention Deficit Hyperactivity Disorder Clinical Workbook. New York: Guilford.

Barkley, R.A. (1997). ADHD and the nature of Self Control. New York: The Guilford Press.

Barkley, R.A. (1997). Behavioural inhibition, sustained attention, and executive functions: constructing a unifying of ADHD. Psychol Bull. 121, 65-94.

Barkley, R.A. (1990). Attention deficit hyperactivity disorders: A handbook for diagnosis and treatment. Nueva York: Guilford.

Barkley, R.A. (2006). Attention- Deficit Hyperactivity Disorder. A Handbook for diagnosis and treatment. Third edition. Nueva York: Guilford Publications.

Barkley, R.A. y Murphy, K.R. (2006). Attention-deficit Hyperactivity Disorder: A Clinical Workbook. Nueva York: Guilford Publications.

Barkley, R.A. (1989). Attention- deficit hyperactivity Disorder: en E.J Mash y R. A Barkley (Eds), Treatment of childhood disorders (pp 39-72) New York: Guilford Press.

Barkley, R.A. (1997). Behavioural inhibition, sustained attention, and executive functions: constructing a unifying of ADHD. Psychol Bull. 121.65-94.

Bernal-Lafuente. M., Valdizán. J. R. y García-Campayo, J. (2004). Estudio polisomnográfico nocturno en niños con trastorno por déficit de atención con hiperactividad. Revista de Neurología. (Supl 1), S103-S110. 
Berwid, O.G., Curko- Kera, E., Marks, D.J., Santra, A., Bender, H.A y Halperin, J.M (2005). Sustained attention and response inhibition in young children at risk for attention deficit/hyperactivity disorder. Journal of Child Psychology and Psychiatry, 46, 1219-1229.

Birch, H.G. (1964) Brain damage in children: the biological and social aspects. Baltimore: Williams y Wilkens.

Boutros, N., Fraenkel, L. y Feingold, A. (2005). A Four-Step Approach for Developing Diagnostic Tests in Psychiatry: EEG in ADHD as a Test Case. The Journal of Neuropsychiatry and Clinical Neurosciences, 17, 455-464.

Buitelaar, J.K. y Engeland, H. (1996). Epidemiological approaches. En S. Sandberg (Ed.). Hyperactivity disorders of childhood. Cambridge: Cambridge University Press.

Burch, N.R., Nettleton, W.J., Sweewey, J y Edwards, R.Y. (1964). "Period analysis of the electroencephalogram on a general purpose digital computer" Ann. Acad. Sci. of New York, 115, 827-843.

Busby, K., Firestone, P. y Pivik. R.T. (1981). Sleep patterns in hyperkinetic and normal children. Sleep, 4, 366-383.

Bradley, C. (1937). The behavior of children receiving benzedrine. Am J Psychiatry, 94, 577585.

Bresnahan, S.M., Anderson, J.W., Barry R.J. (1999). Age related changes in quantitative EEG in attention-deficit/hyperactivity disorder. Biol Psychiatry, 46: 1690-7. 
Broughton, R. y Hasan, J. (1995). Quantitative topographic electroencephalographic mapping during drowsiness and sleep onset. Journal of Clinical Neurophysiology: Official Publication of the American Electroencephalographic Society, 12(4), 372-386.

Brown, T.E. (1996). Atenttion- Deficit Disorder Scales. San Antonio, TX, Psychological Corporation/ Harcout Brace Jovanovich.

Brown T. E. y McMullen, W.J. (2001) Attention deficit disorders and sleep/arousal disturbance. Ann N Y Acad Sci, 931, 271-86.

Brown, T.E (2001). Attention Deficit Disorder Scales for Children. San Antonio Texas: Psychological Corporation.

Brown T.E. (2003). Trastornos por déficit de atención y comorbilidades en niños, adolescentes y adultos. Barcelona: Masson.

Brown, T.E (2006). Trastorno por déficit de atención. Una mente desenfocada en niños y adultos. Barcelona: Masson.

Brown, W. A (1998) Charles Bradley, M.D., 1902-1979. Am J Psychiatry, 155-968.

Cabanyes-Trufino, J. (1999). Cartografía cerebral: metodología y aplicaciones en la clínica neurológica. Rev Neurol, 28, 1090-1098.

Calderón, C. (2003) Trastorno por déficit de atención con hiperactividad. Evaluación y tratamiento psicológico. Tesis doctoral presentada en el Departament Personalitat Avaluació i Tractament Psicológic. Barcelona: Universidad de Barcelona.

Callaway, E., Halliday, R. y Naylor, H. (1983). Hyperactive children's event-related potentials fail to support underarousal and maturationl-lag theories. Arc Gen Psychiatry 40, 1243-1248. 
Capute, A., Nierdermeyer, E. y Richardson, F. (1968). The electroencephalogram in children with minimal cerebral dysfunction. Pediatrics, 41, 1104-1114.

Cardo, E. y Servera-Barceló, M. (2005). Prevalencia del trastorno de déficit de atención e hiperactividad. Rev Neurol, 40. S.11-15.

Casey, B.J., Castellanos F.X., Giedd, J.N., Marsh, W.L, Hamburger y cols. (1997). Implication of right frontostriatal circuitry in response inhibition and attention deficit/hyperactivity disorder. J Am Acad Child Adolesc Psychiatry, 36: 374-83

Cash, S.S., Halgren, E., Dehghani, N., Rossetti, A. O., Thesen, T., Wang, C y cols. (2009). The human k-complex represents an isolated cortical down-state. Science, 324 (5930), 1084-1087.

Castellanos, F.X., Gieed, J.N., Marsh, W.L., Hamburger, S.D., Vaituzis, A.C., Dickstein, D. P y cols. (1996). Quantitative brain magnetic resonance imaging in attention- déficit/ hiperactivity disorder and normal controls. Neurology, 48, 589- 601.

Castellanos F.X. (1997). Neuroimaging of attention-deficit hyperactivity disorder. Child Adolesc Psychiatr Clin N Am, 6: 383-411.

Castellanos, F.X., Lee, P.P., Sharp, W., Jeffries, N.O., Greenstein, D.K., Clasen, L.S y cols. (2002). Developmental trajectories of brain volume abnormalities in children and adolescent with attention- deficit/hyperactivity disorder. JAMA. 288, 1740-1748.

Castellanos. F.X y Acosta, MT. (2002). El síndrome de déficit de atención con hiperactividad como expresión de un trastorno funcional orgánico. Rev Neurol, 35, 1-11. 
Castellanos, F.X. y Acosta, M.T. (2004) Neuroanatomía del trastorno por déficit de atención con hiperactividad. Rev Neurol, (Supl. 1), 131-136.

Castellanos, F.X., Sonuga-Barke, E.J., Milham, M.P y Tannock, R. (2006). Characterizing cognition in ADHD beyond executive dysfunction. Trends in Cognitive Sciences, $10,117-123$.

Castellanos, F.X. y Acosta, M.T. (2011). Hacia un entendimiento de los mecanismos moleculares de los tratamientos farmacológicos del trastorno por déficit de atención / hiperactividad. Rev Neurol, 52, (Supl). S155-S160.

Catelan-Mainardes S.C. (2010). Trastorno de déficit de atenção e hiperatividade na infância e adolescência pela perspectiva da neurobiologia. Revista Saúde e Pesquisa, 3: 38591.

Capdevila-Brophy, C., Artigas-Pallarés, J., Ramírez- Mallafré, A., López- Rosendo, M., Real, J y cols. (2005). Fenotipo neuropsicológico del trastorno de déficit atencional/ hiperactividad: ¿existen diferencias entre los subtipos? Rev Neurol, 40 (Supl 1). S17S23.

Capdevila-Brophy, C., Artigas-Pallarés, J. y Obiols-Llandricha, J.E. (2006). Tempo cognitivo lento: ¿síntomas del trastorno de déficit de atención/hiperactividad predominantemente desatento o una nueva entidad clínica? Rev Neurol, 42 (Supl. 2), S127-S134.

Chabot, R.J,. di Michele, F., L. Prichep,. John, E.R. (2001). The clinical role of computerized EEG in the evaluation and treatment of learning and attention disorders in children and adolescents .J Neuropsychiatry Clin Neurosci, 13, 171-186. 
Chess, S. (1960). Diagnosis and treatment of the hyperactive child. New York State Journal of Medicine, 60, 2379-2385.

Coburn, K.L., Lauterbach, E.C., Boutros, N.N., Black, K.J., Arciniegas, D.B. y cols. (2006). The value of quantitative electroencephalography in clinical Psychiatry: A report by the Committee on Research of the American Neuropsychiatric Association. Journal of Neuropsychiatric Association, 18(4), 460-500.

Coles, M.G.H., Rugg, M.D. (1995). Event-related brain potentials: an introduction. En M.G.H Coles (ed). Electrophysiology of mind. Oxford: Oxford University Press; p. $1-26$.

Colomer-Diago, C., Miranda-Casas, A. y Herdoiza-Arroyo, P., Presentación- Herrero, M.J. (2012). Funciones ejecutivas y características estresantes de niños con trastorno por déficit de atención/hiperactividad: influencia en los resultados durante la adolescencia. Rev Neurol, 54 (Supl. 1), S117-S126.

Connemann, B., Mann, J., Lange-Asschenfeldt, K., Ruchsow, C., Schreckenberger, M., Bartenstein, P y cols (2005). Anterior limbic alpha-like activity: A low resolution electromagnetic tomography study with lorazepam challenge. Clinical Neurophysiology: Official Journal of the International Federation of Clinical Neurophysiology, 116(4), 886-894.

Cooley, J.W. y Tukey, J.W. (1965) An algorithm for the machine computation of the complex Fourier series. Mathematics of Computation, 19. 297-301.

Conners, C.K. (1997). Conners Rating Scales-Revised. North Tonawanda. NY: Multi-Health Systems. 
Conners, C.K (2000) Attention-deficit/hyperactivity disorder: historical development and overview. J Atten Disord, 3, 173-191.

Corkum, P.V. y Siegel, L.S. (1993). Is the continuous performance test a valuable research tool for use with children with attention- deficit- hyperactivity disorder? $J$ Chil Psychol Psychiatry, 34, 1217-1239.

Corkum, P., Tannock, R. y Moldofsky, H. (1998). Sleep disturbances in children with attention-deficit hyperactivity disorder. J Am Acad Child Adolesc Psychiatry, 37, 637-646.

Chabot, R., Di Michele, F. y Prichep, L. (2005). The rol of quantitative electroencephalography in child and adolescent psychiatric disorder. Chid Adolesc Psychiatric Clin N Am, 14, 21-53.

Chabot, R. y Serfontein, G. (1996). Quantitative electroencephalographic profiles of children with attention deficit disorder. Biol. Psychiatry, 40, 951-963.

Chabot, R., Orgill, A., Crawford, G., Harris, M. y Serfontein, G. (1999). Behavioural and electrophysiological predictors of treatment response to stimulants in children with attention disorders. J Child Neurol, 14, 343-351.

Chess, S. (1960). Diagnosis and treatment of the hyperactive child. New York State Journal of Medicine, 60, 2379-85

Chervin, R.D., Archbold, K.H., Dillon, J.E., Pituch, K.J., Panahi, P y cols. (2002). Associations between symptoms of inattention, hyperactivity, restless legs, and periodic leg movements. Sleep, 25(2), 213-218. 
Clarke, A.R., Barry, R.J., McCarthy, R. y Selikowitz, M. (1998) EEG analysis in attentiondeficit/hyperactivity disorder: a comparative study of two subtypes. Psychiatry Research, 81, 19-29.

Clarke, A.R., Barry, R.J., Mc Carthy, R. y Selikowitz, M. (2001). EEG- defined subtypes of children with attention-deficit/ hyperactive disorder. Clinical Neurophysiology, 112, 2098-105.

Clarke, A.R., Barry, R.J., Mc Carthy, R., Selikowitz y M., Brown, C.R (2002). EEG evidence for a new conceptualisation of attention deficit hyperactive disorder. Clinical Neuropsysiology, 113, 1036-1044.

Clarke A., Barry R..J., McCarthy, R., Selikowitz, M., Johnstone S y cols. (2007) Coherence in children with Attention-Deficit/ Hyperactivity Disorder and excess beta activity in their EEG. Clinical Neurophysiology 118 (2007) 1472- 1479.

Crichton, A. (1798) An inquiry into the nature and origin of mental derangement: comprehending a concise system of the physiology and pathology of the human mind and a history of the passions and their effects. Cadell T Jr, Davies W. London.

Crichton A (2008) An inquiry into the nature and origin of mental derangement. On attention and its diseases. J Atten Disord, 12, 200-204.

Dahl, R. (1996). Regulation of sleep and arousal: Development and psychopathology. Development and Psychopathology. 8, 3-27.

Davidson, R.J. (1984). Hemispheric asymmetry and emotion. En K. Scherer y P. Ekman (Ed.). Approaches to emotion, 39-57. Hills-dale, NJ: Eribaum. 
Davidson, R.J. (1988a). Cerebral asymetry, affective style and psychopathology. En M. Kinsbourne (Ed). Hemisphere function in depression, 3-22). Washington, DC: American Psychiatric Association Press.

Davidson, R.J. (1988b). EEG measures of cerebral asymmetry: Conceptual and methodological issues. International Journal of Neuroscience, 39, 71-89.

Díaz Atienza, J. (2006). Tratamiento farmacológico del trastorno por déficit de atención con hiperactividad. Revista de psiquiatría y psicología del niño y del adolescente. 6 (1), 20-43.

D’ Elia, G., y Perris, C. (1973). Cerebral functional dominance and depresión. An análisis of EEG amplitude in depressed patients. Acta Psychiatrica Scandinavica, 49(3),191198.

De Bortoli, M., Barrios, P., Azpiroz, R. (2001). Relaciones entre los potenciales evocados cognitivos auditivos y el Test de Matrices Progresivas de Raven. RIPCS/IJCHP, Vol. 2, 327-334.

De Gennaro, L., Ferrara, M., Curcio, G. y Cristiani, R. (2001). Antero-posterior EEG changes during the wakefulness-sleep transition. Clinical Neurophysiology: Official Journal of the International Federation of Clinical Neurophysiology, 112(10), 1901-1911.

De Gennaro, L., Ferrara, M., y Bertini, M. (2001). The boundary between wakefulness and sleep: Quantitative electroencephalographic changes during the sleep onset period. Neuroscience, 107(1), 1-11. 
De Gennaro, L., Vecchio, F., Ferrara, M., Curcio, G., Rossini, P.M. y cols. (2004). Changes in fronto-posterior functional coupling at sleep onset in humans. Journal of Sleep Research, 13(3), 209-217.

De la Gándara, J.J., García Soto, X. R., Pozo de Castro, J.V. (2006). Despistado, acelerado e inquieto. ¿Es hiperactivo? Barcelona: Planeta.

De Zubicaray, G.I., Zelaya, F.O., Andrew, C., Williams, S.C. y Bullmore, E.T. (2000). Cerebral regions associated with verbal response initiation, suppression and strategy use. Neuropsychologia, 38, 1292- 1304.

Delgado-Mejía, I.D., Palencia-Avendaño, M.L., Mogollón-Rincón, C., Etchepareborda, M.C. (2014). Cociente theta/beta (NEBA) en el diagnóstico del trastorno por déficit de atención/hiperactividad. Rev Neurol, 58 (Supl 1): S57-63.

Delis D.C., Kramer J.H., Kaplan E., Ober B.A. (1987). The California Verbal Learning Test. New York: The Psychological Corporation.

Desmond, J.E., Gabrieli, J.D. y Glover, G.H. (1998). Dissociation of frontal and cerebellar activity in a cognitive task: evidence for a distinction between selection and search. Neuroimage, 7, 368- 376.

Desmond, J.E., Gabrieli, J.D., Wagner, A.D., Ginier, B.L. y Glover, G.H. (1997). Lobular patterns of cerebellar activation in verbal working- memory and finger-tapping tasks as revealed by functional MRI. J Neurosci, 17, 9675- 9685 .

Dishion, T.J., Patterson, G.R., Stoolmiller, M y cols (1991). Family, school, and behavioural antecedents to early adolescent involvement with antisocial peers. Dev Psychol, 27, $172-180$. 
Dykman, R., Holcomb, P., Oglesby, D. y Ackerman, P. (1982). Electrocortical frequencies in hyperactive, learning- disabled, mixed, and normal children. Biol Psychiatry, 17, 675-685.

Douglas, V.I. (1972). Stop, look, and listen: The problem of sustained attention and impulse control in hyperactive and normal children. Canadian Journal of Behavioural Science, 4, 259-282.

Douglas, V.I., Parry, P.A. (1983). Effects of reward on delayed reaction time task performance of hyperactive children. Journal of Abnormal Chil Psychology, 11, 313-326.

Douglas, V.I. (1988). Cognitive deficits in children with attention deficit disorder with hyperactivity. En L.M. Bloomingdale y J. Sergeant (Ed.): Atenttion deficit disorder:

Döofner, M., Frólich, J. y Lehmkuhl, G. (2000) Hyperkinetische Storungen. In: Doofner M, Lehmkuhl G, Peterman F (Eds). Reihe Leitfaden Kinder- und Jugendpsychotherapie, Bd. 1. Hogrefe, Göttingen.

Doyle, A.E. (2006). Executive functions in attention-deficit/hyperactivity disorder. J Clin Psychiatry, 67 (Supl. 8), S21-S26.

Ehlers, L.C., Gizer, I.R., Phillips, E. y Wilhelmsen, K.C (2010). EEG alpha phenotypes: Linkage analyses and relation to alcohol dependence in an American Indian community study. BMC Medical Genetics, 11,43.

Filipek, P.A, Semrud-Clikeman M, Steingard R.J, Renshaw P.F, Kennedy y cols. (1997). Volumetric MRI analysis comparing subjects having attention-deficit hyperactivity disorder and normal controls. Neurology, 48, 589-601. 
Fernández Torre J.L, (2002) Bases tecnológicas de los registros electroencefalográficos en: Manual de electroencefalografía. Mc Graw Hill interamericana, 149-50.

Fernández-Perrone, A.L., Fernández-Mayoralas, D.M., Fernández- Jaén, A.(2013). Trastorno por déficit de atención/hiperactividad: del tipo inatento al tipo restrictivo. Rev Neurol, 56 (Supl 1): S77-84.

Gadow, K.D. y Sprafkin, J. (1994). Child Symptom Inventories Manual. Stony Brook, NY: Check-mate Plus.

Gainotti, G. (1972). Emotional behavior and hemispheric side of the lesion. Cortex, 8, 41-55.

Garcell, Ricardo, J. y Rueda, W. (2009). Electroencefalograma y potenciales evocados relacionados con eventos en el trastorno obsesivo- compulsivo. Salud Mental, 32, (2), 173-181.

Gil-Nagel, A., Parra, J., Iriarte, J. y Kanner, A.M. (2001) Manual de electroencefalografía. Madrid: McGraw- Hill.

Giner I Bayarri, P., Rodrigo I Sanbartolomé, A., Moliner Ibañez, J., Chillet Chillet, R y cols (2010). Papel de la Neurofisiología en el TDAH. 11 Congreso virtual de psiquiatría. www.psiquiatria.com/pdf. Fecha de consulta: 03-04-12.

Golan, N., Shahar, E., Ravid, S. y Pillar, G (2004). Sleep disorders and daytime sleepiness in children with attention-deficit/hyperactive disorder. Sleep, 27(2), 261-266.

Goldesohn, E. (1993). Historical perspectives and future directions. Willie E. ed. The treatment of epilepsy, principles and practice. Pennsylvania: Lea y Febiger, 173184. 
Gloor, P. (1969). Hans Berger on the Electroencephalogram of Man. Amsterdam: Elsevier Publishing Company.

Green, L.M. y Waldman, I.D. (1993). Developmental normative data on the Test of Variables of Attention (TOVA). J Child Psychol Psychiatry, 4, 1019-1030.

Greenhill, L., Puig-Antich, J., Goetz, R., Hanlon, C. y Davies, M. (1983). Sleep architecture and REM sleep measures in prepubertal children with attention deficit disorder with hyperactivity. Sleep, 6, 91-101.

Greenhill, L., Pliszka, S., Dulcan, M., Bernet, W., Arnold, V., Beitchman J, y cols. (2002). Practice parameter for the use of stimulant medications in the treatment of children, adolescents, and adults. J Am Acad Child Adolesc Psychiatry, 41, 26-49.

Grieve, J. y Gnanasekaran, L. (2009). Neuropsicología para terapeutas ocupacionales: cognición en el desempeño ocupacional. $3^{\mathrm{a}}$ Ed. Buenos Aires. Médica Panamericana.

Green, J. (1961). Association of behaviour disorder with an electroencephalographic focus in children without seizures. Neurology, 11, 337-344.

Green, C., y Chee, K. (2000).. El niño muy movido o despistado. Entender el trastorno por déficit de atención con hiperactividad. Madrid: Medici.

Greenberg, L.M., y Waldman, I.D. (1993). Developmental normative data on the Test of Variable of Attention (T.O.V.A). Journal of Child Psychology and Psychiatry, 34, $1019-1030$. 
Gruber, R., Sadeh, A. y Raviv, A. (2000). Instability of sleep patterns in children with attention-deficit hyperactivity disorder. J Am Acad Child Adolesc Psychiatry, 39, 495-501.

Golden, C.J. (1978). Stroop Color and Word Test: A Manual for Clinical and Experimental Use. Chicago: IL. Stoelting.

Goldesohn, E. (1993) Historical perspectives and Future Directions. En E.,Willie (Ed.). The Treatment of Epilepsy, principles and practice. Pennsylvania: Lea y Febiger, 173184.

Gordon, M. (1986). How is a computerized attention test used in the diagnosis of attention déficit disorder? Journal of Children in Contemporary Society, 19(1-2). 53-64.

Gordon, M. (1983). The Gordon Diagnostic System. DeWitt, NY: Gordon Systems.

Gualteri T. (1995). The contribution of the frontal lobes to a theory of psychopathology. En Ratey J, ed. Neuropsychiatry of personality disorders. Cambridge: Blackwell Science. p. 149-71.

Hallowell, E.M. y Ratey, J.J. (1994). Driven to Distraction: Attention Deficit Disorder in Children and Adults. New York: Pantheon.

Henriques, J.B. y Davidson, R.J. (1990). Regional brain electrical asymmetries discriminate between previously depressed and healthy control subjects. Journal of Abnormal Psychology, 99 (1), 22-31.

Henriques, J.B. y Davidson, R.J. (1991).. Left frontal hypoactivation in depression. Journal of Abnormal Psychology, 100 (4), 535-545. 
Herrero Aldama, P (1981). Problemas psiquiátricos y electroencefalografía. Madrid: Editorial EGRAF.

Hill, D.E., Yeo, R.A., Hart, B., Vigil, J. y Brooks, W. (2003). Magnetic resonance imaging correlates of attention- deficit/hyperactivity disorder in children. Neuropsychology. 17, 496- 506.

Hoffman, H., (2007). Pedro Melenas. Barcelona: J.J. Olañeta Editor.

Hughes, J.R. y Roy John, E. (1999). Conventional and quantitative electroencephalography in Psychiatry. Journal of Neuropsychiatry and clinical Neurosciences, 11, 190-208.

Hynd, G.W., Semrud- Clikeman, M., Lorys, A.R., Novey, E.S. y Eliopulos, D. (1990). Brain morphology in developmental dyslexia and attention deficit disorder/ hyperactivity. Arch Neurol, 47, 919- 926.

Idiazábal-Alecha, M.A., Rodríguez-Vázquez, S., Guerrero-Gallo, D., Vicent-Sardinero, X. (2005). Utilidad de los potenciales evocados cognitivos en la valoración de la efectividad del tratamiento con metilfenidato en niños con trastorno de déficit de atención con hiperactividad. Rev Neurol, 40 (Supl. 1):S37-S0

Hynd, G.W., Hern, K.L., Novey, E.S., Eliopulos, D, Marshall R y cols. (1993). Attention deficit hyperactivity disorder and asymmetry of the caudate nucleus. J Child Neurol, 8: 339-47.

Ingersoll, B. y Goldstein, S. (1993). Attention Deficit Disorder and Learning Disabilities: Realities, Myths and Controversial Treatments. New York: Doubleday.

Iriarte, J., Urrestarazu, E., Alegre, M. y Artieda, J (2011). Electroencefalografía del adulto. Atlas bilingüe basado en casos clínicos. Madrid: Elsevier. 
Itil, T.M. (1975). Digital computer period analysed EEG in psychiatry and psychopharmachology. En G. Dolce, y H. Künkel, (Ed.). Computerized EEG analysis. (CEAN Conference). Fisher Verlag, Stuttgart, 289-308.

Janzen, T., Graap, K., Stephanson, S., Marshall, W., Fitzsimmons, G. (1995). Differences in baseline EEG measures for ADD and normally achieving preadolescents males. Biofeedback Self Regul, 20, 65-82.

Jasper, H., Solomon, P. y Bradley, C. (1938). Electroencephalographic analyses of behaviour problem children. Am J Psychiatry, 95, 641-658.

Jensen, P.S. y Abikoff, H. (2003). Adaptación individual a los tratamientos del trastorno por déficit de atención con hiperactividad: perspectivas clínicas y de investigación. En: Brown, T.E. (2003). Trastornos por déficit de atención y comorbilidades en niños adolescentes y adultos. Barcelona: Masson.

John E.R. y Prichep L.S. (1992): Event-related potentials and factor z-score descriptors of P3 in psychiatric patients. Ann ICYAcad Sci, 658, 256-275.

John, E., Prichep, L.S., Alper, K.R., Mas, F.,Cancro, R y cols. (1994). Quantitative electrophysiological characterisitics and subtyping of schizophrenia. Biol Psychiatry, 36, 801-826.

John, E., Prichep, L. y Easton, P. (1987). Normative data banks and neurometrics. Basic concepts, method and results of norm constructions. En A. Gevins y A. Remond (Ed.). Handbook of electroencephalography and clinical neurophysiology 1. Amsterdam: Elsevier, 919-923. 
John, E., Ahn, H., Princhep, L., Trepetin, M., Brown, D y cols. (1980). Developmental equations of the electroencephalogram. Science, 210, 1255- 1258.

Jonhson, K.A., Kelly, S.P., Bellgrove, M .A., Barry, E., Cox, M., Gill, M., y cols (2007). Response variability in attention deficit hyperactive disorder: evidence for neuropsychological heterogeneity. Neuropsychologia, 45, 630-638.

Johnstone, J., Gunkelman, J. y Lunt, J. (2005). Clinical database development: Characterization of EEG phenotypes. Clinical EEG and Neuroscience: Official Journal of the EEG and Clinical Neuroscience Society, (ENCS), 36(2), 99-107.

Kaiser, D.A. (2005). Basic principles of Quantitative EEG. Journal of adult development, Vol $12,99-104$.

Kates, W.R., Frederikse, M., Mostofsky, S.H., Folley, B.S., Cooper, K., Mazur- Hopkins, P y cols. (2002). MRI parcellation of the frontal lobe in boys with attention deficit hyperactivity disorder or Tourette syndrome. Psychiatry Res, 116, 63- 81.

Kazdin, A.E. (1997). Parent management training: evidence, outcomes, and issues. $J$ Am Acad Child Adolesc Psychiatry, 36, 1349-1356.

Kazdin, A.E. y Kagan, J. (1994). Models of dysfunction in developmental psychopathology. Clinical Psychology: Science and Practice, 1. 35-52.

Kennard, M. (1949). Inheritance of electroencephalogram patterns in children with behaviour disorders. Psychosom Med, 11, 151-157.

Kessler, J.W (1980) History of minimal brain dysfunctions. En H.E. Rie y E.D. Rie (Ed.) Handbook of minimal brain dysfunctions: a critical view. Wiley, New York, 18-51. 
Kinsbourne, M. (1973). Minimal brain dysfunction as a neurodevelopmental lag. Ann N Y Acad Sci , 268-273.

Klimesch, W. (1998). EEG oscillations reflect cognitive and memory performance: a review and analysis. Brain Research Reviews, 29, 169-195.

Klorman, R. (1991). Cognitive event related potentials in attention deficit disorder. J Learn Disabil. 24, 130-140.

Kropotov, J. (2009). Quantitative EEG, event-related potentials and neurotherapy. San Diego: Academic Press.]

Láez, M.C., Requejo, M., Silvano, J.J. y Velasco, M.C. (2011). Protocolo de coordinación del trastorno por déficit de atención e hiperactividad. Valladolid: Junta de Castilla y León. Gerencia General de Salud.

Lahey, B.B., Schaughency, E.A., Frame, C.L y Strauss, C.C. (1985). Teacher ratings of attention problems in children experimentally classified as exhibiting attention deficit disorder with and without hyperactivity. J Am Acad Child Psychiatry, 24, 613-616.

Lahey, B.B., Schaughency E.A., Hynd, G.W., Carlson C.L. y Nieves, N. (1987). Attention deficit disorder with and without hyperactivity: comparison of behavioral characteristics of clinic-referred children. J Am Acad Child Adolesc Psychiatry, 26, 718-723.

Lange, K.W., Reichl, S., Lange, KM., Tucha, L. y Tucha, O. (2010). The history of attention deficit hiperactivity disorder. ADHD Atten Def Hyp Disord, 2, 241-255. 
Laufer, M.W. y Denhoff, E., Solomons, G. (1957) Hyperkinetic impulse disorder in children's behavior problems. Psychosom Med, 19, 38-49.

Lazzaro, I., Gordon, E., Whitmont, S., Plann, M., Li, W y cols. (1998). Quantitative EEG activity in adolescents attention deficit hyperactive disorder. Clin Electroencephalogr, 29, 37-42.

Leonard, B.E., McCartan, D., White, J. y King D. J. (2004) Methylphenidate: a review of its neuropharmacological, neuropsychological and adverse clinical effects. Hum Psychopharmacol Clin Exp, 19, 151-180.

Lezak, M. (1995). Neuropsychological assessment (3a. ed.). New York: Oxford University Press.

Lindsley, D. y Cutts, K. (1940). Electroencephalograms of "constitutionally inferior and behaviour problem children: comparison with those of normal children and adults. Arch Neurol Psychiatriy, 44, 1199-1212.

Lipsey, J.R., Spencer, W.C., Rabins, P.V. y Robinson, R.G. (1986). Phenomenological comparison of poststroke depression and functional depression. American Journal of Psychiatry, 143, 527- 529.

Loo, S. K., Makeig, S. (2012). Clinical utility of EEG in attention-deficit/ hyperactivity disorder: a research update. Neurotherapeutics, 9: 569-87.

Loomis, A.L., Harvey, E.N. y Hobart, G.A. (1937). Cerebral states during sleep as studied by human brain potentials. Journal of Experimental Psychology, 21, 127- 144.

Loney, J. y Milich, R. (1982). Hyperactivity inattention and aggression in clinical practice. Journal of Developmental Behavioral Pediatrics, 3, 113-147. 
Lubar, J.F. (1991). Discourse on the development of EEG diagnostics and biofeedback for attention-deficit/hyperactive disorders in clinical setting. Biofeedback Self Regul, 9, $1-23$.

Manga, D. y Fournier, C. (1990). Neuropsicología clínica infantil. Estudio de casos en edad escolar. Madrid: Universitas.

Mataró, M., García-Sánchez, C., Junqué, C., Estévez-González, A., Pujol, J. (1997). Magnetic resonance imaging measurement of the caudate nucleus in adolescents with attention-deficit hyperactivity disorder and its relationship with neuropsychological and behavioral measures. Arch Neurol, 54: 963-8.

Martel, M.M. y Nigg, J. T. (2006). Child ADHD and personality/temperament traits of reactive and effortful control, resiliency, and emotionality. J Child Psychol Psychiatry, 47, 1175-1183.

Matsuura, M., Okubo, Y., Toru, M., Kojima,T.,He, Y. y cols. (1993). A cross-national EEG study of children with emotional and behavioural problems: a WHO collaborative study in the western pacific region. Biol Psychiatry, 34, 52-58.

Matousek M. y Petersen I. (1973). Frequency analysis of the EEG background activity by means of age dependent EEG quotients. En Automation of clinical electroencephalography, ed. P Kellaway, I Peterson, 75-102. New York: Raven.

Matousek, M., Nuth, A.L. y Petersen, I. (1983). Spontaneous vigilance fluctuations in the daytirne as reflected by EEG and psychological variables. Advances in Biolagical Psychiatry, 13, 13-18. 
Menéndez, I. (2001). Trastorno de déficit de atención con hiperactividad: clínica y diagnóstico. Revista de Psiquiatría y Psicología del Niño y del Adolescente, 4(1), 92-102.

Merica, H y Fortune, R.D. (2004). State transitions between wake and sleep, and within the ultradian cycle, with focus on the link to neuronal activity. Sleep Medicine Reviews, $8(6), 473-485$.

Monastra V.J., Lubar J.F., Linden M., Van Deusen, P., Green, G., Wing, W y cols. (1999). Assessing attention deficit hyperactivity disorder via quantitative electroencephalography: An initial validation study. Neuropsychology, 13, 424-433.

Monastra, V.J., Lubar, J.F., y Linden, M. (2001). The development of a quantitative electroencephalographic scanning process for attention deficit-hyperactivity disorder: Reliability and validity studies. Neuropsychology, 15, 136-144.

Morton, W.A. y Stockton, G.G (2000) Methylphenidate abuse and psychiatric side effects. Prim Care Companion. J Clin Psychiatry, 2, 159-164.

Mostofsky, S.H., Cooper, K.L., Kates, W.R., Denckla, M.B. y Kaufmann, W.E.(2002). Smaller prefrontal and premotor volumes in boys with attentiondeficit/hyperactivity disorder. Biol Psychiatry, 52, 785-794.

Musser, C.J, Ahmann, P.A, Theye, F.W, Mundt, P, Broste, S.K. y Mueller-Rizner, N (1998). Stimulant use and potential for abuse in Wisconsin as reported by school administrators and longitudinally followed children. J Dev Behav Pediatr, $19,187 \mathrm{Y} 192$. 
National Institute for Health and Clinical Excellence. (2009). Attention deficit hyperactivity disorder. Diagnosis and management of ADHD in children, young people and adults. Great Britain: The British Psychological Society and The Royal College of Psychiatrist.

Nazari, M.A., Wallois, F., Aarabi, A., Berquin, P. (2011). Dynamic changes in quantitative electroencephalogram during continuous performance test in children with attention deficit/hyperactivity disorder. Int J Psychophysiol, 81: 230-6.

NEURONIC. (2006) EEG Quantitative Analysis QEEGT User manual. http://www.neuronicsa.com/modulos/Descargas/descarga.htm. Fecha de consuta: 2404-14.

Niedermeyer, E. (1997). Alpha rhythms as physiological and abnormal phenomena. International Journal of Psychophysiology. Official Journal of the International Organization of Psychophysiology, 26(1-3), 31-49.

Niedermeyer, E. (1998). Historical aspects. y E. Niedermeyer y F. Lopes da Silva (Eds.). Electroencephalography; Basic Principles, Clinical Applications, and Related Fields, 1-4. Baltimore: Lippincott Williams y Wilkins.

NEBA Health. Summary of Neba clinical investigation -key results. URL: http://www.nebahealth.com/clinicians.html. Fecha de consulta: 10-05-14.

Nogueira de Melo A. y Niedermeyer E. (1999). The EEG in infantile brain damage, cerebral palsy, and minor cerebral dysfunctions of childhood. En E. Niedermeyer y F.H. Lopes da Silva (Ed.). Electroencephalography: basic principles, clinical applications, and related fields. Baltimore: Williams y Wilkins. 
Nuwer M.R. (1998). Assessing digital and quantitative EEG in clinical settings. $J$ Clin Neurophysiol, 15, 458-463.

Nuwer M. (1997). Assessment of digital EEG, quantitative EEG, and EEG brain mapping: report of the American Academy of Neurology and the American Clinical Neurophysiology Society. Neurology, 49, 277-292.

Orjales, I. (2002). Déficit de atención con hiperactividad. Manual para padres y educadores. Madrid: CEPE.

Oller. L. y Ortiz. T. (1987). Mapas de actividad eléctrica cerebral. Madrid: Editorial Garsi.

OMS. (2002). CIE-10. Madrid: Panamericana.

Okie, S. (2006) ADHD in adults. N Engl J Med, 354, 2637-2641.

Overmeyer, S., Bullmore, E. T., Suckling, J., Simmons, A., Williams, S.C.R., Santos, P.J y cols (2001). Distributed grey and white matter deficits in hyperkinetic disorder: MRI evidence for anatomical abnormality in an attentional network. Psychol Med, 31, $1425-1435$.

Palacios, L. (2002). Breve historia de la electroencefalografía. Acta Med Colomb; 18,104107.

Palm, L., Persson, E., Bjerre, I., Elmqvist, D. y Blennow, G. (1992). Sleep and wakefulness in preadolescent children with deficits in attention, motor control and perception. Acta Paediatr, 81, 618-24. 
Palmer, E., Finger, S. (2001) An early description of ADHD (Inattentive Subtype): Dr Alexander Crichton and 'Mental Restlessness' (1798). Child Psychol Psychiatry Rev, 6, 66-73.

Papazian, O., Alfonso, I. y Luzondo, R.J. (2006). Trastornos de las funciones ejecutivas. Rev Neurol, 42 (Supl 3), S45-S50.

Patterson, G.R. y Chamberlain, P. (1994). Functional analysis of resistance during parent training therapy. Clinical Psychology: Science and Practice 1, 53-70.

Papazian, O., Alfonso, I. y Luzondo, R.J. (2006). Trastornos de las funciones ejecutivas. Rev Neurol, 42. (Supl 3)., S45-S50.

Pfefferbaum, A., Ford, M. J., Wenegrat, B.G., Roth, W.T., Kopell, B.S. (1984). Clinical application of the P3 component of event-related potentials. I. Normal aging. Electroencephalogr. Clin. Neurophysiol, 59 .85-103.

Pelham, W.E., Milich, R., Murphy, D.A y cols. (1989). Normative data on the IOWA Conners Teaching Rating Scale. J Clin Child Psychol, 18, 259- 262.

Pennington, B.F. (1991). Diagnosis learning disorders: a neuropsychological framework. New York: Guilford Press.

Periáñez J.A., Barceló, F. (2003). Electrofisiología de las funciones ejecutivas. Rev Neurol, 38 (04):359-365.

Polich, J. (1986). Normal variation of P300 from auditory stimuli. Electroencephalogr. Clin. Neurophysiol, 65. 236-240 
Polich, J. (1990). P300, probability and inter-stimulus interval. Psychophysiology, 27, 396403.

Polich, J. (1998). P300: clinical utility and control of variability. Journal of Clinical Neurophysiology, 15, 14-33.

Pontius, A.A. (1973). Dysfunction patterns analogous to frontal lobe system and caudate nucleus syndromes in some groups of minimal brain dysfunction. J Am Med Wom Assoc, 28, 285- 292.

Popper, C. y West, S.A. (2000). Trastornos de inicio en la infancia, la niñez o la adolescencia. En E. Robert, C. Stuart y S.C. Yudofsky (Edi.). Sinopsis de Psiquiatría clínica: Tratado de Psiquiatría DSM-IV. Barcelona: Masson, 559-588.

Pozo de Castro, J.V., De la Gándara Martín J.J., García Mayoral, V. y García Soto X.R. (2005). Tratamiento farmacológico del trastorno por déficit de atención con hiperactividad. Bol Pediatr; 45, 170-176.

Pueyo, R., Mañeru, C., Vendrell, P., Mataró, M., Estévez-González, A., García-Sánchez, C. y Junqué, C. (2000). Trastorno por déficit de atención con hiperactividad. Asimetrías cerebrales observadas en resonancia magnética. Rev Neurol, 30 (10), 920-925.

Platon, M.J., Vela, A., Espinar, J. y Kales, S. (1999). Hypnopolygraphic alterations in attention deficit disorder (ADD) children. J Neurosci, 53, 87-101.

Pliszka, S.R., McCracken, J.T., y Maas, J.W.(1996). Catecholamines in attention-deficit hyperactivity disorder: Current perspectives. Journal of the American Academy of Child \& Adolescent Psychiatry, 35, 264-272. 
Quinlan, D.M. (2003). Evaluación en el TDAH. En: Thomas Brown (ed) Trastornos por Déficit de Atención y comorbilidades en niños, adolescentes y adultos. Barcelona. Masson. pp. 569-597.

Quintanar, L., Solovieva, Y. y Bonilla, R. (2006). Analysis of visuospatial activity in preschool children with attention deficit disorder. Human Physiology, 32 (1), 43,46.

Quintanar, L., Gómez, R., Solovieva, Y. y Bonilla, R. (2011). Características neuropsicológicas de niños preescolares con trastorno por déficit de atención con hiperactividad. Revista CES Psicología, 4(1). 16- 31.

Randolph, C. y Miller, M.H. (1988). EEG and cognitive performance following closed head injury. Neuropsychobiology, 20, 43-50.

Rao, S.M., Bobholz, J.A., Hammeke, T.A., Rosen, A.C., Woodley,S.J., Cunnigham, J.M y cols. (1997). Functional MRI evidence for subcortical participation in conceptual reasoning skills. NeuroReport, 8, 1987-1993.

Rapin I. (1964) Brain damage in children. En J. Brennemann (Ed.). Practice of paediatrics. Hagerstown: MD Prior.

Reiss, A.L., Abrams, M.T., Singer, H.S., Ross, J.L. y Denckla, M.B. (1996). Brain development, gender and IQ in children. A volumetric imaging study. Brain, 119, 1763-1774.

Reyes-Zamorano, E., Ricardo-Garcell, J., Galindo y Villa, G., Cortes, J y cols.(2003). Los procesos de la atención y el electro- encefalograma cuantificado en un grupo de pacientes con trastorno por déficit de atención. Salud Mental, 26: 11-22. 
Reynolds, C.R. y Kamphaus, R.W. (1992). Behavior Assessment System for Children. Circle Pines, MN, American Guidance Service.

Ricardo-Garcell, J. (2006). Utilidad del electroencefalograma en el estudio del trastorno por déficit de atención. En A. González Garrido y J. Ramos Loyo (Ed.). La atención y sus alteraciones: del cerebro a la conducta. México: Manual Moderno, 207-217.

Ricardo-Garcell, J. y Rueda, W. (2009). Electroencefalograma y potenciales relacionados con eventos en el trastorno obsesivo compulsivo. Salud Mental, 31,173-181.

Robin, A.L (1998). ADHD in Adolescents. New York: Guilford.

Ross, D.M. y Ross S.A. (1976) Hyperactivity: research, theory and action. New York: Wiley.

Roth, B. (1961). The clinical and theoretical importance of EEG rhythms corresponding to states of lowered vigilance. Electroencephalography and Clinical Neurophysiology, $13,395-399$.

Rothenberger, A. y Neumärker, K.J.(2005). Wissenschaftsgeschichte der ADHS. KramerPollnow im Spiegel der Zeit, Steinkopff. Darmstad.

Rubia, K., Alegría, A.A. y Brinson, H. (2014). Anomalías cerebrales en el trastorno por déficit de atención/ hiperactividad: una revisión. Rev Neurol, 58 (Supl 1), S3 - S18.

Ruma, P.R., Burke, R.V. y Thompson, R.W., (1996). Group parent training: is it effective for children of all ages? Behavior Therapy, 27, 159-170. 
Sánchez-Carpintero, R. y Narbona, J. (2001). Revisión conceptual del sistema ejecutivo y su estudio en el niño con trastorno por déficit de atención e hiperactividad. Rev Neurol, $33,47-53$.

Sandberg, S. (2002). Hyperactivity and attention disorders of childhood. Cambridge: Cambridge University Press. deficit disorder: quantitative analysis of CT. Neurology, 33, 1500-1503.

Sasot, J. (2003). Evaluación de la hiperactividad. Entrevista parental y evaluación del niño en la conducta paidopsiquiátrica. En: J. Tomas y M. Casas. (eds). THDA: Hiperactividad: Niños movidose inquietos. Barcelona. Laertes.

Satterfield, J.H., Cantwell, D.P., Saul, R.E., Lesser, L.I. y Podosin, R.L. (1973). Response to stimulant drug treatment in hyperactive children: Prediction from EEG and neurological findings. Journal of Autism and Childhood Schizophrenia, 3(1), 36-48.

Seidman, L.J., Biederman, J., Faraone, S.V y cols. (1997). Toward defining a neuropsychology of attention deficit- hyperactivity disorder: performance of children and adolescents from a large clinically referred sample. J Consult Clin Psychol, 65, 150-160.

Sergeant, J.A. (2005). Modeling attention- deficit/ hyperactivity disorder: a critical appraisal of the cognitive-energetic model. Biological Psychiatry, 57, 1248-1255.

Servera-Barceló, M. (2005). Modelo de autorregulación de Barkley aplicado al trastorno por déficit de atención con hiperactividad: una revisión. Rev Neurol, 40 (6), 358-368.

Solovieva, Yu., Quintanar, L (2007). Principios y estrategias para la evaluación neuropsicológica infantil. En E.A. Escotto, M. Pérez y N.A. Sánchez (Ed.). 
Lingüística, neuropsicología y Neurociencias ante los trastornos del desarrollo infantil. México: UNAM, 87-101.

Solovieva, Yu., Machinskaya, R., Quintanar, L y Bonilla, R. (2007). Correlación neuropsicológica y electrofisiológica en niños con déficit de atención. Revista Española de Neuropsicología, 9(1), 1-15.

Schaffer, C.E., Davidson, R.J. y Saron, C. (1983). Frontal and parietal electroencephalogram asymmetry in depressed and nondepressed subjects. Biological Psychiatry, 18 (7), 753-762.

Spronk, D., Arns, M., Barnett, K.J., Cooper, N.J. y Gordon, E. (2010). An investigation of EEG, genetic and cognitive markers of treatment response to antidepressant medication in patients with major depressive disorder: A pilot study. Journal of Affective Disorders, doi: 10. 1016/j.jad.2010.06.021.

Stein, M. (1999). Unravelling sleep problems in treated and untreated children with ADHD. J. Child Adolesc. Psychopharmacol, 9(3), 157-168.

Stevens, J.R., Sachdev, K., y Milstein, V. (1968). Behavior disorders of childhood and the electroencephalogram. Archives of Neurology, 18(2), 160-177.

Stevens, L.A. (1971). Exploradores del cerebro. Barcelona: Barral Editores, 235-281.

Still, G.F. (1902). Some abnormal psychical conditions in children: the Goulstonian lectures. Lancet, 1, 1008-1012.

Steriade, M., Gloor, P., Llinás, R.R., Lopes de Silva, F.H., y Mesulam, M.M. (1990). Report of IFCN committee on basic mechanisms.Basic mechanisms of cerebral rhythmic activities. Electroencephalography and Clinical Neurophysiology, 76(6), 481-508. 
Stuss D.T., Benson D.F. (1986). The frontal lobes. New York: Raven Press.

Strauss, A.A. y Lehtinen L.E. (1947) Psychopathology and education of the brain-injured child. New York: Grune y Stratton.

Strauss, A.A. y Kephart, N.C. (1955) Psychopathology and education of the brain-injured child. Volume II. Progress in theory and clinic. New York: Grune y Stratton.

Strijkstra, A.M., Beersma, D.G., Drayer, B., Halbesma, N., y Daan, S. (2003). Subjective sleepiness correlates negatively with global alpha $(8-12 \mathrm{hz})$ and positively with central frontal theta $(4-8 \mathrm{hz})$ frequencies in the human resting awake electroencephalogram. Neuroscience Letters, 340(1), 17-20.

Subcommitee on Attention-Deficit/Hyperactivity Disorder and Committee on Quality Improvement. (2000). Clinical practice guideline: diagnosis and evaluation of the child with attention deficit/hyperactivity disorder. American Academy of Pediatrics. Pediatrics, 105(5),1158-70.

Tannock, R. (1998). Attention deficit hyperactivity disorder: advances in cognitive, neurobiological, and genetic research. J Child Psychol Psychiatry. 39, 65-99.

Tanaka, H., Hayashi, M., y Hori, T. (1996). Statistical features of hypnagogic EEG measured by a new scoring system. Sleep, 19(9), 731-738.

Tanaka, H., Hayashi, M., y Hori, T. (1997). Topographical characteristics and principal component structure of the hypnagogic EEG. Sleep, 20(7), 523-534.

Teicher, M. (1996) Objetive measures of hyperactivity and attentional problems in ADHD. Am Acad Child Adolesc Psychiatry, 35, 334-342. 
Teicher, M.H., Anderson, C.M., Polcari, A, Glod C.A, Maas L.C., Renshaw, P.F. (2000). Functional deficits in basal ganglia of children with attentiondeficit/ hyperactivity disorder shown with functional magnetic resonance imaging relaxometry. Nat Med, 6: 470-3.

Tejeiro, J. (2006). Electroencefalografía clínica básica. Barcelona: Viguera Editores.

Tomás, J., Casas, M. (2003) TDHA: Hiperactividad. Niños movidos e inquietos. Barcelona.Laertes.

Thatcher, R., Krause, P. y Hrybyk, M. (1986). Cortico-cortical associations and EEG coherence: a two-compartmental model. Electroenceph clin Neurophysiol, 64, 123143.

Thatcher, R.W., Walker, R.A., Gerson, I. y Geisler, F.H. (1989). EEG discriminant analyses of mild head trauma. Clinical Electroencephalography, 73, 94-106.

Tracy, J.L., Faro, S.H., Mohamed, F.B., Pinsk, M. y Pinus, A. (2000). Functional localization of a "time keeper" function separate from attentional resources and task strategy. Neuroimage, 11, 228-242.

Tredgold, A.F. (1908). Mental deficiency (Amentia).. New York: Wood.

Tejeiro, J. (2006). Electroencefalografía clínica básica. Barcelona: Viguera Editores.

Thomas, K.M., King, S.W., Franzen, P.L., Welsh, T.F., Berkowitz, A.L., Noll, D.C y cols. (1999). A developmental functional MRI study of spatial working memory. Neuroimage. 10, 327-338. 
Thorndike, R.L., Hagen, E.P. y Sattler, J.M. (1986). The Stanford- Binet Intelligence Scale. 4 th Edition. Chicago. IL. Riverside Publishing.

Uclés, P. y Lorente, S. (1996). Electrophysiologic measures of delayed maturation in attention-deficit hyperactivity disorder. J Child Neurol, 11, 155-156.

Ulrich, G y Frick, K. (1986). A new quantitative approach to the assessment of stages of vigilance as defined by spatiotemporal EEG patterning. Perceptual and Motor Skills, 62(2), 567-576.

U.S. Food and Drug Administration (FDA). FDA permits marketing of first brain wave test to help assess children and teens for ADHD. URL: http://www.fda.gov/NewsEvents/ Newsroom/PressAnnouncements/ucm360811.htm. Fecha de consulta: 10.05.14)

Valdizán, J.R., Navascues, M.A. y Sebastián, M.V (1999). Distribución espectral cortical del electroencefalograma infantil en procesos de atención. Rev Neurol, 28,361-365.

Valdizán, J.R., Navascues, M.A. y Sebastián, M.V (2001). Cartografía cerebral y trastorno por déficit de atención con hiperactividad. Rev Neurol, 32, 127-132.

Van- Wielink, G. (2005). Déficit de atención con hiperactividad. Sevilla: Editorial Trillas.

Watkins M.J., Watkins, O.C., Craik, F.I., Mazuryk, G. (1973). Effect of nonverbal distraction of short-term storage. Journal of Experimental Psychology, 101:296-300.

Weinberger, D.R., Luchins, D.J., Morihisa, J. y Wyatt, R.J. (1982). Asymmetrical volumes of the right and left frontal and occipital regions of the human brain. Neurology, 11, 97100.

Wender, P.H. (1971). Minimal brain dysfunction. NewYork: Wiley. 
Wender, P.H. (2002) Aufmerksamkeits- und Aktivita"tssto"rungen bei Kindern, Jugendlichen und Erwachsenen. Ein Ratgeber fürBetroffene und Helfer (F.Badura, Trans.) Kohlhammer, Stuttgart.

Verleger, R. (1997). On the utility of P3 latency as and index of mental chronometry. Psychophysiology, 34,131-156.

Weschler D. (1995). Escala de inteligencia de Weschler para niños. Madrid: TEA Ediciones.

Weschler, D. (1981). Escala de Inteligencia de Weschler para Preescolar y Primaria (WPPSI). Traducción y adaptación a la población española. Madrid: TEA Ediciones.

Wilens, T.E. y Spencer T. (2000). The stimulants revisited. Child Adolesc Psychiatr Clin N $A m, 9,573-603$.

Wilens, T.E., Gignac, M., Swezey, A., Monuteaux, M.C. y Biederman, J. (2006). Characteristic of adolescents and young adults with ADHD who divert or Misuse their prescribed medications. Journal child adolescent psychiatry, 45-49.

Willcutt, E.G., Sonuga-Barke, E.J.S., Nigg J.T. y Sergeant J.A. (2008). Recent developments in neuropsychological models of childhood psychiatric disorders. Adv Biol Psychiatry, 24, 195-226.

Wilker, W., Rothenberger, A. y Lahnert, B. (1970). Test-retest reliability of spectral parameters of the resting EEG in a field sample: a 5 years follow-up in schoolchildren with and without psychiatric disturbances. Electroenceph clin Neurophysiol Suppl, 40, 629-632.

Witkin, H.A., Oltman, P.K., Raskin, E y Karp, S.A. (1982). Test de figuras enmascaradas, Madrid, TEA, Ediciones. 